INCIDENCIA DE LOS CONOCIMIENTOS, COMPORTAMIENTOS Y ACTITUDES PROAMBIENTALES DE LOS ESTUDIANTES Y SUS FAMILIAS DE CUATRO INSTITUCIONES EDUCATIVAS DISTRITALES DE BOGOTA EN EL USO RESPONSABLE DEL RECURSO HÍDRICO

CESAR AUGUSTO CRUZ BAQUERO ADRIANA ZORAIDA MONTES FLÓREZ NANCY ROCIO PORTILLA TORO MARÍA EUGENIA VÁSQUEZ MOGOLLÓN

UNIVERSIDAD DE LA SABANA FACULTAD DE EDUCACIÓN MAESTRÍA EN EDUCACIÓN CHÍA, CUNDINAMARCA 2017 
INCIDENCIA DE LOS CONOCIMIENTOS, COMPORTAMIENTOS Y ACTITUDES PROAMBIENTALES DE LOS ESTUDIANTES Y SUS FAMILIAS DE CUATRO INSTITUCIONES EDUCATIVAS DISTRITALES DE BOGOTA EN EL USO RESPONSABLE DEL RECURSO HÍDRICO

CESAR AUGUSTO CRUZ BAQUERO ADRIANA ZORAIDA MONTES FLÓREZ

NANCY ROCIO PORTILLA TORO MARÍA EUGENIA VÁSQUEZ MOGOLLÓN

Trabajo de grado para optar el título de Magíster en Educación

ASESORES

MG. CARLOS HUMBERTO BARRETO TOVAR MG. JEFFERSON GALEANO MARTINEZ

UNIVERSIDAD DE LA SABANA FACULTAD DE EDUCACIÓN MAESTRÍA EN EDUCACIÓN CHÍA, CUNDINAMARCA 2017 
A Dios por darme la sabiduría, salud y fortaleza de alcanzar un nuevo logro en mi vida profesional, a mi madre, Lucrecia Mogollón, por darme la vida, por animarme en los momentos de debilidad, a mi esposo por ser el punto de equilibrio, fortaleza, tolerancia y amor, a mis hijos por ser la inspiración para ser una mejor persona y a todos aquellos que contribuyeron de diferentes formas a realizar este proyecto, Dios los bendiga.

\section{María Eugenia}

Por haberme dado el privilegio de vivir, ser la primera persona en celebrar mi existencia y acompañarme a dar mis primeros pasos y nunca dejar de hacerlo, incluso en la adversidad... Te dedico mi trabajo Mamá

Por llegar a mi vida y recordarme que puedo lograr todo lo soñado, por brindarme tu confianza para construir una vida a tu lado y darme un aliciente para ser un mejor hombre...

Te dedico este logro Fernanda

\section{César Augusto}

Por mostrarme siempre el camino a la superación a ti amado padre (Q.E.P.D.) y a ti querida madre que me han apoyado en las situaciones más difíciles, que han sido las mejores lecciones de mi vida y por la incondicional motivación a jamás desistir...

Por ustedes y para ustedes, gracias Papitos Por enseñarme cada día de mi vida lo grande que es el amor, el entendimiento y la paciencia, por ser los seres más importantes de mi existencia y subir junto conmigo este nuevo escalón de triunfo y superación... Por ustedes y para ustedes, Gracias mis bellos Hijos

Adriana

Porque tengo, lo que todo ser humano lucha por construir, porque a pesar de la distancia, están siempre presentes y latentes, porque son mi ayer, mi hoy y mi mañana para mi gran familia, que es mi impronta, es mi huella. Oscar y Cata por su paciencia respetuosa, gracias. 


\section{Agradecimientos}

Detrás de cada logro, hay una mano extendida

A todos los que contribuyeron con la construcción de este proyecto:

A quienes nos invitaron: La Secretaría de Educación Distrital de Bogotá

A quienes nos formaron: La Universidad de la Sabana

A quienes nos orientaron: Mag. Carlos Alberto Barreto y Mag. Jefferson Galeano

A quienes participaron: Nuestros estudiantes y padres de familia, del Colegio Manuel Zapata

Olivella, Colegio Luis López de Meza, Colegio Ricaurte y Colegio Reino de Holanda, piezas fundamentales de este proyecto de vida.

Al Ser Supremo, nuestra esencia espiritual que guía, dirige y orienta.

A nuestros amigos, que incidieron en la toma de decisiones, que apoyaron y preguntaron.

Y a nuestras familias, que con su espera paciente, posibilitaron llegar al final tan anhelado.

A todos, mil gracias y bendiciones. 


\section{Contenido}

$\begin{array}{ll}\text { Introducción } & 16\end{array}$

1. Problema de investigación 19

$\begin{array}{ll}1.1 \text { Contexto } & 19\end{array}$

1.1.1 Institución Educativa Distrital Luis López de Mesa. 20

1.1.2 Institución Educativa Distrital Manuel Zapata Olivella 22

1.1.3 Institución Educativa Distrital Ricaurte. 25

1.1.4 Institución Educativa Distrital Colegio Reino de Holanda. 27

1.2 Antecedentes del problema 30

1.3 Justificación $\quad 43$

1.4 Formulación del problema $\quad 47$

$\begin{array}{lll}1.6 & \text { Objetivos } & 48\end{array}$

1.6.1 Objetivo General. $\quad 48$

1.6.2 Objetivos Específicos. 49

2. Marco teórico $\quad 50$

$\begin{array}{ll}2.1 \text { Referentes Teóricos } & 50\end{array}$

2.1.1 Cultura Ambiental. $\quad 50$

2.1.2 Conocimientos, Actitudes y Comportamientos Proambientales. 52

2.1.3 Educación Ambiental. $\quad 54$

2.1.4 Procesos de la educación ambiental en contextos escolares. 64

2.1.4.1 Proyecto escolar ambiental - PRAE. $\quad 64$

2.1.4.2 Comité ambiental escolar (CAE). 66

2.1.5 Familia y Educación Ambiental. $\quad 67$

2.1.5.1 Relación entre familia y escuela. $\quad 69$

2.1.5.2 Conocimientos, actitudes y comportamientos proambientales en la familia 71

2.1.6 Gestión social del recurso hídrico.

2.1.6.1 Estado actual de los recursos hídricos nacionales. 75

2.1.6.2 Estrategias de educación ambiental para la gestión del recurso hídrico. $\quad 77$

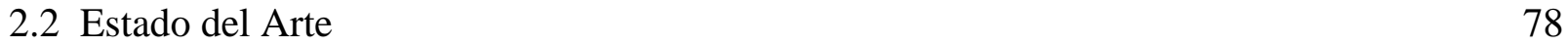

2.3 Marco Legal $\quad 86$ 
3. Marco Metodológico $\quad 97$

$\begin{array}{ll}\text { 3.1. Enfoque } & 98\end{array}$

$\begin{array}{ll}3.2 \text { Alcance } & 98\end{array}$

3.3. Fases de la investigación 99

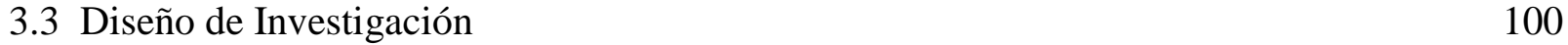

$\begin{array}{ll}3.4 \text { Población } & 102\end{array}$

3.5 Categorías de análisis: 104

3.6 Técnicas e Instrumentos de recolección de información 104

3.8 Proceso de Validación y Análisis de Resultados 107

4. Plan de Acción $\quad 109$

4.1. Estrategia Empoderamiento Líderes del CAE 114

4.1.1. Caracterización del CAE 114

4.1.2. Sensibilización 114

4.1.3. Formación $\quad 115$

4.1.4. Integración: 120

4.1.5 En qué están los estudiantes 122

4.2. Trabajo con familia $\quad 122$

4.2.1. Formación. 123

4.2.2. Disminución en el consumo del recurso hídrico. 124

4.3. Trabajo Colegio y familia $\quad 125$

4.3.1 Campaña uso responsable del agua 125

4.3.2 Elaboración y socialización de normas para el cuidado del agua 125

5. Resultados y análisis de datos $\quad 127$

5.1. Análisis de la caracterización de los estudiantes del CAE $\quad 128$

5.1.1 Caracterización CAE IED Luis López de Mesa. 128

5.1.2 Caracterización CAE IED Manuel Zapata Olivella 129

5.1.3 Caracterización CAE IED Ricaurte 131

5.1.4. Caracterización CAE IED Reino de Holanda 133

5.1.4. Análisis de la caracterización general de los CAE de las cuatro instituciones 137

5.1.4.1 Análisis de la entrevista aplicada varios estudiantes 141

5.1.4.2. Análisis de la actividad: Antes pensaba, ahora pienso 142 
5.2. Análisis del taller formación. 146

5.2.1. Formación “¿Cómo cuidar el agua en el hogar y en el colegio?” 146

5.2.2. Integración "La historia del cambio, la historia de las cosas" 148

5.2.3. Verificación "En que están los estudiantes" 149

5.3. Familias 149

5.3.1. Formación "Taller de padres de los estudiantes miembros del CAE" 150

5.3.2 Integración "Seguimiento de los comportamientos proambientales" 150

5.4. Colegio y familia 151

5.5. Análisis de recibos de acueducto, alcantarillado y recolección de basuras de los hogares de los vigías ambientales 153

5.6. Discusión de los resultados. 156

5.6.1. Análisis de la caracterización de los estudiantes del CAE 156

5.6.2. Análisis del taller formación 157

$\begin{array}{lr}\text { 5.6.3. Familia } & 159\end{array}$

5.6.4. Colegio y familia 160

5.6.5. Recibos de acueducto y alcantarillado y recolección de basuras de los hogares de los vigías ambientales 161

$\begin{array}{lr}\text { Conclusiones } & 163\end{array}$

$\begin{array}{ll}\text { Bibliografía } & 166\end{array}$

$\begin{array}{ll}\text { Anexos } & 181\end{array}$ 
Índice de tablas

Tabla 1. Preguntas de la encuesta diagnóstica y categorías de análisis 36

Tabla 2. Autorías por país en el estado del arte $\quad 79$

Tabla 3. Documentos por continente en el estado del arte 79

Tabla 4. Documentos por año en el estado del arte $\quad 80$

Tabla 5. Categorías de análisis en el estado del arte 81

Tabla 6. Autores en la categoría Dinámica familiar y comportamiento proambientales 84

Tabla 7. Autores de los documentos relevantes para la investigación 85

Tabla 8 Matriz metodológica de la investigación 94

Tabla 9. Fases de la investigación 99

Tabla 10. Miembros del CAE por colegio y género 102

Tabla 11. Número de estudiantes por curso y colegio 102

Tabla 12 Número de estudiantes por jornada y colegio 103

Tabla 13. Estrategias y actividades del plan de acción 111

Tabla 14. Resultados obtenidos en cada una de las estrategias del plan de acción 127 


\section{Índice de figuras}

Figura 1. Ubicación geográfica de las cuatro instituciones educativas’ 19

Figura 2. Fachada de la Institución Educativa Distrital Luis López de Meza 20

Figura 3. Fachada de la Institución Educativa Distrital Manuel Zapata Olivella 23

Figura 4. Fachada de la Institución Educativa Distrital Ricaurte 25

Figura 5. Fachada de la Institución Educativa Distrital Reino de Holanda 27

Figura 6. Río Fucha sector Calle 13 con Calle 83

Figura 7. Río Bogotá al occidente de la ciudad 31

Figura 8. Río Tunjuelito sector Villa de los Sauces 32

Figura 9. Humedal Tibanica en el sector de Bosa 32

Figura 10. Humedal Chucua del Burro 33

Figura 11. Inadecuada disposición de residuos por parte de la comunidad vecina a la IED 35 Manuel Zapata Olivella

Figura 12. Argumentos de la justificación del proyecto $\quad 44$

Figura 13. Evolución de la normatividad ambiental a nivel nacional e internacional 91

Figura 14. Normatividad sobre el recurso hídrico 95

$\begin{array}{ll}\text { Figura } 15 \text { Diseño de la investigación } & 100\end{array}$

Figura 16. Estrategias y actividades del plan de acción $\quad 110$

Figura 17. Formación de conocimientos, actitudes y comportamientos proambientales en $\quad 116$ la IED Reino de Holanda

Figura 18.Formación de conocimientos, actitudes y comportamientos proambientales en la 116 IED Luis López de Mesa

Figura 19. Formación de conocimientos, actitudes y comportamientos 117 proambientales en la IED Reino de Holanda

Figura 20. Formación de conocimientos, actitudes y comportamientos 117 proambientales en la IED Luis López de Mesa

Figura 21. Formación de conocimientos, actitudes y comportamientos 118 proambientales en la IED Colegio Ricaurte

Figura 22. Formación de conocimientos, actitudes y comportamientos 118 proambientales en la IED Ricaurte 
Figura 23. Formación de conocimientos, actitudes y comportamientos

proambientales en la IED Colegio Manuel Zapata Olivella

Figura 24. Formación de conocimientos, actitudes y comportamientos

proambientales en la IED Colegio Manuel Zapata Olivella

Figura 25. Formación de conocimientos, actitudes y comportamientos proambientales en la IED Manuel Zapata Olivella

Figura 26. Vigías ambientales de la IED Reino de Holanda observando un video sobre historia de las cosas

Figura 27. Formación de conocimientos, actitudes y comportamientos proambientales, 122 Colegio Manuel Zapata Olivella

Figura 28. Socialización del Proyecto con padres de familia Colegio Reino de Holanda

Figura 29. Socialización del Proyecto con padres de familia Colegio Reino de Holanda

Figura 30. Formación de conocimientos, actitudes y comportamientos proambientales 126 adecuado del agua Colegio Manuel Zapata Olivella, Taller la 10 reglas del cuidado del agua

Figura 31. Miembros del CAE por grados

Figura 32. Distribución del CAE por edades

Figura 33. Estratificación socioeconómica de los vigías

Figura 34. Características del lavado de ropa

Figura 35. Caracterización de hábitos de aseo personal y del hogar

Figura 36. Codificación axial de la entrevista

Figura 37. Resultados de la actividad antes pensaba, ahora pienso

Figura 38. Integración Colegio Familia, Institución Manuel Zapata Olivella

Figura 39. Integración Colegio Familia, Institución Luis López de Mesa

Figura 40. Promedio del costo del recibo de AARB

Figura 41. Consumo en m3 para los cuatro últimos recibos

Figura 42. Comportamiento del valor en los últimos cuatro recibos de AARB 


\section{Índice de anexos}

Anexo 1. Encuesta Diagnóstica.

Anexo 2. Entrevista inicial y transcripciones.

Anexo 3. Caracterización del Comité Ambiental Escolar.

Anexo 4. Rejillas de Seguimiento de Conductas proambientales.

Anexo 5. Diagnósticos PRAE de las cuatro instituciones educativas.

Anexo 6. DOFA de las cuatro instituciones educativas.

Anexo 7. Talleres y actividades del plan de acción.

Anexo 8. Diarios de campo.

Anexo 9. RAES.

Anexo 10. Referencias Estado del Arte

Anexo 11. Fotografías de actividades del plan de acción 


\section{Resumen}

Esta investigación se implementó con los estudiantes líderes del Comité Ambiental Escolar (CAE) de cuatro instituciones educativas distritales de la ciudad de Bogotá: Luis López de Meza (Loc.7), Manuel Zapata Olivella (Loc.8), Ricaurte (Loc.14) y Reino de Holanda (Loc.18). El trabajo se desarrolló durante el segundo semestre de 2015 y el primer semestre de 2017, el objetivo fue determinar la incidencia que tienen los conocimientos, actitudes y comportamientos proambientales de los estudiantes y sus familias en el uso responsable del recurso hídrico.

La investigación tuvo un enfoque de carácter cualitativo basado en la observación de las actitudes y comportamientos de los sujetos de investigación que permitieron caracterizar su contexto y concluir la existencia de una problemática ambiental relacionada con el uso responsable del recurso hídrico; el estudio fue longitudinal porque se realizó un seguimiento de los procesos durante el tiempo que duró la investigación, lo que implicó la observación sistemática de los hechos; su carácter de investigación - acción - participativa (IAP) porque a partir del reconocimiento del entorno se implementaron estrategias contenidas en el plan de acción, involucrando la participación de estudiantes y sus familias lo que condujo a incidir en sus conductas proambientales.

De la misma forma, se trabajaron algunos documentos como los diagnósticos de los PRAE, planes operativos anuales (POA) y análisis de los DOFA de cada una de las instituciones educativas; se realizaron entrevistas y observaciones a los estudiantes y sus familias que permitieron el desarrollo del trabajo investigativo.

Los resultados mostraron que las campañas ambientales lideradas desde los colegios, inciden en los cambios de comportamientos proambientales de estudiantes y sus familias. De 
otro lado se pudo evidenciar que los líderes del CAE se empoderan cuando existe un proyecto ambiental estructurado y liderado por los docentes, además se fortalece una cultura ambiental, que incluye la administración del recurso hídrico, cuando la familia se integra de forma activa. Consecuentemente cuando las instituciones logran procesos de educación ambiental pertinentes y asertivos, se favorece la participación de otras entidades gubernamentales y sociales en los PRAE.

Palabras Clave: Conocimientos, Comportamientos, Actitudes Proambientales, Recurso Hídrico, Educación Ambiental y Familia. 


\section{Summary}

This research was developed with leader students of the School Environmental Committee (CAE) of four district educational institutions in Bogota city: Luis López de Meza School (Loc.7), Manuel Zapata Olivella School (Loc.8), Ricaurte School (Loc.14 ) and Reino de Holanda School (Loc.18). This research developed between the second half of 2015 and the first semester of 2017. The objective was to determine the impact of pro-environmental knowledge, attitudes and behavior of students and their families on the adequate use of water resources.

The approach of this research is qualitative, as it was based on the observation of the knowledge, attitudes and behavior of students and their families, whose characteristics were described to contextualize the environmental problem. It was a longitudinal study since the processes were monitored throughout the entire investigative period, which implied a systematic observation of the facts. The study was guided by the (PAR), participative action research - since it was developed within a community involving each member of the educational institution and their families.

It was also necessary to collect evidence such as the diagnostics of PRAE (Environmental Educative Proposals), annual operational plans (POA) and analysis of the SWOT of each of the educational institutions. In addition, interviews and observations were carried out, which were systematized in tables, graphs and field journals, of the activities that take place in different spaces inside and outside the institutions.

In the same way, a plan of action was developed, based on the workshops that both students and their parents developed to determine their pro-environmental behaviors in proper use of water resources. 
The results showed that the environmental campaigns led from the schools, affect the changes of pro-environmental behavior of students and their families. On the other hand, it was evident that the CAE leaders are empowered when there is a structured environmental project led by the teachers, and an environmental culture is strengthened, which includes the administration of the water resource, when the family is actively integrated. Consequently, when the institutions achieve relevant and assertive environmental education processes, the participation of other governmental and social entities in the Projects is favored.

Keywords: Knowledge, Behaviors, Attitudes, Environmental Pro, Water Resource, Environmental Education and Family. 


\section{Introducción}

Durante las últimas dos décadas ha aumentado la preocupación por la disponibilidad de los recursos naturales, debido al deterioro ambiental causado por la actividad humana que ha afectado la capacidad del planeta para satisfacer las necesidades de las poblaciones. En este marco el recurso hídrico constituye un elemento fundamental para la satisfacción de las necesidades básicas e insumos para el desarrollo agrícola e industrial, lo que lleva a replantear la relación entre los seres humanos y el agua a través de la educación ambiental.

A pesar del potencial hídrico que tiene Colombia, los casos de sequías en diferentes regiones del país son evidencia que la crisis mundial del agua, pronosticada para 2025 también afectará el territorio colombiano. Por consiguiente las políticas nacionales de educación ambiental se han alineado con la consolidación de una cultura ambiental basada en conocimientos, actitudes y comportamientos proambientales, conceptos que han sido perfilados desde la psicología pero que actualmente tienen amplia aceptación y aplicabilidad en el ámbito educativo.

En este marco las investigaciones desarrolladas durante los últimos años, en la línea de investigación en educación ambiental de la Unisabana han explorado diferentes aspectos que contribuyen al fortalecimiento de conocimientos, actitudes y comportamientos proambientales en ámbitos escolares, en especial con el desarrollo de los Proyectos Ambientales Escolares (PRAE). A pesar de esto se evidencia que los objetivos de los PRAE en las instituciones educativas no responden a la necesidad de fortalecer conocimientos, actitudes y comportamientos proambientales con relación al uso adecuado del agua, las instituciones educativas centran su atención en aspectos como disminución de la contaminación por basuras; concienciación del uso 
de los recursos públicos; establecer cooperación con otras organizaciones para apoyar acciones de conservación del medio ambiente, así lo afirma (García, 2015; Serrato, Suavita \& Jaimes, 2015).

Otro aspecto relevante, destacado en otras investigaciones desarrolladas en la misma línea, es la posibilidad de fomentar procesos de educación ambiental desde el colegio hacía las familias, circunstancia que se ha trabajado en el ámbito local de forma incipiente, estos estudios como por ejemplo: Conocimientos, actitudes y comportamientos proambientales en la construcción de una cultura ambiental de tres colegios de Bogotá de García, Serrato, Suavita \& Jaimes, 2015, donde se busca dar continuidad a los hábitos que adquieren en sus hogares proyectarlos en la escuela; de igual manera el trabajo realizado por Ruth Fagua y otros en Influencia de los espacios escolares en los comportamientos proambientales de los estudiantes de tres colegios públicos de Bogotá, donde se menciona que los PRAE se utilizan como un mecanismo que facilita la vinculación de docentes, estudiantes y padres de familia.

Por lo anterior se planteó determinar la incidencia de los conocimientos, actitudes y comportamientos proambientales de los estudiantes en el uso adecuado del agua dentro de sus hogares. Para llevar a cabo esta investigación se adoptó un enfoque cualitativo, con un alcance descriptivo, diseño IAP (Investigación Acción Participativa) longitudinal durante los años 2015 a 2017, lo cual permitió la transformación de situaciones problemáticas, como el uso adecuado del agua en las instituciones educativas y sus hogares, en acciones positivas mediadas por el fortalecimiento de comportamientos proambientales en los estudiantes y sus familias.

En un primer momento se hizo un diagnóstico a través de la aplicación de una entrevista y un cuestionario, los cuales dan cuenta de conocimientos proambientales que predominan en los 
estudiantes dentro de las cuatro instituciones y en sus hogares. Esta información se corroboró con las notas de campo registradas a partir de la observación directa y con documentos institucionales que muestran los comportamientos que tiene la comunidad educativa en relación al uso del recurso hídrico. Luego se contrastaron los resultados con la información bibliográfica para argumentar la problemática de la investigación y plantear los objetivos, la metodología, el análisis de los resultados y el plan de acción interventiva que consta de 3 estrategias enfocadas a fortalecer los comportamientos proambientales de los miembros de la comunidad educativa, estudiantes y padres de familia en sus hogares.

Este informe de investigación está estructurado en cinco capítulos, el primero presenta la delimitación del contexto, los antecedentes, la justificación, la formulación del problema, la pregunta de investigación y los objetivos. El segundo capítulo presenta una revisión bibliográfica con la que se construyó un marco teórico donde se exponen los principales referentes conceptuales, un estado del arte y el marco normativo de la investigación. El tercer apartado de este documento se centra en la metodología y el cuarto describe el plan de acción pedagógico que se llevó a cabo durante el tiempo que duró la investigación. Finalmente se presenta el capítulo de análisis de resultados, las conclusiones y recomendaciones. 


\section{Problema de investigación}

El presente capítulo muestra la formulación del problema de investigación, con el objeto de contextualizar y caracterizar las cuatro instituciones educativas: Luis López de Mesa, Manuel Zapata Olivella, Ricaurte y Reino de Holanda. A continuación se presenta la descripción de las instituciones educativas, la justificación donde se desarrolla el por qué y para qué de esta investigación, la formulación del problema que incluye la pregunta que orientó esta investigación.

\subsection{Contexto}

Figura 1. Ubicación geográfica de las cuatro instituciones educativas

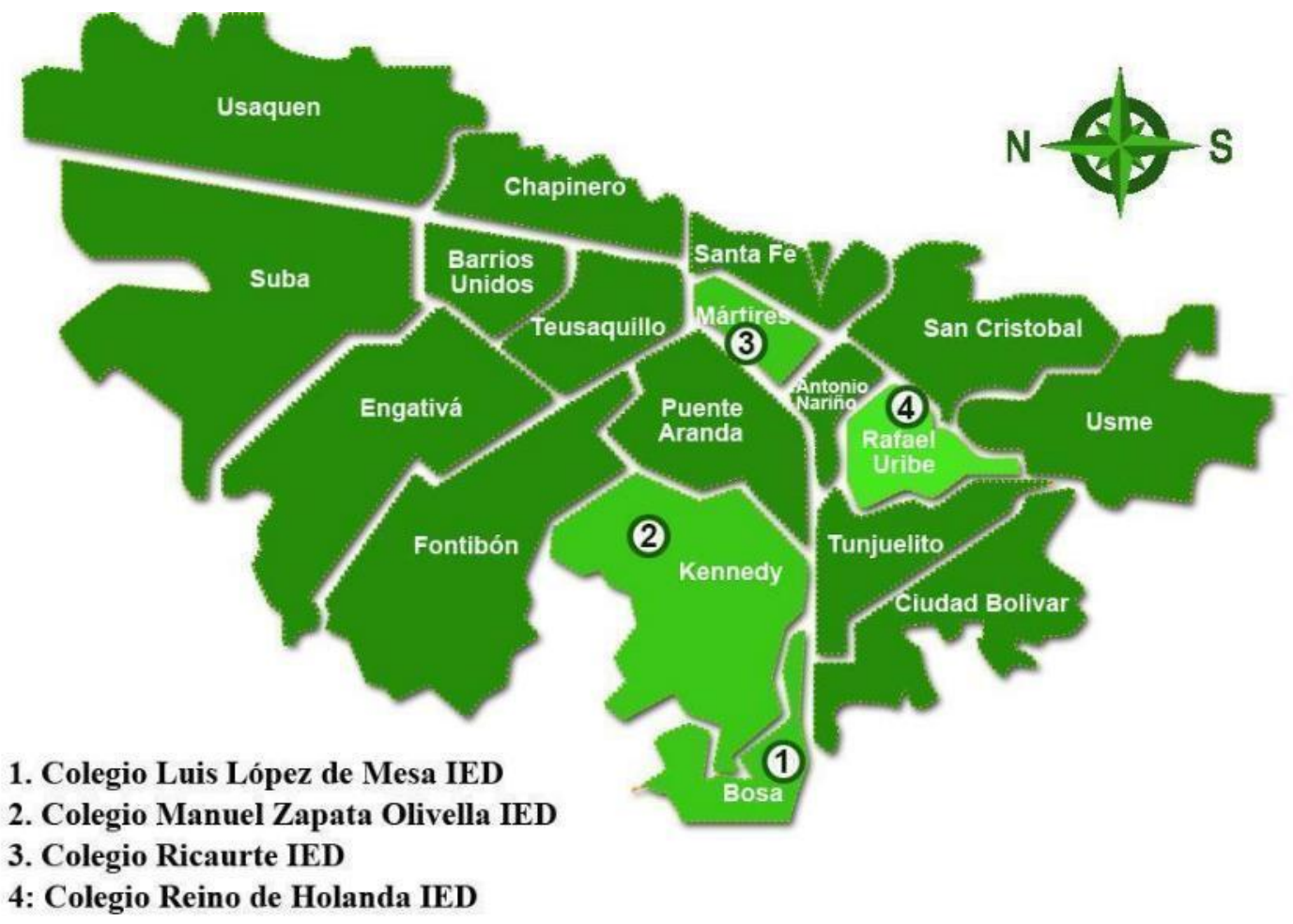

Imagen modificada por el equipo investigador a partir del mapa disponible en https://goo.gl/kjyKM9 
A continuación se presenta la caracterización de las instituciones educativas que participaron en la investigación, la identificación de los aspectos geográficos, históricos, socioculturales, económicos, apoyados en los PRAE y sus planes de acción.

En la Figura 1 se presenta la ubicación geográfica de las instituciones educativas distritales de la ciudad de Bogotá, donde se desarrolló esta investigación: Luis López de Mesa (LLM), Manuel Zapata Olivella (MZO), Ricaurte (CR) y Reino de Holanda (RH), ubicadas en las Localidades 7, 8, 14 y 18 respectivamente, pertenecientes a los estratos 2 y 3 (Alcaldía Mayor de Bogotá, 2010).

\subsubsection{Institución Educativa Distrital Luis López de Mesa.}

Figura 2. Fachada de la Institución Educativa Distrital Luis López de Meza

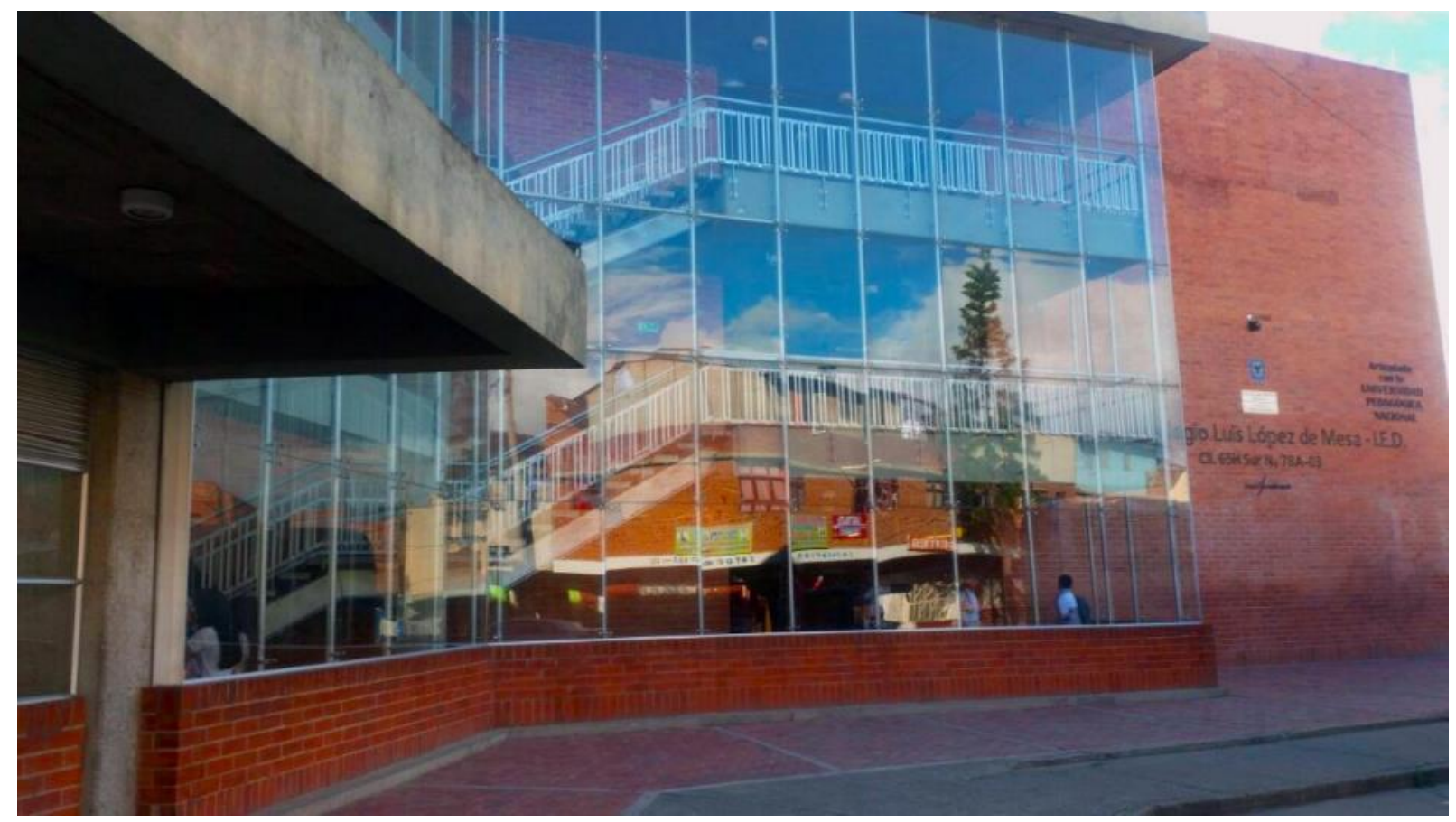

Fuente: Fotografía tomada por María Eugenia Vásquez Mogollón Tomada el 6 de Julio de 2017 
Esta institución se encuentra en el barrio La estación (Calle 65H sur \# 78A-03), que pertenece a la localidad séptima (Bosa) limita al norte con la localidad de Kennedy, al sur con la autopista sur, al occidente con el río Tunjuelito y al oriente con el río Bogotá. Está dividida en cinco UPZ: Apogeo, Bosa Occidental, Bosa Central, El Porvenir y Tintal Sur (Alcaldía Mayor de Bogotá, 2010).

Bosa fue un territorio indígena Chibcha, gobernado por el cacique Techotiva. Este poblado antiguo conserva su nombre, en alusión a sus antepasados, del vocablo Chibcha que significa "cercado de guarda" y "defiende las mieses" era representado en forma de nariz. También significaba "segundo día de la semana" que era compuesta por las unidades temporales Ata, Boza, Mica, Mujica, Jizca, Ta y Cujipucua (Alcaldía Mayor de Bogotá, 2010). Los españoles, liderados por Gonzalo Jiménez de Quezada, firmaron un tratado de paz con los pobladores en 1538 , dejando como testimonio un monumento que aún se encuentra frente a la iglesia de San Bernardino, la cual se empezó a construir en 1618. Los pobladores actuales han conservado los apellidos muiscas, como es el caso de Neuta, Chiguasuque, Tunjo, Orobajo, Buenhombre y Fitata. Para finales de los años cincuenta Bosa fue un municipio habitado por aproximadamente 20.000 personas. Durante el gobierno de Gustavo Rojas Pinilla, Bosa se anexa al distrito especial de Bogotá y se consolida como la séptima localidad de la ciudad, condición que ha sido ratificada por dos acuerdos (14 de 1983 y 8 de 1993) y por la Constitución de 1991 (Secretaria Distrital de Planeación, 2009).

La Institución Educativa (Figura 2) debe su nombre a Luis López de Mesa, médico egresado de la Universidad Nacional de Colombia y especialista en psiquiatría, quien se desempeñó como concejal de Bogotá, profesor universitario, Ministro de Educación y de 
relaciones exteriores, canciller, rector de la Universidad Nacional y escritor (Alcaldía Mayor de Bogotá, 2010).

La institución educativa distrital (IED) Luis López de Mesa, desde ahora (LLM) es una institución oficial, cuenta con educación preescolar, básica primaria y secundaria y media vocacional, media fortalecida y articulada con la educación superior, cuenta con 2600 estudiantes, 101 docentes y 7 directivos, los estudiantes se gradúan como bachilleres gestores culturales, además propende desarrollar en los jóvenes y jovencitas las capacidades académicas, habilidades comunicativas y competencias laborales, con una excelente formación humana teniendo como referentes los valores de responsabilidad, respeto y equidad; así como formar ciudadanos proactivos, autónomos, capaces de desempeñarse de forma efectiva y asertiva, utilizando la comunicación, las nuevas tecnologías, el cuidado y el buen uso de los recursos naturales, siendo gestores de la transformación social (Alcaldía Mayor de Bogotá, 2017).

\subsubsection{Institución Educativa Distrital Manuel Zapata Olivella}

Esta institución educativa, cuya fachada se puede observar en la Figura 3, se encuentra en el barrio Patio Bonito II Sector (calle 1 Bis No. 87-84) pertenece a la localidad octava (Kennedy), esta es una de las localidades con mayor población, la cual limita al norte con el río Fucha y la calle 13, al sur con la Autopista sur, el río Tunjuelito y la Avenida Calle 40 Sur, al occidente con Camino Osorio (Bosa) y el Municipio de Mosquera y al oriente con la Avenida Congreso Eucarístico (Av. Kra. 68). Esta localidad ocupa el tercer puesto, entre las demás localidades por su extensión (11,12\%), así mismo está dividida en doce UPZ: Kennedy Central, Timiza, Carvajal, Américas, Bavaria, Castilla, Tintal Norte, Calandaima, Corabastos, Gran Britalia, Patio Bonito y Las Margaritas. 
Figura 3. Institución Educativa Distrital Manuel Zapata Olivella

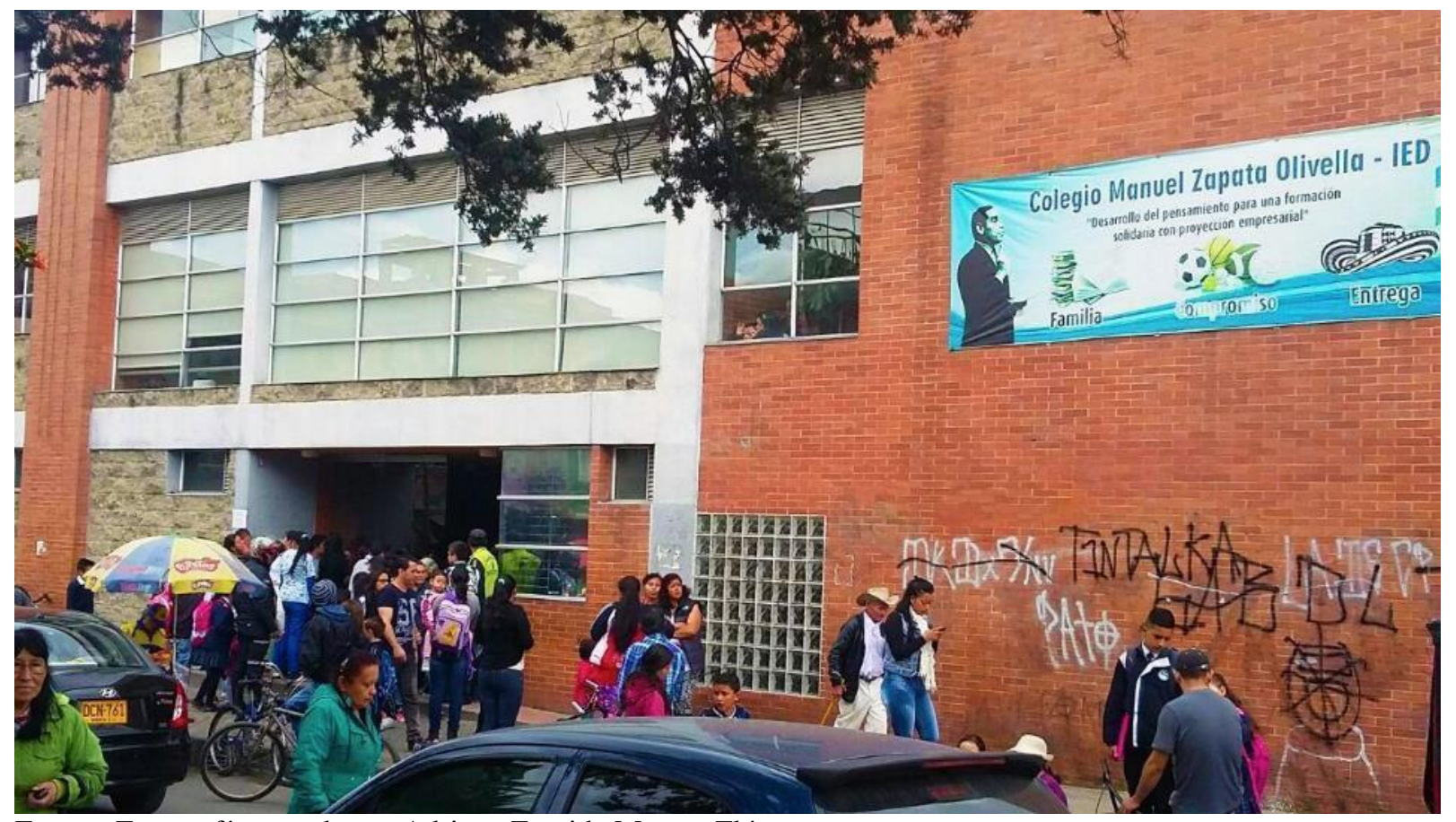

Fuente: Fotografía tomada por Adriana Zoraida Montes Flórez Tomada el 7 Julio de 2017

La localidad de Kennedy cuenta con 438 barrios ubicados en su mayoría en las unidades de planeamiento zonal (UPZ) Castilla y Timiza con 49 barrios cada una, los grupos poblacionales de las UPZ Timiza, Gran Britalia y Patio Bonito cuentan con población indígena representada por el Cabildo Nasa y afrodescendientes y la UPZ de Marsella con población gitana y rom. (Alcaldía Mayor de Bogotá, 2017).

Kennedy fue territorio muisca, en 1992 el arqueólogo Gonzalo Correal descubrió en la hacienda Aguazaque, restos humanos de más de 2.700 años de antigüedad, cuando los ríos Bogotá, Fucha y Tunjuelito eran de gran tamaño, en 1882 se inició la construcción del ferrocarril entre Bogotá y Sibaté, en 1883 se inició la ampliación del camino de Soacha para permitir la entrada de carretas hasta el norte de la localidad, para 1895 se fundó la hidroeléctrica del 
Charquito en Soacha, el aeropuerto de Techo en 1920 inició con algunos vuelos y funcionó hasta 1959 cuando se fundó el aeropuerto internacional El Dorado, en 1948 fue inaugurada la Avenida de Las Américas, la Fuente de la Diosa de las Aguas y el monumento de Banderas cuyo autor fue el escultor bogotano Alfonso Neira Martínez.

Esta localidad toma el nombre de Ciudad Kennedy en el año 1967 en honor al presidente John F, Kennedy entonces presidente de Estados Unidos. En 1971 se inaugura la central de abastos (Corabastos) y en la década de los noventa se llevó a cabo la construcción del sector de La Paz y El Tintal transformando la planta compactadora de basuras, en la biblioteca pública El Tintal Manuel Zapata Olivella (Alcaldía Mayor de Bogotá, 2010).

La IED Manuel Zapata Olivella desde ahora (MZO), obtuvo su nombre mediante la resolución 08-027 del 27 de marzo de 2015 de la Secretaría de Educación Distrital de Bogotá, en homenaje al médico, antropólogo, etnólogo, novelista, cónsul de Colombia en Trinidad y Tobago y el más importante escritor de la literatura afrocolombiana. (Alcaldía Mayor de Bogotá, 2010).

Esta Institución Educativa funciona en una sede única, se enmarca en una formación transdisciplinar, desarrolla en los estudiantes principios de sana convivencia, autorregulación, trabajo en equipo y desarrollo del pensamiento crítico, con una excelente formación humana basada en los valores éticos de tolerancia, respeto y responsabilidad, implementa el modelo de aprendizaje significativo. El colegio MZO cuenta con los niveles preescolar, básica primaria, básica secundaria y media vocacional, dirigido a una población de 2187 estudiantes, 94 docentes y 5 directivos; además ofrece un énfasis educativo en gestión empresarial y la modalidad para la media fortalecida, aplicada en los grados décimo y once donde se articula la educación superior en Gestión Empresarial y Diseño Gráfico, en convenio con la Universidad EAN y la Fundación 
Universitaria del Área Andina. Hay que mencionar que en la institución educativa se ha implementado la jornada extendida, para el grado de preescolar, donde los niños fortalecen sus conocimientos a través de la lúdica (Manual de convivencia Colegio Manuel Zapata Olivella, 2015).

\subsubsection{Institución Educativa Distrital Ricaurte.}

Figura 4. Fachada de la Institución Educativa Distrital Ricaurte

Foto tomada por RedP. Disponible en: http://colegio.redp.edu.co/ricaurte/

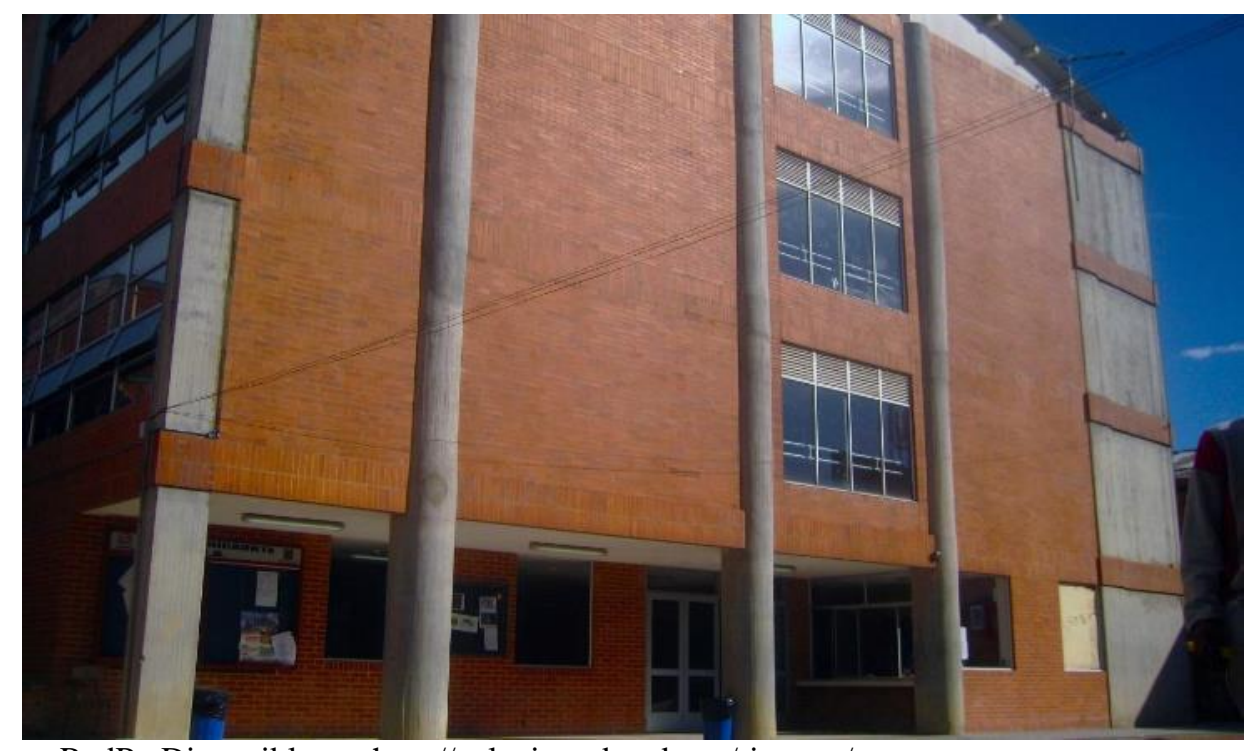

Eoto tomada por RedP. Disponible en: hitt.//colegio.redp.edu.co/ticaurte/

Esta institución educativa (Figura 4) se encuentra ubicada en la localidad 14 de los Mártires (Carrera $27 \mathrm{~N}^{\circ} 7-48$ ), la cual se encuentra en el centro de la ciudad, limita al norte con la calle 13 , al sur con las calles $1^{\mathrm{a}}$ y $8^{\mathrm{a}}$, al oriente con avenida Caracas y al occidente con la carrera 30 (Secretaría Distrital de Planeación, 2009). Los Mártires está dividida en dos UPZ (Santa Isabel y Sabana) y los barrios que hacen parte de la localidad son: Veraguas, El Progreso, Eduardo Santos, El Vergel, Santa Isabel, Santa Isabel Sur, La Pepita, Ricaurte, La Sabana, El Listón, Paloquemao, La Estanzuela, Voto Nacional, San Victorino, La Favorita, Santa Fe, 
Samper Mendoza, Florida, Panamericano, Usatama y Colseguros (Secretaría Distrital de Planeación, 2009).

El nombre de la localidad se debe a los Mártires de la independencia: Policarpa Salavarrieta, Antonia Santos, Mercedes Abrego, Camilo Torres y Antonio José de Caldas. En la localidad se encuentran varios sitios históricos como el cementerio central, creado en 1825, la Iglesia del Voto Nacional, construida en 1891, el convento de Sans Façón y su iglesia Gótica inaugurada en 1918 y la Estación de la Sabana entregada a la ciudad en 1917. Se caracteriza por el sector de Plaza España, Parque de los Mártires y la Plaza de Paloquemao (Secretaría Distrital de Planeación, 2009). Barrios como Santa Fe y la Favorita inicialmente brindaron vivienda a sectores sociales privilegiados, pero debido a las dinámicas poblacionales ahora se han convertido en inquilinatos y prostíbulos. En 1972 se creó la localidad 14 incluyendo sus barrios (Secretaría Distrital de Planeación, 2009).

La IED Ricaurte desde ahora (CR) debe su nombre al prócer de la independencia Antonio Clemente José María Bernabé Ricaurte Lozano, quien colaboró con los Comuneros en la insurrección de 1781, participó en los hechos del 20 de julio de 1810, en Santafé de Bogotá. En 1813 se enlistó en el Ejército Neogranadino de Bolívar y el 25 de marzo de 1814, durante un ataque realista, Ricaurte tomó un tizón y prendió fuego al polvorín que se guardaba en San Mateo (Venezuela) inmolándose y dándole ventaja a Bolívar (Fuerza Aérea Colombiana, 2014).

Atendiendo a las necesidades del sector, el colegio inició labores académicas a partir de 1992, obtuvo su resolución de aprobación en 1998 y de integración en 2002. Actualmente cuenta con 60 docentes, 4 directivos y 1250 estudiantes matriculados desde preescolar hasta grado once, la sección de básica primaria funciona en jornada extendida, básica secundaria en jornada 
mañana y tarde, y media en jornada única. El colegio Ricaurte tiene por misión formar integralmente a sus estudiantes con el fin de desarrollar sus diferentes dimensiones, una actitud crítica y la adquisición de herramientas que le permitan construir su proyecto de vida y el mejoramiento de su entorno. (Colegio Ricaurte 2013).

\subsubsection{Institución Educativa Distrital Colegio Reino de Holanda.}

Figura 5. Fachada de la IED Colegio Reino de Holanda

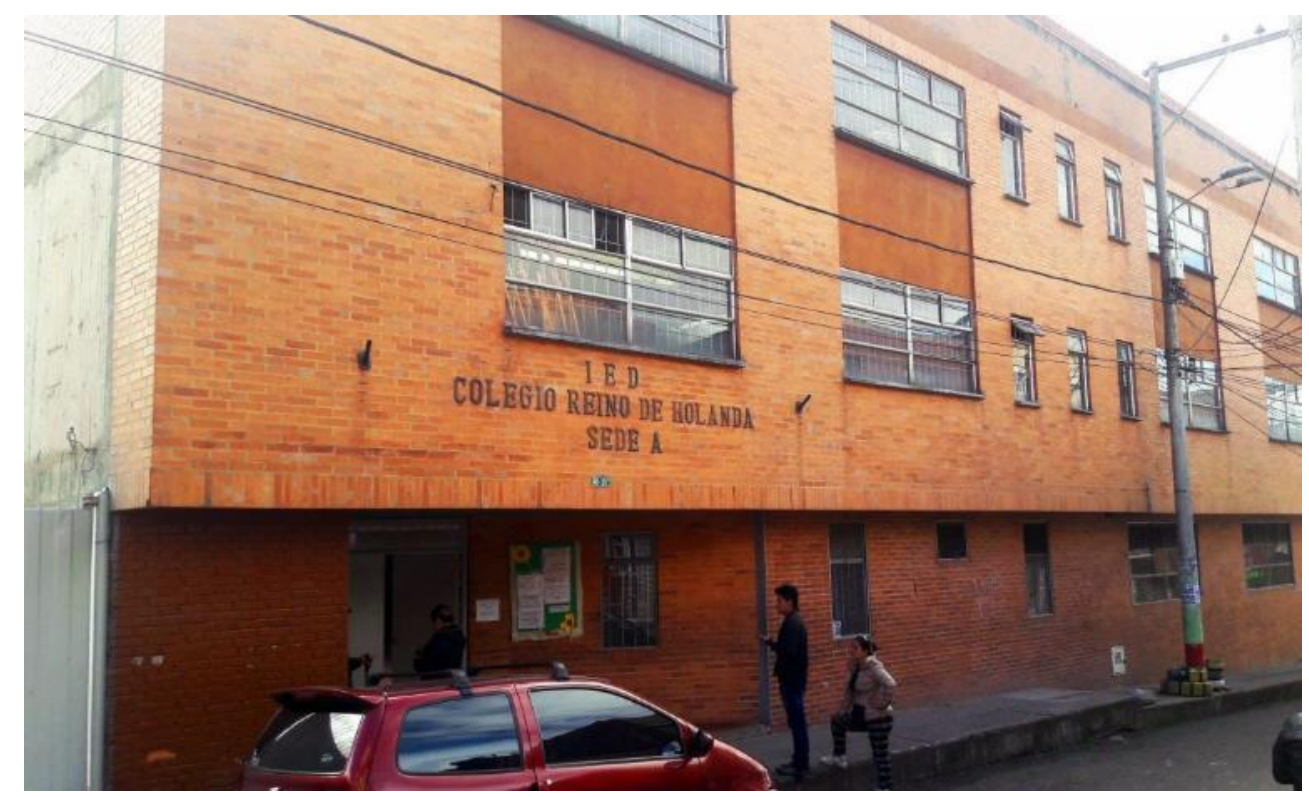

Fuente: Fotografía tomada por Nancy Rocio Portilla Toro,

Tomada el 6 de Julio de 2017

La institución educativa distrital Reino de Holanda desde ahora (RH) se encuentra ubicada en el barrio Marco Fidel Suárez, en la transversal 16 D 46 - 35 Sur, en la localidad 18 Rafael Uribe Uribe, la cual se sitúa al suroriente de Bogotá, limita con las localidades de San Cristóbal (4) al oriente, por el occidente con la localidad de Tunjuelito (6), al norte con la localidad de Antonio Nariño (15) y al sur con la localidad de Usme (5). El nombre de la localidad se debe al parlamentario antioqueño, Rafael Uribe. Está dividida en cinco UPZ: San José Sur, 
Quiroga, Marco Fidel Suárez, Marruecos y Diana Turbay. Según el Plan de Ordenamiento Territorial (POT) tiene una población de 384.851 habitantes en 116 barrios.

Socioeconómicamente la mayor parte de la población presenta condiciones de pobreza, especialmente la que se encuentra ubicada en las zonas altas de la localidad: Marruecos, Marco Fidel Suárez y Diana Turbay (SRD, 2014).

El colegio Reino de Holanda, cuenta con 2867 estudiantes, 120 docentes y 7 directivos, en sus tres sedes; la sede A se encuentra ubicada en el barrio Marco Fidel Suárez, con grados de sexto a undécimo en jornada única, con horario de 6:30 a.m. a 3:30 p.m.; la jornada nocturna trabajan con los ciclos III, IV, V con horario de 6:30 a 10:00 p.m.; la sede B está ubicada en el barrio San Jorge, trabaja con niños de segundo a quinto de primaria en las jornadas mañana y tarde y la sede C se ubicada en el barrio Marco Fidel Suárez, trabaja con niños de jardín y transición, en jornada mañana y tarde.

La institución educativa $\mathrm{RH}$, lidera procesos académicos orientados al fortalecimiento de las matemáticas, de igual manera cuenta con la modalidad académica.

El colegio (RH) basa su filosofía en el PEI "Educación para la productividad basado en los valores y la comunicación", orientando su quehacer pedagógico en la formación integral de los niños, niñas y jóvenes a partir de sus habilidades y destrezas que les permite construirse como personas autónomas y responsables dentro de la sociedad.

1.1.5 Análisis de la caracterización de las Instituciones Educativas

Las cuatro instituciones educativas se encuentran en dos territorios ambientales de Bogotá, LLM y RH en el territorio del río Tunjuelito y CR y MZO en el territorio del río Fucha; 
en cuanto a su ubicación las instituciones LLM y MZO están al suroccidente, en dos grandes localidades (Bosa y Kennedy), mientras que CR y RH están ubicadas en un sector central de la ciudad, en dos localidades más pequeñas (Mártires y Rafael Uribe Uribe).

Otro aspecto a considerar es que, en promedio, LLM, MZO y RH atienden población de estrato 2, mientras CR atiende población de estrato 3. Al revisar el tamaño de las cuatro instituciones educativas, teniendo en cuenta la población que atiende, se puede ordenar por tamaño decreciente LLM, MZO, RH y CR, además las localidades de Bosa y Kennedy tienen una tradición indígena reflejada en su historia y población, la localidad de los Mártires tiene importancia histórica, económica y arquitectónica, la localidad de Rafael Uribe Uribe ha tenido un predominio residencial y actividad comercial minorista.

En cuanto al perfil educativo de las instituciones se pudo establecer que las cuatro IED tienen todos los niveles educativos (Preescolar a Undécimo), dos (LLM y MZO) tienen doble jornada (mañana y tarde), CR ofrece jornada única para la media mientras que la básica está en doble jornada (mañana y tarde), y RH tiene jornada única, mañana y tarde y nocturna. Con respecto al PEI las IED LLM y RH tienen un enfoque comunicativo mientras que MZO está dirigido hacia la formación transdisciplinar y CR a la calidad humana y la competitividad; en relación a la misión institucional la IED LLM está encaminada a la formación de gestores de proyectos culturales, $\mathrm{MZO}$ a la gestión empresarial y diseño gráfico, $\mathrm{CR}$ al diseño gráfico e industrial, y RH a las matemáticas y música. En cuanto a inclusión de conceptos de educación ambiental en el proyecto educativo institucional (PEI), la institución RH no referencia la EA dentro de su PEI, mientras que LLM la incluye en los principios institucionales, MZO en la 
misión, las competencias y los principios institucionales, por último CR la incorpora en la misión y en los principios institucionales.

Por medio de los diferentes instrumentos de observación, como fotografías y diarios de campo, se estableció que los estudiantes hacen uso inadecuado del agua en sus instituciones, juegan en los baños con el agua, las niñas mojan su cabello, dejan la llave abierta mientras lavan sus dientes o enjabonan sus manos. Frente a esta problemática y de acuerdo con los lineamientos de la Unesco, el Ministerio del Medio Ambiente (MMA) y el IDEAM, difundieron campañas como "Todos por el agua", con el propósito de formar conciencia ambiental en los niños, niñas y jóvenes de los colegios distritales, bajo el lema 'Agua y desarrollo sostenible' que a través de acciones pedagógicas llama a la reflexión y promoción del uso racional del agua.

\subsection{Antecedentes del problema}

Para identificar el problema de investigación se aplicaron y analizaron diarios de campo, una encuesta diagnóstica, los PRAE y sus DOFA (Diagrama de Debilidades, Oportunidades, Fortalezas y Amenazas) institucionales y los recibos de acueducto y alcantarillado de los hogares de los líderes ambientales, así mismo se realizó un rastreo y análisis bibliográfico.

Según el estudio realizado de los diagnósticos PRAE de las cuatro instituciones educativas, se evidenció una problemática generalizada con el manejo del agua, la calidad del aire y el exceso de ruido. En relación a la calidad del agua de los ríos (Figura 6) y humedales que se encuentran cerca de las cuatro instituciones educativas, se percibe el deterioro en que se encuentran por su grado de contaminación, Anexo 10, por la disposición inadecuada de los residuos sólidos por parte de vecinos y habitantes de calle, que provoca el estancamiento de los 
desechos y el vertimiento de aguas negras, generando malos olores y convirtiéndose en focos de enfermedades (Figura 11).

Figura 6. Río Fucha, sector de la Calle 16 con Carrera 83

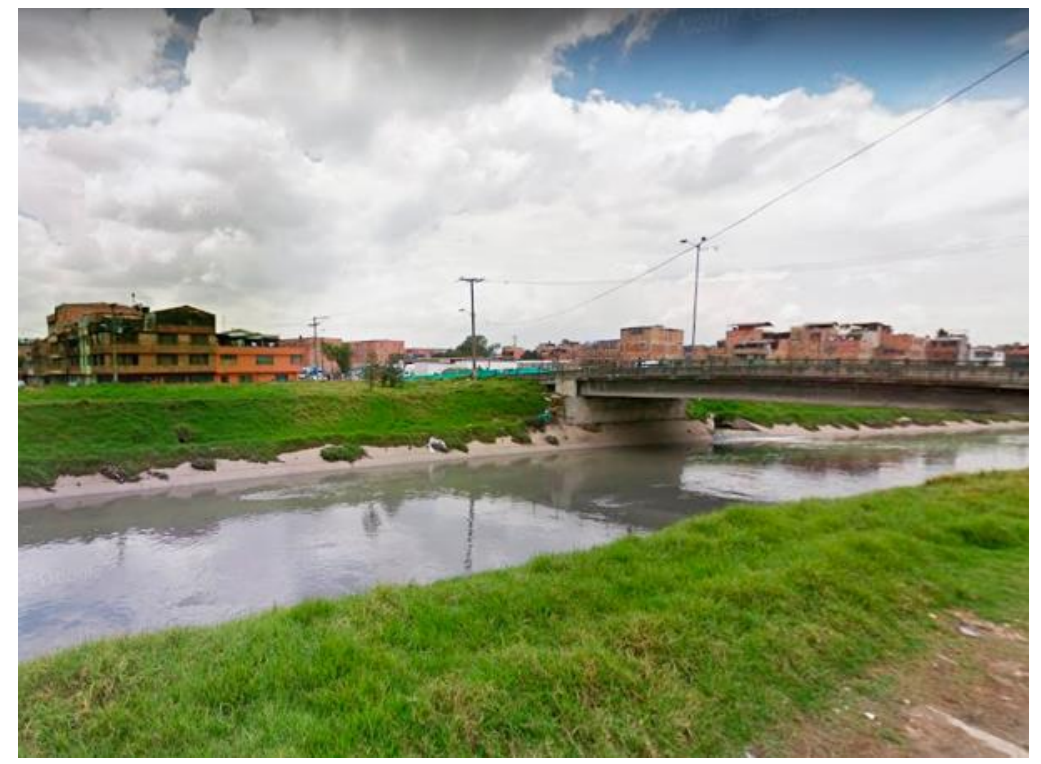

Fuente: Fotografía tomada por Adriana Montes Flórez

Tomada el 29 de Julio de 2017

Figura 7. Río Bogotá al occidente de la ciudad

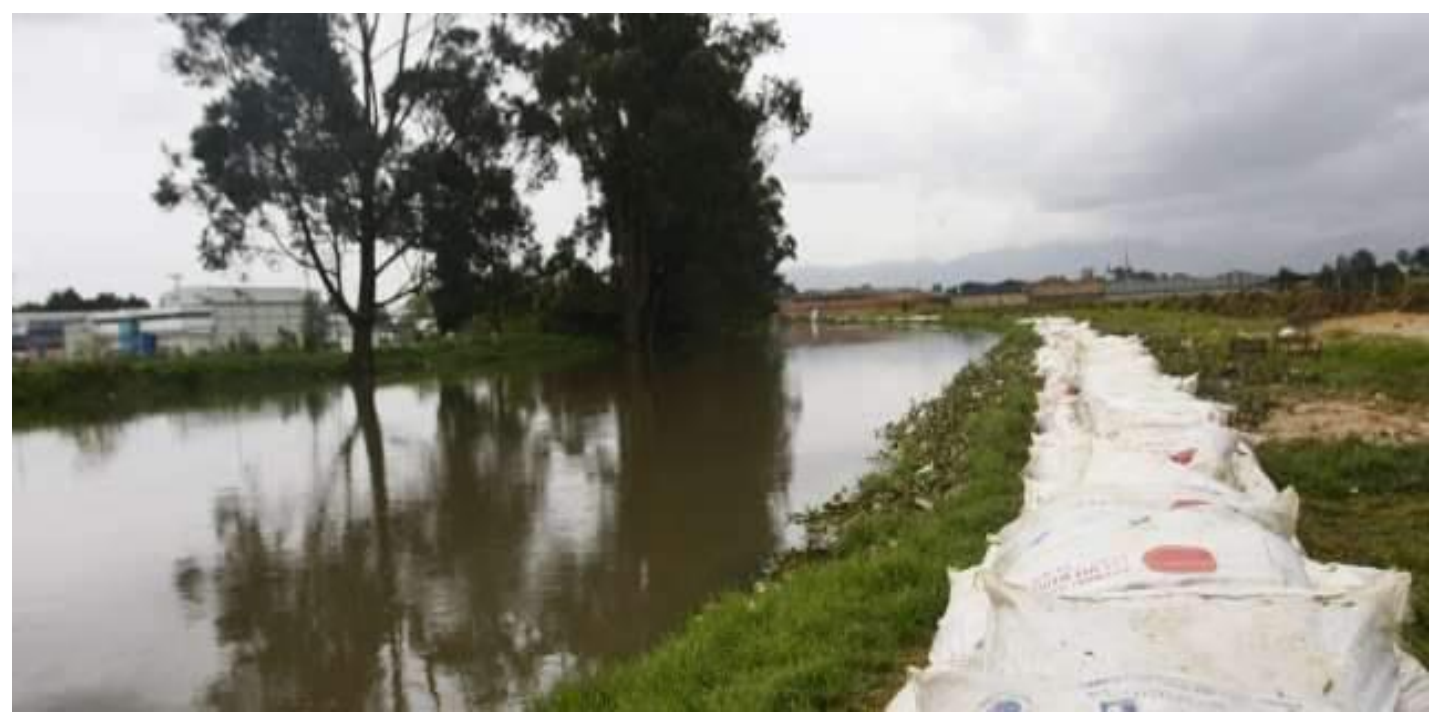

Fuente: Fotografía tomada del diario El Colombiano, Disponible en: https://goo.gl/CeWFGk 
Figura 8. Río Tunjuelito, Sector Villa de los Sauces

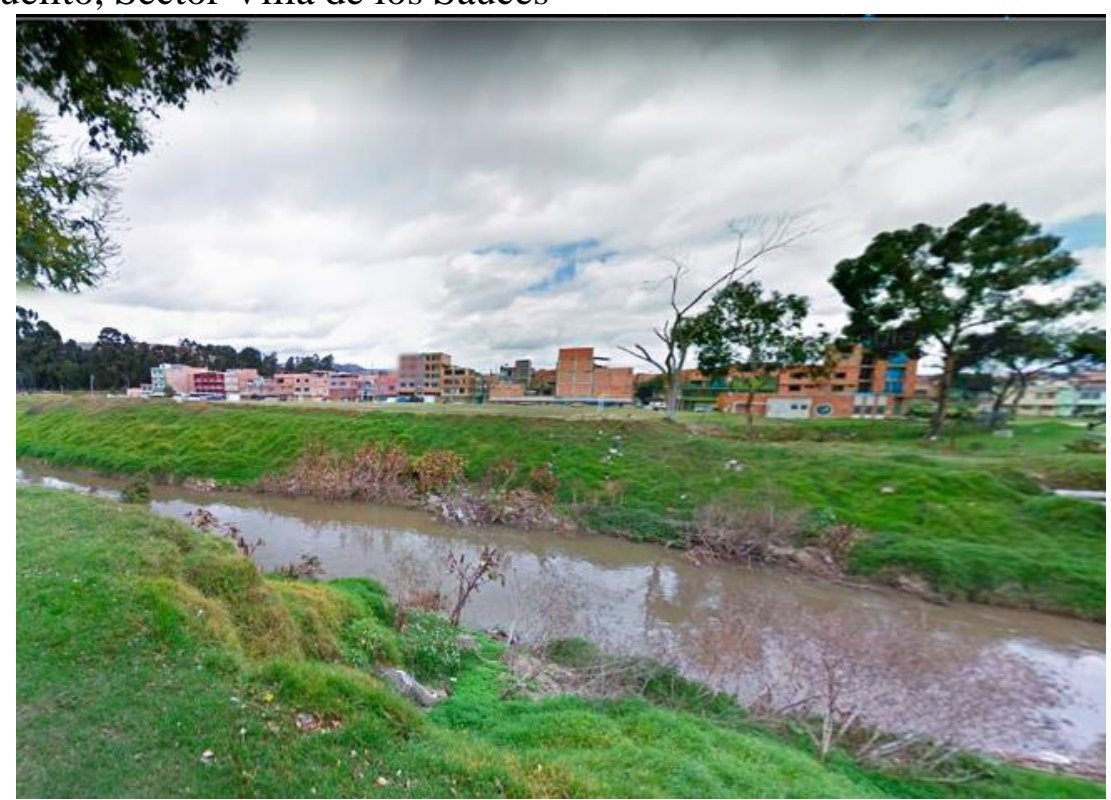

Fuente: Fotografía tomada por María Eugenia Vásquez Mogollón Tomada el 10 de Julio de 2017

La zona de la institución educativa Luis López de Mesa, presenta contaminación de las aguas de los ríos Bogotá (Figura 7), Tunjuelo (Figura 8) y del humedal Tibanica (Figura 9), por desechos domésticos e industriales, de fábrica y frigoríficos, por su ubicación en zonas bajas presenta inundaciones y estancamiento de aguas, provocando mal olor generando contaminación.

Figura 9. Humedal Tibanica ubicado en la localidad de Bosa

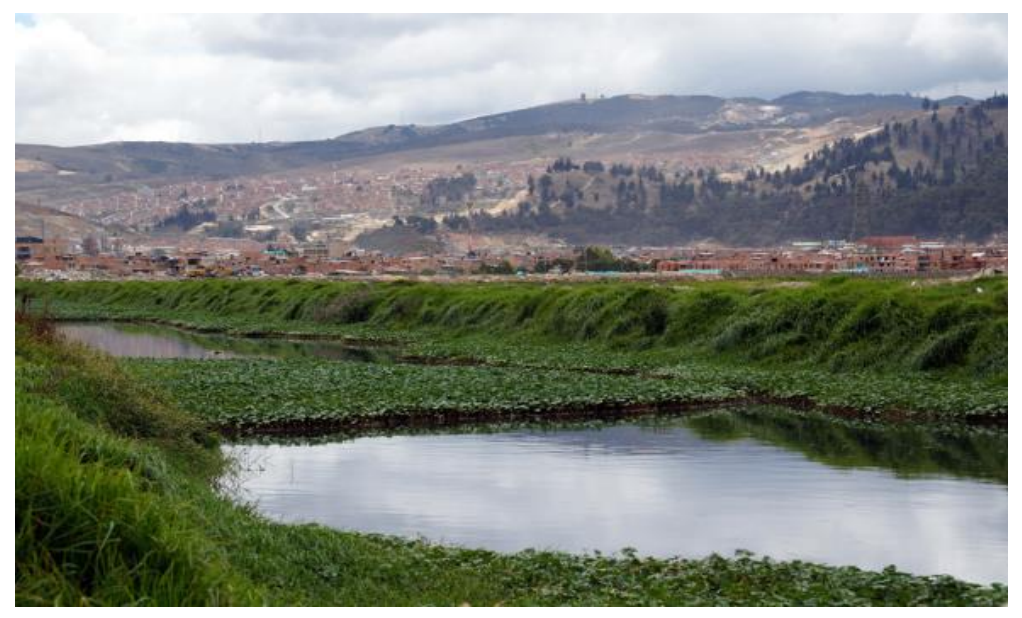

Fuente: Fotografía tomada por Secretaría Distrital del Medio Ambiente, disponible en http://ambientebogota.gov.co/web/web-ninos/tibanica 
La contaminación que presenta la zona de la IED Manuel Zapata Olivella es debido a la afectación del humedal Chucua del Burro (Figura 10), y los ríos Fucha y Bogotá, perjudicados por el vertimiento de aguas negras y basuras, generados en los barrios circunvecinos el Tintal, Patio Bonito, Dindalito, María Paz, Castilla, Valladolid, Ciudadela Kennedy y Roma.

Figura 10. Humedal Chucua del Burro

Fotografía tomada por Adriana Zoraida Montes Flórez

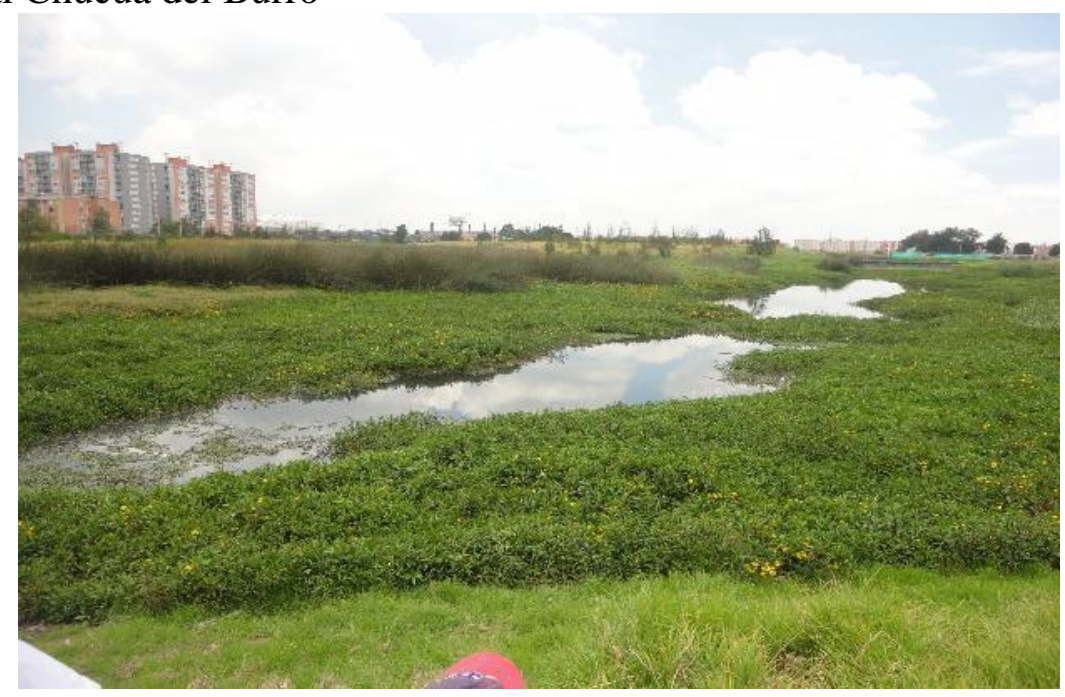

Tomada el 17 de Febrero de 2017

La contaminación que presenta la zona de la IED Ricaurte, es debido al vertimiento de residuos industriales, ocasionado por las empresas comerciales y metalmecánica del sector, sumado a las conexiones hidráulicas inadecuadas y clandestinas que rodean las fuentes hídricas.

La contaminación que presenta el sector de la IED Reino de Holanda, se debe a la polución de las aguas de la quebrada Chiguaza, el vertimiento de aguas negras de los barrios Diana Turbay, Villa Ester, Reconquista y Palermo Sur.

Los efectos provocados en las zonas aledañas a las instituciones educativas, generan riesgos de salubridad y detrimento en la calidad de vida de los habitantes al contagiarse de enfermedades, 
deterioro y agotamiento del recurso hídrico, cambio en las características fisicoquímicas del agua, minimización de la estructura ecológica ambiental, proliferación de vectores, deterioro del paisaje y aumento de riesgo de inundaciones y desastres naturales.

De acuerdo a los DOFA analizados, las instituciones educativas presentan problemas en cuanto a su ejecución y continuidad en el PRAE, al parecer el principal factor que genera esa situación es la falta de coordinación en el trabajo cooperativo entre estudiantes y docentes que participan en él, se evidencia en las pocas actividades que se desarrollan y no se vuelven a ejecutar, además por la falta de sistematización de las experiencias. De igual manera, se evidencia dificultad en la coordinación por parte de los docentes líderes del PRAE, situación que se agrava cuando pertenecen a jornadas diferentes.

En cuanto a las oportunidades, las tres instituciones cuentan con programas de capacitación, tanto para docentes como para estudiantes, lo que les permite fortalecer conocimientos, así mismo disponen de recursos para organizar campañas de aseo y fortalecimiento de conductas proambientales, principal objetivo de los PRAE.

Con relación a las fortalezas, las instituciones educativas han asumido con responsabilidad y empoderamiento las actividades relacionadas con la adecuación de elementos y procesos para hacer la separación de residuos sólidos en puntos ecológicos. Esto ha contribuido a mejorar no solo en conocimientos, sino en comportamientos en el manejo adecuado de residuos como se puede constatar en trabajos anteriores de esta línea de investigación (García, 2015; Serrato, Suavita \& Jaimes, 2015). Otra fortaleza de las cuatro instituciones consiste en la proyección social del proyecto a través de canales de comunicación como Facebook y YouTube, donde se socializaron actividades, avances y divulgación de conocimientos proambientales. 
La mayor amenaza que enfrentan las instituciones educativas consiste en la falta de conciencia y participación de la comunidad vecina, puesto que arrojan las basuras en los alrededores, generando contaminación y deterioro urbanístico (Figura 11). La segunda amenaza es la falta de trabajo cooperativo por parte de los docentes en los cuatro colegios.

Figura 11. Inadecuada disposición de residuos por parte de la comunidad vecina a la IED Manuel Zapata Olivella

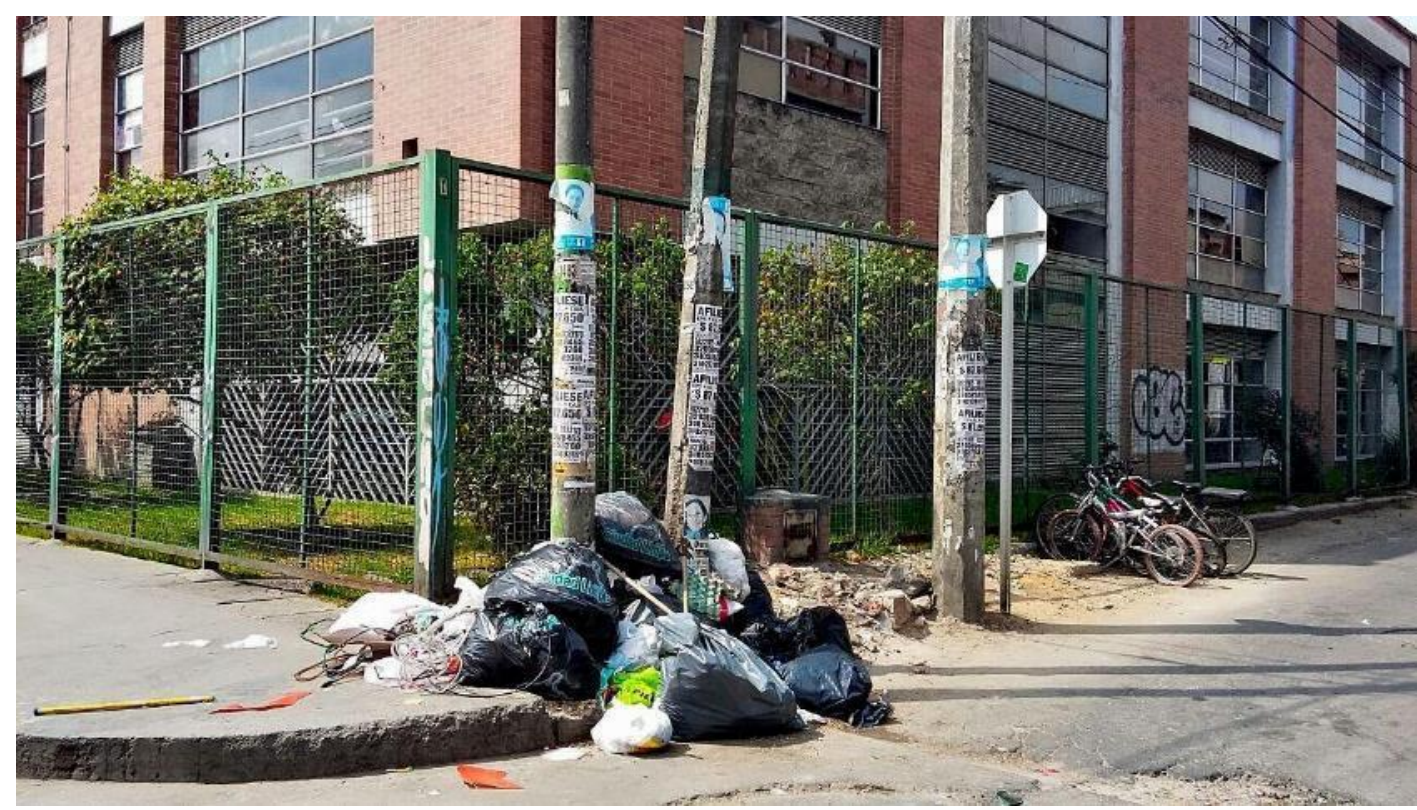

Fuente: fotografía tomada por Adriana Montes Flórez

Tomada el 8 de marzo de 2016

Para reconocer de manera diagnóstica el nivel de conocimientos, actitudes y

comportamientos proambientales de los estudiantes y sus familias, se aplicó una encuesta (Anexo 1) con el fin de reconocer el núcleo familiar, el estrato, el valor que cancelan del servicio de acueducto, alcantarillado y recolección de basuras, y hábitos en el uso del agua dentro del hogar, entre otros. Los resultados demostraron falta de claridad sobre conceptos proambientales como recurso hídrico, importancia del agua, hábitos del uso del agua en el aseo personal y del hogar, esto puede deberse a la falta de un apropiado y continuo direccionamiento en los proyectos de educación ambiental. 
El cuestionario de 23 preguntas se aplicó a 3 estudiantes de cada de las cuatro instituciones educativas los cuales las llevaron a sus casas y lo respondieron con alguno de sus padres, al día siguiente lo entregaron a cada uno de los docentes investigadores para su análisis.

A continuación se presentan los resultados que arrojó su aplicación teniendo en cuenta las categorías de análisis del problema de investigación.

Tabla 1.

Preguntas de la encuesta diagnóstica y categorías de análisis.

\begin{tabular}{|c|c|c|c|c|c|c|c|}
\hline & PREGUNTA & 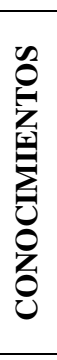 & 罗 & 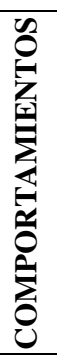 & $\sum_{\underline{\Sigma}}^{\Xi}$ & 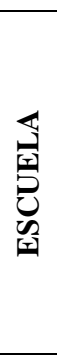 & 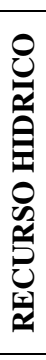 \\
\hline 1 & ¿Cuántas personas conforman su hogar? & & & & & & \\
\hline 2 & ¿A qué estrato pertenece su hogar? & & & & & & \\
\hline 3 & ¿Cuánto paga usted mensualmente por el servicio de agua? & & & & & & \\
\hline 4 & ¿Sabes qué es el recurso hídrico? & & & & & & \\
\hline 5 & ¿Cree que es importante el agua? & & & & & & \\
\hline 6 & ¿Cuenta brevemente qué usos dan al agua en tu casa? & & & & & & \\
\hline 7 & ¿Qué opinas sobre el cuidado del agua? & & & & & & \\
\hline 8 & ¿En tu casa reciclan el agua? & & & & & & \\
\hline 9 & ¿Cuáles hábitos de reciclaje practican con el agua en tu casa? & & & & & & \\
\hline 10 & ¿Qué acción crees que es la correcta cuando se lava un vehículo & & & & & & \\
\hline 11 & $\begin{array}{l}\text { ¿Para lavar el frente de tu casa usarías manguera o cubeta o que otro } \\
\text { elemento? }\end{array}$ & & & & & & \\
\hline 12 & ¿Cuánto tiempo duras en la ducha cuando te bañas? & & & & & & \\
\hline 13 & $\begin{array}{l}\text { Mientras se calienta el agua de la ducha, ¿recoges el agua fría que va } \\
\text { saliendo? }\end{array}$ & & & & & & \\
\hline 14 & $\begin{array}{l}\text { ¿Cierras la llave del agua mientras te enjabonas las manos y/o te } \\
\text { enjabonas los dientes, sí o no? }\end{array}$ & & & & & & \\
\hline 15 & ¿Qué entiendes por reciclar el agua & & & & & & \\
\hline 16 & ¿Qué entiendes por reutilizar el agua? & & & & & & \\
\hline
\end{tabular}




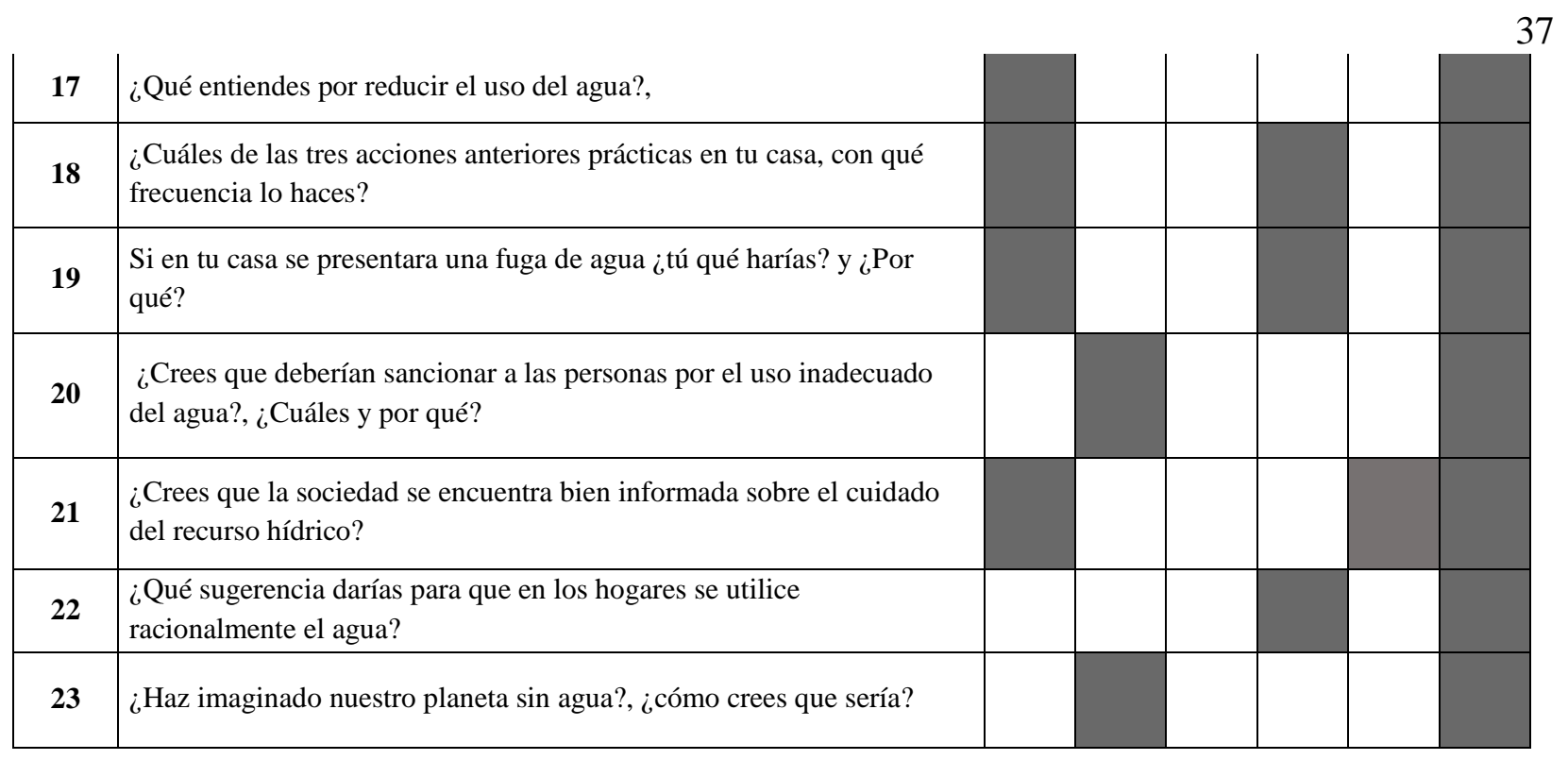

En general se determinó que el 26,09\% de los encuestados tienen conocimientos ambientales relacionados con el uso responsable del recurso hídrico que se evidencia con el manejo adecuado de algunos concepto ambientales como reciclar, reutilizar, separación de residuos sólidos y actúan previendo las consecuencias del empleo inadecuado del agua.

El $34.78 \%$ desarrollaron actitudes y comportamientos ambientales reflejados en el uso adecuado del agua en los diferentes contextos de su vida cotidiana.

De igual manera, en la categoría de familia, algunos ítems que preguntan sobre aspectos de valor en el consumo, los resultados muestran que hay hogares donde los costos son altos, lo que no demuestra que haya un desconocimiento en el uso adecuado del agua; esto es debido diversas circunstancias que afectan los costos, por ejemplo: el estrato en que viven, cantidad de personas que integran el núcleo familiar y ciertas épocas del año que implican un mayor consumo del agua. 
Finalmente en la categoría escuela, se puede inferir que gran parte del desconocimiento de los estudiantes sobre procesos ambientales, es debido a que en las instituciones educativas no se han fortalecido dichos conocimientos y los pocos espacios que se dan no son continuos.

La problemática tratada en esta investigación también fue identificada a través del análisis de 74 diarios de campo (Anexo 8) tomados desde el 12 de agosto del 2015 hasta el 11 de julio de 2017. Las observaciones que se registraron en los diarios de campo durante la etapa diagnóstica y de ejecución de actividades en las cuatro instituciones educativas (14 de LLM, 23 de MZO, 16 de CR y 21 de RH), surgieron del acompañamiento realizado por los docentes investigadores en los diferentes escenarios, actividades y la cotidianidad de los estudiantes en el desarrollo escolar, donde se observaron los comportamientos y actitudes de estudiantes y padres de familia con el entorno escolar y el medio ambiente en general, la mayoría de los diarios de campo tienen registro fotográfico y audiovisual.

Cada diario de campo (Anexo 8) presenta la fecha de observación, el lugar, el grupo observado, el tiempo en minutos que duró la actividad, por lo tanto la observación y el número de registro y código que permite identificarlo cuenta con un espacio de toma de notas descriptivas, donde se relatan los hechos más importantes para esta investigación, también hay un espacio de registro de las pre-categorías, estas son elementos que conforman el objeto de observación (comportamientos, conductas, conocimientos proambientales, familia, escuela y recurso hídrico), otro espacio para las notas interpretativas, estas hacen reflexión sobre lo observado y por último notas metodológicas que son observaciones sobre cada registro y el instrumento utilizado para evidenciar cada hecho.

Para hacer el diagnóstico se tuvieron en cuenta las observaciones de los diarios de campo, las cuales fueron desarrolladas por el equipo investigador y corresponden a las categorías de 
análisis de la investigación. En este caso conductas proambientales frente al uso del recurso hídrico en los diferentes escenarios donde los estudiantes realizan actividades escolares, como son los espacios de cada institución educativa: salones de clase, baños, patios, zonas verdes y espacios comunes, lugares de visita ambiental, parques y calles donde se realizan actividades deportivas, culturales y pedagógicas programadas por las instituciones.

Los tiempos de observación fueron: la hora del descanso, en el desarrollo de actividades extracurriculares, en salidas pedagógicas y recreativas y en el momento de tomar el refrigerio que se realiza dentro de cada aula de clase.

El análisis de los diarios de campo se realizó a partir de las categorías: conocimiento, actitudes y comportamiento proambiental, familia, escuela y recurso hídrico, las cuales surgieron a partir de la necesidad de llevar a los hogares de los estudiantes una cultura ambiental adecuada y propicia para el medio, además de la revisión de la literatura sobre medio ambiente.

Los diarios de campo arrojaron información importante por ejemplo el mal uso del agua en los baños, la recolección del plástico de los refrigerios para entregar a los centros de acopio, el descuido con el orden y aseo en los diferentes espacios, pero de igual manera, los diarios de campo comenzaron a registrar durante el proceso los cambio de actitudes hacia el entorno, un comportamiento más adecuado y reflexivo en las salidas pedagógicas y mayor compromiso en la protección de los espacios y respeto por las especies en la medida en que se iba implementado las actividades de socialización y formación sobre el cuidado del medio ambiente.

Antes de iniciar el plan de acción en esta investigación, se pudo constatar que en las instituciones educativas, no se desarrollaban actividades de educación ambiental hacia los padres de familias. 
También, se hizo una entrevista semiestructurada (Anexo 2) a dos estudiantes de cada una de las instituciones educativas, que incluian preguntas ¿Cómo utilizas el agua en los baños en tu colegio?, ¿Cómo se manejan los residuos sólidos en tu colegios?, ¿En tu colegio se hacen campañas ambientales?, ¿Actúas de alguna forma para cuidar el ambiente del barrio en que vives, es decir, tu intervienes?, ¿Qué estrategias emplean en tu casa para el ahorro del agua?. Esta entrevista fue transcrita y analizada empleando la metodología de teoría fundamentada mediante una codificación que permitió establecer los conocimientos, actitudes y comportamientos de los estudiantes. Se logró determinar que por medio de los PRAE los estudiante han recibido formación en conocimientos y en hábitos en la separación de residuos, en contraste han trabajado el uso adecuado de los recursos hídricos, reconocen con dificultad la función e importancia de los ríos urbanos y señalan que sus compañeros no suelen tener conciencia sobre el desperdicio del agua en los baños y en el hogar los padres de familia, cuestionan el uso inadecuado del agua cuando deben pagar el recibo de acueducto y alcantarillado, en esa misma línea los estudiantes mencionan que no se suelen hacer campañas para enseñarle a las familias a usar de forma adecuada el recurso hídrico.

De hecho la poca participación de la familia en el desarrollo de actividades de educación ambiental en el uso del agua ha sido señalada en trabajos anteriores. Lo anterior se evidencia en estudios realizados por instituciones de educación superior como La Universidad de la Sabana para favorecer conocimientos, comportamientos y actitudes proambientales en población infantil y adolescente de algunas instituciones educativas, algunos de estos trabajos incluyen un estudio sobre cultura ambiental y fortalecimiento de actitudes proambientales en estudiantes de grado sexto (Barreto \& García, 2015); de igual manera Barreto y Moreno (2015) desarrollaron una investigación para fortalecer los comportamientos proambientales de niños de quinto de primaria y sus familias, a través de estrategias pedagógicas; posteriormente Barreto y Suavita (2015), 
mediante la implementación de estrategias socioeducativas, fortalecieron los comportamientos proambientales en niños de transición; Finalmente se debe mencionar el trabajo de Barreto, Olaya y de la Rosa (2015), quienes estudiaron la implementación de reglas proambientales que favorecen la construcción de la cultura ambiental en estudiantes de los grados sexto y séptimo de educación básica secundaria. Como se puede notar, la línea de investigación en comportamientos proambientales ha estudiado varios factores que determinan el fortalecimiento de una cultura ambiental dentro de las instituciones educativas, pero como se menciona en un trabajo de tesis anterior, hacía falta revisar la relación que se da entre el colegio y la familia en torno a procesos de educación ambiental (Fagua et al., 2016).

Esta situación se complementa con la vulnerabilidad que tiene el recurso hídrico, tal como se puede encontrar en la bibliografía rastreada. En ella se menciona que en algunos lugares del planeta la escasez del recurso hídrico está limitando algunas actividades y condiciones del ser humano como es el caso de la salud, la producción de alimentos y el desarrollo industrial (Guerrero, 2006). teniendo en cuenta que no toda la cantidad de agua existente en el planeta es apta para el consumo humano, porque el $2.5 \%$ es agua dulce y poco menos de $0.3 \%$ es agua superficial, lo que quiere decir que sólo $200000 \mathrm{~km}^{3}$ están disponibles para el consumo humano y el sostenimiento de los ecosistemas naturales, por consiguiente, si esa información fuera conocida y comprendida por la mayoría de las personas, se fortalecería la visibilización de este problema facilitando la implementación de estrategias de divulgación, educación y sensibilización apropiadas que garanticen la conservación y uso adecuado del agua para lograr la disponibilidad de este recurso para las futuras generaciones.

El afán por explotar el recurso hídrico en beneficio de unos pocos, está agravando las desigualdades sociales y económicas, y aumentando brechas tecnológicas y niveles de 
productividad entre naciones, lo cual genera relaciones comerciales desfavorables que agravan la crisis ambiental (WWAP, 2015). Esas conductas generan preocupación frente a una futura escasez del agua y hace necesario un cambio de actitud frente al uso responsable del recurso hídrico.

A propósito Castillo (2010) plantea que el actual desequilibrio ambiental, no solo es un problema regional, por el contrario es una problemática global, donde priman los intereses particulares sobre los intereses colectivos, que se manifiestan en el deterioro de la capa de ozono, el efecto invernadero, el cambio climático y la escasez evidente de las fuentes hídricas, que ponen en riesgo el bienestar de la humanidad.

García (2015) manifiesta que las acciones humanas han ocasionado problemáticas ambientales, que obliga a entidades gubernamentales a diseñar normas que regulen y controlen la interacción del hombre con los ecosistemas. En este contexto las instituciones educativas desarrollan estrategias para fomentar comportamientos proambientales que favorecen el uso adecuado del agua y la implementación de procesos de educación ambiental que responda asertivamente a cada ciudadano.

Los antecedentes presentados demuestran que tanto en las instituciones educativas como en los hogares hace falta fortalecer conocimientos, actitudes y conocimientos proambientales, lo cual sucede a pesar de que las IED cuentan, por norma, con el PRAE. Además los proyectos ambientales suelen centrarse en manejo de residuos sólidos, dejando de lado otras problemáticas ambientales, como el caso del uso adecuado del recurso hídrico. De igual modo se constata que dentro de los hogares también hacen falta conocimientos, actitudes y comportamientos proambientales, situación que se convierte en una oportunidad para desarrollar educación ambiental con la familia. De esta forma se genera la necesidad de estudiar la forma como los 
procesos de educación ambiental que se desarrollan en las instituciones educativas pueden incidencia en el ámbito familiar

\subsection{Justificación}

Los seres humanos son los responsables del deterioro ambiental, situación que ha empeorado por los modelos económicos extractivos, la desigualdad social, la pérdida de la biodiversidad, la disminución de las reservas pesqueras, la desertificación de la tierra, el cambio climático, los desastres naturales, la contaminación y la pérdida de los recursos hídricos (ONU, 2002). Estas circunstancias se deben principalmente a la falta de un modelo de desarrollo sostenible que adopte la formación ciudadana en conocimientos proambientales y así lograr que estos muestren actitudes y comportamientos favorables para el ambiente.

Colombia, por su ubicación geográfica, topografía y altas precipitaciones (1800 mm anuales en promedio) cuenta con 90 ríos, arroyos, quebradas y manantiales, 2554 ciénagas, lagunas, embalses y pantanos, y 5 grandes cuencas hídricas que conforman las 1120 fuentes de abastecimiento de agua potable apta para el consumo humano (Carranza 2014). No obstante, debido al manejo inadecuado de este recurso el 50\% del agua disponible no puede utilizarse por problemas de calidad (indicadores de contaminación), se presenta desigualdad en el acceso a dicho recurso (96\% de cobertura en las zonas urbanas y $56 \%$ en las zonas rurales), alta huella hídrica del sector agrícola e industrial y la falta de un adecuado manejo de aguas residuales, lo cual hace prioritario el cambio de comportamientos hacia el agua (Carranza 2014).

Esta investigación se enfoca en el estudio de comportamientos proambientales en relación al manejo adecuado del recurso hídrico en instituciones educativas y el hogar, además otras problemáticas ambientales que debido a su complejidad, la comprensión de sus procesos y la 
labor de comprometer a las comunidades en la generación de soluciones es la esencia de la (EA), (Avendaño, 2012), en el cambio social y en la adopción de la (EA) como filosofía de vida (Coutiño, 2011). La EA tiene estos objetivos, razón por la cual su investigación contribuye a transformar la forma como se entienden esos problemas ambientales, empleando la investigaciónacción como diseño que favorece tanto la descripción de los problemas ambientales como la búsqueda de soluciones (Flores, 2012). La investigación en EA además de estudiar la eficiencia de las estrategias de intervención, la construcción de currículos, la implementación de políticas y el trabajo interdisciplinar, se ha enfocado en analizar los factores psicológicos como es el caso de la generación de comportamientos ambientalmente relevantes (Medina \& Páramo, 2014).

Figura 12. Argumentos de la justificación del proyecto
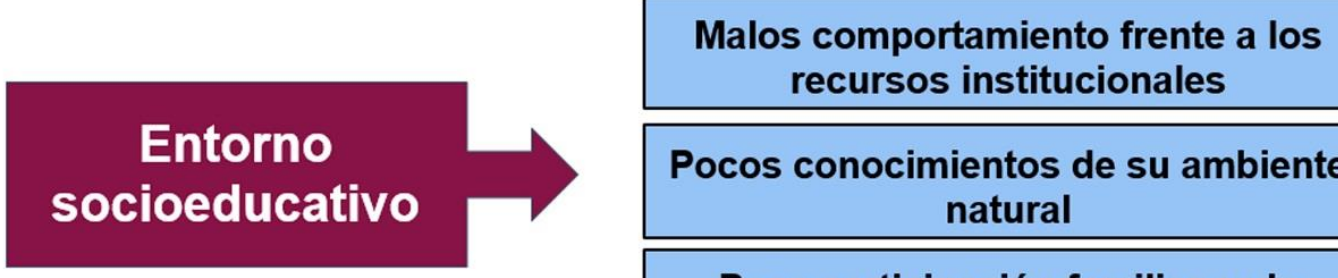

Poca participación familiar en la construcción de cultura proambiental

Contaminación de ecosistemas

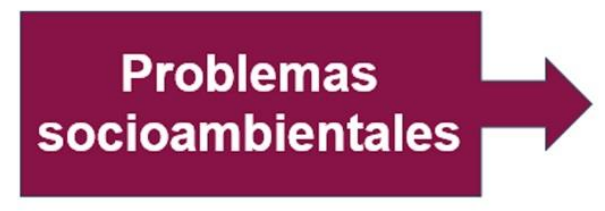

Cambios extremos en el clima

Disminución de la accesibilidad al recurso hídrico

Pérdida de la biodiversidad

Imagen diseñada por el equipo investigador.

Desde este enfoque se pretende lograr que los líderes ambientales y en sus hogares presenten cambios de comportamiento proambiental “entendido como aquella acción humana sobre el medio, que tiene como finalidad disminuir, evitar e idealmente revertir, el deterioro de 
los recursos del ambiente natural que sustentan la vida en la Tierra” (Bustos, Flores \& Andrade, 2004). En esta investigación se acoge la definición postulada por Corral (2000), quien afirma que el comportamiento proambiental es "el conjunto de acciones deliberadas y efectivas que responden a requerimientos sociales e individuales y que resultan en la protección del medio" (Martínez-Soto, 2004, p.5).

Estos comportamientos proambientales son objeto de la EA, teniendo en cuenta que la divulgación y la educación, “incluyendo la concienciación y el entrenamiento, provee el complemento indispensable de otros instrumentos del manejo ambiental" (CAR, 2006, p.20). En este contexto se crearon los Proyectos Ambientales Escolares (PRAE), como herramienta pedagógica que se desarrolla en las instituciones educativas con el fin de promover la EA desde las aulas de clase con el apoyo interdisciplinar de la comunidad educativa, donde se den espacios de formación tanto en valores como en comportamientos ambientales que conlleven a mitigar la problemática local.

Lo anterior se evidencia en los trabajos de investigación realizados en los postgrados de la Universidad La Sabana con las tesis presentada por García (2015). Este trabajo investigativo integró estudiantes del curso 603 de la jornada de la mañana del Colegio Kimy Pernía Domicó, de la localidad séptima de Bosa, el objetivo de este proyecto fue el fortalecimiento de actitudes proambientales en los estudiantes de ciclo tres, el cual incluía la gestión de los residuos sólidos y uso racional del recurso hídrico.

Igualmente, Serrato, Suavita y Jaimes (2015) implementaron y ejecutaron una propuesta de intervención desde el Plan Operativo del Proyecto Ambiental Escolar (PRAE), que promovió la participación de los miembros del Comité Ambiental Escolar (CAE), de tres instituciones 
educativas oficiales de Bogotá D.C. Los resultados revelaron que cuando el PRAE es activo y tiene un plan en ejecución contextualizado, tiene el potencial de ser una herramienta transformadora de la realidad y un instrumento activo del Proyecto Educativo Institucional. Igualmente este proyecto demostró que los hábitos adquiridos en casa y fortaleciendo en las conocimientos y actitudes proambientales en las escuelas promueve comportamientos benéficos para construir una sana cultura ambiental en las instituciones.

Además, González (2016) realizó en el Colegio Costa Rica IED, ubicado en la Localidad de Fontibón, durante el período comprendido entre 2014 y 2015, una intervención pedagógica con el objetivo de fortalecer los procesos de construcción de la cultura ambiental, a través del fortalecimiento de cuatro rutinas de pensamiento ambiental y algunas competencias científicas y pro ambientales, tales como observar, indagar y comunicar, que hizo que los estudiantes actuaran de forma más consciente y responsable con su entorno principalmente dentro del aula.'0p

Por otra parte, Bohórquez, Moreno, Olaya, Piña y Shaw (2016). Implementaron estrategias socio educativas en cinco colegios oficiales de Bogotá, la cual fortaleció la cultura ambiental escolar, a través de acciones pedagógicas basados en cuatro estrategias pedagógicas, generando en estudiantes y maestros conocimientos, actitudes y comportamientos que contribuyen con el cuidado del ambiente.

Por último, Fagua, Moreno, Medina, Serrato y Velásquez (2016). Realizaron un trabajo de investigación en tres colegios oficiales de Bogotá, durante el periodo comprendido entre el 2014 y 2016, en el cual determinaron la influencia de los espacios escolares en los comportamientos proambientales de los estudiantes. 
En esta investigación se pretende identificar la forma como los PRAE articulan los conocimientos, actitudes y comportamientos proambientales en la relación familia y escuela, esto conlleva ver la realidad de la familia con el concepto de desarrollo sostenible (d'Entremont, 2007). Teniendo en cuenta que la familia es el núcleo de la sociedad donde se adquieren los valores éticos y humanos, ambientales, sociales y culturales, resulta fundamental investigar las dinámicas educativas que se llevan en su interior, puesto que, como lo menciona d'Entremont (2007), la familia juega "un papel muy importante con el desarrollo cultural y social como institución natural en la base de la sociedad, ... sólo una familia sostenible y sostenida puede conducir a un verdadero desarrollo sostenible y sostenido". (p.21).

\subsection{Formulación del problema}

En las cuatro instituciones educativas se aplicaron instrumentos como encuestas, entrevistas, desarrollo de talleres y diarios de campo a los estudiantes miembros del Comité Ambiental Escolar (CAE) y sus familias. Dicha indagación permitió inferir que tanto los menores como sus núcleos familiares requieren motivación en torno a asuntos ambientales, situación generalizada en las instituciones en Bogotá, como lo manifiesta Serrato (2015) quien afirma que los proyectos ambientales que se desarrollan en los colegios, no están generando o fortaleciendo conocimientos ambientales que conlleven a adoptar actitudes que favorezcan la preservación de los ecosistemas.

Al parecer la falta de motivación por asuntos ambientales se debe a varios factores, como la condición socioeconómica, la falta de infraestructura necesaria, las características culturales y frecuentemente a la ausencia de conocimientos ambientales. Además los PRAES no tienen la suficiente continuidad, por lo que las interrupciones a lo largo del año escolar impiden que los proyectos cumplan con sus objetivos. 
De esta manera no se generan las actitudes necesarias para evitar comportamientos como mojarse el cabello, dejar las llaves abiertas, jugar con el agua, no alertar sobre escapes de agua, y botar basura que obstruyen sifones, entre otras conductas que reflejan falta de una cultura ambiental hacia los recursos hídricos.

Otro de los aspectos importantes, que se puede destacar a través de los diferentes instrumentos aplicados, es que no se comprende de manera suficiente la influencia que tienen las familias en las conductas proambientales de los estudiantes, puesto que se asume que los hábitos que ellos practican en la escuela son el reflejo de las vivencias cotidianas de sus hogares, de igual forma se desconoce si el colegio puede influir en los conocimientos, actitudes y comportamientos proambientales que se dan en la familia de los estudiantes. Teniendo en cuenta que los PRAE sólo pueden desarrollar actividades educativas directamente con los menores, la presente investigación se enfocó en la forma como las educación ambiental liderada por las instituciones educativa puede generar cambios en la cultura ambiental de las familias.

Teniendo en cuenta el problema identificado, el desarrollo de este proyecto partió de la formulación de la siguiente pregunta de investigación: ¿Cuál es la incidencia que tienen los conocimientos, actitudes y comportamientos proambientales de los estudiantes y sus familias, de cuatro instituciones educativas distritales de Bogotá, en el uso responsable y pertinente del recurso hídrico?

\subsection{Objetivos}

\subsubsection{Objetivo General.}

Establecer la incidencia que tienen los conocimientos, actitudes y comportamientos proambientales de los estudiantes y sus familias de 4 instituciones educativas de Bogotá, en el uso responsable y pertinente del recurso hídrico. 


\subsubsection{Objetivos Específicos.}

- Determinar los contextos socioeconómicos y ambientales de las cuatro instituciones educativas objeto de la investigación

- Identificar y describir los conocimientos, actitudes y comportamientos proambientales de los vigías ambientales y sus familias frente al uso responsable del recurso hídrico

- Desarrollar estrategias pedagógicas en las instituciones educativas que promuevan comportamientos pro-ambientales en la familia con relación al uso responsable del agua. 


\section{Marco teórico}

El presente apartado está conformado por tres subcapítulos, el primero presenta los referentes teóricos que son la base de esta investigación, entre los cuales se encuentran los conocimientos, actitudes y comportamientos proambientales, la educación ambiental y los demás conceptos pertinentes en el desarrollo de este trabajo que son: Proyecto Ambiental Escolar (PRAE), Comité Ambiental Escolar (CAE), la relación familia y escuela, así como los conocimientos, actitudes y comportamientos proambientales en la familia y la gestión social del recurso hídrico. Se enfatiza el estado actual de los recursos hídricos nacionales y las estrategias

de educación ambiental para la gestión de este recurso. En el segundo subcapítulo se presenta el estado del arte, que muestra una revisión bibliográfica de las investigaciones que se han desarrollado recientemente relacionadas con el problema de investigación y el tercero presenta el marco legal con los referentes normativos en los que se apoyó esta investigación.

\subsection{Referentes Teóricos}

Para el desarrollo de este trabajo se tuvieron en cuenta como ejes fundamentales los conceptos de cultura ambiental (CA), Educación y conocimientos, actitudes y comportamientos proambientales en la familia.

\subsubsection{Cultura Ambiental.}

En relación a la ubicación geográfica de las instituciones educativas, se pueden identificar convergencias socioeconómicas, tales como la alta actividad comercial, contaminación auditiva, elevado flujo vehicular, desplazamiento de habitantes de calle y presencia de basuras, insectos y roedores. Estas situaciones han permitido que estas zonas, como lo afirma Torres (2011), carecen 
de cultura ambiental, que ha impedido que se generen cambios de comportamiento necesarios para preservar los ecosistemas.

Se entiende por cultura ambiental la manera como el hombre se relaciona con el medio, partiendo de la práctica de valores, que determinan la actitud que le imprime al comportamiento ambiental (Miranda, 2013). La Cultura Ambiental está ligada a los conocimientos, actitudes y comportamientos que el hombre práctica en las acciones diarias, por ende es necesario desarrollar habilidades cognitivas, conductas y actitudes proambientales que integren procesos, los cuales conlleven a la formación de personas capaces de liderar soluciones a problemáticas ambientales ocasionadas por estos mismos. (Corral-Verdugo, Víctor, \& Domínguez Guedea, Rosario Leticia 2011).

De esta forma, Miranda L. (2013) expresa que la CA

Es la manera como los seres humanos se relacionan con el medio ambiente... donde intervienen diferentes disciplinas delimitadas por cuatro variables: creencias, valores, las actitudes y los comportamientos... en la cual se establecen parámetros de relación y reproducción social con relación a la naturaleza. (p.2).

Por otra parte, González- Gaudiano (2002), considera la CA como la disposición para adquirir hábitos, comportamientos y valores que favorecen y fortalecen la relación hombre cultural - medio. La CA pretende disminuir el impacto y los problemas ambientales, contribuir a la transformación de mejoramiento del medio, mediante compromisos y estrategias de acción colectiva en contextos escolares. 


\subsubsection{Conocimientos, Actitudes y Comportamientos Proambientales.}

Los conocimientos proambientales, según la Carta de Belgrado, son las relaciones que mantiene el ser humano consigo mismo y con la naturaleza, esto implica un área de estudio multidisciplinar que abarca distintos elementos como el estudio de los problemas ambientales actuales, la responsabilidad en el actuar humano y los modelos de desarrollo sostenible (UNESCO-PNUMA, 1975).

Algunos estudios manifiestan que no se ha comprobado que poseer conocimientos proambientales esté relacionado con conductas favorables a la conservación del ecosistema (Barazarte, Neaman, Vallejo \& García, 2013), pero sí lo relacionan con el nivel de ingresos, entre mayor sea el ingreso y mayor los conocimientos ambientales, mejor será su conducta proambiental. Lo anterior es apoyado por Hungerford y Volk (1990) citados por Barazarte y otros (2013), quienes afirman que en las personas de menor ingreso, sus conductas proambientales no se ven modificadas por el grado de conocimientos que posean, concluye que las personas de mayor ingreso, son menos indiferentes a la problemática ambiental, que las de menor ingreso.

Adicionalmente otros estudios manifiestan que los comportamientos proambientales (CPA) son herramientas que se adquieren en las instituciones educativas y los medios masivos de comunicación, mientras los hogares intervienen en el cambio de actitudes y comportamientos hacia el ecosistema, y en consecuencia plantean soluciones a la problemática ambiental (Barreto, Serrato, Suavitá \& Jaimes, 2014).

Las actitudes reflejan creencias, preferencias, sentimientos a favor o en contra de algo o alguien y están relacionadas con otras actitudes ya sean aprendidas por el ejemplo o son formadas por el nivel de valores que posea el individuo en relación a la cultura ambiental. Así se 
configuran los pensamientos, acciones y sentimientos que de manera consciente realiza una persona en relación al ambiente (Barraza, 1998).

En relación a las actitudes proambientales Pablo Páramo manifiesta que son las actitudes las que inciden en la disposición que se tenga hacia aspectos o elementos ambientales, por lo tanto si hubiese una inadecuada actitud frente al medio ambiente por parte de los individuos, es en las actitudes donde se debe intervenir para generar cambios proambientales (Páramo, 2015). Así mismo Páramo y Gómez (1997) definen la actitud como la suma de tres elementos: cognitivo, afectivo o conductual, donde el individuo de acuerdo a sus conocimientos sobre el entorno puede generar sentimientos favorables o desfavorables lo que lo lleva a actuar o accionar teniendo en cuenta el sentimiento que le genere determinado aspecto ambiental.

Aun así existe, dentro de la literatura, algunas definiciones que se le atribuyen a los comportamiento proambientales (CPA), puede decirse que son un hábito, una conducta intencional y dirigida o inducida. De otra parte Martínez-Soto (2004) considera que es importante tener claro este concepto para no caer en errores, por ejemplo direccionar mal una investigación, obtener resultados o proponer intervenciones ambientales erradas.

Corral (2000) contribuye con la caracterización del término, con el fin de que se puedan equiparar las diferentes investigaciones evitando concepciones inadecuadas y conclusiones erróneas sobre esta conducta con el fin de contar con una definición más precisa en el desarrollo de objetivos claros de educación ambiental. De acuerdo con su análisis las características fundamentales de la conducta proambiental son:

- Es un producto o resultado, es decir de la preservación de los recursos naturales o al menos la reducción del deterioro.

- Es efectiva, en el sentido de ser intencional y resultado de desplegar habilidades concretas. 
- Presenta un cierto nivel de complejidad, pues requiere la anticipación del resultado de la acción, deliberación para actuar y dirección hacia una meta concreta.

Entendiendo que la huella ecológica es la cantidad de superficie terrestre que la humanidad necesita para extraer los recursos naturales necesarios para sus supervivencia, se puede inferir que la huella ecológica que el hombre deja con el afán de conseguir su sustento y permanencia afecta negativamente los ecosistemas; pero también es cierto que hace un esfuerzo por adoptar conductas proambientales para minimizar los efectos de su acción sobre los recursos naturales, definiendo comportamiento proambiental a un conjunto de acciones que responden a requerimientos sociales e individuales que resultan de la protección del medio (Corral-Verdugo, 2000).

\subsubsection{Educación Ambiental.}

La Ley 99 del 22 de diciembre de 1993 crea el Ministerio del Medio Ambiente (MMA), un organismo encargado de administrar y definir las políticas para la recuperación, conservación, ordenamiento, manejo y protección de los recursos naturales renovables y del medio ambiente, de igual forma la citada ley estructura el Sistema Nacional Ambiental (SINA).

Entendiéndose como SINA al conjunto de programas, recursos, actividades y normas orientadas al logro de los objetivos del MMA y los principios generales de la Constitución Política, las leyes y demás normatividad ambiental. Este sistema lo integran las entidades del Estado responsables de la política y de la acción ambiental, las organizaciones comunitarias y no gubernamentales, entidades públicas, privadas y mixtas relacionadas con la problemática 
ambiental, así como organizaciones dedicadas a la investigación científica y desarrollo tecnológico en el campo ambiental (Villalobos, 2016).

Por otro lado la Ley 115 de 1994 (Ley General de Educación) en su artículo 5, fundamenta la adquisición de una conciencia para la conservación, protección y mejoramiento del medio ambiente, de la calidad de vida, del uso racional de los recursos naturales, de la prevención de desastres, la defensa del patrimonio cultural de la nación, dentro de una cultura ecológica

Cabe destacar la importancia, sobre los esfuerzos que la educación ambiental, ha venido desarrollando en el país, en términos legislativos. En el año de 2002, en el marco de la Política Ambiental del Plan de Desarrollo: “Cambio para construir la paz”, el Ministerio del Medio Ambiente pone en ejecución el Proyecto Colectivo Ambiental, cuya intención es fomentar en los ciudadanos la ética, la responsabilidad, el conocimiento y capacidad, para que se dé soluciones a los problemas ambientales, relevando la importancia a la educación ambiental (MEN-MMA, 2004)

Se debe tener presente que los esfuerzos de la Educación Ambiental se remontan a 1991, cuando fueron dirigidos a implementar de manera sistemática la temática ambiental, dentro del currículum, en el sector educativo tanto formal como informal, esto dentro del marco de la reforma educativa nacional.

Se han logrado avances significativos en el proceso de institucionalización del programa de Educación Ambiental, para dar cumplimiento a las expectativas del Ministerio del Medio Ambiente, de explorar las estratégicas y metodológicas, que conlleven a reflexionar críticamente en torno al concepto de medio ambiente. 
El concepto de ambiente ha sido objeto de análisis y debates académicos desde que la política internacional sobre asuntos ambientales, sentó sus bases en la Cumbre de la Tierra, celebrada en Estocolmo en junio de 1972. La declaración, producto de esta conferencia, presenta al ambiente como un derecho fundamental (Londoño. 2010), Concepto que aún sigue siendo central en la políticas ambientales a nivel global. El principio 1 de la declaración menciona que:

El hombre tiene el derecho fundamental a la libertad, la igualdad y el disfrute de condiciones de vida adecuadas en un medio ambiente de calidad tal que le permita llevar una vida digna y gozar de bienestar, y tiene la solemne obligación de proteger y mejorar el medio ambiente para las generaciones presentes y futuras. (ONU, 1972, p.2).

La Constitución Política de Colombia adoptó esta visión del ambiente como queda consagrado en el artículo 79, donde se menciona:

Todas las personas tienen derecho a gozar de un ambiente sano. La ley garantizará la participación de la comunidad en las decisiones que puedan afectar. Es deber del Estado proteger la diversidad e integridad del ambiente, conservar las áreas de especial importancia ecológica y fomentar la educación para el logro de estos fines (Colombia, 1991, p.14)

En este mismo sentido la Constitución Política, respalda los procesos ambientales a través de varios de sus artículos: La obligación del Estado y de las personas de proteger las riquezas culturales y naturales de la Nación (art. $8^{\circ}$ ); La atención del saneamiento ambiental como servicio público a cargo del Estado (art. 49); la función social que cumple la propiedad, (a la que le es) inherente una función ecológica (art. 58); El reconocimiento de condiciones especiales de crédito 
agropecuario teniendo en cuenta las calamidades ambientales (art. 66); La educación como proceso de formación para la protección del ambiente (art. 67); El derecho de todas las personas a gozar de un ambiente sano; la participación de la comunidad en las decisiones que puedan afectar; y el deber del Estado de proteger la diversidad e integridad del ambiente, conservar las áreas de especial importancia ecológica y fomentar la educación para el logro efectivo de estos fines (art. 79); La obligación del Estado de planificar el manejo y aprovechamiento de los recursos naturales para garantizar su desarrollo sostenible, su conservación, restauración o sustitución; prevenir y controlar los factores de deterioro ambiental, imponer las sanciones legales y exigir la reparación de los daños causados; y cooperar con otras naciones en la protección de los ecosistemas en las zonas fronterizas (art. 80); La prohibición de fabricación, importación, posesión y uso de armas químicas, biológicas y nucleares, como la introducción al territorio de residuos nucleares y desechos tóxicos; la regulación de ingreso y salida del país de los recursos genéticos y su utilización, conforme al interés nacional (art. 81); El deber del Estado de velar por la protección de la integridad del espacio público y su destinación al uso común, que prevalece sobre el interés particular (art. 82); Las acciones populares para la protección de los derechos e intereses colectivos como el espacio y el ambiente; así mismo, definirá los casos de responsabilidad civil objetiva por el daño inferido a los derechos e intereses colectivos (art. 88); El deber de la persona y del ciudadano de proteger los recursos culturales y naturales del país y de velar por la conservación de un ambiente sano (art. 95.8); La función del Congreso de reglamentar la creación y funcionamiento de corporaciones autónomas regionales (art. 150.7); La declaratoria de la emergencia ecológica por el Presidente de la República y sus ministros y la facultad de dictar decretos legislativos (art. 215); El deber del Estado de promover la internacionalización de las relaciones ecológicas sobre bases de equidad, reciprocidad y 
conveniencia nacional (art. 226); La vigilancia de la gestión fiscal del Estado incluye un control financiero, de gestión y de resultados fundado en la valoración de los costos ambientales (art. 267, inc. $3^{\circ}$ ); Presentación por el Contralor General al Congreso de un informe anual sobre el estado de los recursos naturales y el medio ambiente (art. 268.7); Función del Procurador General de defender los intereses colectivos, especialmente el ambiente (art. 277.4); Función del Defensor del Pueblo de interponer acciones populares (art. 282.5); Por mandato de la ley, la posibilidad que los departamentos y municipios ubicados en zonas fronterizas adelanten con la entidad territorial limítrofe del país vecino, de igual nivel, programas de cooperación e integración dirigidos a la preservación del medio ambiente (art. 289); La competencia de las asambleas departamentales para regular el ambiente (art. 300.2); Posibilidad legal de establecer para los departamentos diversas capacidades y competencias de gestión administrativa y fiscal diferentes a las mencionadas constitucionalmente, en atención a mejorar la administración o prestación de los servicios públicos de acuerdo a las circunstancias ecológicas (art. 302); El régimen especial previsto para el departamento archipiélago de San Andrés, Providencia y Santa Catalina, uno de cuyos objetivos es la preservación del ambiente y de los recursos naturales (art. 310); La competencia de los concejos municipales para dictar normas relacionadas con el control, la preservación y defensa del patrimonio ecológico (art. 313.9); La destinación mediante ley de un porcentaje de los tributos municipales sobre la propiedad inmueble a las entidades encargadas del manejo y conservación del ambiente y de los recursos naturales renovables (art. 317); Las funciones que se atribuyen a los territorios indígenas (consejos) para velar por la aplicación de las normas sobre usos del suelo y la preservación de los recursos naturales (art. 330, núms. $1^{\circ}$ y $5^{\circ}$ ); La creación de la Corporación Autónoma Regional del Río Grande de la Magdalena la cual tiene entre sus objetivos el aprovechamiento y preservación del ambiente, los recursos ictiológicos y 
demás recursos naturales renovables (art. 331); El Estado es propietario del subsuelo y de los recursos naturales no renovables, sin perjuicio de los derechos adquiridos y perfeccionados con arreglo a las leyes preexistentes (art. 332); La empresa tiene una función social que implica obligaciones; la ley delimitará el alcance de la libertad económica cuando así lo exija el interés social, el ambiente y el patrimonio cultural de la Nación (art. 333) (negrilla fuera de texto); La intervención del Estado por mandato de la ley en la explotación de los recursos naturales, en el uso del suelo, en la producción, distribución utilización y consumo de los bienes, y en los servicios públicos y privados, para racionalizar la economía con el fin de conseguir el mejoramiento de la calidad de vida de los habitantes, la distribución equitativa de las oportunidades y los beneficios del desarrollo y la preservación de un ambiente sano (art. 334); La necesidad de incluir las políticas ambientales en el Plan Nacional de Desarrollo (art. 339); Existencia de un Consejo Nacional de Planeación integrado por representantes de los sectores ecológicos, entre otros (art. 340); El señalamiento de la preservación del ambiente como una destinataria de los recursos del Fondo Nacional de Regalías (art. 361); y la inclusión del saneamiento ambiental como uno de las finalidades sociales del Estado (art. 366),

Además de la perspectiva del ambiente desde el punto de vista normativo, varios autores han desarrollado una conceptualización sobre el ambiente, por ejemplo Daniel Vidart, (1997) presenta una extensa reflexión acerca del ambiente como sistema complejo partiendo del origen etimológico e histórico de la palabra, a partir de la cual desarrolla un concepto dinámico y complejo basado en una visión ecológica donde el ser humano tiene la obligación ética de entender esa complejidad y mantener el equilibrio entre lo social y lo natural.

Para Enrique Leff (2006) el ambiente es "la complejidad del mundo; es un saber sobre las formas de apropiación del mundo y de la naturaleza a través de las relaciones de poder que se han 
inscrito en las formas dominantes de conocimiento" (p.6). A partir de esa idea propone una ética ambiental que responde a una crisis causada por la visión de civilización predominante, desembocando en lo que Leff denomina pedagogía ambiental (Noguera, 2006, p.18).

En la bibliografía se dispone de numerosas definiciones de ambiente, Lucie Sauvé (2004), desarrolla un análisis de quince conceptos, pero para el caso de este trabajo, cobra importancia la concepción sistémica del ambiente, lo cual permite "identificar los diferentes componentes de un sistema ambiental y de poner en relieve las relaciones entre los elementos biofísicos y los elementos sociales de una situación ambiental" Sauvé, (2004, p.5).

Esta concepción, toma al ambiente como un concepto que entraña una complejidad que incluye no solo lo natural, sino además lo social teniendo en cuenta tanto los problemas como las potencialidades. Para el SINA la idea de ambiente presenta y desarrolla el concepto de sistema ambiental, definido "como un conjunto de relaciones donde la cultura actúa como estrategia adaptativa entre el sistema natural y el sistema social” (MEN-MMA, 2004, p. 18), de esta forma considera que para comprender el funcionamiento del ambiente "se hace necesaria, por un lado, una aproximación sistémica en donde el todo dé cuenta de las partes y cada una de ellas dé cuenta del todo" (MEN-MMA, 2004, p. 18).

Dados los avances en materia del medio ambiente, se destaca que los conceptos surgidos recientemente sobre Educación Ambiental (EA), se han originado por las diferentes actividades puestas en marchas para mitigar la crisis del ambiente, acciones que se han implementado desde los años 70 y que se han realizado desde el primer encuentro Internacional de Belgrado, en 1975 y el Programa Internacional de Educación Ambiental, proceso que ha sido modificado a través de su práctica en los diferentes contextos educativos. Con lo anterior la Educación ambiental, aduce Zamudio (2013): 
Es un proceso de formación que puede contribuir a solucionar y mitigar la crisis ambiental que enfrenta la sociedad contemporánea...requiere de enfoques interdisciplinares y transdisciplinares, donde tengan cabida las distintas áreas del conocimiento, con sus diferentes enfoques epistemológicos y pedagógicos y su respectiva diversidad de métodos de investigación e intervención. De modo que las acciones en esta materia se enmarquen en procesos a mediano y largo plazo que contribuyan significativamente a revertir las tendencias de insostenibilidad ambiental. (p. 27).

Desde esta postura, la EA debe integrar el interés de las instituciones educativas, que son los lugares donde subyacen diferentes temáticas que aportan distintas soluciones y sugerencias a las problemáticas ambientales, que se derivan de las relaciones del hombre con el medio, asimismo las escuelas son espacios propicios, en los cuales se imparte una formación con estructura ordenada y sistemática de valores ambientales. Por otra parte, para Sarmiento (2013):

La educación ambiental es un proceso dinámico en el que participan muchas personas e instituciones, que busca sensibilizar e informar la población para identificarse con la problemática ambiental global y local. Su objetivo fundamental consiste en promover la relación armónica entre la naturaleza y las actividades humanas; este propósito, esencialmente bioético, apunta a lograr una cultura de conservación, en la que se aplique en todos sus procesos productivos, técnicas limpias en consonancia con la posibilidad de un desarrollo sostenible. (p. 34).

Es importante que desde las instituciones educativas se implemente la EA, puesto que en estos contextos se tiene mayor participación de la comunidad ya que se trabaja de forma continua en beneficio del bienestar propio y de los demás, aunando esfuerzos y llevando a cabo estrategias 
que les permite integrarse como seres sociales críticos y participativos capaces de liderar acciones y generar respuestas a los procesos de educación ambiental.

Retomando los objetivos de la EA, decretados en la Conferencia de Belgrado en 1975, se puede considerar La EA como: "el apoyo que se le brinda a las personas y grupos, en la toma de decisiones, adquisición de conocimientos, para que con base a ellos, adquieran actitudes, aptitudes y comportamientos más sensibles con relación del ambiente para transformar su propio contexto y vivir una mejor calidad de vida, con la participación activa de cada individuo que fomente no sólo un mejor entorno, sino un mejor desarrollo social y económico para la población menos favorecida". (Flores, 2012, p.1021) para Novoa (2009) la EA es una vía para el "replanteamiento de nuestras relaciones con la biosfera, a la vez que un instrumento de transformación social y empoderamiento de los más débiles, todo ello con la meta final de conseguir sociedades más armónicas y equitativas” (p. 198). De esta forma, una de las principales acciones de la EA es tener cursos de consideración y razonamiento, acerca de las acciones directas o indirectas del hombre con su entorno natural, específicamente cuando interactúa con los recursos naturales, para que estas no afecten negativamente y por el contrario mejoren la calidad de vida no solamente individual, sino colectiva.

De igual manera, la EA necesita ser aplicada en contextos formativos, los cuales lideren un pensamiento ambiental, creativo, crítico y pertinente que provea de soluciones a las problemáticas que enmarcan el recurso hídrico, como es la falta de planificación, infraestructura y conciencia humana con el agua.

La EA, según la Política Nacional del Ministerio del Medio Ambiente, posibilita la interrelación del hombre con el entorno, a partir del conocimiento de una realidad social, política, 
económica y cultural, que propicie actitudes y comportamientos proambientales para garantizar la permanencia del hombre, satisfaciendo sus necesidades actuales y futuras.

De igual manera las diferentes concepciones de EA coinciden en que es un proceso que contribuye a mitigar problemas ambientales y se da cuando los seres humanos interactúan con el otro y el entorno natural, pero esta relaciones deben darse aplicando conocimientos, actitudes y comportamientos proambientales, valores ambientales que propenden a sociedades sostenibles y sustentables. Igualmente, la Política Ambiental, retoma el concepto de EA que maneja el MMA y el MEN, en ese sentido, la EA, debe implementarse en contextos pedagógicos donde establezcan estrategias transversales, que desarrollen el ser humano habilidades y destrezas que transformen los diferentes ámbitos con cada acción que realiza en su cotidianidad e inciden en su propio beneficio y el del otro, y que responde a cambios radicales para el fomento de ambientes saludables, no solamente a nivel natural sino social y cultural.

Observando la crisis ambiental que se ha agudizado en las últimas décadas, los diferentes organismos, grupos y asociaciones han establecido estrategias que logren objetivos eficaces para el empleo y cuidado de los recursos, adoptando múltiples concepciones sobre EA, Es así como Sauvé (2004) define a las corrientes de pensamiento ambiental como una manera de conceptualizar y diseñar estrategias para mitigar los efectos que el hombre ha provocado en la naturaleza.

Sauvé (2004), ha categorizado en dos grupos las corrientes de pensamiento, las primeras son las que han tenido una trayectoria, entre ellas la naturalista, la sistémica, la humanística y la moral y ética; la segunda son las corrientes modernas como la holística, la etnografía y la ecoeducación entre otras; todas las corrientes anteriores se basan en la concepción sobre el medio ambiente, la intención central y los enfoques privilegiados. 
Este trabajo de investigación comparte características semejantes con la corriente Sistémica de Sauvé (2004), la cual plantea estrategias de solución a las problemáticas ambientales reales, estas acciones están constituidas por las relaciones que se establecen entre el medio y los elementos sociales: hombre-naturaleza.

Por otro lado en EA, ha tomado protagonismo y relevancia la preocupación por impartir educación a las personas y concienciar sobre la importancia del ecosistema en la vida de la humanidad, como lo manifiestan García y Muñoz (2013) en sus enfoques, cuando trabajan tres aspectos relevantes en la EA: Educar para conservar el medio, el segundo, educar para concienciar sobre el medio y el tercero educar para cambiar el medio a través de un desarrollo sostenible.

Este trabajo de investigación converge con estas corrientes, al plantear la importancia de impartir conocimientos a los estudiantes, porque generan procesos de pensamiento crítico que involucra directamente al hombre con la naturaleza en la creación y conservación de una conciencia ambiental

\subsubsection{Procesos de la educación ambiental en contextos escolares.}

\subsubsection{Proyecto escolar ambiental-PRAE.}

El Proyecto Ambiental Escolar (PRAE) es una metodología de construcción colectiva donde participa toda la comunidad educativa, estos proyectos están diseñados para ser desarrollados por las instituciones educativas con el fin de aportar estrategias para el mejoramiento de los problemas ambientales y del entorno, donde se pretende formar un estilo de vida sostenible y se brindan espacios para la reflexión y el fortalecimiento de valores ambientales que buscan generar conciencia entre los miembros de la comunidad. (Holguin \& Rodríguez, 2006). 
Los proyectos PRAE, buscan una integración con las diferentes áreas del conocimiento, disciplinas y saberes según lo indica la CAR (2004):

Los proyectos PRAE buscan la incorporación de la Educación Ambiental dentro de los procesos educativos en la escuela, de esta manera se llegará a una construcción colectiva con la intencionalidad de formar a los estudiantes, docentes, padres de familia y demás miembros de la comunidad educativa en la compresión de los problemas que actualmente presenta el medio ambiente y las acciones que se pueden implementar para lograr una mitigación de estos ya que aporta conocimientos sobre la realidad ambiental del país y del mundo. (p.4).

Según el MEN (2004) es importante que los proyectos transversales para la mejora en la calidad educativa, la dimensión ética, cultural y científica de la educación ambiental presenten continuidad en sus procesos, por tal razón es necesario el diseño de estrategias que aporten positivamente al desarrollo de las políticas nacionales ambientales que han sido propuestas con el fin de consolidar líneas de acción en pro de una educación para un ambiente sostenible.

El objetivo primordial de los PRAE, según lo establece el MEN, es proporcionar marcos referenciales de carácter conceptual, estratégico y proyectivo desde la visión sistémica del ambiente y los propósitos de formación integral de los individuos y colectivos, orientando acciones educativas ambientales en diferentes escenarios y niveles de la educación formal e informal, educación para el trabajo y desarrollo humano, promoviendo la construcción de territorio, en el contexto de una cultura ética de manejo sostenible del ambiente.

Estos proyectos están orientados según el MEN-MMA (2004) a: 
la incorporación de la educación ambiental en el desarrollo local, regional y nacional, atendiendo a la diversidad de contextos ambientales del país y a sus realidades particulares de participación y gestión, a partir de un trabajo coordinado entre las diferentes entidades y grupos de población, con competencias y responsabilidades en el tema y la adecuación a las necesidades del desarrollo, desde los propósitos de descentralización y autonomía local. (p.3 )

Es importante, considerar a la EA, como un eje transversal en todos los niveles de la educación, como por ejemplo en los programas curriculares de estudio, en los proyectos ambientales escolares (PRAE), de igual manera, debe tenerse en cuenta, en los programas de educación superior, tanto en los procesos formativos, como en el campo de la investigación y en el laboral, en los Proyectos Ciudadanos de Educación Ambiental (PROCEDA) (MEN-MMA, 2004)

Por tal razón este proceso educativo conlleva al trabajo en equipo ya que es importante y necesario involucrar a toda la comunidad educativa para lograr avances efectivos en el mejoramiento de la calidad de vida de los seres vivos, la reflexión y la crítica en pro del ambiente.

\subsubsection{Comité ambiental escolar (CAE).}

¿Qué es el Comité Ambiental Escolar? Es un organismo asesor en materia ambiental que toda institución educativa debe tener, creado el 23 de septiembre de 2005, mediante el cual el Concejo de Bogotá, y facultado para hacer parte del Gobierno Escolar (Acuerdo 166, 2005). Las

funciones son, velar por el cuidado del medio ambiente, a través de campañas institucionales, está 
integrado por un directivo docente, un docente, sin importar el área, pero preferiblemente que tenga conocimientos ambientales, por los estudiantes vigías escolares, nombrados por votación, de cada uno de los cursos, y un representante de los padre de familia.

Las funciones de los integrantes del CAE, es la protección y la regulación de las relaciones entre los miembros de la comunidad educativa y el ambiente, con espacios para la formación, capacitación y creación de conocimientos ambientales, cada integrante actúa como un veedor ambiental al interior de la institución y es el dinamizador de las políticas de educación ambiental.

\subsubsection{Familia y Educación Ambiental.}

A lo largo de la historia se han encontrado variados conceptos de familia, que dependen de la perspectiva, por ejemplo (Carbonell, 2012) manifiesta que la familia es el lugar donde convergen todas las manifestaciones sociales de quienes lo conforman, refiriéndose éste exclusivamente a un punto geográfico, contrario a lo que afirma (De Pina Vara, 2005) familia es el grupo de personas unidas por parentescos consanguíneos, dos conceptos que difieren el uno del otro, el primero manifiesta un lugar y el segundo refiere a un grupo humano con un vínculo natural. Un concepto más amplio que recoge parte de los dos autores anteriores afirma que "La familia es el conjunto de individuos que viven alrededor de un mismo hogar" (Febvre, 1961, p. 145), esta definición es un poco ambigua, porque limita el concepto, al hecho de que solo pertenecen a la familia, aquellos que comparten el mismo espacio. Por otro lado el Artículo 42 de la Constitución Política de Colombia, dice que familia es el núcleo fundamental de la sociedad, constituida por vínculos naturales o jurídicos, por la decisión libre de un hombre y una mujer de contraer matrimonio, donde el Estado y la sociedad están en la obligación de garantizar su 
protección integral, concepto involucra la existencia de un Estado garante, que propiciará la supervivencia de la misma.

Lo anterior, demuestra que a lo largo de la historia la definición de familia ha evolucionado y adquirido mayor importancia por los cambios sociales y se asume que la familia como "elemento natural y fundamental de la sociedad debe ser protegido por el Estado" (ONU, 1948). A partir de esa declaración y como resultado de los profundos cambios en la sociedad durante las últimas décadas, el concepto de familia ha sido objeto de profundas reflexiones debido a su trascendencia, un ejemplo de esto es el concepto de familia como institución propuesto por Cerquera y Cuellar (2008):

La familia es el conjunto de personas que viven juntas, relacionadas unas con otras, que comparten sentimientos, responsabilidades, informaciones, costumbres, valores, mitos y creencias. Cada miembro asume roles que permiten el mantenimiento del equilibrio familiar. Es una unidad activa, flexible y creadora, es una institución que resiste y actúa cuando lo considera necesario. La familia como institución social es un sistema de fuerzas que constituyen un núcleo de apoyo para sus miembros y la comunidad. (pp.13-14).

Empleando un enfoque alternativo, otros autores han concebido a la familia como el espacio de desarrollo más esencial, como es el caso de Bernal (2005), quien la define como: El espacio que gesta la crianza, nos forma como personas estableciendo nuestros valores morales y el que nos orientará a lo largo de nuestro desarrollo como seres humanos. En la familia es donde se educa a los hijos para que adquieran dichos valores motivados por el amor; solo en la familia se aceptan a las personas con sus cualidades y sus defectos, la naturaleza propia de la familia como comunidad originaria de personas significa que su 
misión consiste en la actualización y planificación de su ser original mediante el reconocimiento y el crecimiento de sus miembros. (p.12).

El concepto de familia es importante en el desarrollo de este trabajo y se complementa con la clasificación de tipos de familias propuesto por las Naciones Unidas (1997), citado por Cerquera y Cuellar (2008):

1. la familia nuclear, integrada por padres e hijos.

2. familias uniparentales o monoparentales, se forman tras el fallecimiento de uno de los cónyuges, el divorcio, o la separación, el abandono o la decisión de no vivir juntos.

3. familias compuestas, que habitualmente incluye tres generaciones, abuelos, padres e hijos que viven juntos.

4. familias extensas, además de las tres generaciones otros parientes tales como tíos, tías, primos, o sobrinos viven en el mismo lugar.

5. familia reorganizada, que vienen de otros matrimonios o cohabitación de personas que tuvieron hijos con otras parejas. (p. 14).

\subsubsection{Relación entre familia y escuela.}

La familia y la escuela han tenido una relación directa desde su aparición, de hecho son consideradas las instituciones sociales más antiguas de la civilización humana, aunque, como lo menciona Baruch Belmar (2003) "permanentemente han tenido un accionar distante, superficial y mutuamente cuestionador”(p. 2). Esto resulta paradójico, al pensar que ambas instituciones tienen la función de educar, la familia lo hace considerando la individualidad de la persona, mientras la escuela lo hace considerando una finalidad educativa, no obstante, en lugar de 
complementarse, la familia ha delegado la importante función educativa a la escuela (Altarejos, 2002). En ese sentido, desde la práctica y la teoría se busca fortalecer la labor conjunta entre la escuela y la familia, puesto que de esta forma los procesos educativos alcanzan mayor calidad y alcance (Díez, 2009).

La relación entre escuela y familia como manifiesta López-Larrosa (2003) suele “ir” a la escuela a través del consejo escolar, las asociaciones y las reuniones con el directivo, orientador o profesor, frecuentemente con un fin meramente informativo y de forma más excepcional en actividades escolares o extraescolares. De otro lado la escuela "va" a la familia aún en menos intensidad, a través de las tareas, las notas, las circulares y las pocas reuniones individuales. Esta participación insuficiente por parte de las dos instituciones parece empeorar por el uso de las TIC, que promueve una comunicación más unilateral entre los dos estamentos (Fominaya, 2003).

Esta crítica relación entre la escuela y la familia contrasta con el objetivo de la creación de la escuela "para ayudar a la familia en el importante cometido de la educación" (Sosa, 2009). Es evidente que no se tiene la suficiente preparación para establecer una relación adecuada entre estas dos instituciones, razón suficiente para convertirlo en un aspecto esencial en el mejoramiento de la calidad educativa. Sosa (2009) propone varias alternativas, como la creación de leyes para evitar los conflictos entre padres de familia y docentes, y por otro lado regular la relación entre la escuela y la familia mediante el seguimiento y la participación activa.

Un aporte interesante es la visión del ambiente como un sistema, puesto que resulta de particular importancia en esta investigación la teoría que concibe a la familia como un sistema, compuesto por subsistemas, integrado con otros sistemas, como la escuela, y articulado con un sistema mayor: la sociedad (Espitia \& Montes, 2009). Esta visión de sistema resulta crucial en el proceso educativo, Sauceda y Maldonado (2003) afirma que "al alterarse uno de los elementos 
del sistema, se altera indefectiblemente a todo el conjunto sistémico en sí” (Espitia \& Montes, 2009, p. 88). En este marco se hace posible reflexionar acerca de la influencia que puede tener un sistema como la escuela en la familia al modificar conductas en los hijos y de esta forma alterar el sistema familiar produciendo cambios en su dinámica. De esta forma, al ser la familia el elemento primario de la sociedad se pueden generar profundos cambios sociales, esta es la base teórica sobre la que se adelantó este trabajo.

\subsubsection{Conocimientos, actitudes y comportamientos proambientales en la familia}

De acuerdo con Díaz-Pulido et al (2009) el desarrollo sostenible consiste en "satisfacer las necesidades actuales sin poner en peligro la posibilidad de que las generaciones futuras satisfagan sus propias necesidades y procuren un estado de bienestar generalizado entre sus ciudadanos" (p.85). Teniendo en cuenta este concepto, el autor define a la familia y el hogar como el "hábitat" natural de los seres humanos, donde se desarrollan, se realiza y emergen para cumplirle a la sociedad. d'Entremont, (2007, p.21) expresa que la familia es el lugar donde deben llevarse a cabo las grandes transformaciones sociales, económicas políticas y desde luego ambientales y afirma que "sólo una familia sostenible y sostenida puede conducir a un verdadero desarrollo sostenible y sostenido"

El estudio de las dinámicas familiares en la construcción y fortalecimiento de comportamientos proambientales ha sido escaso y la información disponible es escasa. Evans y Gill (1996) reportaron en su estudio las dificultades que generan las diferencias generacionales en la forma como los miembros de una familia entienden el ambiente, y deducen que los adultos crecieron en una época cuando no se le daba tanta importancia a los asuntos ambientales y mencionan que muchos padres de familia participan con poco interés en actividades escolares y extraescolares de EA.. 
En un estudio desarrollado por Leger y Pruneau (2012) para analizar el comportamiento del núcleo familiar en torno al cambio climático se determinó que las familias donde se comparten valores "altruistas y biosféricos" tienen mayor éxito en la adopción de comportamientos proambientales, además de manifestar competencias colectivas como colaboración, autorregulación, perseverancia y toma de decisiones. Finalmente sugieren una estructura general de cualquier programa educativo que incluye una etapa preliminar para compartir valores "biosféricos" comunes a toda la familia, seguida de una etapa para compartir ideas, revisar mentas y fomentar un sentido de contribución y colaboración entre todos los miembro de la familia, para finalmente terminar en momentos periódicos a lo largo del programa para celebrar éxitos, reforzando la percepción de autoeficacia y contribuyendo a la eficacia colectiva. Leger y Pruneau, (2012).

Mandel (2005) complementa estas iniciativas de educación ambiental en la familia al proponer la inclusión de proyectos de aprendizaje de educación ambiental dentro del hogar teniendo en cuenta tres ideas: la necesidad de integrar la educación ambiental, la participación activa en actividades relevantes clave para el éxito y finalmente el estudio de la influencia intergeneracional en la adopción de comportamientos proambientales. Este último aspecto resulta de particular importancia al tener en cuenta que los niños pueden influenciar a los padres, como lo demuestra un estudio de Evans, Gill y Marchant (1996) citado por Mandel (2005). En otro estudio Vaughn, Gack, Solorazano y Ray (2003) se demuestra que los estudiantes son capaces de enseñarles a sus padres y entre ambos lograr influenciar a la comunidad en la adopción de comportamientos proambientales. Incluso se alienta a investigar y fortalecer los procesos de comunicación e influencia intergeneracional en los programas de educación ambiental (Mandel, 2005). 


\subsubsection{Gestión social del recurso hídrico.}

Desde el punto de vista químico el agua es un compuesto elemental que consta de un átomo de oxígeno y dos átomos de hidrógeno. Aunque su fórmula química es sencilla, se trata de un compuesto que posee características particulares, por ejemplo encontrarse en los tres estados de la materia, poseer gran estabilidad química, un alto calor específico y ser el solvente más común de los compuestos de origen biológico, lo cual lo convierte en unas sustancia clave en el origen y mantenimiento de los seres vivos, de hecho se puede establecer una relación directa entre la vida y la gran abundancia de esa sustancia en la Tierra (Encrenaz, 2004).

Además de ser un compuesto vital en la Tierra, también ha sido fundamental en la historia de la civilización, razón por la cual el agua posee diferentes significados dependiendo del punto de vista con que se le estudie. De acuerdo con los enfoques internacionales actuales, se considera al agua como un recurso al cual se le puede asignar costos, beneficios y administración, connotaciones con una clara intención económica que ha permitido integrar la gestión de este recurso a la dinámica política global (GWP, 2000; Viveros, 2013). Aunque esa visión utilitaria tiene también sus detractores (Shiva, 2004), el concepto de recurso hídrico es ampliamente utilizado, pero ha sido reevaluado constantemente, por ejemplo inicialmente el agua era considerada un recurso renovable, pero debido a los efectos del cambio climático, la contaminación, la sobreexplotación y la pérdida de ecosistemas clave, durante las últimas dos décadas se le ha empezado a considerar como un recurso vulnerable y finito (GWP, 2000) que debe ser protegido a nivel global por medio de la participación de usuarios, administradores y políticos en todo nivel.

El desarrollo de nueva conciencia frente al recurso hídrico exige comprender sus funciones, como es el caso de satisfacer las necesidades humanas en cuanto a consumo y 
saneamiento, empleo en cultivo de vegetales y cría de animales, uso con fines industriales, producción de energía y conservación de ecosistemas clave (ONU, 2003; Leyva, 2012).

Teniendo en cuenta estas funciones, el agua es la base para el desarrollo sostenible, de acuerdo con el Informe de las Naciones Unidas sobre los Recursos Hídricos en el Mundo (2015) “Desde la alimentación y la seguridad energética hasta la salud humana y ambiental, el agua contribuye a mejorar el bienestar social y el crecimiento inclusivo, lo cual afecta a la subsistencia de miles de millones de seres humanos" (p.2). En ese mismo informe se presenta la llamada visión 2050, donde el agua tiene un rol fundamental en las tres dimensiones del desarrollo sostenible: 1. Pobreza e igualdad social: para una "mejor gestión del agua y de los servicios hídricos que ayuden a reducir la pobreza y sustentar el crecimiento económico" (ONU, 2015, p.3); 2. El desarrollo económico: "el agua es un recurso esencial en la producción de la mayoría de bienes y servicios, incluidos los alimentos, la energía y las manufacturas” (ONU, 2015, p.3); y 3. Protección ambiental y servicios para el ecosistema: caso en el que "la evaluación de los ecosistemas demuestra que los beneficios superan con creces los costes de las inversiones relacionadas con el agua en la conservación del ecosistema” (ONU, 2015, p.4).

Desde el primer informe de las Naciones Unidas sobre los Recursos Hídricos en el Mundo (2003), esta organización internacional ha señalado los retos de las comunidades frente a una apropiada administración, el cuidado y protección del agua para alcanzar un adecuado desarrollo, en el informe 2015 se sintetizan los más importantes, como la falta de suministro de agua, saneamiento e higiene, en especial en los sectores urbanos, la demanda creciente de agua por parte del sector agrícola y de la industria manufacturera, y el impacto negativo del cambio climático (ONU, 2015). Dadas estas condiciones, autores como Vandana Shiva (2004) denuncian problemas futuros relacionados con el agua, como es el caso de desplazamientos de 
población, conflictos políticos, desertificación y privatización del recurso. Frente a este panorama el Programa Mundial de Evaluación de los Recursos Hídricos de las Naciones Unidas desarrolla actividades como encuentros mundiales, producción de conocimiento y labores de divulgación. Entre los principales objetivos de este programa están el cumplimiento de los objetivos del milenio como es el caso de lograr un compromiso compartido por "un amplio abanico de representantes de la sociedad, a través de estructuras de gobernanza inclusivas para la gestión del recurso" (ONU, 2015, p.7), ampliar la inversión y mejorar la viabilidad financiera en todos los aspectos de la gestión del recurso hídrico y lograr la igualdad en el acceso al agua por parte de todas los miembros de la sociedad (ONU, 2015).

\subsubsection{Estado actual de los recursos hídricos nacionales.}

Aunque los cálculos de la cantidad de agua que existe en el planeta Tierra resultan en 1400 millones de kilómetro cúbicos, tan solo 35 millones corresponden a agua dulce. De esta última cifra, el 70\% se encuentra en forma de hielo y nieve, el 29,7\% como agua subterránea, y el 0,3\% se encuentran en forma de ríos, pantanos, lagos y lagunas. Si se tiene en cuenta que los ríos solo contienen el $2 \%$ de toda el agua superficial, basta para comprender la poca cantidad de agua dulce disponible, uno de los argumentos más importantes para protegerla y gestionarla (Carranza, 2014).

En el caso de Sudamérica, su reserva de $17273 \mathrm{Km}^{3}$ de agua dulce, la convierte en la mayor reserva a nivel mundial. En este contexto Colombia tiene el 13\% del total sudamericano, detrás de Brasil, que tiene el 50\% de toda la oferta de agua dulce del continente (Carranza, 2014). Por esta razón, se debe pensar que Colombia tendrá un papel fundamental en las dinámicas económicas y políticas relacionadas con el agua durante el presente siglo. 
Este protagonismo se afianza con la información aportada por el Estudio Nacional del Agua -2014 publicado por el IDEAM en 2015. De acuerdo con este documento Colombia, debido a su régimen pluviométrico (1800 mm anuales), cuenta con cinco grandes cuencas hidrográficas, 1120 fuentes hídricas para cabeceras municipales, 2554 cuerpos de agua como ciénagas, lagunas, embalses y pantanos, y 90 ríos, arroyos caños, quebradas y manantiales. El informe también menciona importantes ecosistemas que dependen y suministran agua, como los bosques amazónicos inundables, los páramos (57\% del total mundial) y 2378 humedales. A pesar de esta significativa oferta hídrica que permite que en promedio, cada colombiano disponga de $34.000 \mathrm{~m}^{3}$ anuales (2014), de no desarrollar políticas de gestión y gobernanza del agua, para el 2020 esa oferta disminuirá a $1890 \mathrm{~m}^{3}$ por persona (IDEAM, 2015).

Teniendo en cuenta tanto el creciente interés en el desarrollo de políticas de gestión del recurso hídrico, como la riqueza hídrica que tiene el país, con sus implicaciones, no solo sociales, sino políticas y económicas, se hacen necesario el diseño, aplicación y evaluación de estrategias de EA con el fin de brindar conocimientos y construir actitudes para desarrollar comportamientos proambientales frente al recurso hídrico.

En este contexto el desarrollo de esta investigación responde a la necesidad de buscar estrategias de EA, para desarrollar conocimientos, actitudes y comportamientos proambientales, tanto en las instituciones educativas, como dentro de las familias. La comprensión por parte de los menores y sus hogares de la situación del recurso hídrico y de la oportunidad que tiene la comunidad para conservarlo y preservarlo para las futuras generaciones constituye un concepto a tener en cuenta dentro del análisis de los resultados de esta investigación. 


\subsubsection{Estrategias de educación ambiental para la gestión del recurso hídrico.}

Organizaciones internacionales encabezadas por la ONU han priorizado la conservación y gestión adecuada del agua como quedó establecido en la agenda 2030 donde se incluyen los objetivos del desarrollo sostenible como el 6: "Garantizar la disponibilidad de agua y su gestión sostenible y el saneamiento para todos" y el $14^{\circ}$ : "Conservar y utilizar en forma sostenible los océanos, los mares y los recursos marinos para el desarrollo sostenible" (CEPAL, 2016, pp. 3-4).

En este contexto la propuesta de la Asociación Mundial para el Agua (Global Water Partnership, GWP), llamada Manejo Integrado del Recurso hídrico (MIHR) (GWP, 2000) adquirió la importancia suficiente para que sea adoptada como política nacional, denominándose Gestión Integral del Recurso Hídrico por el gobierno colombiano (GIRH) (MAVDT, 2010). La GIRH se define como "es un proceso que promueve el manejo y desarrollo coordinado del agua, la tierra y los recursos relacionados, con el fin de maximizar el bienestar social y económico resultante de manera equitativa sin comprometer la sustentabilidad de los ecosistemas vitales." (GWP, 2000, p. 24). Este concepto emergió al entender que el principal problema que tiene el agua consiste en una inadecuada gestión y gobernabilidad del recurso, razón por la cual la política nacional busca integrar los diferentes sectores económicos, sociales, políticos en el diseño de sistemas de gestión adecuados a las necesidades, demanda, condiciones naturales y disponibilidad del recurso (MAVDT, 2010). Actualmente se ha sectorizado la nación en las principales cuencas y acuíferos teniendo en cuenta su manejo y monitoreo estatal y se adelanta la implementación de estrategias regionales y municipales para la GIRH:

La política nacional de gestión integral del recurso hídrico tiene como objetivo general garantizar la sostenibilidad del recurso hídrico, mediante una gestión y un uso eficiente y eficaz, articulados al ordenamiento y uso del territorio y a la conservación de los ecosistemas que regulan la oferta hídrica, considerando el agua como factor de desarrollo 
económico y de bienestar social, e implementando procesos de participación equitativa e incluyente. (MAVDT, 2010, p. 96).

Para lograrlo se han diseñado estrategias que respondan al logro de los objetivos específicos de esta investigación: “ que buscan fortalecer la gobernabilidad para la GIRH, la cual incluye la mejora de mecanismos y espacios de participación, el manejo de conflictos que surjan en torno al uso, accesibilidad y asequibilidad del recurso hídrico y el desarrollo de una cultura del agua para "incrementar la conciencia y el conocimiento sobre la importancia de conservar y hacer uso sostenible del recurso hídrico, así como, de abolir prácticas y hábitos de consumo no sostenibles del agua" (MAVDT, 2010, p. 104).

Es indispensable para el desarrollo de una cultura del agua la educación ambiental, lo cual resulta en la articulación de la política de GIRH con la política nacional de educación ambiental (SINA) a través de los PROCEDA (Proyectos Ciudadanos de Educación Ambiental), los PRAU (Proyectos Ambientales Universitarios) y los PRAE (Proyectos Ambientales escolares). De acuerdo con el Observatorio Ambiental de Bogotá (2008) el agua es un asunto primordial en el desarrollo de cualquier iniciativa de educación ambiental que se adelante en el distrito capital, por lo cual esta investigación retoma estos conceptos teóricos y con ellos realiza el análisis de sus resultados para responder a su pregunta de investigación.

\subsection{Estado del Arte}

A partir del problema planteado y los referentes teóricos de esta investigación se hizo un rastreo de las investigaciones que se han hecho sobre comportamientos proambientales y familia durante el periodo de 2010 a 2017. Se buscaron los conceptos que responden a las principales categorías de análisis de este trabajo, tales como comportamiento, proambiental, familia, hogar y 
agua y sus equivalentes en el idioma inglés: pro environmental, behavior, family, home y wáter.

Se hizo énfasis en la combinación de comportamientos proambientales y familia, puesto que constituye el núcleo central del problema de investigación, también se revisaron algunas entradas relacionadas con psicología ambiental.

El rastreo de información se llevó a cabo en las bases de datos Dialnet, EBSCO, Proquest, Scielo, Scopus, Taylor \& Francis Online y Google Académico. Por otro lado se revisaron repositorios de la Universidad de la Sabana, Universidad Nacional de Colombia, Universidad Distrital, Universidad Pedagógica Nacional, Universidad Javeriana, Universidad de los Andes, Universidad Santo Tomás, Universidad del Valle, Universidad de Antioquia y el sitio http://www.tesisenred.net. Por último se hizo rastreo bibliográfico en tres de las publicaciones con mayor reconocimiento en educación ambiental a nivel internacional: Environmental Education Reseach, International Research in Geographical and Environmental Education y The Journal of Environmental Education.

Tabla 2.

Autorías por país en el estado del arte

\begin{tabular}{cccccc}
\hline \multicolumn{3}{c}{ Países con mayor número de autorías } \\
Estados & España & Colombia & México & Australia & Reino Unido \\
Unidos & 9 & 9 & 7 & 6 & 6 \\
32 & 9 & & & & \\
\hline
\end{tabular}

Al hacer un análisis por continentes se encontró que

Tabla 3.

Documentos por continente en el estado del arte

Continente con mayor número de documentos relacionados con temas de educación ambiental

Norteamérica

35
Europa

30
Latinoamérica

19 
En cuanto al año de publicación, 20 documentos fueron publicados en 2013, 14 en y 2015, 9 en 2016 y 8 en 2014

Tabla 4.

Documentos por año en el estado del arte

\section{Documentos por año de publicación}

2012

14
2013

20
2014 8
2015

9

Aunque la mayor parte de las investigaciones fueron realizadas por investigadores de un solo país, se resaltan 9 publicaciones en las que participaron profesionales de dos o más nacionalidades.

Los documentos encontrados se clasificaron en cuatro categorías, la primera sobre comportamientos proambientales, la cual a su vez se dividió en dos subcategorías, una que cubre creencias, normas y factores que determinan esos comportamientos y la otra que cubre estrategias y prácticas para fortalecerlos. Las otras tres categorías abordan educación ambiental y familia, cuidado del agua y familia, finalmente documentos relacionados directamente con la dinámica familiar, educación ambiental y comportamientos proambientales, como se muestra en la tabla 1, que incluye la distribución de los documentos por categoría. 
Tabla 5.

Categorías de análisis de contenido en el estado del arte

\begin{tabular}{|c|c|}
\hline Categorías de análisis & Cant \\
\hline 1 Creencias, normas y factores & 53 \\
\hline 2 Estrategias y prácticas & 19 \\
\hline 3 Educación Ambiental y familia & 13 \\
\hline 4 Cuidado del agua y familia & 5 \\
\hline 5 Artículos sobre dinámica familiar y conducta proambiental & 20 \\
\hline TOTAL & 110 \\
\hline
\end{tabular}

Tabla elaborada por el equipo investigador.

En la categoría creencias, normas y factores se rastrearon 53 investigaciones, 39 corresponden a artículos, 9 a tesis de doctorado y 5 a tesis de maestría. La mayoría de ellos corresponden a estudios sobre las relaciones entre comportamientos proambientales y factores como las motivaciones (Markowitz, Goldberg, Ashton, \& Lee, 2012; Nye, M., \& Hargreaves, 2010; Rainear \& Christensen, 2017; Stevenson, Peterson, Carrier, Strnad, Bondell, KirbyHathaway, \& Moore, 2014; Steg \& Vlek, 2009; Wade, 2012), las diferencias individuales (Redondo \& Puelles, 2017), la edad (Broom, 2017), el género (Sonja, 2013), la cultura (Prati, Albanesi, \& Pietrantoni, 2017; Sanvichith, 2011; Winter, 2008; Willuweit, 2009), la religión (Zaleha, 2013), las dinámicas intergeneracionales (Yatsko, 2010) y las creencias y normas (Nag, 2012; Torres-Hernandez, Barreto, \& Rincón, 2015). En el anexo 10 se presenta la totalidad de las referencias de esta categoría y la temática de la que tratan.

En la categoría de estrategias y prácticas se encontraron 19 documentos, de los cuales 12 son artículos y 7 corresponden a trabajos de grado de maestría. En estas investigaciones se evalúan metodologías para desarrollar o fortalecer comportamientos proambientales, las cuales 
incluyen el uso de las TIC (Massung, Coyle, Cater, Jay, \& Preist, 2013), el empleo de claves visuales, Ferreiro (2013), la integración del comportamiento proambiental con la cotidianidad (Berthou, 2013; Chawla, \& Flanders-Cushing, 2007; Pacheco, 2012), el manejo de residuos sólidos (Martinportugués, Canto \& Hombrados, 2007), la influencia de la prensa y la publicidad (Rodríguez \& Bezunartea, 2016; Toole, 2010), el uso de energía (Carrico, 2009), actividades comunitarias para disminuir la huella de carbono (Haq, Cambridge, \& Owen, 2013), la influencia de la educación ambiental no formal en la educación formal (Goldman, Zvi Assaraf \& Shaharabani, 2013; Yee-Kee, 2013), el estímulo financiero (Furrow, 2015), el estudio desde la Teoría Ecológica de Urie Bronfenbrenner (Cano-Sterling, 2012) y el fortalecimiento de comportamientos proambientales en aulas formales (Bergman, 2016; Darner, 2012; García, \& Vilá, 2015; Özden, 2008; Varela-Losada, Vega-Marcote, Pérez-Rodríguez \& Álvarez-Lires, 2016).

En cuanto a la categoría de educación ambiental y familia se pudieron rastrear 6 artículos científicos y un documento de la OCDE (Organización para la Cooperación y el Desarrollo). Las investigaciones incluyen los paisajes residenciales (Cook, Hall, \& Larson, 2012), la relación entre comportamiento proambiental y comportamiento económico (Cortés-Peña, 2011), los predictores a nivel individual del uso de energía en los hogares (Frederiks, Stenner \& Hobman, 2015), educación ambiental para adultos en Canadá (Clover, 2002), formación de una identidad ambiental en programas no formales (Colvin-Williams \& Chawla, 2016) y el aprendizaje por proyectos en educación ambiental (Genc, 2015). Se resalta el documento "Household Behaviour and the Environment Reviewing the Evidence" de la Organización para la Cooperación y el Desarrollo Económico (OCDE, 2009) basados en los talleres desarrollados por esta organización sobre los hogares en cuanto a los determinantes del comportamiento ambiental en los hogares en 
cuestiones como el manejo del agua y la forma cómo mejorar la eficiencia y eficacia de políticas ambientales que afectan los hogares. Se debe mencionar que en esta categoría se encontraron 6 documentos sobre el trabajo en educación ambiental que pueden ser estratégicos en el desarrollo de esta investigación como es el caso de investigación y pedagogía en educación ambiental (Florez, 2012; Florez, 2013), tendencias futuras en educación ambiental (Ardoin, Clark, \& Kelsey, 2013; Kopnina, 2014), resiliencia y aprendizaje (Lundholm, \& Plummer, 2010) y una investigación sobre la importancia del compromiso en los profesores de educación ambiental (Kunz Shuman \& Ham,1997), se incluye la referencia anterior porque ha sido citada por 19 autores, dada la importancia de sus comentarios.

En la siguiente categoría cuidado del agua y familia se encontraron cinco artículos provenientes de cinco países distintos, las investigaciones abordan temáticas como un análisis descriptivo de las actitudes hacia el ahorro del agua (Canto, Hidalgo, García \& Martimportugués, 2002), marcos conceptuales y modelos mentales como determinantes de un comportamiento ambiental en el uso del agua (El Sawah, Mclucas, \& Mazanov, 2013; García, Carreón, Hernández, López, \& Bustos, 2013) y conciencia en el uso del agua a nivel escolar (Coban, Akpınar, Kucukcankurtaran, Y1ldız, \& Ergin, 2011; Mendieta, \& Gutiérrez, 2014). 
Tabla 6.

Autores en la categoría Dinámica familiar y comportamiento proambientales

\begin{tabular}{|c|c|c|}
\hline Categoría & Subcategoría & Autores \\
\hline \multirow{5}{*}{$\begin{array}{l}\text { Dinámica } \\
\text { familiar y } \\
\text { comportamiento } \\
\text { proambientales }\end{array}$} & $\begin{array}{l}\text { Influencias intergeneracionales de los } \\
\text { comportamientos proambientales a nivel } \\
\text { social y familiar }\end{array}$ & $\begin{array}{l}\text { Ando, Yorifuji, Ohnuma, } \\
\text { Matthies, \& Kanbara, 2015; } \\
\text { Jianan \& Chunlin, 2016; } \\
\text { Leppänen, Haahla, Lensu \& } \\
\text { Kuitunen, 2012; Meeusen, } \\
\text { 2014; Payne, 2010; } \\
\text { Thompson, 2010 }\end{array}$ \\
\hline & $\begin{array}{l}\text { Normas y el compromiso familiar como } \\
\text { determinantes del comportamiento } \\
\text { proambiental }\end{array}$ & $\begin{array}{l}\text { Dyck, 2013; García \& Baldi, } \\
\text { 2006; Griffioen, 2015; } \\
\text { Grønhøj \& Thøgerse, 2012; } \\
\text { Rashid \& Wahid, } 2013\end{array}$ \\
\hline & $\begin{array}{l}\text { Influencia del papel activo en la } \\
\text { organización de actividades de protección } \\
\text { ambiental }\end{array}$ & $\begin{array}{l}\text { Baur, \& Haase, 2015; } \\
\text { Morrissey \& Werner-Wilson, } \\
2005\end{array}$ \\
\hline & $\begin{array}{l}\text { Cuidado y la conservación de la energía } \\
\text { eléctrica en los hogares }\end{array}$ & $\begin{array}{l}\text { Blackwell, 2009; Clark, } \\
\text { Kotchen, \& Moore, } 2003\end{array}$ \\
\hline & $\begin{array}{l}\text { Dinámicas sociales en los comportamientos } \\
\text { proambientales }\end{array}$ & $\begin{array}{l}\text { Nye \& Hargreaves, 2010; } \\
\text { Robertson, \& Barling, 2013; } \\
\text { Videras, Owen, Conover \& } \\
\text { Wu, } 2012\end{array}$ \\
\hline
\end{tabular}

Tabla elaborada por el equipo investigador.

En la última categoría se incluyeron investigaciones acerca de dinámica familiar y comportamientos proambientales, de las cuales cinco corresponden a tesis de maestría, 14 son artículos científicos y uno corresponde a un informe. Las investigaciones corresponden a la influencias intergeneracionales de los comportamientos proambientales a nivel social y familiar (Ando, Yorifuji, Ohnuma, Matthies, \& Kanbara, 2015; Jianan \& Chunlin, 2016; Leppänen, Haahla, Lensu \& Kuitunen, 2012; Meeusen, 2014; Payne, 2010; Thompson, 2010), las normas y el compromiso familiar como determinantes del comportamiento proambiental (Dyck, 2013; García \& Baldi, 2006; Griffioen, 2015; Grønhøj \& Thøgerse, 2012; Rashid \& Wahid, 2013), la 
influencia del papel activo en la organización de actividades de protección ambiental (Baur, \& Haase, 2015; Morrissey \& Werner-Wilson, 2005), el cuidado y la conservación de la energía eléctrica en los hogares (Blackwell, 2009; Clark, Kotchen, \& Moore, 2003), las dinámicas sociales en los comportamientos proambientales (Nye \& Hargreaves, 2010; Robertson, \& Barling, 2013; Videras, Owen, Conover \& Wu, 2012).

Tabla 7.

Autores de los documentos relevantes para la investigación

\begin{tabular}{|c|c|c|}
\hline Categoría & Subcategoría & Autores \\
\hline \multirow{3}{*}{$\begin{array}{l}\text { Documentos } \\
\text { relevantes } \\
\text { para la } \\
\text { investigación }\end{array}$} & $\begin{array}{l}\text { Cómo los contextos de trabajo y cotidianidad } \\
\text { de las personas influyen en sus actitudes } \\
\text { ambientales y en su nivel de participación en la } \\
\text { acción ambiental, tanto en el lugar de trabajo } \\
\text { como en el hogar }\end{array}$ & Chapman, \& Walton, 2012 \\
\hline & $\begin{array}{l}\text { Incidencia de la educación ambiental en las } \\
\text { prácticas de cuidado y preservación del recurso } \\
\text { hídrico por parte de las comunidades }\end{array}$ & Tovar, 2016 \\
\hline & $\begin{array}{l}\text { Influencia que tiene la educación ambiental } \\
\text { escolar en los niños y en sus padres }\end{array}$ & $\begin{array}{l}\text { Vaughan, Gack, Solórzano } \\
\text { \& Ray, } 2003\end{array}$ \\
\hline
\end{tabular}

Tabla elaborada por el equipo investigador.

Tres documentos resultan relevantes en el desarrollo de esta investigación, el primero es un informe técnico del Consejo Australiano de Investigación (Chapman, \& Walton, 2012) donde se presentan los resultados de investigaciones sobre cómo los contextos de trabajo y cotidianidad de las personas influyen en sus actitudes ambientales y en su nivel de participación en la acción ambiental, tanto en el lugar de trabajo como en el hogar; el segundo corresponde a una investigación, desarrollado en un curso de maestría, sobre la incidencia de la educación ambiental 
en las prácticas de cuidado y preservación del recurso hídrico por parte de las comunidades (Tovar, 2016), el tercer documento es el único donde se documenta la influencia que tiene la educación ambiental escolar en los niños y en sus padres (Vaughan, Gack, Solórzano \& Ray, 2003), el cual, a pesar de de su antigüedad, responde a la pregunta de investigación del presente trabajo,

Los resultados generados dentro del estado del arte demuestran lo poco que se ha investigado sobre la incidencia que tienen los procesos de educación ambiental desarrollados en la escuela sobre las familias de los educandos. La única investigación a nivel nacional encontrada en la maestría, desarrollada por Tovar (2016), no se enfocó en la escuela, y analizó los procesos de los PRAE de forma indirecta. También se debe resaltar que los estudios de comportamientos proambientales en la comunidad y en las familias no han tenido el suficiente desarrollo en latinoamérica, lo cual hace que sea pertinente y relevante el desarrollo de esta investigación, la cual busca aportar elementos para determinar la incidencia que tienen la educación ambiental escolar en el ámbito familiar, en especial con el uso responsable del recurso hídrico.

\subsection{Marco Legal}

En esta investigación se tuvo en cuenta el marco legal mundial y nacional que se remonta a finales de los años sesenta, teniendo en cuenta los diferentes acuerdos internacionales que influenciaron la posterior aparición de la normatividad ambiental a nivel nacional. En esta revisión teórica se tuvo en cuenta los referentes directamente relacionados con educación ambiental y cuidado del recurso hídrico. 
El interés por la problemática ambiental empezó durante el segundo lustro de la década de los sesenta, cuando se tuvieron suficientes evidencias sobre el impacto que generaba la actividad humana sobre los ecosistemas y su posterior perjuicio en la calidad de vida de la población, es así que en 1968 las Naciones Unidas (NU) priorizaron el tema del medio ambiente, como se expresa en la resolución 1346 (XLV) del 30 de julio de 1968, donde se consideró “el acelerado deterioro ambiental causado por la contaminación del aire y del agua, la erosión y el deterioro del suelo...por dicha situación es necesario y conveniente que el hombre mejore su relación con el medio ambiente a fin de mitigar las acciones negativas hacia este, por ello es importante intensificar las acciones tanto a nivel nacional como internacional en la proposición de objetivos que conlleven a la minimización del deterioro ambiental” (p. 8), en esta resolución se convocó la conferencia sobre el Medio Humano en 1974, donde se trataron asuntos sobre el deterioro ambiental y sus efectos sobre la vida humana, este evento se dio durante la Cumbre de la Tierra, en Estocolmo, cuyo objetivo principal fue la promoción de hábitos y estilos de vida para lograr una sustentabilidad.

Durante la Cumbre de la Tierra se tuvo en cuenta la importancia del entendimiento humano, en cuanto a su relación con el medio y sus acciones, porque estas conllevan al deterioro ambiental. Como resultado se produjo una declaración sobre medio ambiente humano y se creó en 1975, el Programa de las Naciones Unidas para el Medio Ambiente (PNUMA), dando inicio a los programas educativos relacionados con el medio ambiente dentro del Programa Internacional de Educación Ambiental (PIEA) (Bermúdez, 2003), cuyo objetivo fue sentar las bases para una iniciativa educativa ambiental global e interdisciplinaria.

En ese mismo año (1975) en la ciudad de Belgrado se celebró un seminario internacional sobre Educación Ambiental, en el cual la E.A. se vinculó a las iniciativas políticas y sociales. En 
su documento oficial (La carta de Belgrado) "se describe la problemática ambiental estableciéndose metas, objetivos y directrices bases para la implementación de los programas de Educación Ambiental” (Pedraza \& Medina, 2000) citados por Santiago (2008, p.3).

Durante la conferencia internacional de Nairobi, en 1976 la Organización de las Naciones Unidas para la Educación, la Ciencia y la Cultura (UNESCO) propuso el Programa Internacional de Educación Ambiental, teniendo en cuenta al "medio ambiente como la interacción entre el medio social y natural, en el marco de las diversas alternativas de desarrollo" (Bermúdez, 2003, p.28). La_propuesta de la UNESCO se materializó en 1977, cuando se celebró la conferencia de Tbilisi, cuyo objetivo fue introducir la EA, en las poblaciones para fortalecer conocimientos que permitan una interrelación entre el medio y el hombre, que favorezca la solución a los problemas del medio ambiente, a través la información, la formación y la generación de actitudes positivas hacia el medio.

Posteriormente, en 1987, durante el Congreso Internacional UNESCO-PNUMA, llevado a cabo en Moscú, se presenta la propuesta internacional en el campo de la educación y formación ambiental para la década de los noventa, incluyendo propuestas de carácter curricular. Para recalcar la importancia de la naciente EA, durante ese mismo año se presenta el informe Brundtland, donde se pone de manifiesto que las problemáticas ambientales están relacionadas con el desarrollo y actividad humana. Durante la Cumbre de Río, celebrada en 1992, se revalida la problemática y la trascendencia de la EA para el fortalecimiento de los conocimientos y el alcance de modelos económicos sostenibles para el medio ambiente (Dujo \& Rodríguez, 2013).

En 1996 se presentó a la Unesco el informe de la Comisión Internacional para la educación del siglo XXI "La educación encierra un tesoro", donde se relacionan los cuatro pilares educativos para enfrentar las condiciones del mundo: aprender a conocer, aprender a 
hacer, aprender a vivir juntos y aprender a ser. En el informe se destaca "la importancia de conocer el medio ambiente para preservarlo como un propósito a lograr para el futuro de la humanidad" (Bermúdez, 2003, p. 29).

La importancia de la relación hombre - naturaleza, adquiere relevancia, a partir del reconocimiento del documento Informe Brundtland de 1987, creado en la Comisión Mundial de Medio Ambiente y Desarrollo de Naciones Unidas, donde se reconoce por primera vez, el término de desarrollo sostenible, y asumido en el Principio $3^{\circ}$ de la Declaración de Río (1992) aprobada en la Conferencia de las Naciones Unidas sobre el Medio Ambiente y el Desarrollo (ONU, 1996 ).

A nivel nacional la evolución de la normatividad ambiental se ha desarrollado de forma paralela y respondiendo tanto a las necesidades internas como las exigencias de la UNESCO y PNUMA. En los años 70 se diera inicio a la implementación de la normatividad relacionada al cuidado, protección y conservación del medio ambiente, en 1973 aparece la Ley 23 sobre prevención y control de la contaminación ambiental, y el mejoramiento de los recursos ambientales y luego, en 1974, se introdujo el tema ambiental a la educación en el Código Nacional de Recursos Naturales Renovables y de Protección del ambiente, por medio de la Ley 2811, donde se expresa “el medio ambiente es un patrimonio común, por tal razón es necesario que el estado y los habitantes de la nación procuren la conservación de este y velen por su preservación, conservación, mejoramiento y uso racional de sus recursos naturales" (Decreto Ley 2811, 1974)

La cátedra de ecología se reglamenta en 1978 con el Decreto 1337, se implementó en algunas escuelas y colegios del país; lo cual coincide con la firma de tratados y convenios ambientales internacionales por parte del gobierno colombiano como es el caso del Tratado de 
Cooperación Amazónica (Ley 74 de 1979), el Convenio para la protección y desarrollo del medio marino en la región del gran Caribe (Ley 56 de 1987) y el, Convenio de Viena para la protección de la Capa de Ozono (Ley 56 de 1987). 
Figura 13. Evolución de la normatividad ambiental a nivel nacional e internacional

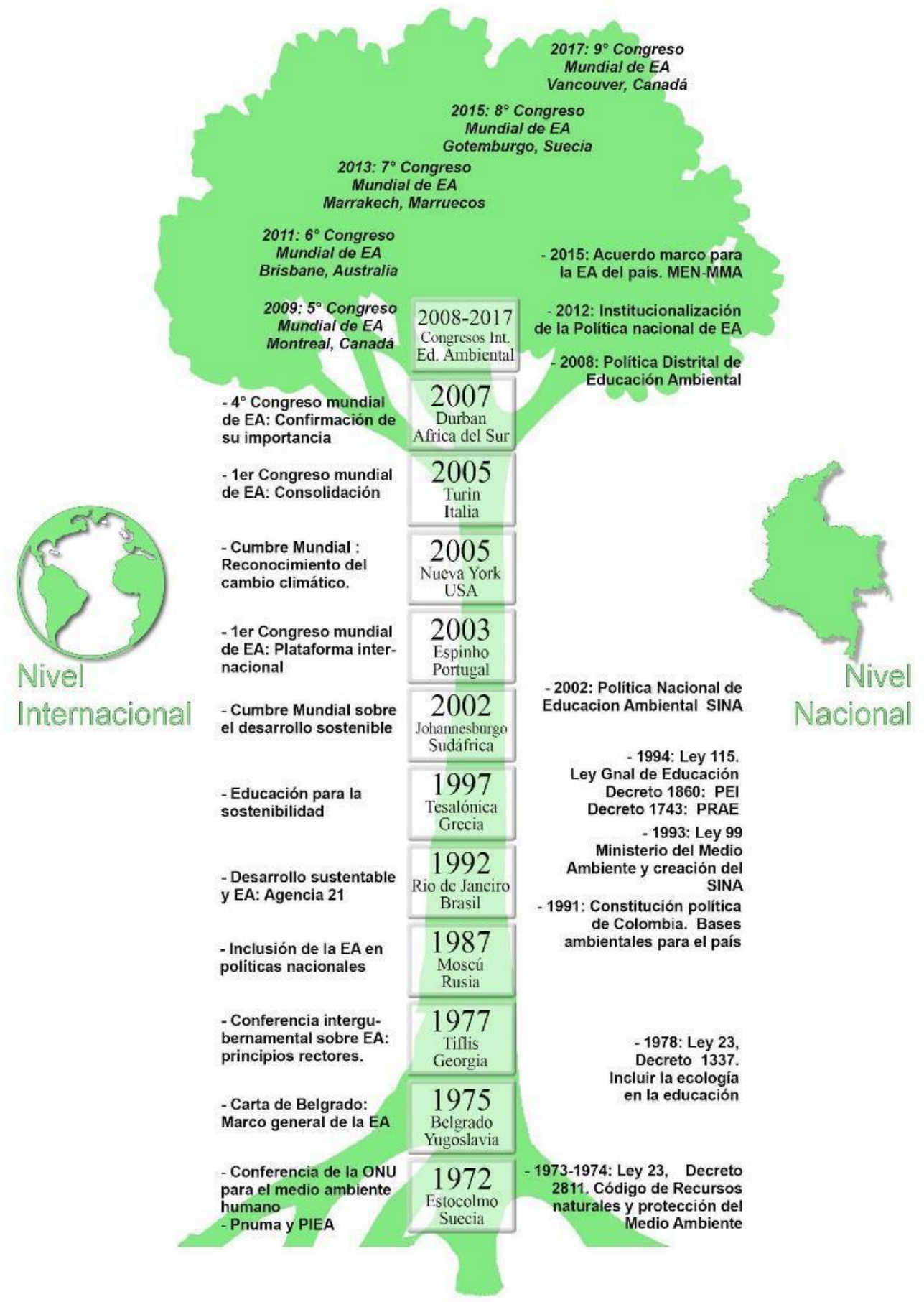

Imagen diseñada por el equipo investigador.

La participación de Colombia en el ámbito internacional demuestra su compromiso ambiental, el cual se refleja en la Constitución Política de Colombia, donde se encuentra la 
importancia del cuidado, protección y conservación del ambiente. Entre otros apartados se considera la educación como componente y mediación del cuidado y preservación del ambiente (Cap.2, Art. 67), además la carta política también incluye, la importancia de un ambiente sano, el manejo adecuado de los recursos naturales y la función social de los ciudadanos y del Estado para el cuidado y conservación del medio ambiente (Artículos 79, 80 y 85)

Ya en el marco de la nueva constitución del 91, se hizo posible la creación del Ministerio del Medio Ambiente (MMA) (Ley 99 de 1993) y el desarrollo de propuestas de trabajo conjunto con el Ministerio de Educación Nacional (MEN) para vincular en los currículos educativos temáticas ambientales, se incorpora la dimensión ambiental dentro de los programas de etnoeducación bajo la Ley 70 de 1994, la cual va dirigida a las comunidades afrocolombianas del país.

De otro lado, en 1994 se publica la Ley 115 (Ley General de Educación), y dentro de ella se estableció la EA como una de las áreas obligatorias del currículo educativo junto con ciencias naturales. Para complementar la nueva normativa aparece el Decreto 1743, que reglamenta el desarrollo de los proyectos ambientales escolares (PRAE) como una de las iniciativas transversales dentro del Proyecto Educativo Institucional (PEI). Los PRAE, a pesar de sus limitaciones y dificultades para su ejecución, son la principal herramienta de educación ambiental escolar en las instituciones educativas estrategia propia de la educación ambiental en Colombia.

En 1995 se crea la Ley 181, con la cual se reglamenta Ley de la Recreación y el Deporte, que permite el desarrollo de proyectos recreativos ambientales educativos y el ecoturismo (Rodríguez, 2008). Al año siguiente se plantea el Primer Plan Decenal de Educación (1996 2005), donde adquiere la importancia la EA, al considerarla primordial en el desarrollo curricular y pedagógico para la calidad educativa (MEN, 1996). 
La nación no ha cesado en darle elementos jurídicos y otros recursos a la EA, razón por la cual en 2002 se crea la Política Nacional de Educación Ambiental, en la que participan los Ministerios de Educación y de Medio Ambiente, y concibe la EA desde una visión sistémica del ambiente, clave tanto en la investigación, como en la educación para hacerle frente a la problemática ambiental del país (MMA-MEN, 2004).

En Bogotá se propuso en 2008 la Política Distrital de Educación Ambiental, la cual tiene en cuenta el contexto y las características particulares que tiene la ciudad, fortaleciendo las iniciativas de EA, incluidos los PRAE nacionales. Esto se ha fortalecido con el Plan de Desarrollo Distrital 2012 - 2016, al proponer los objetivos ambientales frente al cambio climático, por lo cual se propusieron 7 programas estratégicos: Recuperación, rehabilitación y restauración de la estructura ecológica principal y de los espacios del agua, Estrategia regional frente al cambio climático, movilidad humana, gestión integral de riesgos, Basura Cero, Bogotá Ambientalmente Saludable, y Bogotá territorio en la región.

En 2014 el Consejo de Estado expidió el Fallo del Río Bogotá (28 de marzo), para la recuperación de esta fuente de recurso hídrico de la ciudad de Bogotá, adoptando un enfoque interdisciplinario, sistémico e interinstitucional para recuperar y conservar este ecosistema fluvial de una manera integral, se incluye el compromiso por desarrolla procesos de EA en las comunidades que hacen parte de la cuenca, donde los PRAE son protagonistas.

Por otro lado, el gobierno nacional en 2015 lanzó una de las estrategias más importantes en el campo de la educación ambiental del país: La Alianza Nacional por la formación, de ciudadanía responsable: Un país más educado y una cultura ambiental sostenible para Colombia (MinAmbiente, 2015) 
El convenio se firmó entre el Ministerio de Ambiente yel Ministerio de Educación, es un acuerdo macro, donde se establecen los pilares fundamentales de la formación ciudadana responsable frente al manejo sostenible del ambiente, la educación y la participación.

Las iniciativas de educación ambiental en Colombia se articulan con la legislación sobre el agua que empezó a ser visible por medio de la ley 23 de 1973, que otorgaba facultades extraordinarias al presidente para expedir el Código de Recursos Naturales y protección al medio ambiente, en dicho documento se presenta las bases conceptuales del código, el cual se materializó en 1974 mediante el decreto 2811. Dicho código tiene en cuenta el recurso hídrico como un asunto de influencia internacional, presenta por primera vez las tasas retributivas de su uso, normas para su preservación, define la propiedad y la responsabilidad en el uso y conservación del agua y dedica todo un apartado (Parte III) específicamente al agua no marítima (Ministerio de Ambiente y Desarrollo sostenible, 2014).

Dos leyes han contribuido al fortalecimiento de la legislación hídrica, una dedicada al mar territorial (Ley 10 de 1978) y la otra que creó el Programa de uso eficiente y ahorro del agua (Ley 373 de 1997) en la cual resalta el artículo 13, donde el programa se articula a la ley 99 (SINA) para asegurar que los programas de educación ambiental promuevan el uso adecuado del agua, este programa junto con el Plan Nacional de Desarrollo 2006 -2010 se constituyen en la base de las actual política nacional de gestión integral del recurso hídrico.

Las leyes han sido enriquecidas con decretos que se ocupan de asuntos más específicos, como es el caso del decreto 1933 de 1994, el cual reglamenta las condiciones de diseño, construcción, funcionamiento, ambientales y de eficiencia de embalses y plantas hidroeléctricas en el país. De otro lado cuatro decretos han reglamentado las tasas del uso del agua así como de vertimientos de aguas residuales (3100 de 2003, 3440 de 2004, 4741 de 2005), los cuales son 
complementados y fortalecidos tanto en lo conceptual como en lo normativo por el decreto 3930 de 2010 en lo que tiene que ver con los usos del agua y residuos sólidos.

Figura 14. Normatividad sobre recurso hídrico

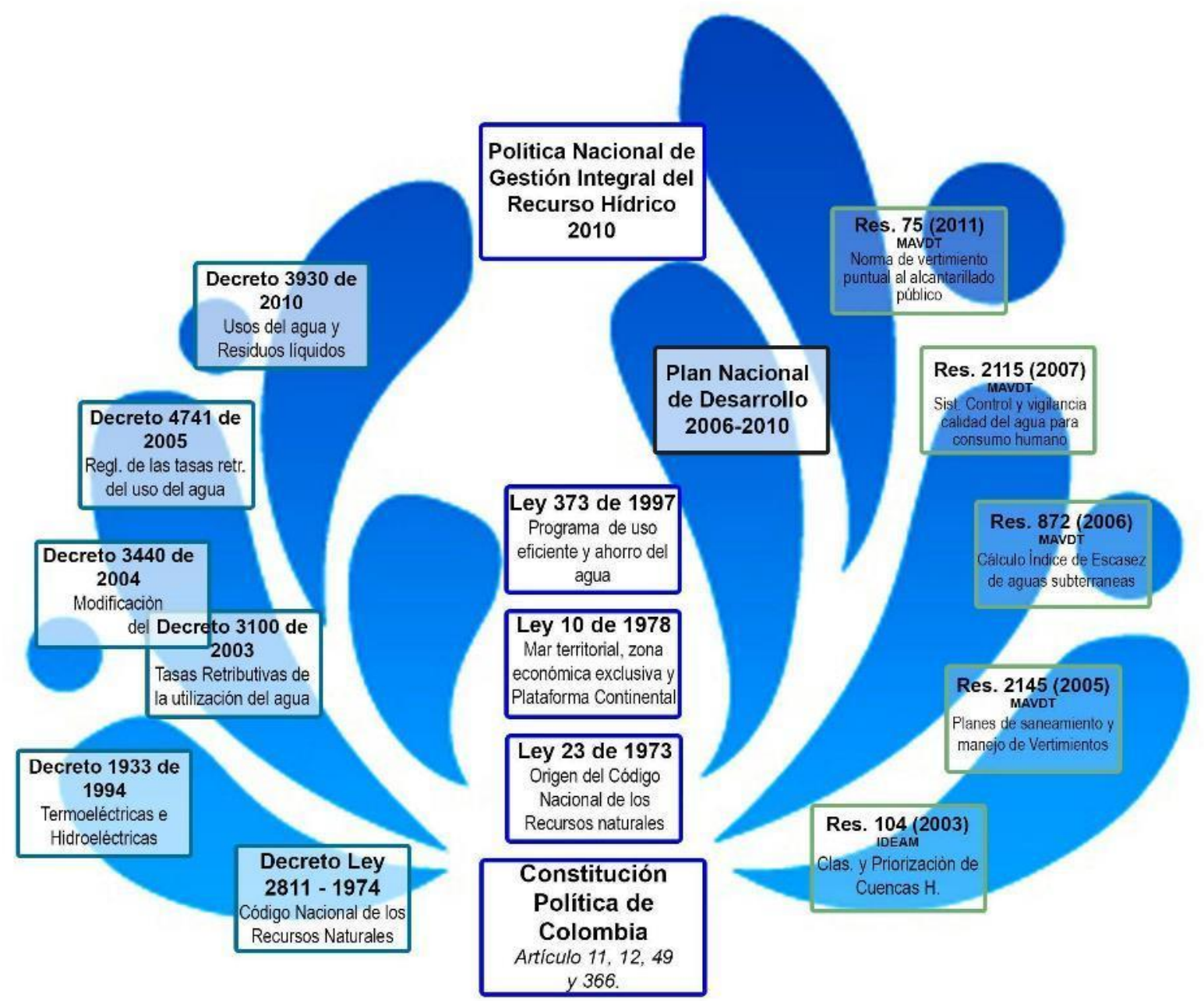

IDEAM: Instituto de Hidrología, Meteorologia y Estudios Ambientales MAVDT: Ministerio de Ambiente, Vivienda y Desarrollo territorial

Imagen diseñada por el equipo investigador.

Adicionalmente están las diferentes resoluciones publicadas por entidades estatales, como es el caso de la 104 de 2003 del IDEAM que establece la clasificación y priorización de las cuencas hídricas del país, y cuatro resoluciones del Ministerio de Ambiente, Vivienda y Desarrollo Territorial, las cuales establecen planes de manejo y manejo de vertimientos (Res. 
2145 de 2005), una metodología para el cálculo del índice de escasez para aguas subterráneas (Res. 872 de 2006), la definición de características, instrumentos básicos y frecuencias del sistema de control y vigilancia para la calidad del agua para consumo humano (Res. 2115 de 2007), y las normas de vertimiento puntual al alcantarillado público (Res. 75 de 2001).

Después de puntualizar los referentes legales internacionales y nacionales (Figura 6) sobre educación ambiental y su evolución, además de presentar brevemente la normatividad nacional sobre recurso hídrico (Figura 7), se puede indicar que la normatividad vigente en la que se contextualiza la presente investigación respalda la importancia y preocupación por implementar estrategias que generen el desarrollo de acciones para sensibilizar a los estudiantes líderes del CAE y sus familias, en cuanto al cambio de sus actitudes hacia el cuidado y protección del ambiente, en especial el recurso hídrico. 


\section{Marco Metodológico}

En este capítulo se presentan el enfoque, alcance y diseño aplicados en esta investigación, además la caracterización de la población objeto de estudio, los instrumentos utilizados para la recolección de la información y las técnicas de análisis de los datos (Tabla 6).

Dentro de las técnicas de análisis de datos se aplicó la teoría fundamentada, la que incluye la codificación abierta y axial; la primera me permite fragmentar los datos para asignarles un nombre, que luego se convierten en códigos. La codificación axial agrupa conceptos y aspectos recurrentes o similares que se convierten en categorías.

Tabla 8 .

Matriz Metodológica de la investigación

\begin{tabular}{|c|c|c|c|c|c|}
\hline $\begin{array}{l}\text { Problema de } \\
\text { investigación }\end{array}$ & Objetivos & $\begin{array}{c}\text { Tipo de } \\
\text { investigación }\end{array}$ & Categorías & Instrumentos & $\begin{array}{c}\text { Sujetos de } \\
\text { investigación }\end{array}$ \\
\hline $\begin{array}{l}\text { ¿Cuál es la } \\
\text { incidencia que } \\
\text { tienen los } \\
\text { conocimientos, } \\
\text { actitudes y } \\
\text { comportamient } \\
\text { os } \\
\text { proambientales } \\
\text { de los } \\
\text { estudiantes y } \\
\text { sus familias, de } \\
\text { cuatro } \\
\text { instituciones } \\
\text { educativas } \\
\text { distritales de } \\
\text { Bogotá, en el } \\
\text { uso responsable } \\
\text { y pertinente del } \\
\text { recurso } \\
\text { hídrico? }\end{array}$ & $\begin{array}{l}- \text { Determinar los } \\
\text { contextos } \\
\text { socioeconómicos y } \\
\text { ambientales de las cuatro } \\
\text { instituciones educativas } \\
\text { objeto de la investigación } \\
- \text { Identificar y } \\
\text { describir los } \\
\text { conocimientos, actitudes } \\
\text { y comportamientos } \\
\text { proambientales de } \\
\text { los vigías ambientales y } \\
\text { sus familias frente al uso } \\
\text { responsable } \\
\text { recurso hídrico del } \\
\text { - } \\
\text { estrategias pedagógicas } \\
\text { en las instituciones } \\
\text { educativas } \\
\text { promuevan que } \\
\text { comportamientos pro- } \\
\text { ambientales en la familia } \\
\text { con relación al uso } \\
\text { responsable } \\
\text { del agua. }\end{array}$ & $\begin{array}{l}\text { Enfoque } \\
\text { Cualitativo } \\
\text { Carácter } \\
\text { Descriptivo } \\
\text { Longitudinal } \\
\text { IAP }\end{array}$ & $\begin{array}{l}\text { Conocimientos } \\
\text { Actitudes } \\
\text { Comportamientos } \\
\text { Proambientales } \\
\text { Escuela } \\
\text { Familia } \\
\text { Recurso hídrico }\end{array}$ & $\begin{array}{l}\text { Encuestas } \\
\text { Cuestionarios } \\
\text { Entrevista } \\
\text { Diarios de } \\
\text { Campo } \\
\text { Rejillas de } \\
\text { seguimiento } \\
\text { para } \\
\text { estudiantes }\end{array}$ & $\begin{array}{l}\text { Estudiantes } \\
\text { de las cuatro } \\
\text { instituciones } \\
\text { educativas } \\
\text { distritales } \\
\text { donde se } \\
\text { desarrolló la } \\
\text { investigación }\end{array}$ \\
\hline
\end{tabular}




\subsection{Enfoque}

La investigación en las cuatro Instituciones Educativas Distritales, aplicó un enfoque cualitativo, ya que pretende mostrar un fenómeno social, donde los principales actores son los estudiantes vigías ambientales y sus familias; Hernández Sampieri, explica que este enfoque utiliza la recolección de datos sin la medición numérica y son importantes para abordar temas significativos de investigación, Hernández (2006) por lo tanto ésta tendrá un carácter subjetivo de las actitudes de estudiantes y sus familia con relación al uso responsable del recurso hídrico; de igual manera González (2016) manifiesta que la intención en este tipo de investigación, es visibilizar un fenómeno social de tipo ambiental en un escenario educativo, cuyo propósito es analizar el entorno escolar para comprender las actitudes ambientales de los estudiantes líderes del CAE; así mismo Bonilla-Castro y Rodríguez (2005) manifiestan que la principal característica de la investigación cualitativa es su interés por captar la realidad social "a través de los ojos de la gente" donde a partir de la percepción que cada uno tiene sobre las conductas hacia la conservación del medio ambiente, para generar el constructo del cual se analizará la realidad ambiental escolar, por último Álvarez-Gayou (2003) manifiesta que este tipo de investigación parte de una realidad a la que debe observarse, descubrirse, explicarse para poder llegar al conocimiento sistemático de una realidad

\subsection{Alcance}

El alcance de esta investigación es de carácter descriptivo y está destinado al estudio de una

problemática poco manejada a nivel nacional, puesto que el rastreo bibliográfico mostró escaso 
conocimiento sobre el uso adecuado o inadecuado del agua por parte de estudiantes y sus familias, y la importancia del fortalecimiento en conocimientos, conductas y comportamientos proambientales que puedan generar un impacto positivo o negativo para la construcción sociocultural y familiar.

\subsection{Fases de la investigación}

Tabla 9.

Fases de la investigación

FASES

ACTIVIDAD

OBJETIVO

FECHA

DIAGNÓSTICO

Encuesta y entrevist:

Indagar acerca de

Abril 2016

conocimientos actitudes y

comportamientos

ambientales

$\begin{array}{clll}\text { DISEÑO Y } & \begin{array}{l}\text { Presentación de } \\ \text { encuesta y entrevista }\end{array} & \begin{array}{l}\text { Evaluar la eficacia del diseño } \\ \text { de los instrumentos }\end{array} & \text { Mayo 2016 } \\ \text { VALIDACIÓN DE LA } & \text { a pares } & \end{array}$

$\begin{array}{lllr}\text { IMPLEMENTACIÓN } & \begin{array}{l}\text { Aplicación de los } \\ \text { instrumentos }\end{array} & \begin{array}{l}\text { Recolección de la información } \\ \text { para contextualizar el entorno } \\ \text { de vigías ambientales y sus } \\ \text { familias }\end{array} & \begin{array}{r}\text { Julio } 2016 \\ \text { Mayo } 2017\end{array} \\ & & \end{array}$

ANÁLISIS DE RESULTADOS Y CONCLUSIONES
Analizar la información para el diseño del plan de acción
Determinar la influencia de las actitudes, comportamientos proambientales en el uso responsable del agua.
Mayo octubre 2017 


\subsection{Diseño de Investigación}

Figura 15: Diseño de la investigación

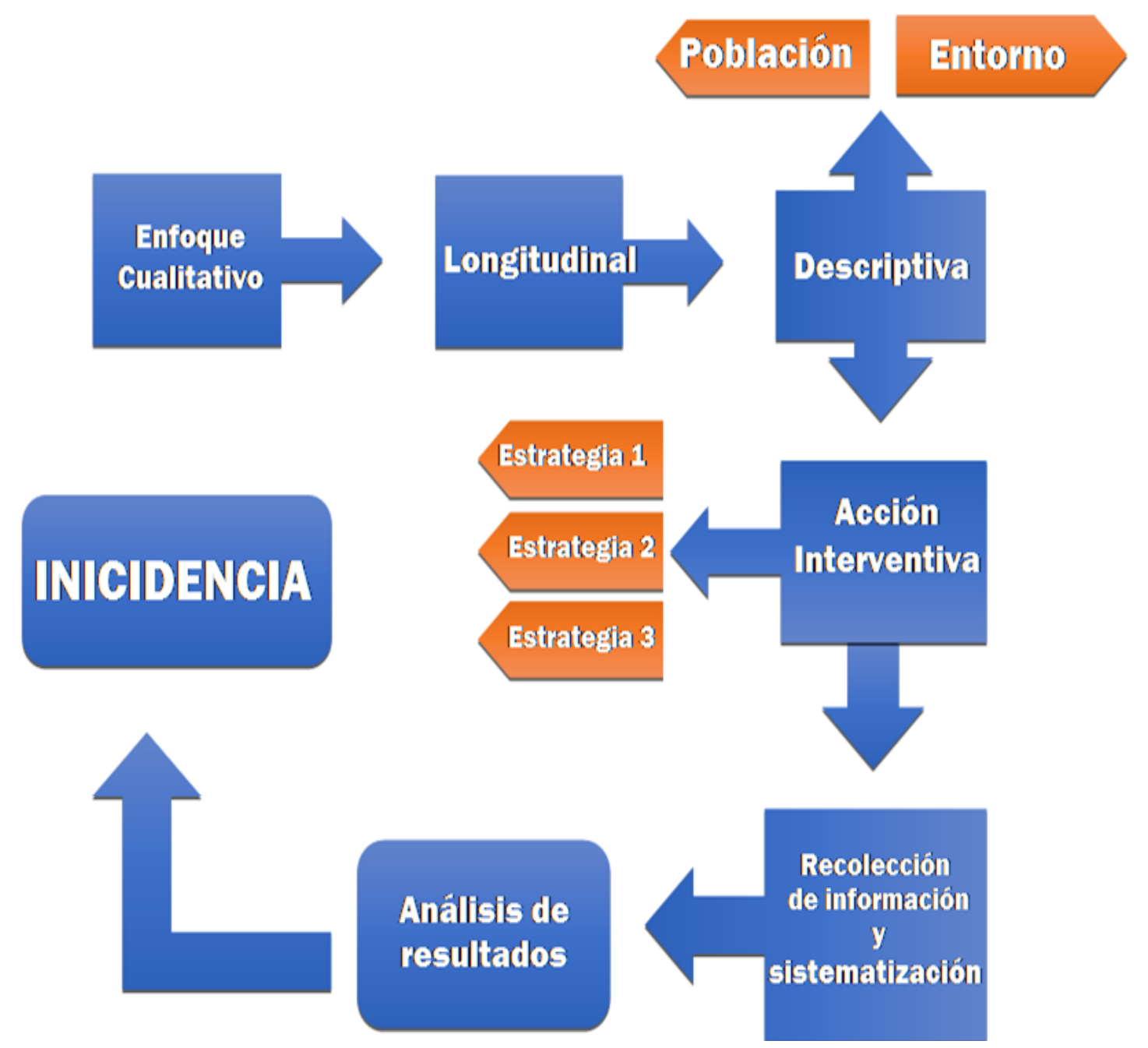

Fuente: Equipo investigador

Este trabajo investigativo tiene carácter longitudinal puesto que se desarrolló durante un periodo de tiempo, descriptivo porque recogió información de un grupo de estudiantes y sus respectivas familias, sobre aspectos ambientales para luego identificar la incidencia que se logra, después de fortalecer procesos de conocimientos, comportamientos y actitudes proambientales. 
Se trata de una investigación acción debido a la implementación de estrategias aplicadas al grupo de familias en las cuatro instituciones educativas que permitieron analizar cambios generados durante el transcurso del tiempo de la investigación, además se pretendió impactar positivamente, con lo anterior se evidencia un trabajo de naturaleza acción interventiva.

Álvarez-Gayou (2003) y Merriam (2009) citados por Hernández, Fernández y Baptista, (2010) manifiestan que a partir de la realización de un diagnóstico o revisión de datos se puede tomar decisiones que logren impactar y modificar los procesos y comportamientos de un grupo específico de población, para la construcción de una cultura ambiental a partir de comportamientos del grupo en estudio y de esta manera acercarse a la comprensión de las dinámicas propias que se dan al interior del aula en cuanto a los procesos de enseñanza aprendizaje de la EA (Hernández, Fernández, \& Baptista, 1991). En palabras de Orlando Fals Borda (1999) las formas confluyentes en que se puede articular la investigación y la acción también determinarán la supervivencia de las “escuelas” de Investigación Participativa y la traslación de puntos de vista a la aplicación local en ciudades y barrios, en las familias, empresas, iglesias, universidades y escuelas (Herrera \& López, 2014, p. 282).

Por tal razón se implementaron estrategias pedagógicas con el fin de promover conocimientos, actitudes y comportamientos proambientales en los estudiantes miembros del CAE, para que ellos con las acciones y enseñanzas prácticas orientadas desde la institución, fueran promotores de liderar procesos ambientales a sus compañeros y a la vez inciden en las actividades familiares, pretendiendo de esta manera crear una cultura del cuidado y protección del medio ambiente. 


\subsection{Población}

La población objeto de esta investigación estuvo conformada por estudiantes de las instituciones educativas distritales: Luis López de Meza, Manuel Zapata Olivella, Ricaurte y Reino de Holanda. Este grupo de alumnos miembros del Comité Ambiental Escolar (CAE), son los vigías ambientales de cada colegio, quienes son los gestores y multiplicadores de las estrategias de intervención socioambiental en las instituciones y en sus familias.

Tabla 10.

Miembros de los CAE por colegio y género

\begin{tabular}{lll}
\hline \multicolumn{1}{c}{$*$} & Femenino & Masculino \\
\hline LLM & 8 & 9 \\
\hline MZO & 18 & 16 \\
\hline CR & 11 & 6 \\
\hline RH & 8 & 11 \\
\hline TOTAL & 45 & 39
\end{tabular}

Tabla elaborada por el equipo investigador.

* LLM: Luis López de Mesa, MZO: Manuel Zapata Olivella, CR: Colegio Ricaurte, RH: Reino de Holanda

Tabla 10.

Número de estudiantes por curso y colegio

\begin{tabular}{llllllllll}
\hline $\boldsymbol{G R A D O}$ & $\mathbf{4}^{\circ}$ & $\mathbf{5}^{\circ}$ & $\mathbf{6}^{\circ}$ & $\mathbf{7}^{\circ}$ & $\mathbf{8}^{\circ}$ & $\mathbf{9}^{\circ}$ & $\mathbf{1 0}^{\circ}$ & $\mathbf{1 1}^{\circ}$ & TOTAL \\
\hline LLM & 1 & 2 & 2 & 2 & 2 & 3 & 3 & 2 & 17 \\
\hline MZO & 4 & 4 & 4 & 4 & 6 & 4 & 4 & 4 & 34 \\
\hline CR & & & 4 & 2 & 3 & 4 & 2 & 2 & 17 \\
\hline RH & 6 & 8 & 2 & 0 & 0 & 2 & 1 & 19 \\
\hline TOTAL & 3 & 10 & 16 & 8 & 8 & 9 & 9 & 7 & 70 \\
\hline
\end{tabular}

Tabla elaborada por el equipo investigador. 
Tabla 12.

Número de estudiantes por jornada y colegio

\begin{tabular}{llll}
\hline JORNADA & Mañana & Tarde & Otro \\
\hline LLM & & 17 & \\
\hline MZO & 34 & & \\
\hline CR & & 17 & \\
\hline RH & & 19 & \\
\hline TOTAL & 34 & 53 & 0 \\
\hline
\end{tabular}

Tabla elaborada por el equipo investigador.

Según la tabla 2, se evidencia mayor participación femenina en los colegios Ricaurte y Manuel Zapata Olivella con relación a los colegios Luis López de Mesa y Reino de Holanda; en la tabla 3, se muestra mayor vinculación de estudiantes en el colegio Manuel Zapata Olivella, debido que presenta mayor cantidad de representantes por curso con relación a las demás instituciones; también se destaca mayor participación en los estudiantes de los grados inferiores. Se aclara que en el colegio Manuel Zapata Olivella, la profesora integrante de esta investigación trabaja en la jornada mañana y los demás docentes en la jornada contraria, lo que explica la no representación de estudiantes en contra jornada por institución, esto influyó en las instituciones que solo se implementaran las estrategias del proyecto de investigación en una jornada por lo tanto la jornada contraria no resultó favorecida, por ser un tipo de investigación descriptivo no se puede generalizar los resultados de dicha implementación ya que estos responden a cada contexto en particular. 


\subsection{Categorías de análisis:}

Las categorías son generadas a partir de la exploración de los datos que arroja la investigación, estos se organizan en unidades y clases, según los temas tratados, aspectos de similitud que se repiten y asociaciones se les asigna sentido, para interpretarlos y describirlos con relación al planteamiento del problema. (Hernández, Fernández \& Baptista. 2014).

Las categorías establecidas en este trabajo son: conocimientos, actitudes y comportamientos proambientales, además de familia, escuela y recurso hídrico.

\subsection{Técnicas e Instrumentos de recolección de información}

Uno de los instrumentos metodológicos que se implementó para la medición de los conocimientos, actitudes y comportamientos proambientales al grupo seleccionado en esta investigación, fue una encuesta diagnóstica (Anexo 1), este instrumento es uno de los métodos más idóneos y precisos que permiten describir la realidad social, como lo señalan Alonso, Lucas y Abellán (1998), quienes lo consideran como uno de los métodos más utilizados, fácil de aplicar y con resultados directos. De igual manera García (1986), citado por Amérigo (1993) define el cuestionario como un instrumento que a partir de un conjunto de respuestas sistemáticas permite medir una gran variedad de aspectos relevantes para la investigación.

Este instrumento, resuelto por los estudiantes y sus familias, que se elaboró a partir de la pregunta problema y los objetivos, que considera las 6 categorías: conocimientos, actitudes y comportamientos proambientales, escuela, familia y recurso hídrico. Además, incluye preguntas cerradas tipo escala Likert, y busca medir las actitudes proambientales de los participantes frente a determinadas actividades y la disposición que tienen los encuestados frente a rutinas diarias en el hogar, la escuela y su entorno. Los resultados mostraron el nivel de conocimientos, actitudes y 
comportamientos proambientales que presentaban los estudiantes y sus familias en los diferentes escenarios donde conviven.

Un segundo instrumento, la entrevista es un mecanismo usado en la investigación cualitativa “es más íntima, flexible y abierta que la cuantitativa “.'Se define como una reunión para conversar e intercambiar información entre una persona (el entrevistador) y otra (el entrevistado) u otras (entrevistados)" (Hernández, Fernández \& Baptista, 2014, p.403). En la entrevista, a través de las preguntas y respuestas se logra una comunicación y la construcción conjunta de significados respecto a un tema“. Las entrevistas se dividen en estructuradas, semiestructuradas y no estructuradas o abiertas dependiendo de los objetivos de la investigación. Las entrevistas semi estructuradas se basan en una guía de asuntos o preguntas y el entrevistador tiene la libertad de introducir preguntas adicionales para precisar conceptos u obtener mayor información. Las entrevistas abiertas se fundamentan en una guía general de contenido y el entrevistador posee toda la flexibilidad para manejarla. Regularmente en la investigación cualitativa, las primeras entrevistas son abiertas y de tipo "piloto", y van estructurando conforme avanza el trabajo de campo.. El principio y el final de la entrevista no se predeterminan ni se definen con claridad, incluso puede efectuarse en varias etapas de forma flexible. La entrevista cualitativa es en buena medida anecdótica y tiene un carácter más amistoso. (Hernández, Fernández \& Baptista, 2014). La entrevista (Anexo 2a), y sus transcripciones (Anexo 2b), relaciona el adecuado uso del agua en el hogar, en el colegio y en diferentes contextos en los cuales permanece el estudiante.

Otro instrumento que se utilizó es el diario de campo (Anexo 8), herramienta usada por los investigadores para sistematizar los acontecimientos y analizar los resultados. Para Cerda (2011), el diario de campo "es una narración minuciosa y periódica de las experiencias vividas y los hechos observados por el investigador" (p. 303). Dentro del diario de campo, la descripción de la situación 
problema debe ser de manera objetiva; teniendo en cuenta la relación que existe entre el lugar y el objeto de estudio, siendo este un proceso continuo y sistemático que permite demostrar de igual forma las relaciones de las personas con su vida cotidiana. Al respecto Páramo (2008) afirma que: “es el registro de información en relación con el paso del tiempo en forma anecdótica. Los registros se hacen según lo experimentado, lo que se aprende a través de las diferentes interacciones con las personas y de lo que se observó" (p.178).

El diario de campo es un instrumento que permite día a día sistematizar la práctica investigativa para organizarla, es decir, analizarla e interpretarla para poder transformarla. Según Bonilla y Rodríguez (1997) citados por Martínez (2007): "El diario de campo permite al investigador un monitoreo permanente del proceso de investigación. Puede ser útil al investigador puesto que en él se toma nota de los aspectos que se consideran importantes para organizar, analizar e interpretar la información recogida“. (p.77).

El análisis de los diarios de campo se realizó teniendo en cuenta cada uno de las categorías en el actual trabajo: conocimientos, actitudes y comportamientos proambientales, igualmente familia, escuela y recurso hídrico, para identificar en las cuatro instituciones los aspectos en que convergen o son similares y las divergencias que se presentaron en los estudiantes y que se evidencian también en los hogares.

Por otra parte, se manifestó el grado de compromiso de los docentes investigadores al compartir en varias oportunidades los conocimientos y sus ideas con los estudiantes para lograr que estos desarrollen habilidades cognitivas y procedimentales que inciden con sus compañeros y a la vez en sus familias con relación al uso adecuado del agua.

Además de lo anterior, se aplicaron unas rejillas (Anexo 4a), cuyo objetivo era llevar control diario de algunas actitudes y comportamientos de los niños y sus familias con relación al 
uso adecuado del agua, como por ejemplo, si cerraban la llave al cepillarse, si tomaban duchas cortas, si recolectaban y utilizaban el agua lluvia, al igual la frecuencia del uso de la lavadora y si era un hábito reciclar el agua de dicha actividad.

Luego de que cada estudiante integrante del CAE, daba respuesta a los ITEMS, de esta rejilla por espacio de un mes, los docentes investigadores describieron la frecuencia con que los estudiantes y sus familias realizaban las acciones con el uso del agua. Esto manifestó un grado de actitud y comportamientos de las diferentes familias.

Otra rejilla que se aplicó (Anexo 4b), fue un seguimiento de comportamientos proambientales desde los hogares; que comparaba ciertas acciones que tienen lo padres y sus hijos con actividades que implica el uso del agua.

\subsection{Proceso de Validación y Análisis de Resultados}

Para el análisis de resultados se utilizó el método de triangulación de datos obtenidos y su respectivo análisis a partir de la aplicación de instrumentos en los diferentes actividades realizados con los estudiantes vigías ambientales y sus respectivas familias.

Para dar cuenta de la investigación de tipo cualitativo, se analizaron los datos de los diarios de campo (Anexo 8) con el uso de la teoría fundamenta, en los cuales se incluyeron fecha, lugar, grupo objeto de observación, notas descriptivas, precategorias y notas interpretativas, estos diarios se identificaron con un código alfanumérico de forma ascendente para identificar cada uno de los colegios que participaron en este trabajo.

En la realización de talleres se utilizaron tres videos relacionados con el problema de investigación, los cuales muestran las consecuencias del uso irresponsable del agua y motivan al ahorro y cuidado del recurso hídrico.

- Caillou ahorra agua: https://www.youtube.com/watch?v=C6WQ7uY5W7o. 
- Consejos para ahorrar agua: https://www.youtube.com/watch?v=9iN-YhMORmY

- Cuidado del agua: https://www.youtube.com/watch?v=C6WQ7uY5W7o

Luego de observar los videos, los estudiantes desarrollaron una serie de actividades como el diseño de carteles donde se sintetiza el mensaje principal, los cuales se colocaron y socializaron en las áreas comunes del colegio; de otro lado también se organizaron grupos de discusión con estudiantes y padres de familia que asistieron a los talleres, lo cual se aprovechó para identificar cuáles de esas acciones que se observan en los videos se practican en la casa y cuales se adoptarán por primera vez (Anexo 11). Esta actividad fue registrada a través de los diarios de campo y permitieron observar la forma como la escuela puede incidir en los conocimientos, actitudes y comportamientos proambientales dentro de la familia. 


\section{Plan de Acción}

Después de realizar el diagnóstico sobre las actitudes que tienen los estudiantes líderes ambientales y sus familias con relación al uso adecuado del agua, tanto en el colegio como en sus hogares, se elaboró un plan de acción para lograr los objetivos educativos del proyecto en las cuatro instituciones educativas, se establecieron estrategias pertinentes, así como lo sugiere Lewin (1940) que define al plan de acción como el proceso que avanza en ciclos sucesivos de planeación de las estrategias y las acciones que se implementan en torno a la idea de mejorar.

El plan de acción se aplicó en forma de intervención educativa, es decir, involucrando dicho proceso investigativo tanto a estudiantes vigías ambientales como a padres de familia, incluso a algunos que de manera voluntaria se sumaron aun no siendo miembros del proyecto. El plan contempla tres estrategias pedagógicas, o conjunto de acciones, aplicadas de forma lúdica que facilitan el aprendizaje en los niños y adultos a través de actividades creativas y dinámicas que hacen de esta acción una forma diferente de adquirir el conocimiento que luego se pone en práctica, motivando a las personas a crear soluciones a problemas que enfrenta a diario y que a la vez fortalecen el desarrollo de su nivel cultural.

La primera está dirigida a los líderes ambientales, la segunda a las familias y la tercera al colegio (Ver figura 14). En la primera se desarrollaron cinco actividades con el fin de caracterizar, sensibilizar, integrar y formar, a los líderes ambientales. La segunda estrategia consistía en tres actividades, lideradas desde el colegio, cuyo objetivo fue formar e integrar a los padres de familia en los procesos de educación ambiental. La tercera estrategia se desarrolló en el colegio, integrando estudiantes y familia a los procesos de educación ambiental que conforman las tres estrategias pedagógicas, respondieron a una o varias categorías de análisis de las planteadas en este trabajo de investigación 
Figura 16. Estrategias y actividades del plan de acción
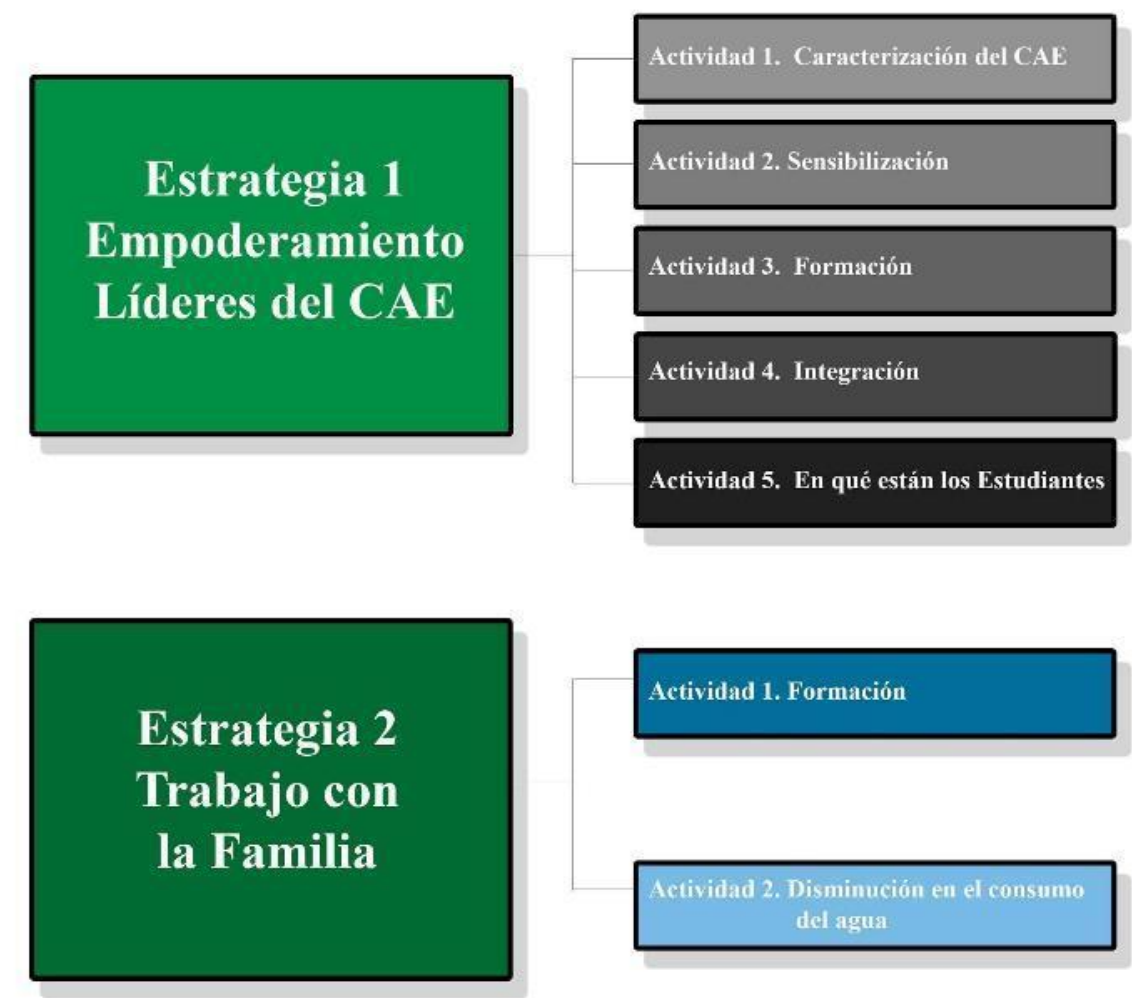

Actividad 1. Formación

Estrategia 2

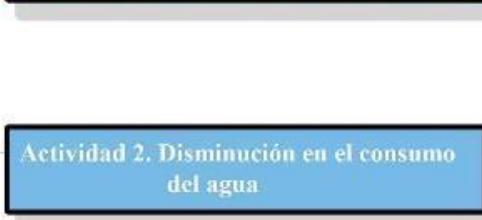

\section{Estrategia 3} Trabajo Colegio y Familia

Imagen diseñada por el equipo investigador. 
Tabla 13.

Estrategias y actividades del plan de acción

\begin{tabular}{|c|c|c|c|c|}
\hline \multirow{4}{*}{$\begin{array}{l}\text { Estrategia } \\
\text { Estrategia } \\
\quad 1 \\
\text { Lideres } \\
\text { ambiental } \\
\text { es } \\
\text { CAE }\end{array}$} & Actividad & Recursos & Responsable & Fecha \\
\hline & $\begin{array}{l}\text { Actividad 1. Caracterización de los } \\
\text { estudiantes a través de la aplicación de } \\
\text { una encuesta. Se adelantará una encuesta } \\
\text { dirigida a los estudiantes que hacen parte } \\
\text { del CAE. En ella se recoge información } \\
\text { acerca de las actitudes y comportamientos } \\
\text { tanto a nivel personal como en el hogar. }\end{array}$ & Encuestas & $\begin{array}{l}\text { Docente investigador } \\
\text { y estudiantes del CAE }\end{array}$ & 20 de septiembre \\
\hline & $\begin{array}{l}\text { Actividad 2: Sensibilización: } \\
\text { Objetivo: Sensibilizar a los estudiantes } \\
\text { sobre la responsabilidad que tenemos los } \\
\text { seres humanos en el cuidado de nuestro } \\
\text { planeta. } \\
\text { 1. Lectura "La carta de la Tierra" } \\
\text { 2. Actividad grupal: elaboración de cartel y } \\
\text { exposición del mismo teniendo en cuenta } \\
\text { una guía de trabajo. } \\
\text { 3. Taller "Antes pensaba, ahora pienso" } \\
\text { NOTA: ACTIVIDAD REALIZADA CON } \\
\text { DOCENTES MIEMBROS DEL PRAE y } \\
\text { ESTUDIANTES VIGÍAS } \\
\text { AMBIENTALES }\end{array}$ & $\begin{array}{lc}- & \text { Auditorio } \\
- & \text { Proyector } \\
\text { de video } \\
- & \text { Computado } \\
\text { r } & \\
- & \text { Estudiantes } \\
\text { del CAE } & \\
- & \text { Docentes } \\
\text { CAE } & \end{array}$ & $\begin{array}{c}\text { Docente investigador } \\
\text { y estudiantes del } \\
\text { CAE }\end{array}$ & 23 de setiembre \\
\hline & $\begin{array}{l}\text { Actividad 3: Formación: } \\
\text { Taller sobre ideas sobre cómo cuidar el } \\
\text { agua en el hogar y en el colegio. } \\
\text { Objetivo: Brindar información a los vigías } \\
\text { ambientales acerca de diferentes métodos } \\
\text { para disminuir y optimizar el uso del } \\
\text { recurso hídrico en el colegio y en hogar. } \\
\text { Inicialmente se proyectarán videos que } \\
\text { muestran ideas sobre uso racional del } \\
\text { recurso hídrico. } \\
\text { En una guía de trabajo (anexo guía) los } \\
\text { estudiantes consignan las ideas para ahorrar } \\
\text { agua que podrían implementar tanto en el }\end{array}$ & 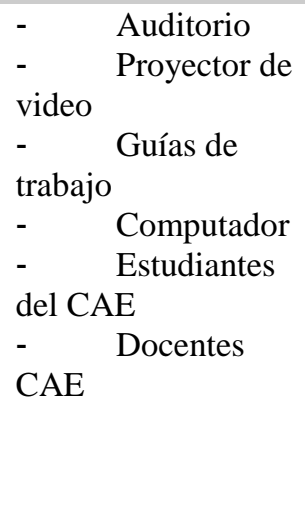 & $\begin{array}{l}\text { Docente investigador } \\
\text { y estudiantes del CAE }\end{array}$ & $\begin{array}{c}27 \mathrm{de} \\
\text { septiembre }\end{array}$ \\
\hline
\end{tabular}


colegio como en el hogar. Además se les invita a proponer en otras alternativas de ahorro.

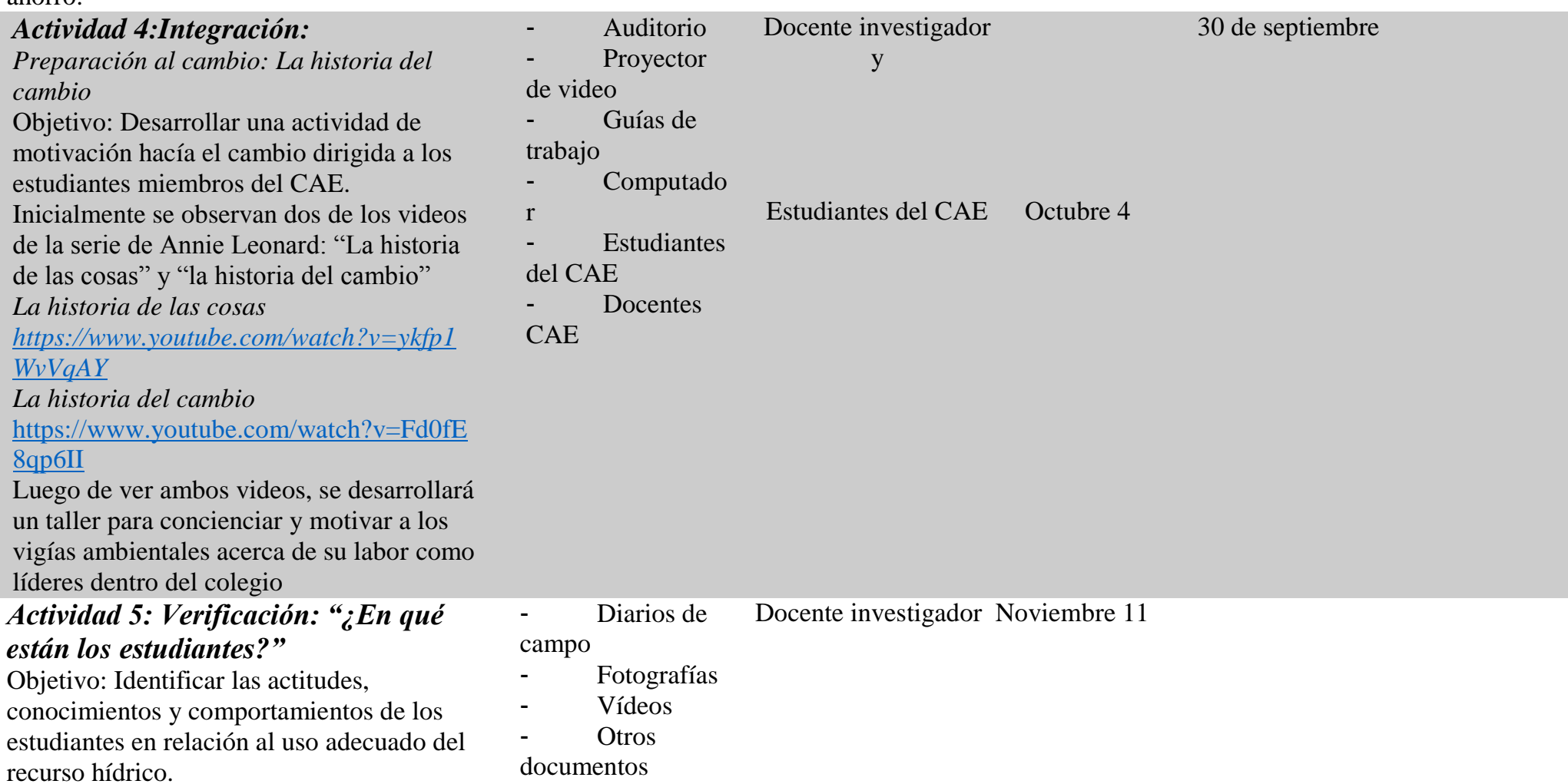

Empleando diferentes métodos, como es el

caso de diarios de campo, fotografías,

vídeos, testimonios de los estudiantes, entre otros.

\begin{tabular}{clll}
\hline $\begin{array}{c}\text { Estrategia } 2 \\
\text { Familias }\end{array}$ & Actividad 1: Formación & Daller de padres: & Diarios de campo \\
& Socialización del Proyecto de Investigación y definición de & - & Presentación en Power Point \\
& conceptos pertinentes a la problemática ambiental & Otros documentos \\
& Actividad 2: Integración: & - & Rejillas de seguimiento \\
& & - & Fotografías \\
\hline
\end{tabular}




\begin{tabular}{lll}
\hline $\begin{array}{l}\text { Seguimiento de los comportamientos proambientales } \\
\text { durante varios meses. }\end{array}$ & Otros documentos \\
Actividad. 3: Disminución en el consumo del agua. & Recibos del servicio de \\
Trabajo con los recibos & acueducto \\
& Informáticos como Excel & Mayo de 2017 \\
& Resp.Docentes y vigías & Otros documentos \\
\hline
\end{tabular}

\begin{tabular}{|c|c|c|c|}
\hline \multirow[t]{3}{*}{$\begin{array}{c}\text { Estrategia } 3 \\
\text { Colegio }\end{array}$} & $\begin{array}{l}\text { Act 1: Formación } \\
\text { CAMPAÑA CUIDADO DEL RECURSO HÍDRICO } \\
\text { Los estudiantes pasarán por cada aula de clase y realizarán } \\
\text { una exposición sobre el tema y tendiente o en cuenta la } \\
\text { información obtenida del documento La Carta de la Tierra y } \\
\text { el video "Uso racional del agua.. Conciencia para todos } \\
\text { TODOS" } \\
\text { 2. Los vigías ambientales colocaran en cada aula una } \\
\text { cartelera relacionada al tema con el fin de generar conciencia } \\
\text { acerca del uso adecuado del recurso hídrico. } \\
\text { OBJETIVO: Multiplicar la información adquirida dentro de } \\
\text { las actividades anteriores a los demás estudiantes de la } \\
\text { institución con el fin que ellos adquieran conocimientos sobre } \\
\text { el tema y lleven información relevante a sus hogares. }\end{array}$ & $\begin{array}{l}\text {-Cartulina } \\
\text {-Marcadores } \\
\text {-Revistas } \\
\text {-Estudiantes CAE sección } \\
\text { bachillerato } \\
\text {-Cinta } \\
\text {-Dulces } \\
\text {-Docentes } \\
\text {-Estudiantes del CAE de los } \\
\text { grados } 6^{\circ} \text { a } 11^{\circ}\end{array}$ & $\begin{array}{c}\text { Febrero a junio de } 2017 \\
\text { Docentes líderes del PRAE y } \\
\text { estudiantes del CAE }\end{array}$ \\
\hline & $\begin{array}{l}\text { Act 2: Integración: } \\
\text { 1.Elaboración friso tema: uso racional del agua y } \\
\text { recomendaciones para el lavado de manos } \\
\text { 2.Ubicación de frisos en los baños de la institución } \\
\text { 3.Llevar y pegar en casa (baño) instructivo de adecuado } \\
\text { lavado de manos } \\
\text { OBJETIVO: Generar conciencia en los estudiantes y sus } \\
\text { familias en cuanto al manejo y cuidado personal y del agua. }\end{array}$ & $\begin{array}{l}\text {-Estudiantes CAE sección } \\
\text { bachillerato } \\
\text {-Materiales de papelería } \\
\text {-Docentes }\end{array}$ & $\begin{array}{c}\text { Febrero a junio de } 2017 \\
\text { Docentes líderes del PRAE y } \\
\text { estudiantes del CAE }\end{array}$ \\
\hline & Act. 3: Disminución en el consumo del agua. & $\begin{array}{ll}\text { - } & \text { Recibos del servicio de } \\
\text { acueducto } \\
\text { - } & \text { Informáticos como Excel } \\
\text { - } & \text { Otros documentos }\end{array}$ & $\begin{array}{c}\text { Febrero a junio de } 2017 \\
\text { Docentes líderes del PRAE }\end{array}$ \\
\hline
\end{tabular}




\subsection{Estrategia Empoderamiento Líderes del CAE}

Esta estrategia consta de cinco acciones que se desarrollaron de forma continua, sistemática y transversal con el fin de contribuir a la solución de problemas ambientales como es el caso del uso inadecuado de los recursos. Estas actividades estuvieron orientadas a la formación de estudiantes capaces de generar alternativas de solución, en especial al uso adecuado del recurso hídrico.

\subsubsection{Caracterización del CAE}

Para lograr uno de los objetivos específicos de este trabajo de investigación, fue necesario caracterizar a los estudiantes integrantes del CAE (Anexo 3), para resaltar algunos aspectos como: género, estrato, tipo de vivienda, nivel socioeconómico, estructura familiar entre otros, que orienten las clases de estrategias a implementar..

\subsubsection{Sensibilización}

Este aspecto dentro del plan de acción, se diseñó con el objetivo de generar en la comunidad la capacidad de entender los beneficios que representa el líquido vital y el valor que este simboliza, como recurso natural, necesario para el bienestar común, por ende se hace necesario sensibilizar a nivel ambiental a la comunidad, mostrando la problemática actual que se evidencia en diferentes sectores del mundo, debido a la escasez de agua que ha generado el hombre desde que se ha servido de la naturaleza para su supervivencia, desarrollo y beneficio. Se desarrolló un taller el cual incluía la lectura de "Carta a la tierra" para identificar, entre todos, la necesidad de crear una sociedad sostenible fundada en el respeto hacia la naturaleza, los derechos humanos universales, la justicia económica y una cultura de paz para legar un mejor futuro. Además, se realizó un taller “Antes 
pensaba ...ahora pienso... Se trató de una rutina de pensamiento con carácter metacognitivo que permite a los líderes ambientales concienciarse en cuanto al cambio que han presentado sus ideas una vez se ha trabajado en el aula un determinado contenido curricular.

Esta actividad permitió evidenciar una cambio de actitud en el manejo adecuado del agua y de otras acciones que permiten la conservación del medio ambiente, por ejemplo: el ahorro de energía, manejo de residuos sólidos, higiene en áreas comunes, etc.

\subsubsection{Formación}

El fortalecimiento de conocimientos, actitudes y comportamientos proambientales, permitió a los líderes ambientales y a la comunidad educativa, generar estructuras básicas del pensamiento que dio soluciones apropiadas a diferentes eventos. El segundo taller, brindó información a los vigías ambientales en relación con comportamientos para hacer uso responsable y pertinente del agua en el hogar y en el colegio, Esta actividad incluyó la observaciòn, reflexión y socialización de tres videos. Luego de observar los videos, se generaron en los estudiantes diferentes inquietudes sobre cómo conservar el agua, estas ideas se plasmaron en carteles (Figura 15 y 16), socializados en lugares visibles de los colegio. (Anexo 11). 
Figura 17: Formación de conocimiento, actitudes y comportamientos proambientales en la IED Reino de Holanda

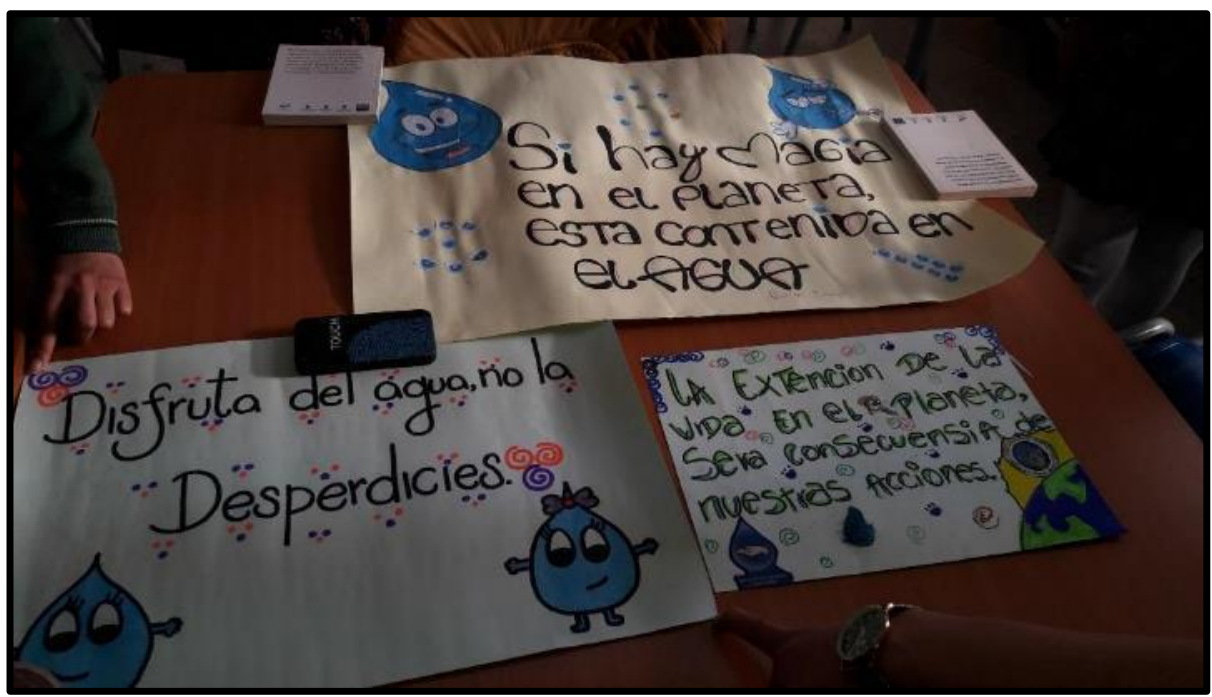

Fuente: foto: tomada por Nancy Portilla Toro

Tomada el 18 de abril de 2016

Figura 18. Formación de conocimiento, actitudes y comportamientos proambientales colegio Luis López de Meza

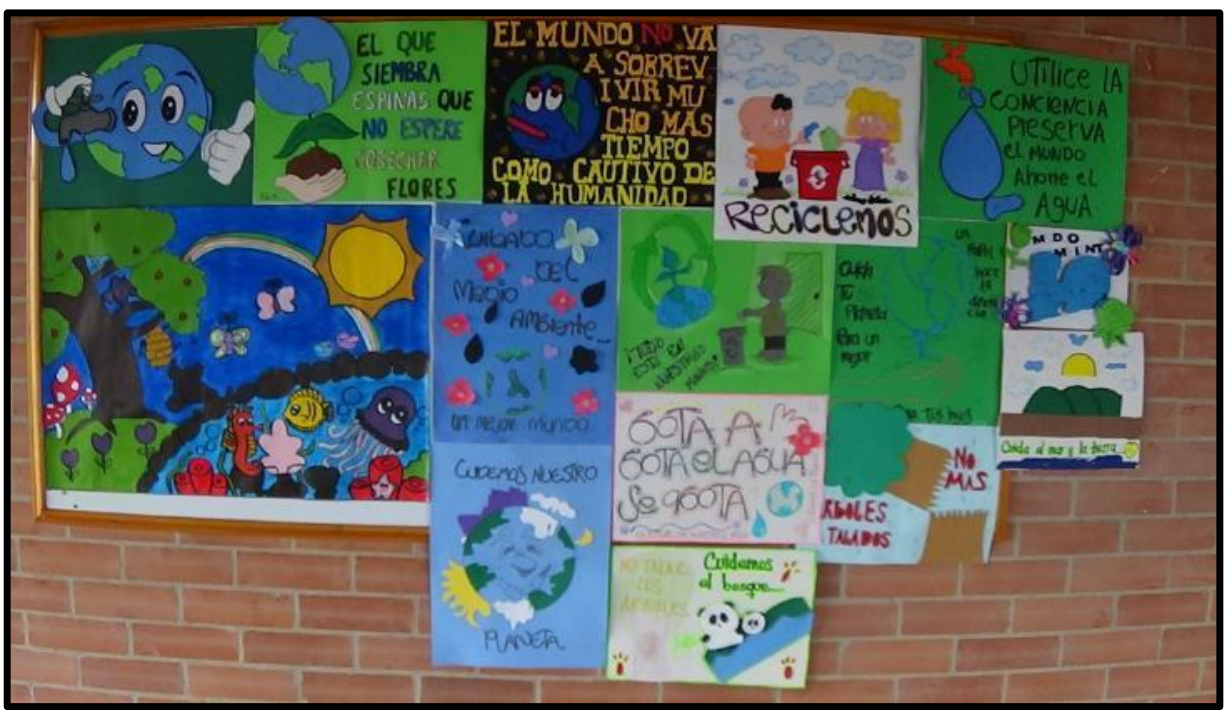

Fuente: Foto: tomada por María Eugenia Vásquez

Tomada el 9 de junio de 2016 
Figura 19. Formación de conocimiento, actitudes y comportamientos proambientales colegio Reino de Holanda

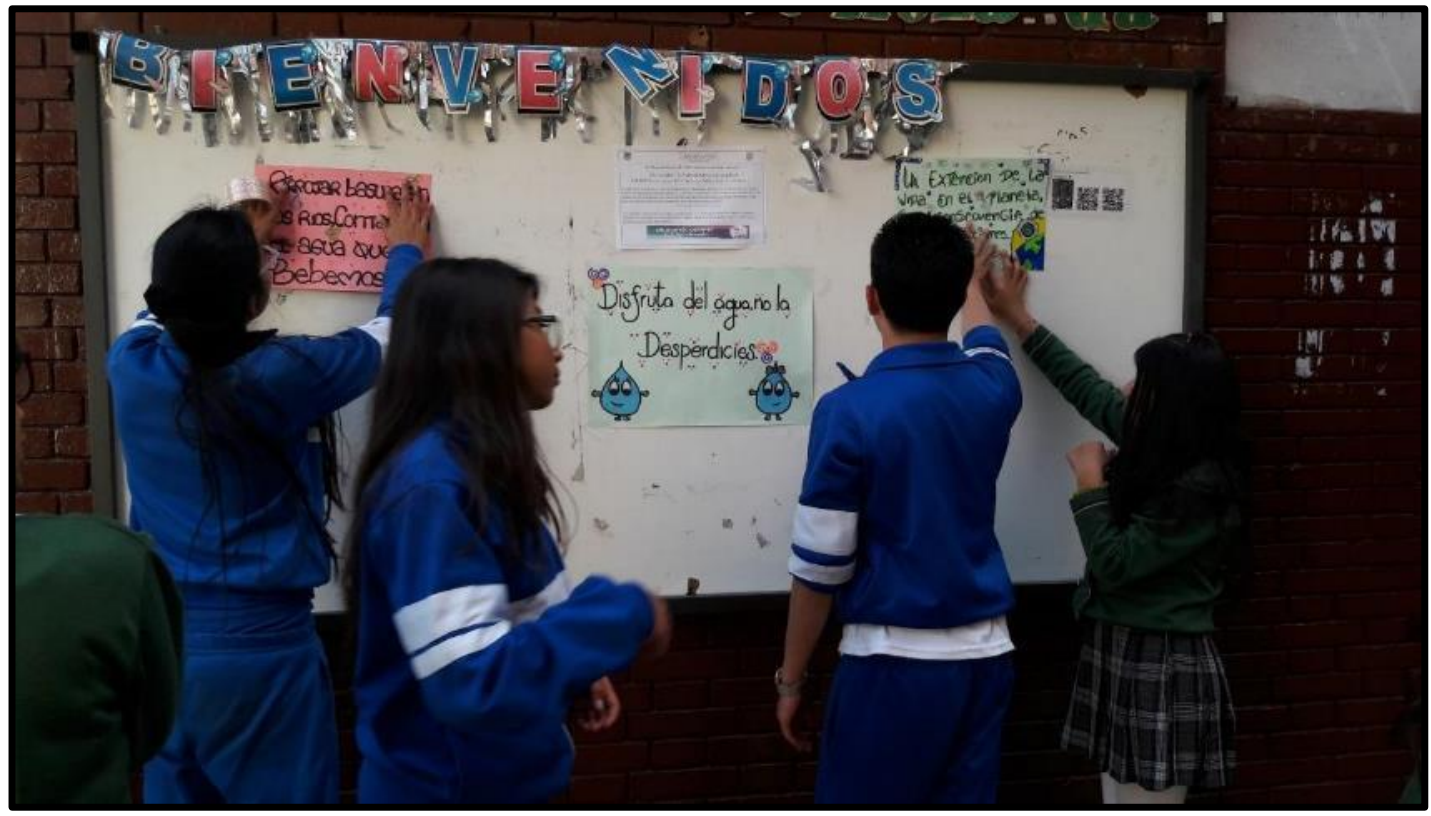

Fotografía tomada por Nancy Portilla Toro

Tomada el 18 de abril de 2016

Figura 20. Formación de conocimiento, actitudes y comportamientos proambientales colegio Reino de Holanda

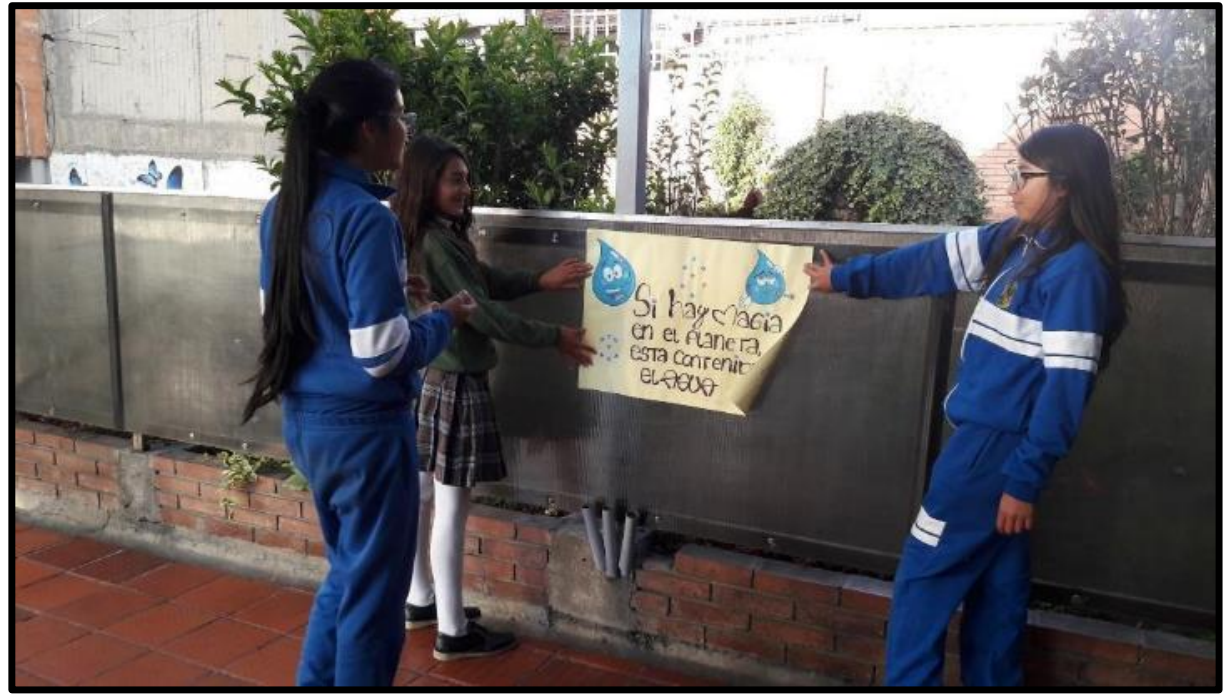

Fotografía tomada por Nancy Portilla

Tomada el 18 de abril de 2016 
Figura 21. Formación de conocimientos, actitudes y comportamientos proambientales colegio Ricaurte

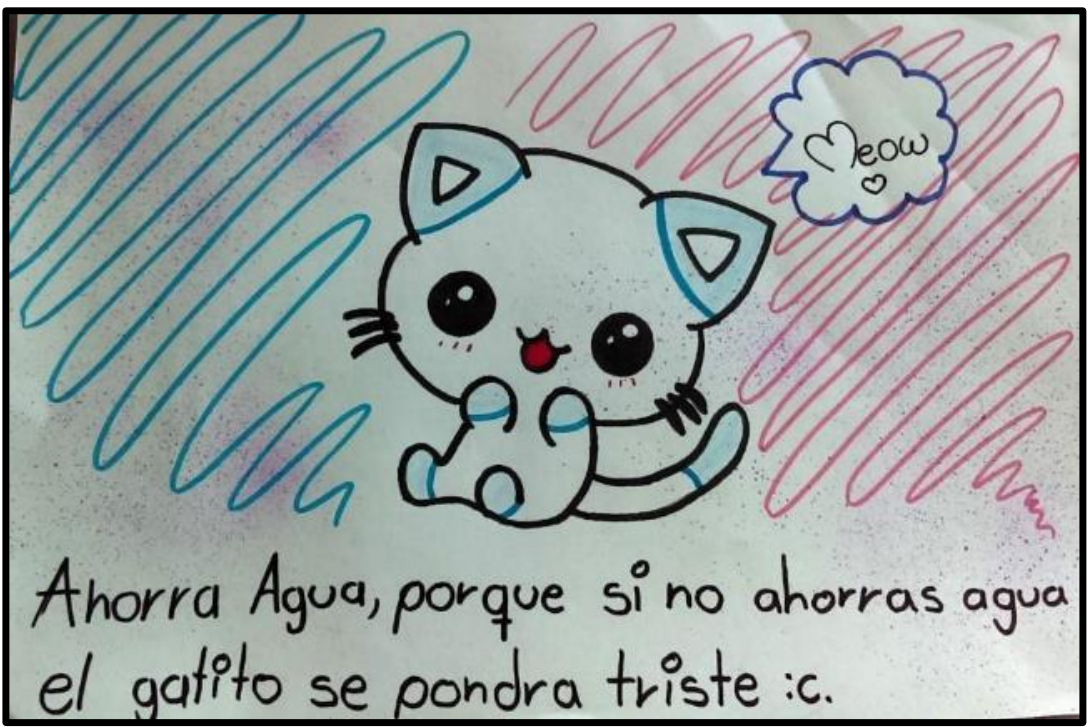

Fotografía tomada por Cesar Augusto Cruz

Tomada el 3 de mayo 2017

Figura 22. Formación de conocimiento, actitudes y comportamientos proambientales colegio Ricaurte

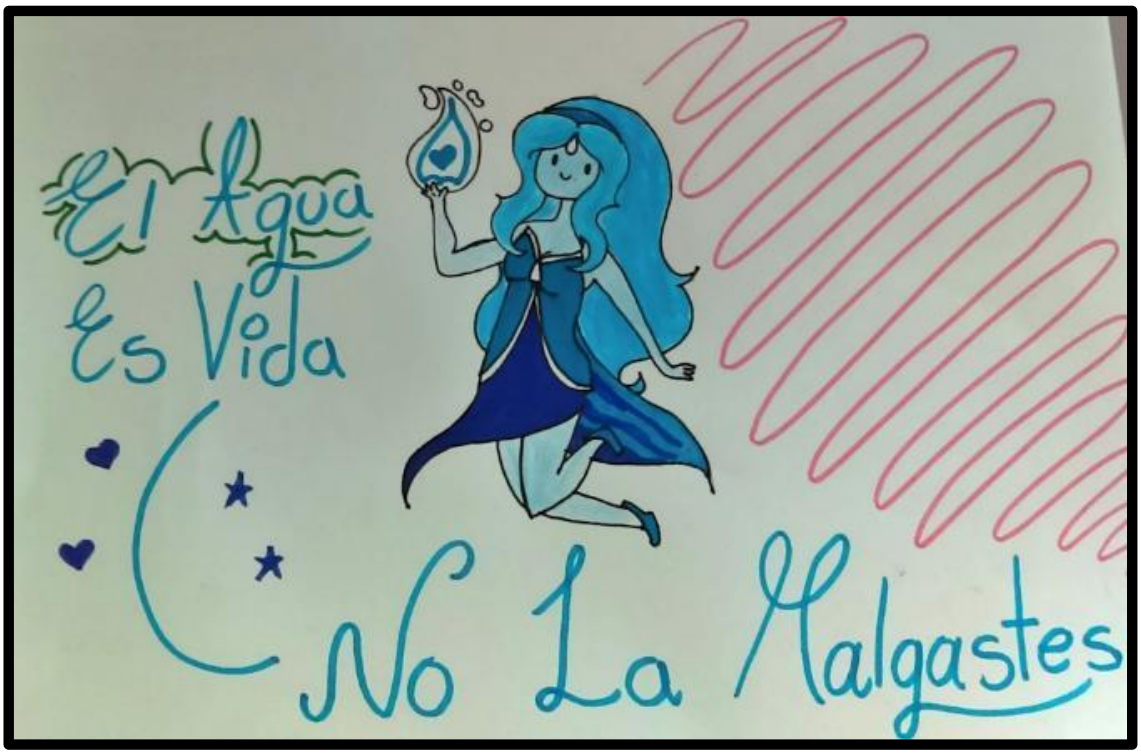

Fotografía: tomada por Cesar Augusto Cruz

Tomada el 3 de mayo de 2017 
Figura 23. Formación de conocimientos, actitudes y comportamientos proambientales adecuado del agua Colegio Manuel Zapata Olivella

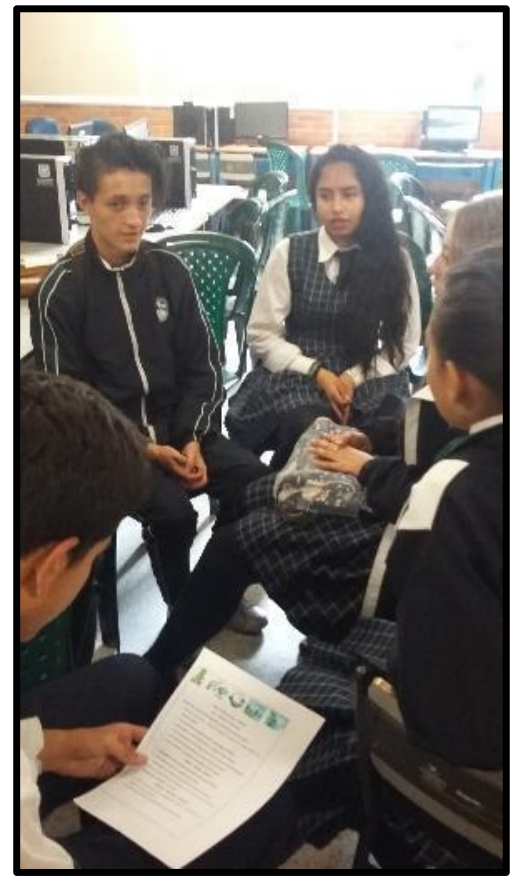

Fotografía tomada por Adriana Zoraida Montes Flórez

Tomada el 8 de Marzo de 2017

Figura 24. Formación de conocimientos, actitudes y comportamientos proambientales adecuado del agua en el Colegio Manuel Zapata Olivella

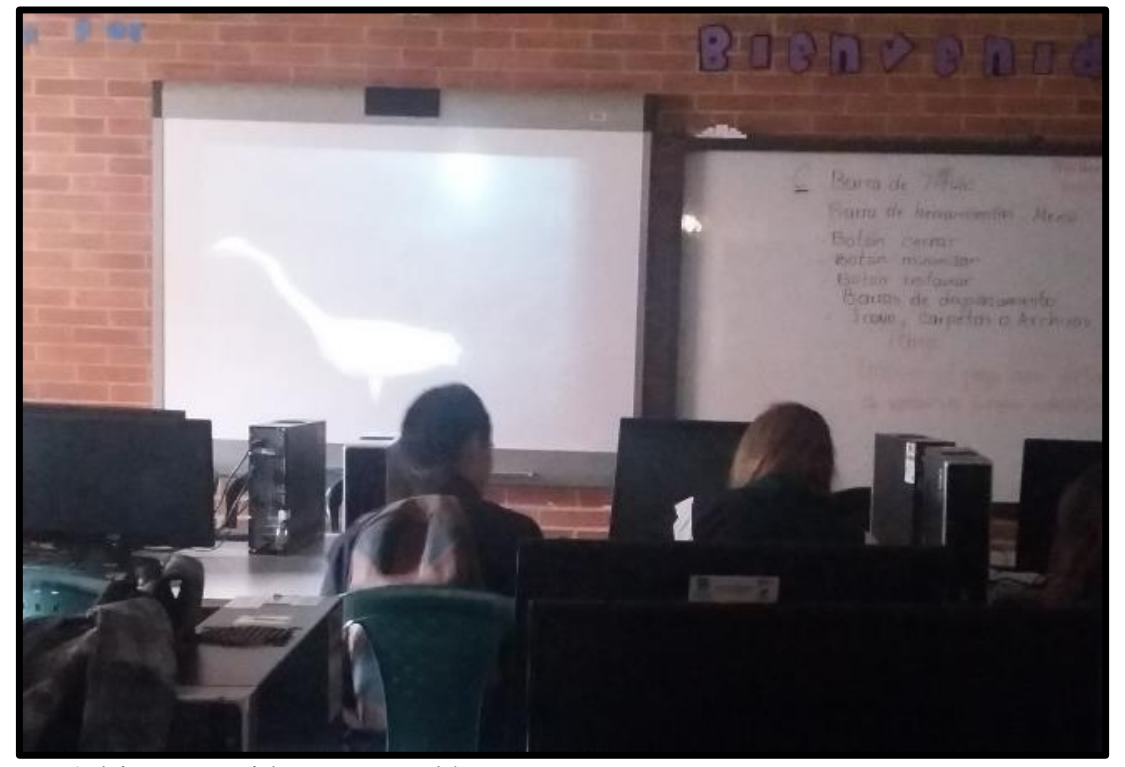

Fotografía tomada por Adriana Zoraida Montes Flórez

Tomada el 20 de Abril de 2017 
Figura 25. Formación de conocimientos, actitudes y comportamientos proambientales adecuado del agua Colegio Manuel Zapata Olivella

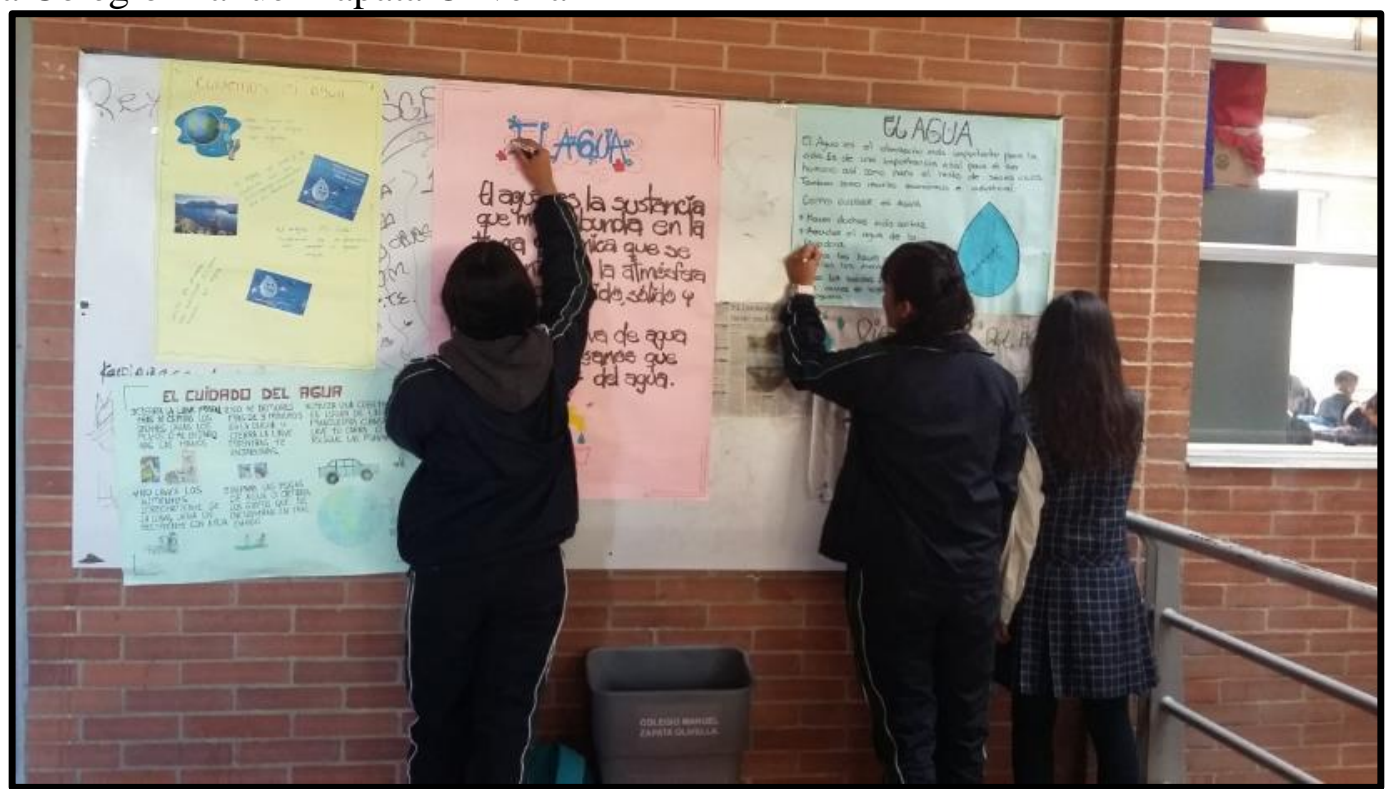

Fotografía tomada por Adriana Zoraida Montes Flórez

Tomada el 16 de Marzo de 2017

\subsubsection{Integración:}

Se proyectó a los estudiantes dos videos:

- La historia de las cosas ( https://www.youtube.com/watch?v=ykfp1WvVqAY)

- La historia del cambio (https://www.youtube.com/watch?v=Fd0fE8qp6II)

Los videos plantearon la problemática que origina la producción de artículos como el celular, los audífonos, baterías y controles entre otros, los que requieren de un proceso desde la extracción de recursos naturales, la producción, distribución, consumo, hasta la disposición final.

Estas acciones provocan daños irreversibles en el ecosistema, porque son elaborados con materiales difíciles de degradar, aumentando de manera incontrolable los residuos sólidos, afectando de manera significativa el bienestar de los seres vivos, por la contaminación ambiental que genera. 
Posteriormente los estudiantes desarrollaron una guía de trabajo, que fue socializada, se concluyó, que la mayoría de estudiantes no sabían la magnitud del problema ambiental que origina la adquisición de los productos, sin observar de qué materiales y el proceso que requiere estos artefactos para ser fabricados para el uso diario y continuo.

Figura 26. Vigías ambientales de la IED Reino de Holanda observando un video sobre la historia de las cosas

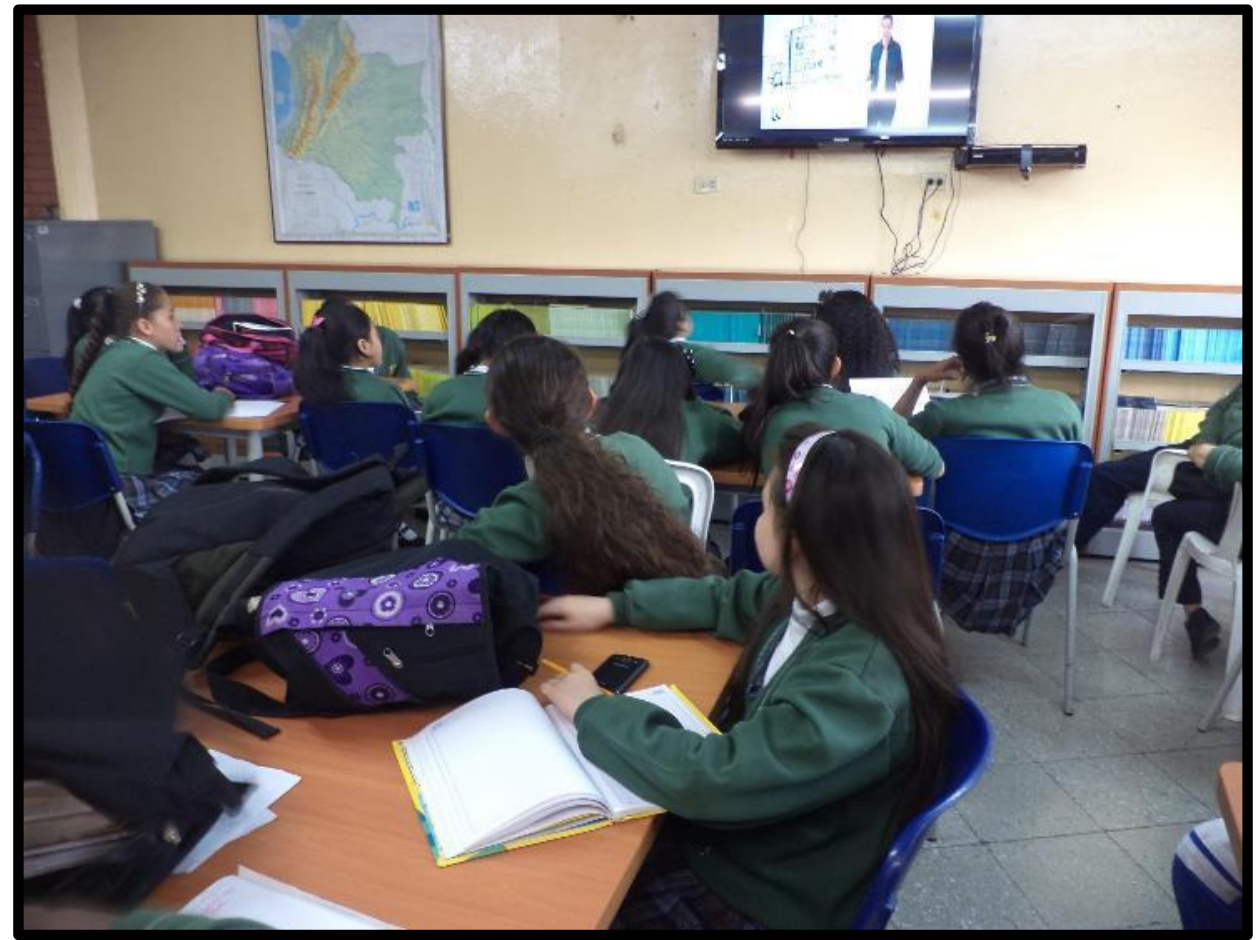

Fuente: Fotografía tomada por Nancy Rocio Portilla

Tomada el 10 de abril de 2017 


\subsubsection{En qué están los estudiantes}

Figura 27. Formación de conocimientos, actitudes y comportamientos proambientales adecuado del agua Colegio Manuel Zapata Olivella

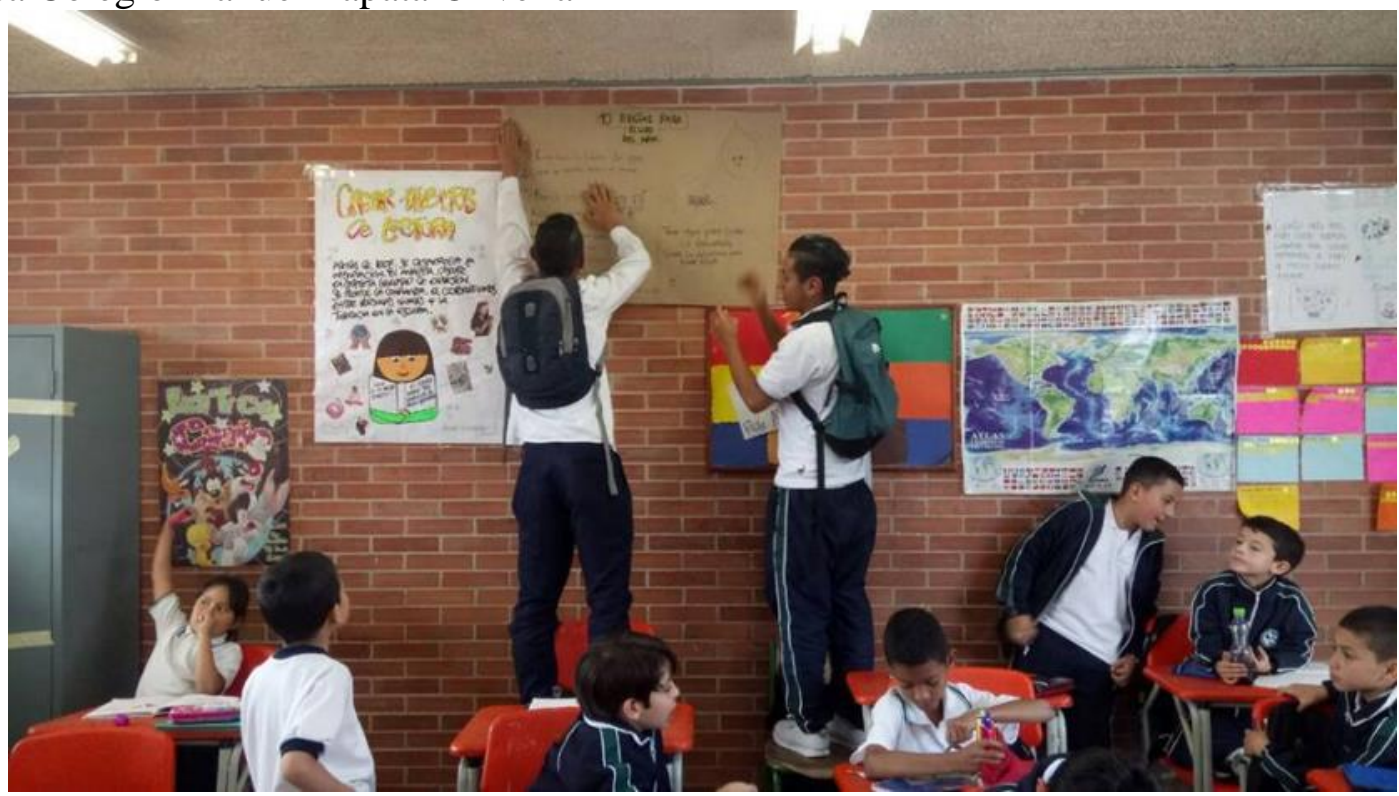

Fotografía tomada por Adriana Zoraida Montes Flórez

Tomada el 14 de Marzo de 2017

Los estudiantes de las cuatro instituciones educativas se encuentran en proceso continuos de formación en conocimientos, actitudes y comportamiento proambientales, a través de las diferentes acciones que permitan sensibilizar las actitudes hacia el uso responsable del recurso hídrico, tanto en el colegio como en el hogar.

\subsection{Trabajo con familia}

Desarrollando el segundo objetivo específico de vincular a los padres de familia y los vigías ambientales al proyecto investigativo, se realizaron algunas actividades que realizaron junto con sus hijos.

Con los diferentes talleres que se aplicaron a los estudiantes y los padres de familia, se logró integrar las instituciones educativas con los hogares para crear una cultura ambiental que favorezca la conservación del entorno. 


\subsubsection{Formación.}

Con el propósito de fortalecer el rol de los padres de familia y convertirse en parte activa dentro de los procesos de formación de sus hijos, se invitó a padres y acudientes para hacer parte del proyecto de investigación.

Es claro, que el trabajo conjunto de padres y estudiantes en la construcción de proyectos facilita el mejoramiento de los resultados en los procesos educativos.

Para tal fin, se realizó una actividad con los padres de familia con el propósito de socializar el proyecto de investigación y mencionar los beneficios para sus hogares y el ecosistema.

Se realizó la socialización del proyecto investigativo, contextualizando elementos afines del proyecto ambiental, por ejemplo: concepto de PRAE, sus objetivos, plan de acción y quienes lo integran; de igual manera, se definió que es el CAE, quienes lo integran y cuáles son sus

objetivos; y a sí mismo los conceptos de vigía ambiental, se aclararon conceptos sobre medio ambiente, ecosistema, recursos renovables, sostenibilidad y sustentabilidad.

El propósito de esta actividad, fue que los padres de familia conocieran los conceptos mínimos, para comprender la problemática ambiental, específicamente con el uso responsable y pertinente del recurso hídrico. 
Figura 28. Socialización del Proyecto con padres de familia Colegio Reino de Holanda

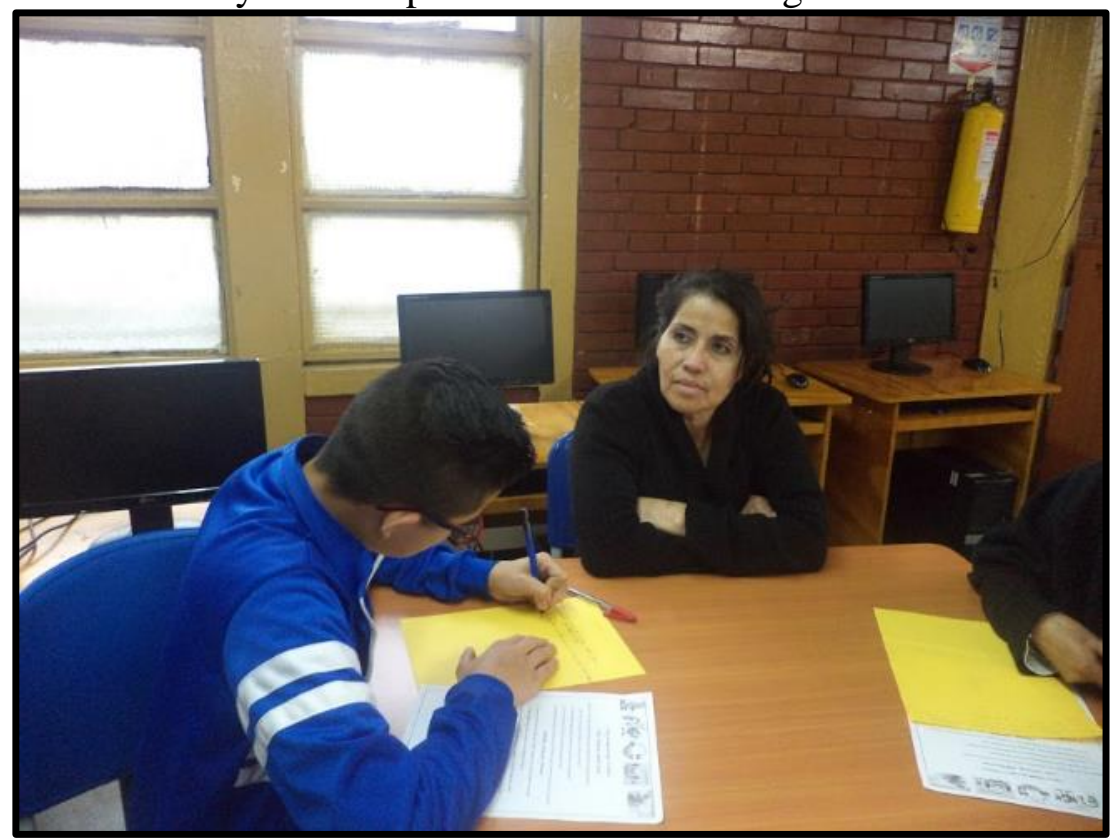

Fotografía tomada por Nancy Portilla Toro

Tomada el 10 de abril de 2017

Figura 29. Socialización del Proyecto con padres de familia Colegio Reino de Holanda

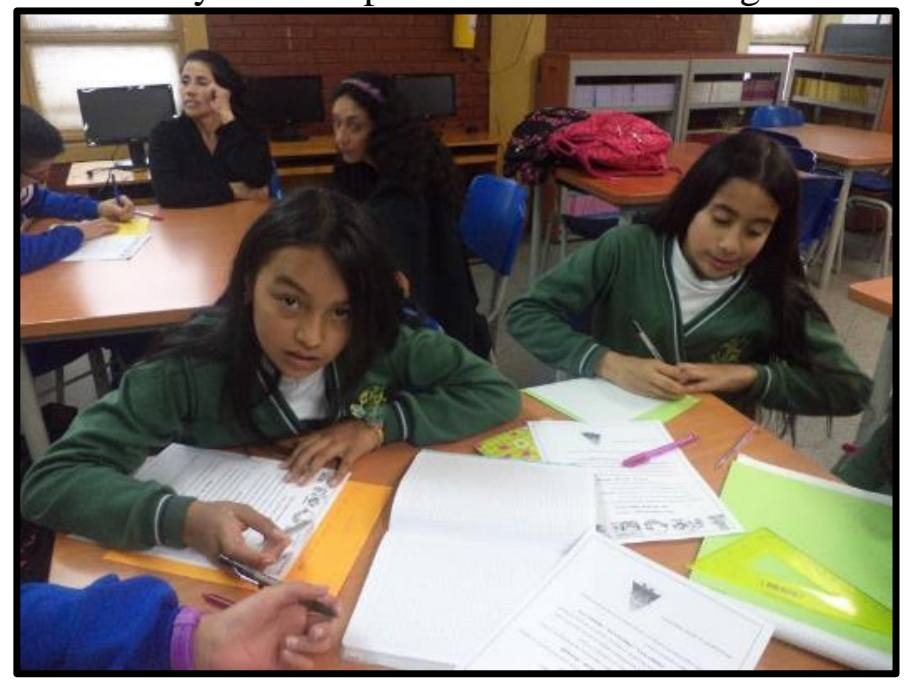

Fotografía tomada por Nancy Portilla Toro

Tomada el 10 de abril de 2017

\subsubsection{Disminución en el consumo del recurso hídrico.}

Para el logro de ítem, se pidió a los vigías, facilitaran una factura de agua, alcantarillado y recolección de basuras, para determinar el estado en el que se encontraban las familias, con relación 
al consumo del servicio, al finalizar el proceso investigativo, se vuelve a solicitar una nueva factura, para determinar si la dinámica de sensibilización a estudiantes y padres de familia, tuvo un impacto positivo o negativo.

\subsection{Trabajo Colegio y familia}

En estas actividades se integró las acciones de los estudiantes con su respectiva familia, para que en conjunto crearán estrategias que mitiguen los daños ambientales con relación al recurso hídrico y que son aplicables en los ámbitos escolares y familiares

\subsubsection{Campaña uso responsable del agua}

Se realizó en las instituciones educativas la campaña del agua, donde los padres de familia junto con sus hijos elaboraron un decálogo sobre el uso responsable del agua, estas se introdujeron en una botella plástica con el fin de relacionar este elemento con reciclaje y motivar a los estudiantes su reutilización; los estudiantes socializaron esta actividad en cada uno de los cursos para explicar cada una de las reglas ambientales por ellos elaboradas y lograr sensibilizar a la comunidad educativa sobre la importancia de cuidar el medio ambiente.

\subsubsection{Elaboración y socialización de normas para el cuidado del agua}

Inicialmente se hace una conferencia sobre las reglas para el cuidado del agua, se crearon nuevas y luego se escogieron solamente 10 normas que se publicaron en los baños de la institución 
Figura 30. Formación de conocimientos, actitudes y comportamientos proambientales adecuado del agua Colegio Manuel Zapata Olivella, Taller las 10 reglas del cuidado del agua

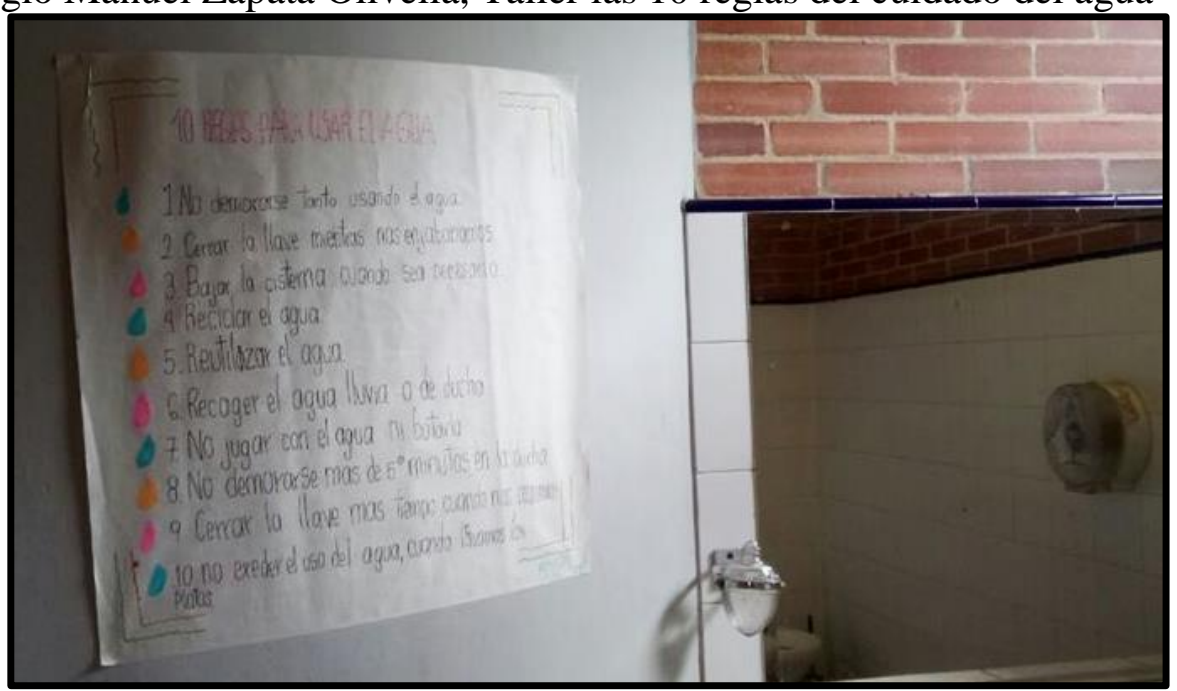

Fotografía tomada por Adriana Zoraida Montes Flórez

Tomada el 24 de Febrero de 2017 


\section{Resultados y análisis de datos}

Este capítulo presenta el análisis de los resultados, en las cuatro instituciones educativas distritales, para determinar si las estrategias que se desarrollaron al inicio del proceso investigativo, logró el objetivo planteado al finalizar la investigación.

El análisis se realizó para cada una de las estrategias desarrolladas en el plan de acción: Estrategias 1: Empoderamiento de los líderes CAE; Estrategia 2: Trabajo con la familia; y Estrategia 3: Trabajo, colegio y familia. Con los resultados obtenidos, y teniendo en cuenta las categorías de análisis de la investigación se establecieron puntos de convergencia, divergencia e incidencia.

Tabla 14.

Resultados obtenidos en cada una de las estrategias del plan de acción

\begin{tabular}{ll}
\hline \multicolumn{1}{c}{ ESTRATEGIAS } & \multicolumn{1}{c}{ RESULTADOS } \\
\hline ESTRATEGIA 1 & $\begin{array}{l}\text { La mayoría de los integrantes del CAE pertenecen a los grados } \\
\text { sextos y séptimos, niños entre los 10 y 11 años, las niñas son más } \\
\text { Empoderamiento } \\
\text { receptivas a liderar este tipo de proyectos; la jornada de la tarde se } \\
\text { apropia más de estas responsabilidades. } \\
\text { La dispersión territorial de los estudiantes es más notoria en el } \\
\text { colegio Ricaurte debido a que viven fuera de la localidad, } \\
\text { comportándose como población flotante. }\end{array}$ \\
\hline ESTRATEGIA 2 & $\begin{array}{l}\text { La participación de las familias en el proceso es beneficiosa } \\
\text { porque los estudiantes comenzaron a reflejar cambios en sus } \\
\text { actitudes y comportamientos, gracias a la adquisición de } \\
\text { conocimientos que les permitieron generar conciencia sobre el uso } \\
\text { responsable y pertinente del agua. }\end{array}$ \\
\hline ESTRATEGIA 3 & $\begin{array}{l}\text { La interacción Escuela -familia son fundamentales en la } \\
\text { construcción de una cultura ambiental (Espitia-Montes 2009). Al } \\
\text { sustentar que la familia es la primera institución educativa que } \\
\text { favorece la dinámica entre el proceso de aprendizaje y el } \\
\text { Trabajo colegio - }\end{array}$ \\
familia &
\end{tabular}

Fuente: Equipo investigador 


\subsection{Análisis de la caracterización de los estudiantes del CAE}

Uno de los instrumentos utilizados, en este trabajo de investigación, fue la realización de una encuesta a los estudiantes que conforman el CAE en cada una de las instituciones educativas, objeto de estudio.

\subsubsection{Caracterización CAE IED Luis López de Mesa.}

Los resultados de la caracterización muestran que en esta institución, dos estudiantes de cada curso son vigías ambientales, excepto en $10^{\circ}$, donde hay 3; 9 de los integrantes son niños y 8 son niñas; sus edades oscilan entre los 9 y 16 años, el $88 \%$ se ubican en el estrato 2 y el restante en el uno; igualmente el $88 \%$ tiene acceso a internet, se observa que todos viven en la localidad séptima de Bosa, en los barrios la Amistad, Nueva Granada, Bosa la Estación San José, San Pablo y el Porvenir. En cuanto a vivienda 9 viven en casa y 8 en apartamento, de los cuales 5 son propietarios de su vivienda y el resto viven en arriendo; de los 17 vigías ambientales, 13 son integrantes del CAE desde hace un año y 4 desde hace más de un año; todos creen que es importante ser vigía ambiental porque ayudan a cuidar el medio ambiente, aducen que ayudar al medio ambiente y al colegio en los diferentes procesos es lo que los motiva a ser vigías ambientales, en cuanto al grupo étnico, todos son mestizos.

En cuanto al aspecto socioeconómico, en la pregunta sobre el valor de la factura del servicio de agua y alcantarillado, muestra que 3 familias, oscila entre $\$ 31.000$ y $\$ 40.000$ pesos; para 8 familias entre $\$ 41.000$ y $\$ 50.000$ pesos y para 4 familias pagan $\$ 51.000$ pesos. Cabe anotar, que dentro de las familias que viven en arrendamiento con otras personas, que el valor total, lo dividen entre las personas que habitan la casa o apartamento y pagan lo correspondiente 
al número de personas que la habitan. En relación al lavado de la ropa, se pregunta si lavan o no con lavadora, contestan: 12 familias emplean lavadora y 3 lavan a mano, a la pregunta sobre cuántas veces por semana utilizan la lavadora, 9 de ellos la utilizan entre una y tres lavadas por semana y 5 familias entre tres y cinco veces por semana; para el lavado de la loza se concluye que: 15 familias lavan la loza después de cada comida, 2 hacen una sola lavada diaria; para el lavado de la boca, manifiestan que 16 de las familias recogen agua en un vaso para cepillarse los dientes y una mantiene la llave abierta mientras se cepilla, enjuaga y lava el cepillo.

Para realizar el aseo de los pisos en su casa, todas las 17 familias compuestas en su mayoría por más de 4 personas, recogen agua en un balde para ir enjuagando el trapero cada vez que sea necesario; en el momento de ducharse 5 familias suelen cerrar la llave mientras se enjabonan y 12 la abren únicamente cuando es necesario.

De los estudiantes del colegio, 11 participan en campañas ambientales dentro o fuera de la institución, 4 incentivan campañas ambientales en su comunidad y 3 dentro de la institución educativa, además, uno de ellos promueve conferencias, 7 incentiva la celebración de fechas ambientales, dos promueven la capacitación a docentes, uno a estudiantes, tres a vigías y ninguno desarrolla este tipos de actividades a padres. Los 17 estudiantes asisten a caminatas o salidas ambientales y ecológicas e igualmente hacen autocapacitaciones sobre temas ambientales y todos generan espacios de concienciación con los miembros de su familia y su comunidad.

\subsubsection{Caracterización CAE IED Manuel Zapata Olivella}

La caracterización de los vigías ambientales de la institución educativa Manuel Zapata

Olivella se hizo con los grados cuarto de básica primaria y grado once, en ella se evidencia la participación de 18 niñas y 16 niños para un total de 34 vigías ambientales, todos estudiantes de la 
jornada mañana; sus edades oscilan entre los 9 y los 17 años de edad y son elegidos dos por cada curso.

Para la caracterización de los vigías ambientales, se desarrolló una encuesta que respondieron de la siguiente manera: a la pregunta si los estudiantes tienen acceso de internet, todos los estudiantes responden afirmativamente; en cuanto al lugar de vivienda responden que se encuentra en la localidad octava (Kennedy) en estrato 2 en los barrios Patio Bonito II, Altamar, Tierrabuena, Riberas, Maria Paz, Dindalito; a la pregunta si viven en casa o apartamento 11 familias viven en casa y 23 en apartamento; con relación al tipo de vivienda contestan que 9 familias tienen vivienda propia, 13 en vivienda familiar y 12 en vivienda arrendada.

Se pregunta, quienes ya han sido vigías ambientales 14 responden que sí; y con relación al tiempo de participación manifiestan que 14 lo han sido por un periodo menor a un año y 20 por más de 1 año, en relación con sus motivaciones todos están de acuerdo que ser vigía ambiental es una labor importante en las instituciones educativas porque aportan estrategias para el cuidado del ambiente, minimizando la problemática ambiental, gracias a la influencias que ellos ejercen en sus familias y en sus pares.

Los núcleos familiares de los vigías están conformados en general por cuatro miembros de los cuales en promedio uno es menor de 10 años, dos tienen entre 11 y 20 años y 2 son mayores de 20 años de edad. Por otra parte 31 vigías son mestizos, 2 de descendencia afro y uno indígena.

Sobre el pago promedio de la factura de agua y alcantarillado manifiestan que 8 familias cancelan entre $\$ 31.000$ y $\$ 40.000$ pesos, 17 familias pagan entre $\$ 41.000$ y $\$ 50.000$, y 9 pagan $\$ 51.000$.

A la pregunta, sobre cuántas familias usan lavadora, las 34 familias usan lavadora; de los cuales 19 hacen entre una y dos lavadas por semana, 6 entre tres y cinco lavadas y 9 entre cinco y 
ocho lavadas por semana; en la pregunta sobre el lavado de la loza 6 familias acostumbran a lavar cada vez que usan un utensilio, 24 lavan la loza después de cada comida y 4 acumulan la loza del día para hacer una sola lavada que generalmente es en la noche.

Los estudiantes responden a la pregunta sobre si utilizan vaso o no para lavarse los dientes, contestan que 31 núcleos familiares tienen el hábito de recoger agua en un vaso para cepillarse los dientes y tres abren la llave cada vez que se van a enjuagar la boca y el cepillo.

Para realizar el aseo de la casa 2 familias recogen agua en un balde y la riegan por todo el piso, 32 enjuagan el trapero a medida que se hace necesario; con relación al aseo personal, 4 familias mantienen la llave abierta mientras se enjabonan, 29 familias suelen cerrar la llave mientras se enjabonan y 1 abre la llave del agua únicamente cuando es necesario.

Se pregunta a los estudiantes vigías, sobre si participan o no en campañas ambientales, 26 vigías participan en campañas ambientales dentro o fuera de la institución y 8 incentivan campañas ambientales dentro de la institución educativa, 2 de ellos promueven conferencias, 14 promocionan la celebración de fechas ambientales, 4 la capacitación a docentes, 6 a estudiantes, 3 a vigías y 5 a padres de familia. Los 34 vigías asisten a caminatas o salidas ambientales y ecológicas, 24 hacen autocapacitación sobre temas ambientales, 10 no las hacen; en cuanto a generan espacios de concientización con los miembros de su familia 28 si generan esos espacios, 6 no lo hacen.

\subsubsection{Caracterización CAE IED Ricaurte}

Para el caso de la IED Ricaurte la totalidad de los 17 estudiantes miembros del CAE estudian en la jornada de la tarde, pertenecen a los grados sexto a undécimo y tienen edades que oscilan entre los 12 y 17 años; se presenta mayor participación de las niñas (11), por encima de los niños (6). En cuanto a sus condiciones socioeconómicas el $88 \%$ se encuentra en el estrato 3 , 
lo cual se relaciona con el acceso a internet en sus hogares. En promedio las familias de los estudiantes están compuestas por cuatro personas mestizas que habitan en apartamentos arrendados, la mayoría en la misma localidad de los Mártires pero algunos provienen de la localidad de Puente Aranda y una de las estudiantes de la localidad de Ciudad Bolívar.

En cuanto al tiempo que lleva desempeñándose como vigía ambiental, el 23\% más de un año, el 46\% de los estudiantes han estado en el CAE durante el último año, y el 23\% entre 3 y 6 meses. Todos manifiestan que es importante la labor que desempeñan los vigías ambientales y las razones que aducen para ser vigías incluyen el hacer un cambio y cuidar el entorno, aunque la mayoría coincide que es cambiar las ideas y conductas de las personas frente al ambiente.

En relación al uso del recurso hídrico se pudo evidenciar que el 46\% de las familias ricaurtistas pagan facturas mayores de $\$ 51.000$ por el servicio de acueducto y alcantarillado, lo cual es coherente tanto con el estrato como con el uso de la lavadora (81\%) y la frecuencia de lavadas, que oscila entre 1 y 3 veces a la semana (64\%) y 3 a 5 veces a la semana (17\%). En cuanto al uso del agua en otras labores doméstica resalta que el $87 \%$ de las familias de los vigías lavan la loza después de cada comida o la acumulan para una sola lavada al día; además un alto porcentaje (58\%) abren la llave del agua cada vez que se enjuagan la boca y lavan el cepillo de dientes. Refiriéndose al aseo de los pisos el $70 \%$ de las familias sostiene que recogen en un balde agua para ir enjuagando el trapero cada vez que sea necesario y frente al momento de ducharse el $81 \%$ manifestó que cierran la llave mientras se enjabonan.

Las últimas preguntas de la encuesta de caracterización estuvieron relacionadas con las motivaciones de los vigías frente a su labor dentro del CAE, resalta la participación en campañas ambientales pero se evidencia poca iniciativa en la organización de las mismas. La mayoría se 
limita a participar en celebraciones del calendario ambiental, en salidas pedagógicas y a recoger las bolsas reciclables del refrigerio escolar. Muy pocos consultan e investigan por su cuenta sobre temas ambientales, aunque es de resaltar que el 50\% afirma generar espacios de concienciación dentro de su núcleo familiar aunque no suele hacer lo mismo dentro de la comunidad donde vive.

\subsubsection{Caracterización CAE IED Reino de Holanda}

El análisis de la caracterización realizada a los estudiantes integrantes del CAE, de la Institución Educativa Reino de Holanda, arrojó los siguientes resultados: A la pregunta número 1en cuanto al género de los estudiantes, hay una mayor participación de niños que de niñas donde 11 son niños y 8 son niñas; en la pregunta 2 relacionada con el grado escolar al cual pertenecen, se muestra que en el grado sexto es donde se evidencia una mayor participación con 8 estudiantes y caso contrario los grados octavo y noveno no se encuentran representados.. En el punto 3 referida a la jornada se aclara que al momento de hacer la encuesta el colegio contaba con dos jornadas mañana y tarde, es por eso que en la tabla de resultados los 19 niños hacían parte de la jornada de la tarde, ya que el docente investigador laboraba en este espacio; para el desarrollo del trabajo de investigación el colegio cambió de modalidad y pasó a jornada única, pero los estudiantes con quienes se venía trabajando continuaron con el proceso.

Continuando con el análisis, en la pregunta número 4, relacionada con la edad de los estudiantes participantes del proyecto PRAE, se pudo inferir que los estudiantes de 11 años son los de mayor participación con 11 estudiantes, hay 4 estudiantes de 12 años de edad, 2 estudiantes con 13 años de edad y de 15 años hay 3 estudiantes.

Los estudiantes integrantes del PRAE en relación al estrato al que pertenecen la encuesta muestra que 16 estudiantes pertenecen al estrato 2 y 3 estudiantes al estrato 3 . La pregunta número 
6 referida al número de estudiantes que tienen acceso a Internet, se concluye que 14 niños cuentan con este servicio y 5 carecen de él. En la pregunta número 7 que indaga el lugar de residencia el 98\% viven en la localidad 18 Rafael Uribe Uribe, en los barrios Marco Fidel Suárez, San Jorge, San Pablo, el 2\% vive en el municipio de Soacha.

En las preguntas 8 y 9, relacionada con el tipo de vivienda, se concluyó que 14 estudiantes viven en casa y 5 en apartamento; en cuanto al tipo de propiedad se determinó que de los 19 niños 5 viven en casas familiares, 7 familias tienen casa propia y las 7 restantes están en calidad de arrendatarios; la pregunta 10 habla sobre el tiempo de permanencia donde de las 19 familias ya viven más de 1 año.

En las preguntas de la 10 a la 13 dirigidas a determinar la importancia que tiene para los estudiantes la participación del PRAE en su desarrollo como personas y en el desenvolvimiento dentro del colegio respondieron de la siguiente manera: ¿cuánto hace que participan como vigía ambiental? los 19 niños respondieron que desde hace un año, a la pregunta si es importante ser vigía ambiental, los 19 manifiestan que sí y al porqué es importante responden que a través de la participación ellos pueden contribuir al cuidado del medio ambiente y su protección. La pregunta 13 manifiesta cuál es su máxima motivación, ellos responden que les gusta proteger y cuidar el barrio, la casa y el colegio.

La pregunta 14 hace referencia a las personas que viven en la casa y responden que viven con más de 6 personas dentro de las cuales, 4 de ellas son más de 20 años y en el intervalo entre 11 y 20 años hay 8 personas, finalmente 7 personas son menores de 10; la pregunta número 15 está relacionada con el grupo étnico donde 4 estudiantes son afros y 15 estudiantes son mestizos.

En la pregunta 16 hace un sondeo sobre el costo bimensual del servicio de agua: donde 9 familias pagan un promedio de $\$ 51.000,6$ familias pagan $\$ 40.000$ y 4 familias pagan $\$ 31.000$; 
las preguntas de la 17 al 22 están orientadas al aseo de la casa, ropa y al aseo personal, al respecto se obtienen los siguientes resultados: 15 familias tienen lavadora y 5 familias no la tienen por lo que lo hacen manualmente; de las familias que tienen lavadora 10 familias la utilizan de 1 a 3 veces en la semana, 3 familias la utilizan de 3 a 5 veces por semana y 1 familia la utiliza de 6 a 8 veces semanales; en cuanto al lavado de la loza, 13 familias acostumbran a la lavar la loza después de cada comida y 6 dejan acumular la loza para lavar en un solo momento. En el aseo personal 17 familias lavan los dientes utilizando un vaso y 2 abren la llave para enjuagar su boca y lavar su cepillo de dientes.

De igual manera en el aseo de la casa 7 familias recogen agua en un balde y la riegan por todo el piso, 11 familias recogen el agua en un balde para enjuagar el trapero en el y 1 familia deja correr indiscriminadamente el agua para hacer aseo en la casa. La pregunta 22 investiga sin cierran el agua mientras se duchan y ellos manifiestas que 19 familias cierran la llave de agua y la abren únicamente cuando sea necesario. En relación con su participación activa o pasiva en campañas de ahorro de agua contestaron de la siguiente manera: 11 estudiantes participan en campañas pro ambientales dentro y fuera de la institución; 2 incentivan la realización de campañas ambientales en su comunidad y 6 estudiantes promueven campañas ambientales dentro de la institución educativa, la pregunta 24 hace referencia sobre qué actividades ambientales como miembro del CAE promociona dentro de la institución y ellos señalan que 8 estudiantes celebran las fechas relacionadas con el medio ambiente, 4 promocionan capacitación a docentes y 5 a estudiantes, 2 estudiantes promocionan capacitación a los vigías ambientales. Se indago cuántos estudiantes asisten a caminatas ecológicas y solo 7 de los 19 lo hacen. Con la pregunta sobre autocapacitación de los 19 estudiantes solo 4 manifiestan que se auto capacitan, pero en la pregunta sobre si Genera espacios de concientización con los miembros de su familia 16 estudiantes si propician dichos 
ambientes y 3 no generan esos espacios propicios para para la concientización ambiental en sus familias. La última pregunta sobre generar espacios de concientización con los miembros de su comunidad solo 5 propiciar esos espacios con la comunidad pero los 14 restantes no. 


\subsubsection{Análisis de la caracterización general de los $\mathrm{CAE}$ de las cuatro instituciones}

Figura 31. Miembros del CAE por grados

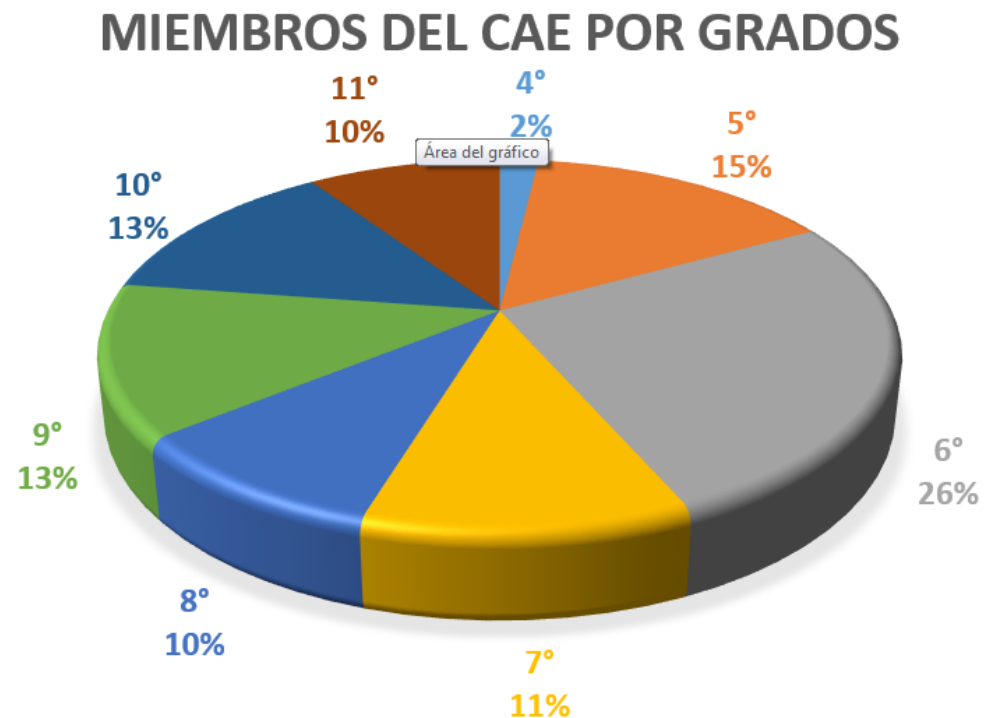

Gráficas producidas por el equipo investigador

Figura 32.Distribución del CAE por edades.

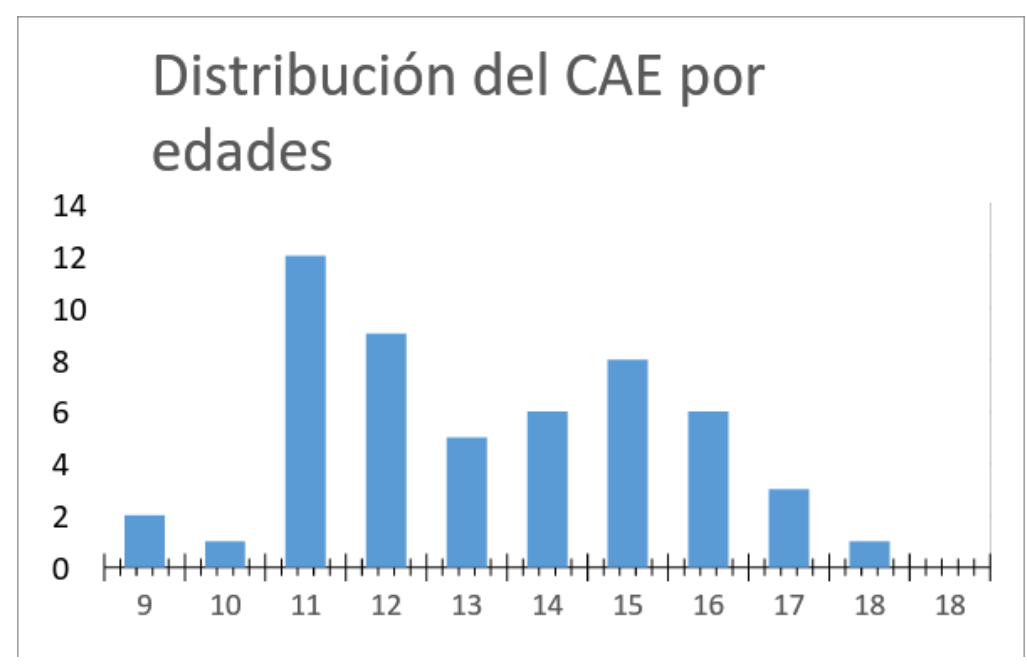

Gráficas producidas por el equipo investigador

Los resultados muestran que los integrantes del CAE, están conformados en su mayoría por estudiantes de grados sextos, entre las edades de 10 y 11 años y las niñas tienen mayor disposición de participar en estos grupos de trabajo; además la jornada de la tarde es la que se apropia de esta responsabilidad. 
En relación a la situación socioeconómica, son niños de estrato 2, la mayoría viven en apartamentos, tendencia propia de los colegios R y MZO, contrario a los colegios LLM y RH, que en su mayoría viven en calidad de arrendamiento a excepción del colegio RH que viven en condiciones de arrendatarios y propietarios..

De igual manera, se determina, que los estudiantes de las instituciones educativas, objeto de investigación viven con más de 6 personas mayores de 20 años, cuyo grupo étnico pertenece a los mestizos y en menor porcentaje a afroraizales.

Figura 33. Estratificación socioeconómica de los vigías
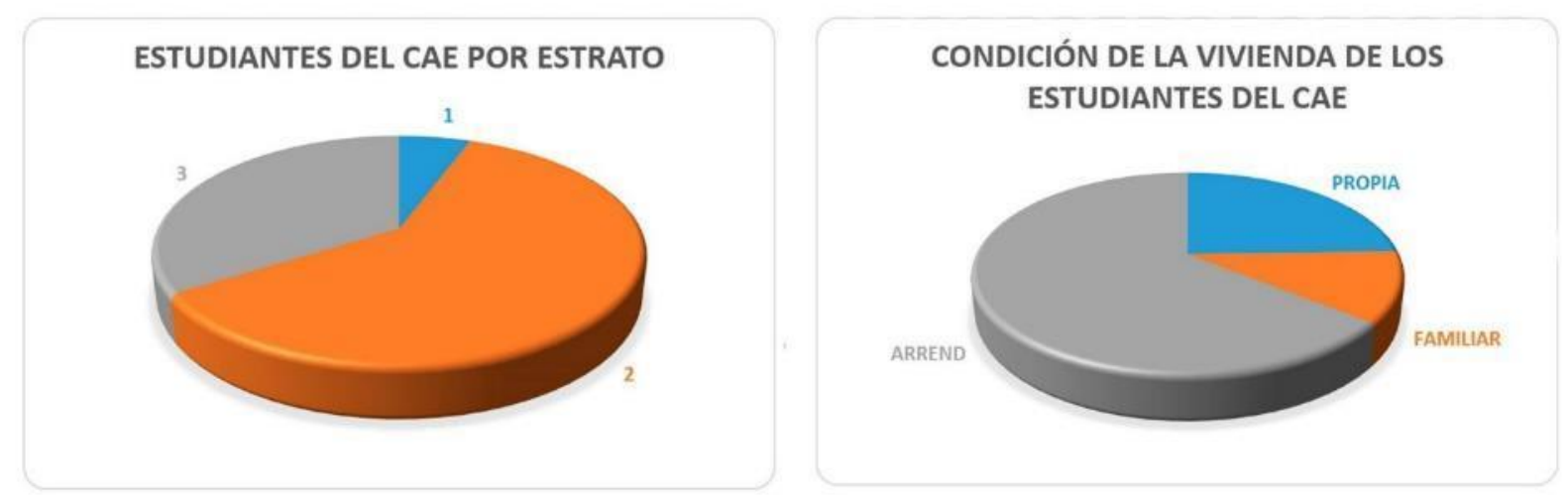

Gráficas producidas por el equipo investigador

Se observa, que hay una tendencia a la dispersión territorial de los estudiantes en los barrios cercanos a la institución educativa, en especial el colegio Ricaurte, los niños se distribuyen en más de 12 barrios, convirtiéndolo en población flotante, afectado en cierta medida la permanencia de los estudiantes en el colegio, a sí mismo se encuentran los colegio LLM y MZO, pero en la institución educativa RH los estudiantes se ubican en su mayoría en dos barrios: San Jorge y Marco Fidel Suárez, permitiendo mayor estabilidad en la población estudiantil.

La caracterización de los estudiantes del CAE muestran gran interés en la participación en estos grupos; ante la pregunta de por qué es importante pertenecer en el Comité Ambiental, se 
refiere que a través de ellos pueden contribuir a cuidar el medio ambiente y ser multiplicadores en sus hogares.

Figura 34. Características del lavado de ropa
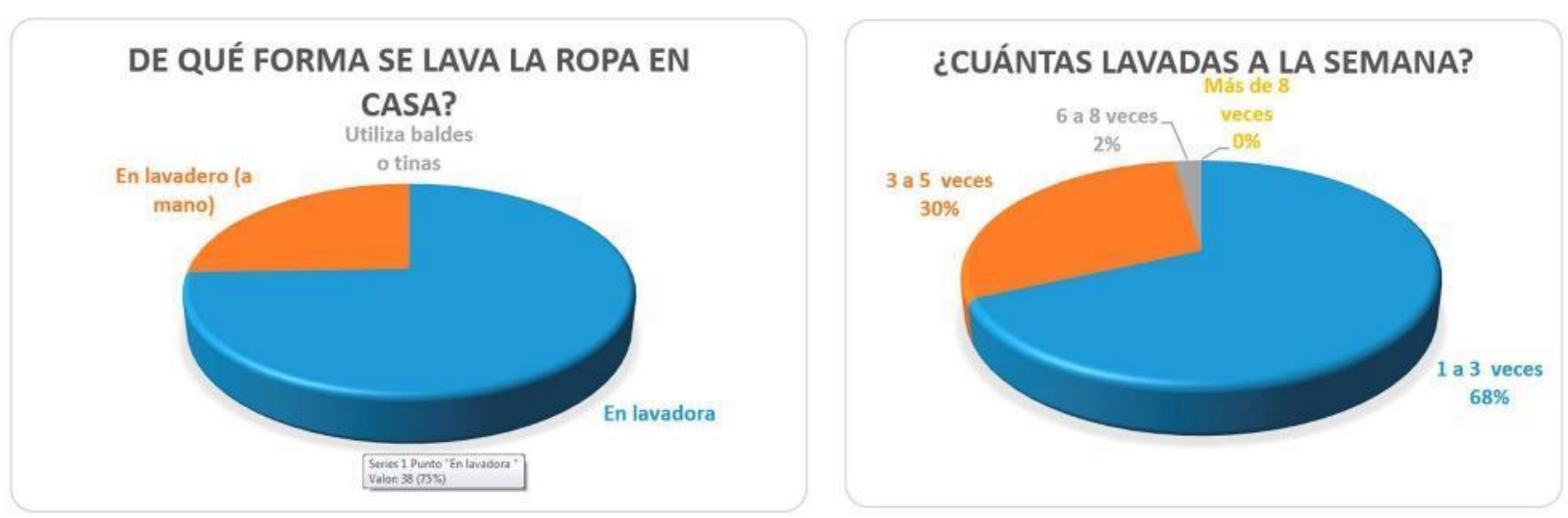

Gráficas producidas por el equipo investigador

Se les pregunta además, sobre algunos hábitos que tienen en sus casas relacionados a la forma como utilizan el agua para el desarrollo de actividades cotidianas como ducharse, lavarse los dientes, lavado de ropa, loza, aseo de sus casas, a esto respondieron de la siguiente manera: para el lavado de la ropa, la mayoría utiliza la lavadora, lavan en promedio 1 a 3 veces en la semana, acostumbran a lavar la loza después de cada comida; con relación a su aseo personal, acostumbran cerrar la llave para enjabonarse, utilizan el vaso para lavado de sus dientes; esta práctica es recurrente en los colegios MZO y LLM, pero para los colegio RH y R, hay una fuerte tendencia a abrir la llave para hacerlo.

Con relación al costo por el consumo del agua, se evidencia que los valores oscilan entre $\$ 31.000$ y $\$ 41.000$, destacándose los colegios MZO y LLM; para los casos de R y RH, los costos de facturación en el servicio son superior a $\$ 51.000$, con lo anterior podemos afirmar, que a pesar de estar en estratos bajos, las personas tienden a pagar sumas altas por consumo, teniendo en cuenta que los estratos 1 y 2 son subsidiados, comparados con las familias que se encuentran en el estrato 
$3(\mathrm{CR})$ y el colegio $(\mathrm{RH})$, que tiene 2 estudiantes en estrato 3 , los valores son similares a los de estratos 1 y 2 los cuales no tienen el beneficio del subsidio. Además, cabe destacar, que en los estratos 1 y 2 las familias que viven en arrendamiento, los costos totales del servicio son distribuidos entre el número de integrantes de cada una de las unidades familiares.

Lo anterior, nos permite concluir, así como lo afirma Hungerford y Volk (1990) citado por (Barazarte et al, 2013), que no necesariamente el tener conocimientos proambientales, lleve al individuo a tener conductas que favorezcan el ecosistema, al contrario, manifiesta el autor, que la actitudes proambientales están relacionadas con el ingreso, aquellos que tienen un mayor ingreso, tienen una actitud favorable con el medio y están dispuestos a adquirir más conocimientos proambientales, que aquellas familias que reciben un menor ingreso económico, así tengan conocimientos proambientales, el tema ambiental no los inquieta tanto por el hecho de que afecte el ecosistema, sino porque se afecten sus gastos.

La encuesta, nos refiere además, a las capacitaciones e información que los estudiantes reciben y tienen sobre la importancia de cuidar el medio ambiente a lo que responden: los integrantes del CAE son formados con regularidad, en especial el colegio MZO y el colegio LLM manifiesta además que la institución educativa incentiva las campañas ecológicas a través de celebraciones en fechas alusivas al medio ambiente, a capacitaciones para los estudiantes y a los vigías ambientales. 
Figura 35. Caracterización de hábitos de aseo personal y del hogar
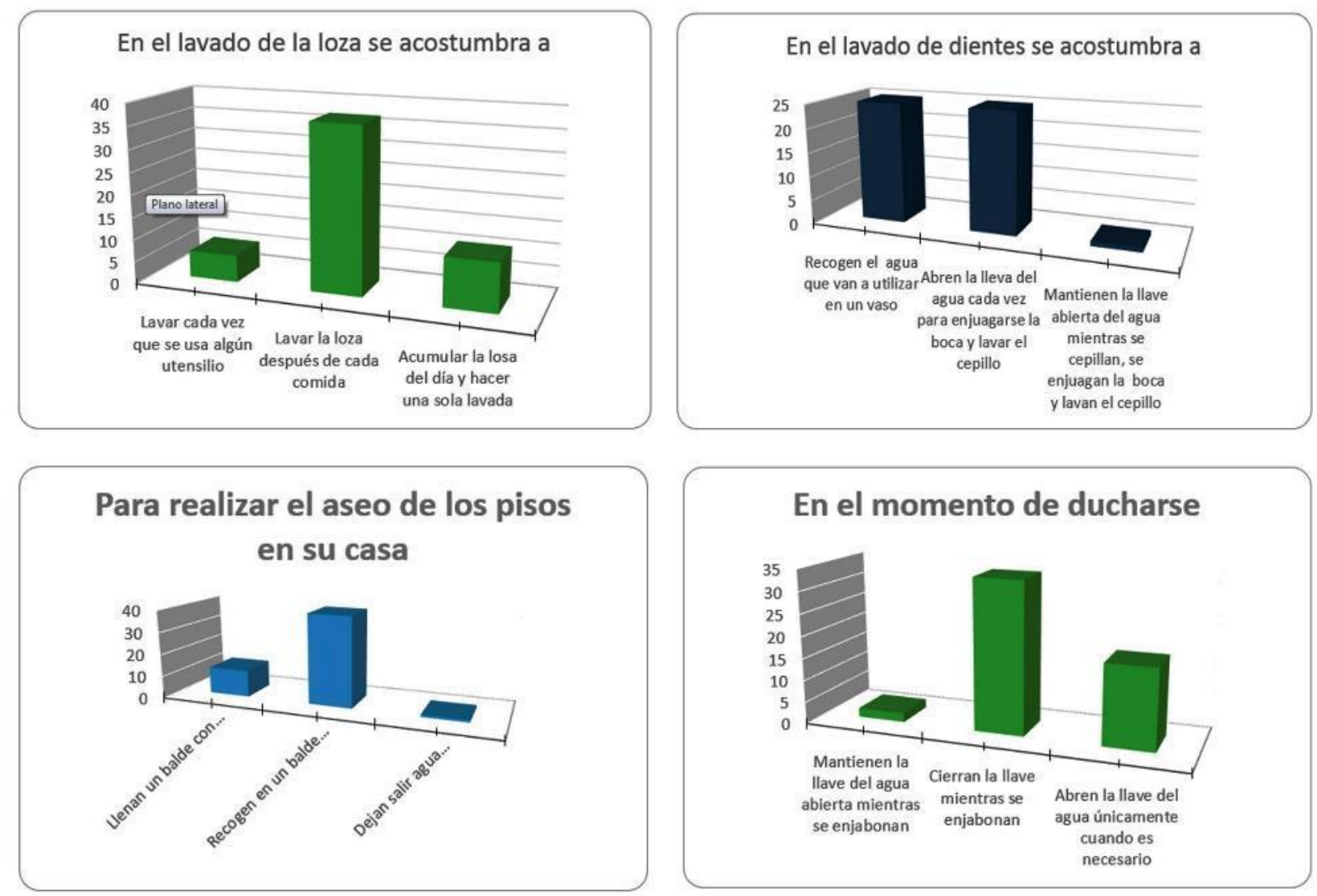

Gráficas producidas por el equipo investigador

Los colegios MZO y CR manifiestan que realizan caminatas ambientales que favorecen su formación e interés por los temas ambientales, contrario a los colegios LLM y RH quienes afirman que han sido muy pocas las experiencias que han tenido con estas prácticas ecológicas, además los estudiantes de manera personal se informan sobre las tendencias ambientales, en especial los alumnos de los colegios MZO y LLM y en una menor proporción están las instituciones educativas R y RH.

\subsubsection{Análisis de la entrevista aplicada varios estudiantes}

A través de la codificación axial (Figura 8), se pudo identificar que las campañas escolares influyen positivamente en las actitudes proambientales de los estudiantes, pero no hay evidencias 
de este proceso que integren los hogares para impactar en la comunidad educativa, además son programas direccionados al cuidado de los recursos naturales y no del agua específicamente.

Figura 36. Codificación axial de la entrevista

CODIFICACIÓN AXIAL

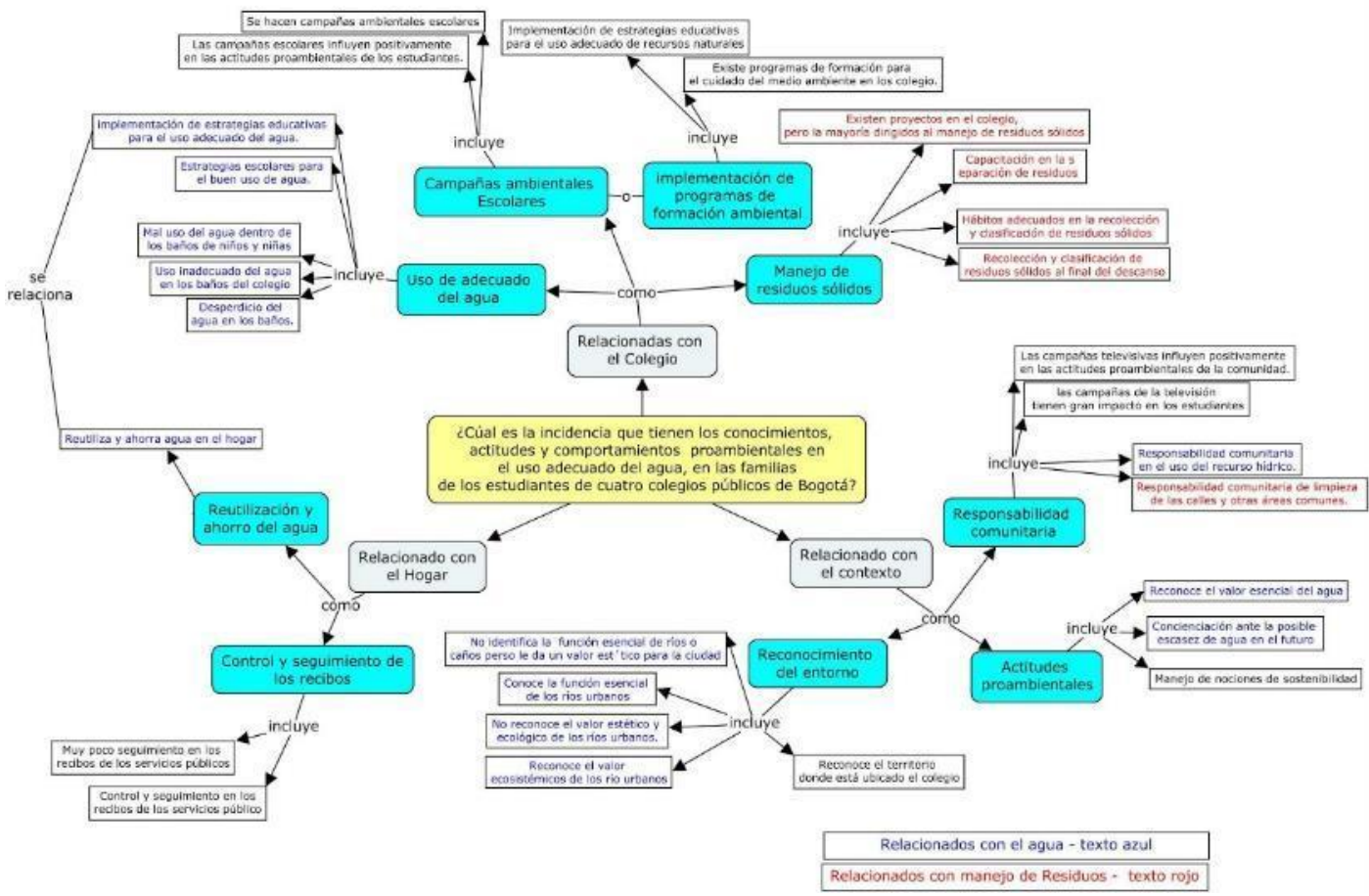

Diagrama producido por el equipo investigador

\subsubsection{Análisis de la actividad: Antes pensaba, ahora pienso}

Esta actividad pretende que a través de una lluvia de ideas, los estudiantes generen conciencia frente a las afectaciones ambientales que se presentan en el barrio debido a falta de cultura por parte de los habitantes de sus comunidades.

Para el logro del objetivo de esta actividad, se les pide a los estudiantes, que escriban las ideas que tienen sobre educación ambiental, propósito del PRAE y función del Vigía Ambiental, y contestar la pregunta ¿Es posible hacer educación ambiental en el hogar? 
Figura 37. Resultados de la actividad antes pensaba, ahora pienso
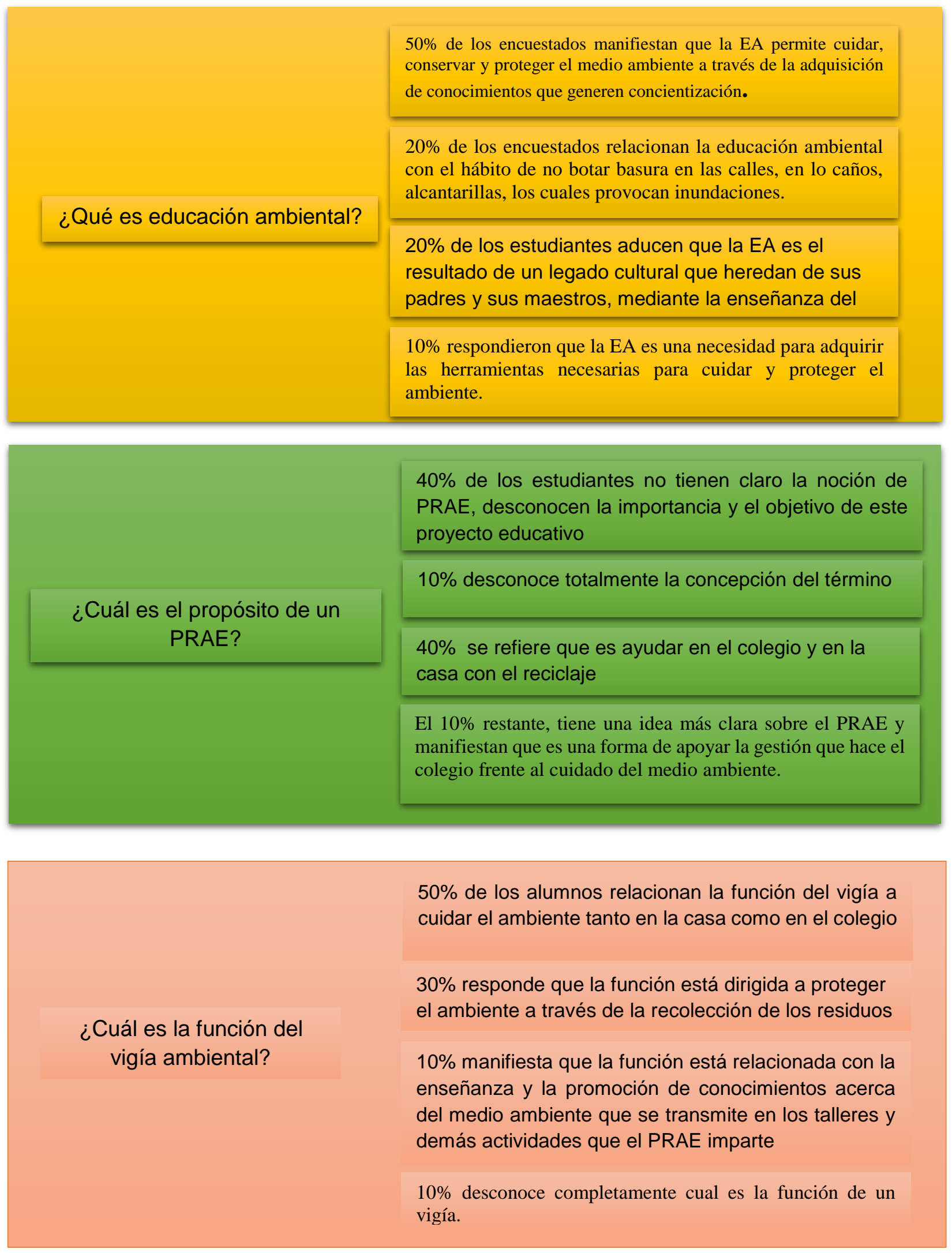
$50 \%$ afirman que sí se puede hacer EA desde el hogar, a través del hábito del reciclaje

$20 \%$ objetaron que se puede hacer EA en la casa a partir del conocimiento que se adquiere en ¿En mi hogar puedo hacer educación ambiental? distintos contextos cotidianos

$20 \%$ argumentaron que es en el hogar donde se forman las actitudes frente a la conservación del medio ambiente

$10 \%$ de los encuestados afirman que a través de la implementación de normas y reglas se puede educar en el hogar

Por lo tanto, a la primera pregunta: ¿Qué es educación ambiental?, el 50\% de los encuestados manifiestan que la EA permite cuidar, conservar y proteger el medio ambiente a través de la adquisición de conocimientos que generen concientización.

Por otro lado, un $20 \%$ de los encuestados relacionan la educación ambiental con el hábito de no botar basura en las calles, en lo caños, alcantarillas, los cuales provocan inundaciones.

Otro $20 \%$ de los estudiantes aducen que la EA es el resultado de un legado cultural que heredan de sus padres y sus maestros, mediante la enseñanza del respeto a las normas ambientales y a reconocer los puntos ecológicos.

Y un $10 \%$ respondieron que la EA es una necesidad para adquirir las herramientas necesarias para cuidar y proteger el ambiente.

A la segunda pregunta, ¿Cuál es el propósito de un PRAE? el 90\% de los estudiantes no tienen claro la noción de PRAE, desconocen la importancia y el objetivo de este proyecto educativo generando respuestas, no relacionadas con el PRAE de esta manera se determinó que dentro de este 
porcentaje el $40 \%$ desconoce totalmente la concepción del término; el otro $40 \%$ se refiere que es ayudar en el colegio y en la casa con el reciclaje y el 10\% restante relaciona con cuidar el ambiente y dar ejemplo. Contrario a lo anterior, el 10\% restante, tiene una idea más clara sobre el PRAE y manifiestan que es una forma de apoyar la gestión que hace el colegio frente al cuidado del medio ambiente.

Al tercer ítem ¿Cuál es la función del vigía ambiental? el 50\% de los alumnos relacionan la función del vigía a cuidar el medio ambiente tanto en la casa como en el colegio; el 30\% responde que la función está dirigida a proteger el ambiente a través de la recolección de los residuos sólidos, un $10 \%$ replica que la función está relacionada con la enseñanza y la promoción de conocimientos acerca del medio ambiente que se transmite en los talleres y demás actividades que el PRAE imparte; el otro $10 \%$ desconoce completamente cual es la función de un vigía.

Con el 4 y último ítem: ¿En mi hogar puedo hacer educación ambiental? los estudiantes en un 50\% replicaron que sí se puede hacer EA desde el hogar, a través del hábito del reciclaje; un $20 \%$ objetaron que se puede hacer EA en la casa a partir del conocimiento que se adquiere en distintos contextos cotidianos; el otro $20 \%$ argumentaron que es en el hogar donde se forman las actitudes frente a la conservación del medio ambiente; para finalizar el 10\% de los encuestados afirman que a través de la implementación de normas y reglas se puede educar en el hogar. (Anexo taller antes pensaba, ahora pienso).

La actividad permitió identificar concepciones erradas sobre educación ambiental y fortalecer las ideas sobre el PRAE, funciones del Comité Ambiental Escolar, entre otros. 


\subsection{Análisis del taller formación.}

\subsubsection{Formación “¿Cómo cuidar el agua en el hogar y en el colegio?”}

Luego de ver los videos, los estudiantes líderes del CAE de las cuatro instituciones educativas desarrollaron un taller "Ver, pensar, preguntar" (Anexo 7) que consta de 10 preguntas, con el propósito de sensibilizar a los líderes ambientales sobre la importancia de cuidar el agua.

Para la primera pregunta del primer video: ¿Por qué es importante el agua en la vida del hombre? el $60 \%$ de los encuestados manifiestan que la importancia del agua está relacionada con las diferentes actividades que el hombre desempeña en su cotidianidad y el $40 \%$ restante considera que el agua es necesaria para la vida del hombre.

La segunda pregunta: ¿Qué porcentaje de agua es apta para el consumo humano? todos los estudiantes encuestados respondieron que el $3 \%$ del total del agua es dulce, pero solo el $1 \%$ es para el consumo humano, porque del $70 \%$ es utilizado por la agricultura y la ganadería, el $20 \%$ es para la industria y el $10 \%$ es para consumo humano.

Para el punto tres que indaga ¿Por qué es importante que el hombre cuide y conserve el agua en el planeta? los estudiantes después de mirar el video concluyeron que es importante cuidar y conservar el agua porque el porcentaje que está destinado para el consumo humano es únicamente el 10\%, que corresponde a una cantidad mínima para el total de las actividades diarias que realiza el hombre, además es escasa en algunos lugares del mundo o difícil transportarla a otras zonas donde habita el hombre, de ahí la importancia de hacer un uso adecuado del agua para que sirva a generaciones presentes y futuras.

Continuando con el segundo video: “Consejos para ahorrar agua” los alumnos desarrollan la cuarta pregunta que se refiere a los diferentes tips que implementa en la casa para ahorrar agua mencionados dentro del video, ellos respondieron en su mayoría: cerrar la llave de agua mientras 
realizan diferentes actividades como cepillarse los dientes y lavar los platos, reciclar el agua de la lavadora para reutilizarlas en otras labores domésticas; dos estudiantes contestaron que no botaba aceite en los ríos y caños y otro pequeño grupo de estudiantes, consideran que reciclar botellas plásticas contribuye a disminuir la cantidad de desechos y permite prolongar la vida útil de estos elementos; por último un grupo de estudiantes determinó que las duchas más cortas y el no arrojar papeles a los inodoros, aportaba al ahorro del agua.

Los estudiantes en la pregunta número cinco ¿Creen que estos consejos son valiosos para conservar el agua? ellos manifiestan que los consejos son válidos para conservar un ambiente sano y apto para la vida que redundará en el bienestar de toda la humanidad.

La pregunta número seis, plantea, ¿Cuáles serían los beneficios obtenidos al ahorrar el agua? el $80 \%$ de los estudiantes responden que el mayor beneficio sería económico, ya que al consumir menos los costos del mismo se reducirían notablemente, un $10 \%$ de los alumnos argumenta que el beneficio permitirá garantizar calidad de vida porque aseguraría la conservación de los recursos naturales; el 10\% de los encuestados plantea que el beneficio radica en la capacidad de enseñar a los demás a hacer buen uso del agua, para que se generalice los buenos hábitos del uso adecuado del líquido.

A la pregunta siete, ¿Qué actitudes tienen sus familiares en la casa, con relación al consumo del agua?, los estudiantes respondieron en un 90\%, que la actitud con quienes conviven: padres, tíos, primos, abuelos es muy buena porque son ellos los que recalcan en la importancia de ahorrar el agua para la protección y conservación del medio ambiente; un 10\% restante de los estudiantes manifiestas que sus familiares en el caso de los hermanas sus actitudes no son las mejores, porque son los que más gastan el agua. 
La tercera parte de esta guía de trabajo, es: "Pregunta... pregunta"; actividad en la cual, los estudiantes responden y plantean una pregunta sobre la presentación del video. La pregunta que se formuló en la guía de trabajo fue: ¿Cuál fue la duda que te genero el video?, a ello contestaron lo siguiente: el $40 \%$ de los estudiantes preguntan ¿por qué el agua salada no es para el consumo humano?, hay un $20 \%$ que se cuestiona ¿por qué el porcentaje de agua de consumo humano es mínimo?, el 20\% de los estudiantes que se cuestiona ¿por qué no se demanda las empresas multinacionales que son responsables de contaminar el agua?, el 10\% se pregunta ¿por qué el hombre no ha tomado la suficiente conciencia sobre la importancia de hacer un uso adecuado del agua? y un $10 \%$ no les generó ninguna clase de dudas.

Por último, los estudiantes debían plantearles a sus familias una pregunta relacionada con la problemática del agua, a esto la familia respondió: el $40 \%$ se indaga ¿por qué no ahorramos agua?, un $20 \%$ pregunta ¿de verdad nos preocupamos por la cantidad de agua que gastamos?, otro $20 \%$ se pregunta ¿el uso inadecuado del agua perjudicará a las futuras generaciones?, el 20\% restante se indaga ¿cuánto tiempo sobreviviríamos sin agua?

\subsubsection{Integración "La historia del cambio, la historia de las cosas"}

Después de que se observaron los dos videos

- La historia de las cosas ( https://www.youtube.com/watch?v=ykfp1WvVqAY)

- La historia del cambio (https://www.youtube.com/watch?v=Fd0fE8qp6II)

Se concluye que los estudiantes de las cuatro instituciones educativas desconocían la incidencia negativa o positiva que genera sobre el ecosistema el uso inadecuado de artículos elaborados con materiales que tardan mucho tiempo en degradarse, así mismo el hecho de que los estudiantes no realicen una adecuada separación en la fuente, 
Adicionalmente los estudiantes manifiestan que el proceso para la elaboración de los artículos que diariamente se usan conlleva a una serie de procedimientos que afectan sustancialmente el ecosistema, como por ejemplo, la tala de bosques y la producción de químicos, que ocasionan enfermedades a los trabajadores de fábricas y lo más preocupante a madres trabajadoras gestantes o lactantes que son vulnerables a contaminarse y a transmitirles esa contaminación a sus hijos. Los vigías ambientales expresan que en una sociedad consumista como la actual es fácil encontrar estos artículos que generan dependencia, de igual manera expresan la necesidad de conciencia para una buena calidad de vida por lo tanto la importancia de comenzar procesos de reciclaje y separación de residuos de manera adecuada.

\subsubsection{Verificación "En que están los estudiantes"}

Para el logro de este objetivo, se implementó la rejilla "Seguimiento de conductas proambientales desde los hogares en cuanto al adecuado uso del agua" (Anexo 4), esta rejilla registró un control diario durante un mes de diferentes acciones cotidianas con relación al uso del agua en el hogar, para implementar y señalar diariamente qué acciones ejecutaron en casa, al finalizar el mes la entregaron a cada docente investigador.

\subsection{Familias}

La integración de los padres de familia a las actividades escolares con sus hijos, frente a la formación de hábitos adecuados sobre el manejo responsable del agua es necesario para fortalecer los procesos de educación ambiental. 


\subsubsection{Formación "Taller de padres de los estudiantes miembros del CAE"}

la vinculación de los vigías ambientales de las cuatro instituciones educativas y sus familias al proyecto investigativo se hizo mediante convocatoria donde se dio a conocer concepto, funciones e integrantes del CAE, para la presentación del PRAE se observó el video: https://www.youtube.com/watch?v=RQCQrutQk14, y se realizó la lectura "Carta a la Tierra", a partir de estos ejercicios los estudiantes y padres de familia cambiaron su percepción sobre la EA, por ejemplo, dejar de pensar que esta se remite únicamente a reciclar, ahorrar y reutilizar el agua y concluir que la EA implica la práctica de ciertas conductas sociales como el respeto a las comunidades y a la biodiversidad, de igual manera resaltan la práctica de la democracia, la transparencia de los gobernantes y los gobernados, como la importancia de hacer buen uso de los recursos naturales disponibles para tener un mundo mejor considerando que esto empieza en los hogares, con la formación de los padres a sus hijos desde los primeros años de edad. (Anexo de la producción de los talleres Carta a la Tierra).

Como segunda actividad, los estudiantes y padres asistentes interpretaron los propósitos del PRAE de cada institución educativa, de igual manera reconocen la importancia que tiene el vigía ambiental desde de su vinculación como integrante del CAE; además identifican varias acciones que se pueden realizar desde el hogar con un criterio educativo.

$\mathrm{Y}$, finalmente la tercera actividad de la primera estrategia tuvo como fin brindar información a los vigías ambientales sobre las diferentes maneras de cuidar el agua en el hogar y en colegio.

\subsubsection{Integración "Seguimiento de los comportamientos proambientales"}

En esta actividad los estudiantes líderes ambientales y sus familias realizaron un seguimiento sobre acciones con el uso responsable del agua (Anexo 4), dieron respuesta a 
inquietudes relacionadas con actitudes y hábitos cuando hacen uso de este recurso en diferentes espacios, que evidenció los comportamientos inadecuados, como el caso del desperdicio de agua, los hábitos de higiene que no ahorran agua y la falta de seguimiento frente al consumo, los cuales presentan tanto padres como los hijos ya que no proyectan esos hábitos en otros lugares diferentes a su hogar como son centros comerciales, viviendas de familiares y amigos, entre otros.

\subsection{Colegio $y$ familia}

Para fortalecer la relación familia - institución educativa, se realizaron una serie de actividades que permitieron involucrar a los padres de los líderes ambientales para que desarrollaran dentro y fuera de la institución.

Se invitó a los padres de familia a la institución educativa, para desarrollar algunas actividades como la presentación de algunos videos como por ejemplo:

5.4.1. Formación "Campaña del cuidado del recurso hídrico" e Integración “Uso racional del agua"

Los padres de familia y los estudiantes, observaron un video sobre "Consejos para ahorrar agua en la casa", a partir de esta actividad, los estudiantes concluyen lo siguiente:

- Adquirir conductas que propicien el ahorro de agua, permiten abastecimiento de agua para las generaciones futuras.

- El ahorro de agua en las diferentes actividades cotidianas, no solo benefician los costos pecuniarios, también se beneficia el ecosistema.

- Uno de los mecanismos para preservar el abastecimiento del agua, no solo es minimizar el consumo del recurso del agua, sino también en la conservación de ríos y afluentes del agua. 
Figura 38. Integración Colegio Familia, Institución Manuel Zapata Olivella

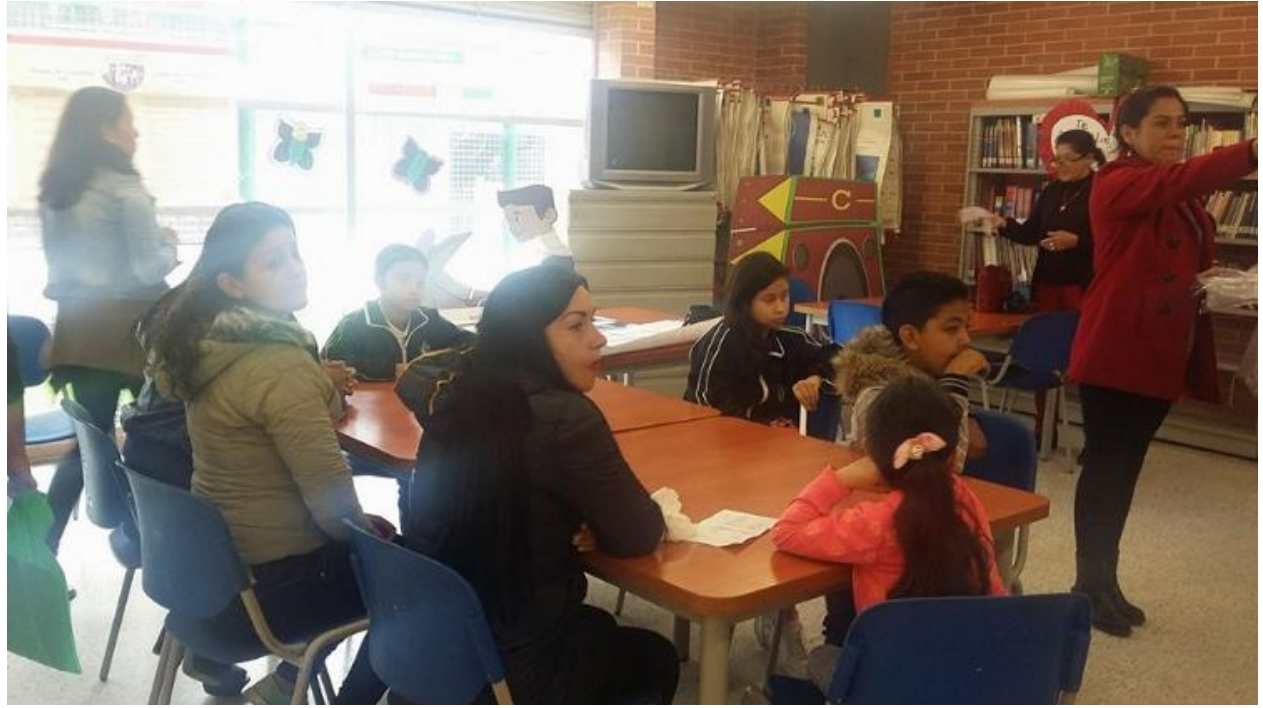

Fotografía tomada por Adriana Zoraida Montes Flórez

Tomada el 27 de Abril de 2017

Figura 39. Integración Colegio Familia, Institución Luis López de Mesa

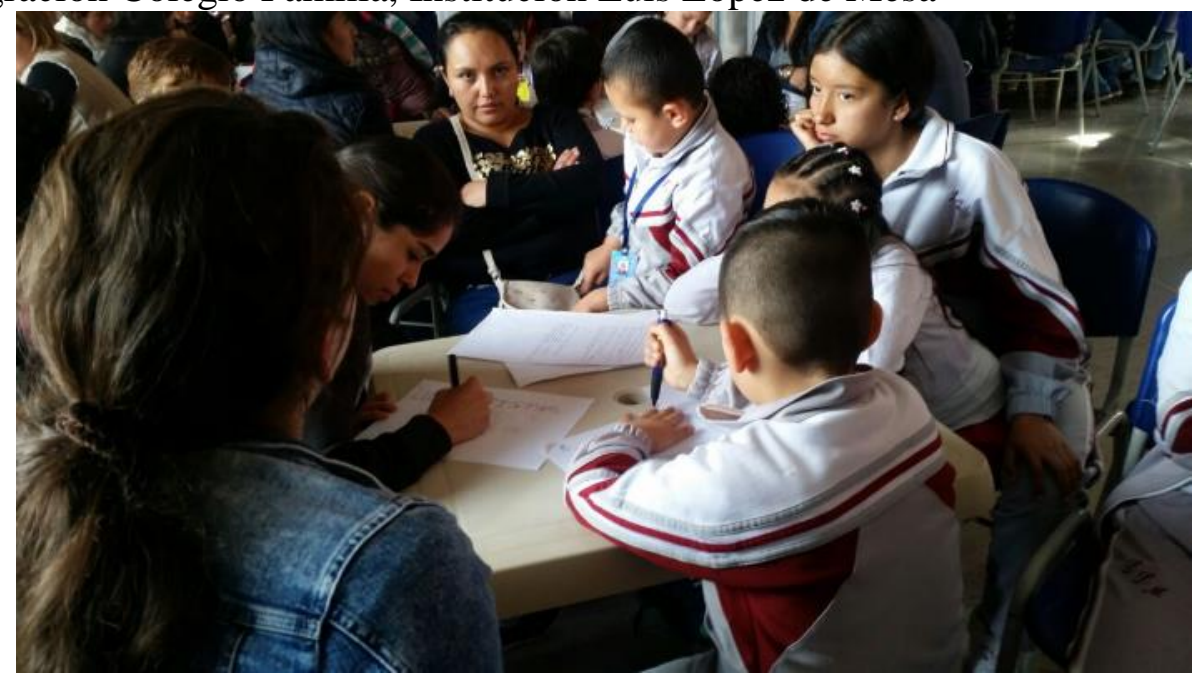

Fotografía tomada por Maria Eugenia Vasquez Mogollon

Tomada el 27 de Julio de 2017 
5.5. Análisis de recibos de acueducto, alcantarillado y recolección de basuras de los hogares de los vigías ambientales

Figura 40. Promedio del costo del recibo de EAAB

$\$ 200.000,00$

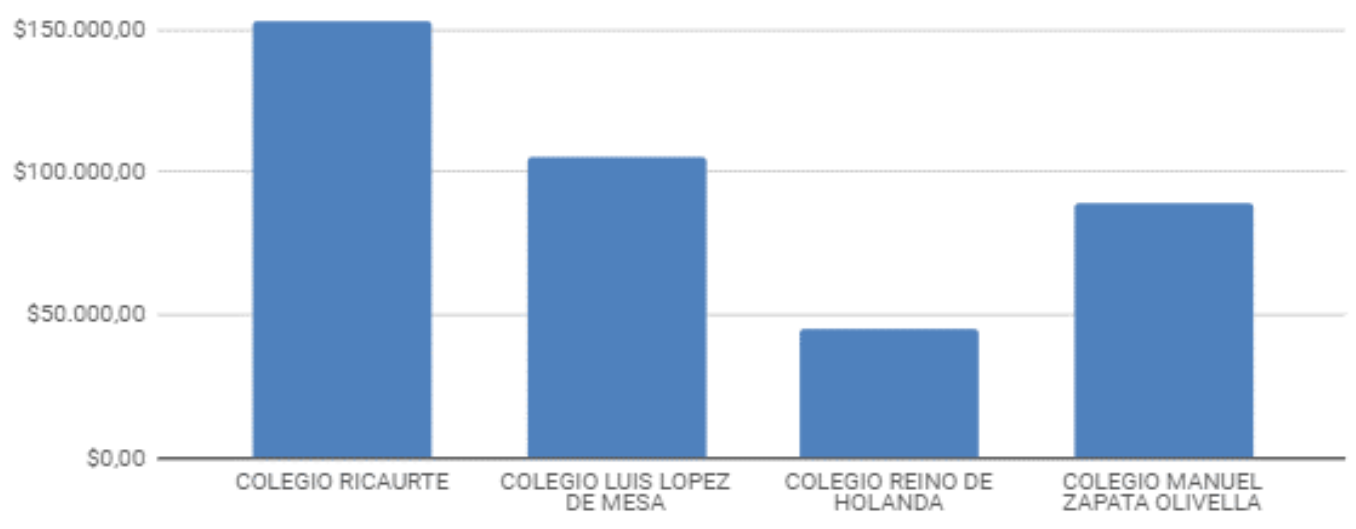

Gráfica producida por el equipo investigador

La gráfica muestra, el valor por consumo bimestral de los hogares de cada una de las instituciones educativas, por lo tanto, se concluye que las familias del colegio Ricaurte, son los de mayor consumo, con un promedio de $\$ 150.000$ bimestrales, comparado con las familias del colegio Reino de Holanda que es de $\$ 49.000$

Esta característica, se presenta por varios factores, primero: el estrato al cual pertenece el Colegio Ricaurte, es de estrato 3, por ende el valor por metro cúbico de agua es más costoso, que estudiantes del colegio Reino de Holanda que pertenece al estrato 1 y 2.

A pesar de que las familias del Colegio Manuel Zapata Olivella y Luis López de Meza, pertenecen a los mismos estratos 1 y 2 que el Reino de Holanda, los costos en las facturas por servicio de acueducto y alcantarillado son mayores: $\$ 101.000$ y $\$ 90.000$ respectivamente, se explica porque los Colegio Manuel Zapata Olivella y Luis López de Meza, se encuentra ubicados en zonas comerciales, donde por su actividad económica, exige consumo de agua mayores que los del Colegio Reino de Holanda, que es de vivienda familiar. 
Figura 41. Consumo en m3 para los cuatro últimos recibos

\section{Consumo en $\mathrm{m} 3$ para cuatro ultimos recibos}

40

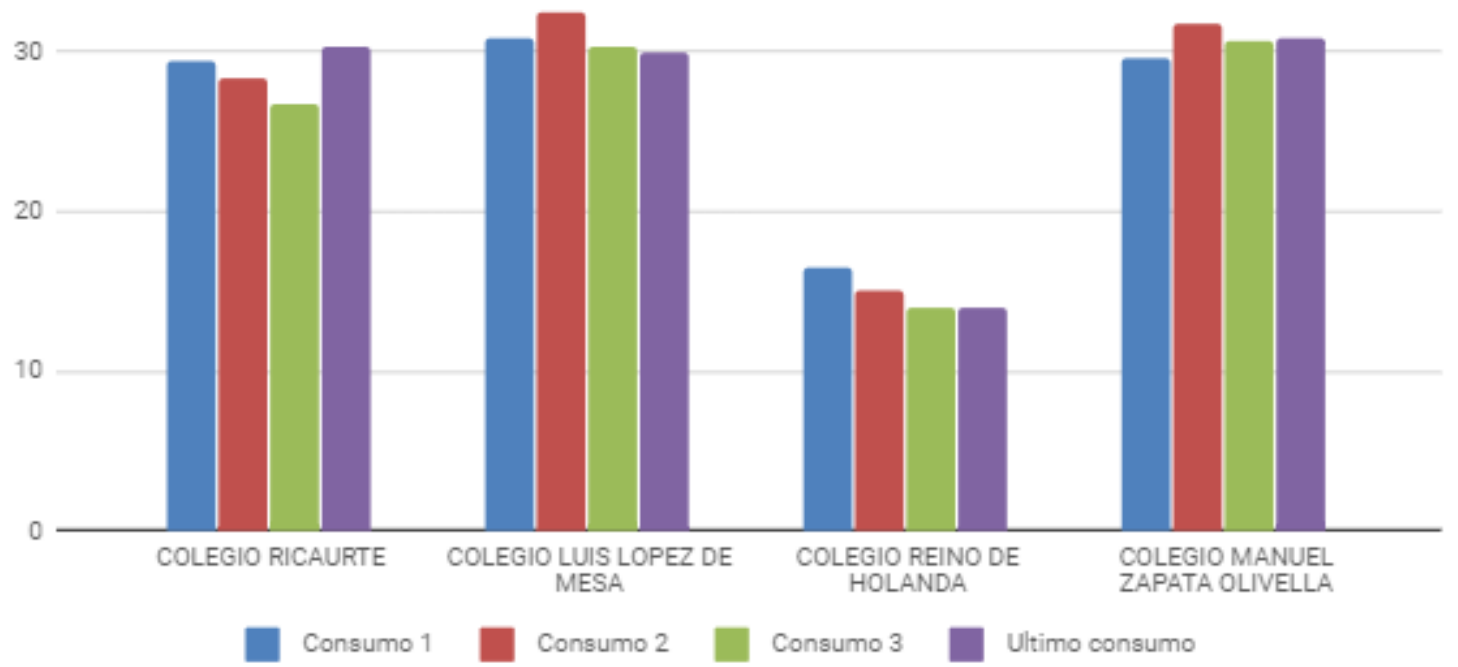

Gráfica producida por el equipo investigador

En la gráfica anterior se evidencia el consumo de agua en periodos de cuatro meses, donde se denota que en las instituciones educativas Ricaurte, Luis López de Mesa y Manuel Zapata Olivella hay un consumo promedio de $30 \mathrm{~m}^{3}$, mientras que en la institución Reino de Holanda no alcanza a los $20 \mathrm{~m}^{3}$, debido a que las tres instituciones con mayor consumo se encuentran ubicados en sectores comerciales e industriales y el colegio que registra menor consumo se encuentra en una zona netamente residencial. 
Figura 42. Comportamiento del valor en los últimos cuatro recibos de EAAB Comportamiento del valor en los ultimos cuatro recibos del servicio de acueducto

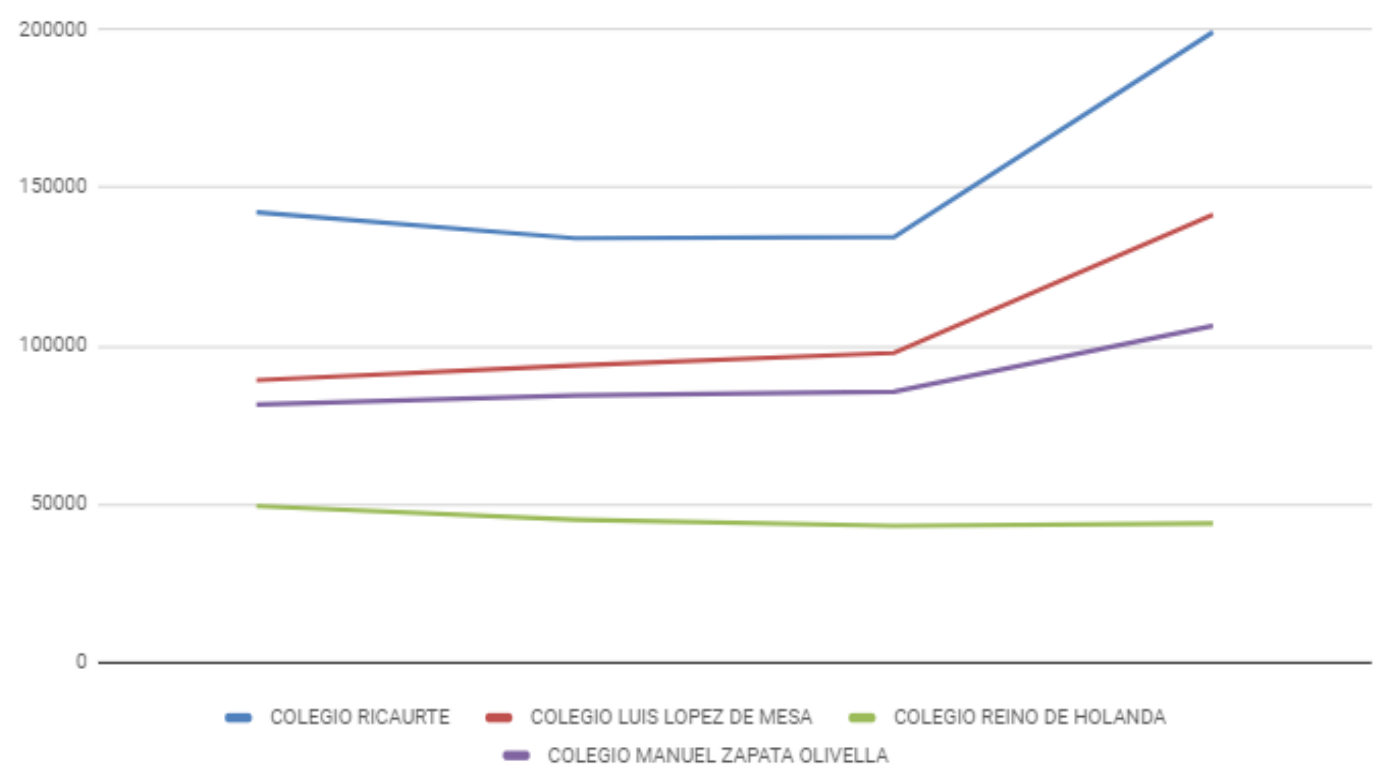

Gráfica producida por el equipo investigador

Las gráficas, sobre el valor del recibo de consumo de acueducto, alcantarillado y recolección de basuras muestran que las instituciones educativas Ricaurte, Luis López de Mesa y Manuel Zapata Olivella presentan un aumento en el valor de la factura: de $\$ 100.000$ a $\$ 200.000$ para el colegio Ricaurte, de $\$ 90.000$ a $\$ 140.000$ para el colegio Luis López de Mesa y de $\$ 80.000$ a $\$ 110.000$ para el colegio Manuel Zapata Olivella, pero para el caso del Colegio Reino de Holanda, el comportamiento es al contrario, de $\$ 100.000$ a $\$ 48.000$ aproximadamente, donde se evidencia una baja en el valor del consumo. Lo anterior nos lleva a concluir que en la zona donde se encuentra ubicado el colegio Reino de Holanda, el valor sufre una disminución en el valor.

En un segundo momento, se vuelve a solicitar las facturas de pago de 2017 para comprobar si el impacto que se deseaba con la implementación de estrategias para sensibilizar a los estudiantes y padres de familia en el uso responsable y pertinente del agua fue positivo. 
A lo anterior podemos concluir que se evidenció un cambio significativo en la cantidad de agua consumida y por lo tanto, el costo por consumo fue menor, por ejemplo: una de las familias del colegio Manuel Zapata Olivella, en la factura 77748339117, el consumo por metro cúbico en el periodo comprendido entre abril - junio 2015 fue de 128, comparado con el periodo octubre diciembre 216 , y el valor a pagar fue de $\$ 497.916$ a $\$ 435.134$ (ver anexo 11).

\subsection{Discusión de los resultados.}

\subsubsection{Análisis de la caracterización de los estudiantes del CAE}

Los Comités Ambientales Escolares (CAE) están conformados por estudiantes que hacen parte del territorio donde se encuentran cada una de las instituciones educativas, esto permite un reconocimiento más directo de las problemáticas ambientales. Aunque no todos los jóvenes comprenden totalmente las funciones de este comité, es frecuente que manifiesten su interés por mejorar las condiciones ambientales de su institución, lo cual coincide con la razón de ser de este colectivo (Acuerdo 166, 2005).

Esta caracterización permitió determinar que la mayor parte de los miembros del CAE pertenecen a los grados sexto y séptimo, con edades que oscilan entre los 11 y 12 años y cuyas familias, en su mayoría, viven en condiciones de arriendo en los estratos 2 y 3, situación que obliga al núcleo familiar a adoptar actitudes y comportamientos proambientales en razón al uso adecuado del recurso hídrico, desarrollando procesos de compromiso familiar como lo mencionan varios autores (Dyck, 2013; García \& Baldi, 2006; Griffioen, 2015; Grønhøj \& Thøgerse, 2012; Rashid \& Wahid, 2013).

Al indagar sobre esos hábitos cotidianos, llama la atención que la mayoría de las familias utiliza lavadora, a pesar de pertenecer a estratos 1 y 2, utilizándose de 1 a 3 veces por semana, 
además manifiestan hábitos de ahorro del agua como cerrar la llave mientras se cepillan o enjabonan o emplear un balde para lavar pisos.

\subsubsection{Análisis del taller formación}

Teniendo en cuenta la importancia de la EA y los esfuerzos de las naciones para lograr impactar en las sociedades tal como se muestra en la participación de Colombia en el ámbito internacional el cual se refleja en la Constitución Política de Colombia, (Cap.2, Art. 67), y la generación de conciencia ciudadana en cuanto a la importancia de un ambiente sano, el manejo adecuado de los recursos naturales y la función social de los ciudadanos y del Estado para el cuidado y conservación del medio ambiente (Artículos 79, 80 y 85).

En 1994 con la Ley 115 (Ley General de Educación), se establece la EA como una de las áreas obligatorias del currículo educativo anexo a las ciencias naturales, de igual manera en el año 2008 se implementa la Política Distrital de Educación Ambiental, la cual tiene como principios contextualizar y determinar las características particulares que tiene la ciudad fortaleciendo las iniciativas de EA incluidos los PRAE nacionales y con ellos los CAE, que tienen como finalidad formar grupos de estudiantes y docentes líderes en el manejo de actividades escolares encaminadas al mejoramiento del medio ambiente escolar y familiar.

La participación de los padres de familia y los líderes ambientales de las cuatro instituciones educativas encontraron respuesta a muchas de sus inquietudes, se logró junto con el PRAE el desarrollo de actividades para fomentar la conciencia de conservación y cuidado ambiental y se contó con la vinculación de diferentes miembros de la comunidad educativa que se encontraban fuera del proyecto. 
Lo anterior se evidenció en una actividad "El Aguatón", realizada en el entorno de las cuatro instituciones educativas, vinculando la participación de los agentes de policía del CAI (Centro de Atención Inmediata), los vecinos de los barrios aledaños, con el objetivo de difundir la importancia de implementar acciones que favorezcan la conservación de los recursos del ambiente.

Figura 43. Fotografías del Aguatón, desarrollado en la IED Reino de Holanda

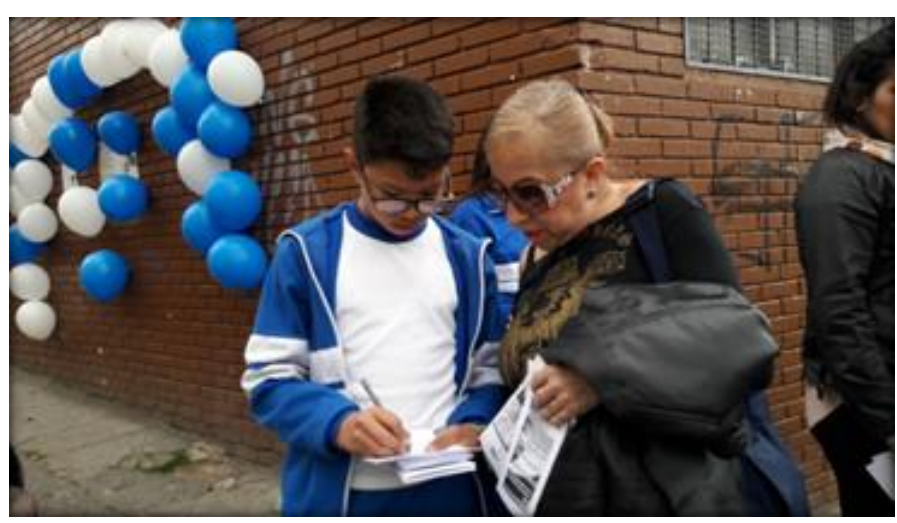

Fotografía tomada por Nancy Portilla Tomada el 14 de septiembre de 2017

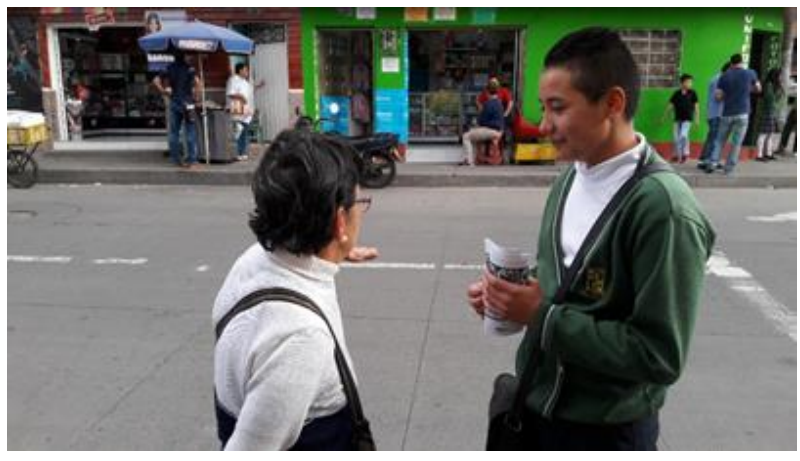

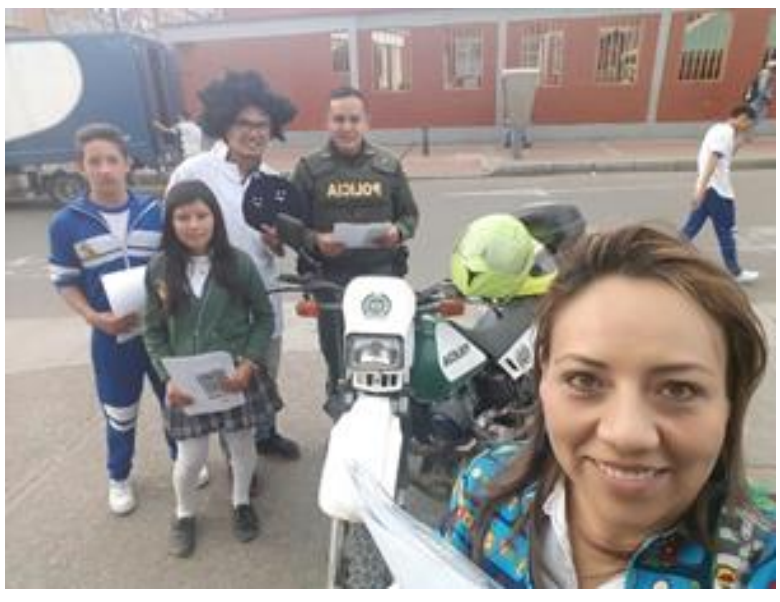

Fotografía tomada por Nancy Portilla Tomada el 14 de septiembre de 2017

Fotografía tomada por Nancy Portilla

Tomada el 14 de septiembre de 2017 
Además, la disminución en el costo del consumo del agua, reflejado en los recibos de pago en término de un año, demostraron que la familias implementaron algunas prácticas tendientes al buen uso del agua en sus hogares.

\subsubsection{Familia}

En el marco de este trabajo de investigación, se vinculó uno de los pilares fundamentales para el logro de los objetivos: la familia, puesto que al hablar de conductas y comportamientos queda inmerso el concepto de familia, siendo esta el principio de un proceso de enseñanza aprendizaje, es el primer eslabón donde los conceptos de valores adquieren su verdadero significado o como también lo manifiesta (Bernal, 2005) la familia es donde se gestan el entramado de relaciones personales y el espacio donde se practican la calidad de relaciones entre sus integrantes.

De los planteamientos anteriores, se pudo comprobar que estos valores, actitudes y comportamientos se ven reflejados en la escuela, en su quehacer diario, en las diferentes dinámicas que exige el permanecer en la institución educativa.

El grupo de estudiantes, objeto de investigación al inicio de la implementación de las estrategias planteadas, evidenció ausencia de actitudes y comportamientos en el uso responsable del agua, sus hábitos reflejaban las costumbres de sus hogares, no había compromiso con la conservación y protección del medio ambiente.

Finalmente, con la participación de las familias en el proceso, los estudiantes comenzaron a reflejar cambios en sus actitudes y comportamientos, gracias a la adquisición de conocimientos que les permitieron generar conciencia sobre el uso responsable y pertinente del agua. 


\subsubsection{Colegio y familia}

Uno de los objetivos específicos planteados fue identificar y describir los conocimientos, actitudes y comportamientos proambientales de los vigías y sus familia frente al uso responsable del recurso hídrico, por ello el trabajo de dos instituciones fundamentales: escuela y padres de familia con el fin de determinar la influencia de cada uno de ellos en la práctica de actitudes y hábitos proambientales.

De acuerdo con lo anterior, los estudiantes junto con sus padres asistieron a cada una de las instituciones educativas con el fin de desarrollar varias actividades que se programaron dentro y fuera de los colegios; al interior de la institución se presentaron algunos videos que ilustraron la importancia de cuidar y conservar el recurso hídrico, las diferentes modos de ahorrar agua en la cotidianidad de sus hogares; dentro de las actividades externas, se aplicaron rejillas de control tendientes a la generación de hábitos de uso responsables del agua y motivar a todos los miembros de la familias para adoptar hábitos que fortalezcan una cultura ambiental que garantice la conservación y protección del medio ambiente.

Lo anterior permitió concluir que en la interacción familia - escuela, las dos instituciones son fundamentales en la construcción de una cultura ambiental, como lo expresa Espitia y Montes (2009) al sustentar que la familia es la primera institución educativa y que favorece la dinámica entre el proceso de aprendizaje y el desarrollo de sus miembros, de igual manera Galvis (2010) afirma que los comportamientos de los niños con relación a las actitudes ambientales son resultado de los primeros momentos de aprendizaje desde sus hogares, aspectos como adquisición de hábitos, conductas, valores y actitudes son el reflejo del aprendizaje significativo adquirido en el hogar.

De igual manera la escuela ocupa un lugar predominante en los procesos de formación de una cultura ambiental, Miranda (2014) sostiene es la escuela quien debe dar continuidad a las 
políticas del gobierno en los temas ambientales de manera sistemática, permanente y continua, a través de las diferentes disciplinas del proceso de enseñanza-aprendizaje, donde se incluya desde las asignaturas actividades que les permita abordar las problemas ambientales de su entorno y desarrollen hábitos de cuidado, protección y amor por el medio que lo rodea en la escuela.

Por lo anterior podemos concluir que la intervención de la escuela generó receptividad al mensaje y demostró que es un mecanismo que favorece la formación de conductas en las personas, puesto que los centros educativos ejercen influencia en el entorno donde se encuentran, son instituciones consolidadas, empoderadas y jerarquizadas, por lo que se sugiere orientar trabajos de investigación dirigidos a la influencia que ejercen los centros educativos en los procesos de aprehensión de conductas proambientales.

\subsubsection{Recibos de acueducto y alcantarillado y recolección de basuras de los hogares de los vigías ambientales}

Mediante Sentencia C-060/05, el Estado Social de Derecho debe garantizar de manera efectiva los derechos constitucionales de carácter fundamental para prevalecer el bienestar de los ciudadanos, entre ellos los servicios públicos domiciliarios (Corte Constitucional, 2005), de igual manera la sentencia dispone que la empresa prestadoras de servicios públicos genere las facturas para el pago por el servicio prestado, ello con el fin de financiar los costos administrativos de mantenimiento y tratamiento de los mismos.

Por medio de este mecanismo de verificación y control, los usuarios tienen la facilidad de regular la cantidad de agua consumida con el fin de minimizar los costos. Así mismo el estado implementó algunas políticas para incentivar el ahorro en el consumo del recurso hídrico como son los subsidios, manejo de costos por estrato socioeconómico o por el contrario sanciones por consumos excesivos; estas medidas ha logrado que los usuarios tomen conciencia acerca del uso 
responsable del agua, ya que se sienten afectados por los costos elevando del servicio y de una manera indirecta están contribuyendo con el cuidado y preservación del agua.

Por lo anterior, se solicitaron a los vigías ambientales los recibos de pago de acueducto y alcantarillado y recolección de basuras, estos facilitaron determinar en un primer momento que los hogares de los estudiantes registran consumos altos, teniendo en cuenta que el valor por metro cúbico para los estratos 1 y 2 es bajo, para los casos de las instituciones educativas Manuel Zapata Olivella, Luis López de Meza y Reino de Holanda, a excepción del colegio Ricaurte que pertenece al estrato 3, donde los valores por consumo son altos, dado que el colegio se encuentra en una zona industrial donde se requiere grandes cantidades de agua por lo tanto los costos también son elevados.

En un segundo momento se solicitan nuevamente los recibos de pago de los períodos de facturación de 2017 y se comparan con los primeros recibos, del análisis se llega a la conclusión que el impacto generado por la implementación de las estrategias fue significativo, puesto que en varios casos se pudo evidenciar una disminución en el consumo, se evidenció un cambio de actitud en los estudiantes vigías ambientales y despertó el interés por estar atentos con los llamados que los integrantes del proyecto PRAE realizaba en las instituciones educativas, 


\section{Conclusiones}

- Al comienzo de esta investigación, los estudiantes y sus familias mostraron una limitada cultura ambiental, evidenciada en sus conocimientos, actitudes y comportamientos proambientales, pero en el transcurso del trabajo se fueron logrando cambios en sus comportamientos para estimular el ahorro del agua. De igual manera se aclararon algunos conceptos errados sobre la conservación del ambiente, por ejemplo creían que conservar el ambiente estaba únicamente relacionado con el reciclaje de residuos sólidos, confundían los términos de reciclaje y reutilización o la concepción de que sólo se debe ahorrar agua para que la factura por el servicio no sea tan costosa. Después del desarrollo de las actividades tanto los estudiantes como sus padres dedujeron que la práctica de hábitos responsables del consumo del recurso hídrico beneficia a toda la sociedad a mediano y largo plazo. De acuerdo con lo anterior, la implementación de las estrategias diseñadas en el plan de acción, generó conciencia con relación al uso responsable y pertinente del recurso hídrico, demostrado a través del interés y participación en las actividades desarrolladas, el cambio de hábitos en el uso del agua y el fortalecimiento de los comportamientos proambientales en los hogares de esta forma se pudo concluir que la cultura y los conocimientos proambientales de una comunidad educativa se fortalecen significativamente cuando existe participación activa de la familia.

- Se pudo demostrar que las campañas de educación ambiental lideradas por docentes y estudiantes, que conforman los Comités escolares Ambientales, de las instituciones educativas, inciden de manera significativa en el cambio de actitudes y comportamientos proambientales tanto de los menores involucrados en el proyecto como de sus familias. La integración de la familia con la escuela fortalece la construcción de una cultura ambiental, 
puesto que los roles principales en el hogar, como es el caso de padres, abuelos y tíos, tienen un papel determinante en el proceso inicial de aprendizaje. En otras palabras, es en la familia donde empieza la formación en valores de los niños y niñas en aras de llegar a ser reconocidos e incluidos en la sociedad.

- Aunque los contextos sociales, económicos y ambientales de las cuatro instituciones educativas objeto de esta investigación son distintos, en ellos se evidencia la necesidad de conservación y preservación del ambiente en aspectos puntuales como el manejo adecuado de residuos, y la conservación del agua y la energía; adicionalmente se cuenta con el potencial humano de estudiantes y padres de familia que están motivados al cambio. Esta situación puede ser aprovechada por las instituciones educativas para implementar campañas ambientales pero, como se demostró en esta investigación, solo se logra empoderamiento de los líderes y miembros del Comité Ambiental Escolar cuando existe un proyecto ambiental estructurado y liderado por los docentes.

- Por medio de la implementación de las diferentes estrategias, propuestas en el plan de acción, se logró influir en los comportamientos y actitudes proambientales de los estudiantes líderes del CAE y sus familias, lo cual se vio reflejado en el fortalecimiento de hábitos relaciona la conservación y protección del medio ambiente. Esto se pudo evidenciar a través del seguimiento diario con rejillas, que realizaron los estudiantes a sus familias, allí quedó registrado el cambio gradual en cuanto a los diferentes comportamientos proambientales frente al uso responsable del agua (Ver anexo 4).

- Aunque en su concepción, el Proyecto Ambiental Escolar incluye la participación de la comunidad educativa dentro y fuera de la institución, pocas veces se logra concretar la integración de otras entidades gubernamentales y sociales. Se pudo evidenciar que la 
participación de esas entidades es favorecida en el momento en que las instituciones educativas logran procesos de educación ambiental contextualmente pertinentes y asertivos, incluyendo metodologías adecuadas y enfocados en logros.

- Finalmente se puede afirmar que el desarrollo adecuado de proyectos de educación ambiental impacta de manera positiva el desarrollo de iniciativas de administración del recurso hídrico por parte de comunidades educativas.

- Para futuras investigaciones se sugiere continuar con este tipo de iniciativas, pero ampliando el campo de acción y vinculando a la comunidad educativa en general con el fin de incorporar un mayor número de actores sociales y de esta forma crear una cultura de protección y cuidado hacia el ambiente, fortaleciendo los conocimientos, comportamientos y actitudes proambientales. Un ejemplo de esto es la campaña del aguatón, la cual permitió a los habitantes del entorno de las cuatro instituciones educativas, fortalecer sus conocimientos ambientales a favor de una sociedad más sostenible y sustentable. 


\section{Bibliografía}

Abraham, J. , Pane, M. \& Chairiyani, R. (2015). An Investigation on Cynicism and Environmental Self-Efficacy as Predictors of Pro-Environmental Behavior. Psychology, 6, 234-242. doi: 10.4236/psych.2015.63023.

Alcaldía Mayor de Bogotá (1 de Septiembre de 2010) Bogotá y sus localidades. Disponible en: https://goo.gl/qVWZ8W

Alcaldía Mayor de Bogotá, (2017), Bogotá. Luis López de Mesa, Reseña Histórica. Disponible en: https://goo.gl/Aru5G5

Alcaldía Mayor de Bogotá, (16 de Marzo de 2017) Localidad de Kennedy. Disponible en: https://goo.gl/5WjeB6

Altarejos, F. (2002) La relación familia-escuela. Estudios sobre educación. 3, II3-II9. Disponible en:_https://goo.gl/1K42dS

Álvarez -Gayou, (2003). Cómo hacer investigación cualitativa. Disponible en https://goo.gl/mPCfSZ

Amérigo, M., García, J. A. \& Sánchez, T. (2013). Actitudes y comportamientos hacia el medio ambiente natural. Salud medioambiental y bienestar emocional. Universitas Psychologica, 12:3, 845-856. doi:10.11144/Javeriana. UPSY12-3.acma

Ando, K., Yorifuji, K., Ohnuma, S., Matthies, E., \& Kanbara, A. (2015). Transmitting proenvironmental behaviours to the next generation: A comparison between Germany and Japan. Asian Journal Of Social Psychology, 18(2), 134-144. doi:10.1111/ajsp.12078

Aoyagi, M., Vinken, H. \& Kuribayashi, A. (2003) Pro-environmental attitudes and behaviors: An international comparison. Human Ecology Review 10(1): 23-31

Ardoin, N.M., Clark, C. \& Kelsey, E. (2013) An exploration of future trends in environmental education research, Environmental Education Research, 19:4, 499-520, DOI: 10.1080/13504622.2012.709823

Arribas, M. (2004). Diseño y validación de cuestionarios. Matronas profesión, 5(17), 23-29.

Asamblea Nacional Constituyente (1991). Constitución política de Colombia [Const.] 2da Ed. Legis

Asociación Mundial para el Agua (GWP) (2000) Manejo integrado de recursos hídricos. TAC Background Papers $N^{\circ} 4$, Estocolmo: Global Water Partnership.

Avendaño, W. (2012). La Educación ambiental (EA) como herramienta de la responsabilidad social, Revista Luna Azul, 35, 94-115 
Ball, P. (2010). $\mathrm{H}_{2} \mathrm{O}$ : Una biografía del agua. México: Fondo de Cultura Económica-Turner

Baur, A. \& Hans-Martin Haase (2015) The influence of active participation and organization in environmental protection activities on the environmental behaviour of pupils: study of a teaching technique, Environmental Education Research, 21:1, 92-105, DOI: 10.1080/13504622.2013.843645

Barazarte Castro, R., Neaman, A., Vallejo Reyes, F., \& García Elizalde, P. (2014). El conocimiento ambiental y el comportamiento proambiental de los estudiantes de la Enseñanza media, en la Región de Valparaíso (Chile). Ministerio de Educación.

Belmar, B. (2003) Familia y escuela: Realidades y desafíos. Horizontes Educacionales, 8(1), 714

Bergman, B. (2016) Assessing impacts of locally designed environmental education projects on students' environmental attitudes, awareness, and intention to act, Environmental Education Research, 22:4, 480-503, DOI: 10.1080/13504622.2014.999225

Bermúdez, O. (2003) Cultura y ambiente: La educación ambiental, contexto y perspectivas, Bogotá: Ideas-UNAL. Disponible en: https://goo.gl/L9mj2H

Bernal, A. (2005). La familia como ámbito educativo. Madrid: Madrid : Ediciones Rialp Universidad de Navarra.

Berthou, S. K. G. (2013). The everyday challenges of Pro-environmental practices. The Journal of Transdisciplinary Environmental Studies, 12(1), 53-68.

Bertoldo,R.; Castro, P. \& Bousfield, A. B. (2013), Pro-environmental beliefs and behaviors: two levels of response to environmental social norms. Revista latinoamericana de psicología. 45(3), 435-446.

Blackwell, S. (2009) Electricity conservation in context: A mised methods study of residential conservation behaviour during an electricity shortage in New Zealand. Thesis Master of Environmental Studies. Victoria University of Wellington

Broom, C. (2017). Exploring the relations between childhood experiences in nature and young adults' environmental attitudes and behaviours. Australian Journal of Environmental Education, 33(1), 34-47. doi:http://dx.doi.org/10.1017/aee.2017.1

Bruun-Jensen, B. (2002) Knowledge, Action and Pro-environmental Behaviour, Environmental Education Research, 8:3, 325-334. DOI:10.1016/j.proenv.2015.01.005

Bustos, A. J., Flores, H, M., Andrade, P.P. (2004). Predicción de la conservación de agua a partir de factores socio-cognitivos. Medio ambiente y comportamiento humano, , 5(1y2), 53-70. 
Canto, J.M., Hidalgo, M.C., García, M.A., Martimportugués, C. (2002) Actitudes hacia el ahorro de agua: un análisis descriptivo. Revista internacional de psicología ambiental,3(2), págs. 119-143

Carbonell, J; Carbonell, M y González Martín, N (2012) Las Familias en el siglo XXI: Una mirada desde el Derecho. Universidad Autónoma del Estado de México, Instituto de investigaciones jurídicas. Serie: Estudios Jurídicos, Núm. 205. Coordinadora México. Editorial: Elvia Lucía Flores Ávalos.

Carmi, N. (2013) Caring about tomorrow: future orientation, environmental attitudes and behaviors, Environmental Education Research, 19:4, 430-444, DOI: 10.1080/13504622.2012.700697

Carranza, S. (2014) El agua en el mundo. Huella social - El Tiempo. 17, 14-23.

Carrico, A. (2009). Motivating pro-environmental behavior: the use of feedback and peer education to promote energy conservation in an organizational setting (Master's thesis, Graduate School of Vanderbilt University, 2009) (pp. 1-126). Nashville, Tennessee: Vanderbilt University.

Cerquera, L. \& Cuellar, M. (2008) Análisis de información recopilada sobre familia y afectividad (Tesis de especialización, Especialización en desarrollo personal y familiar) Universidad de la Sabana, Chía, Colombia.

Chapman, J., \& Walton, H. (2012). Encouraging pro-environmental action: Lessons for Australian workplaces and households.Adelaide: Centre for Work + Life, University of South Australia.

Chawla, L. \& Flanders-Cushing, D. (2007) Education for strategic environmental behavior, Environmental Education Research, 13:4, 437-452, DOI: 10.1080/13504620701581539\}

Chen, X., Peterson, M., Hull, V., Lu, C., Lee, G., Hong, D., \& Liu, J. (2011). Effects of attitudinal and sociodemographic factors on pro-environmental behaviour in urban China. Environmental Conservation, 38(1), 45-52.DOI:10.1017/S037689291000086X

Clark, C., Kotchen, M. \& Moore, M. (2003) Internal and external influences on proenvironmental behavior: Participation in a green electricity program. Journal of Enviromental Psychology. 23 (3) 237-246. DOI: 10.1016/S0272-4944(02)00105-6

Clayton, S. \& Kilinc, A. (2013) Proenvironmental concern and behavior in Turkey: The role of national and environmental identity. Psyecology, 4(3), 311-330.

DOI:10.1174/217119713807749850

Clover, D. (2002) Traversing the Gap: Concientización, educative activism in environmental adult education, Environmental Education Research, 8(3), 315-323 
Coban, G., Akpınar, E., Kucukcankurtaran, E., Y1ldı, E. \& Ergin, O. (2011). Elementary school students' water awareness. International Research In Geographical \& Environmental Education, 20(1), 65-83.

Colegio Manuel Zapata Olivella [Manual de Convivencia]. ( 27 de Marzo de 2015) Bogotá: Subdirección Imprenta Distrital.

Colvin-Williams, C. \& Chawla, L. (2016) Environmental identity formation in nonformal environmental education programs, Environmental Education Research, 22:7, 978-1001, DOI: 10.1080/13504622.2015.1055553

Congreso de Colombia (18 de Diciembre de 1974). Código Nacional de Recursos Naturales y Renovables y de Protección al Medio Ambiente. [Decreto Ley 2811 de 1974] Disponible en: https://goo.gl/eRWHNa

Congreso de Colombia (27 de Agosto de 1993) Por la cual se desarrolla el Artículo transitorio 55 de la Constitución Política. [Ley 70 de 1993] Disponible en: https://goo.gl/tBEWWn

Cook, E.M., Hall, S.J. \& Larson, K.L. (2012) Residential landscapes as social-ecological systems: a synthesis of multi-scalar interactions between people and their home environment. Urban Ecosyst 15(1) 19-52. DOI: 10.1007/s11252-011-0197-0

Cordano, M., Welcomer, S., Scherer, R., Pradenas, L., \& Parada, V. (2010). Understanding cultural differences in the antecedents of pro-environmental behavior: A comparative analysis of business students in the United States and Chile. The Journal of Environmental Education, 41(4), 224-238. Disponible en: https://goo.gl/upY9gB.

DOI:10.1080/00958960903439997

Corral Verdugo, Víctor; (2006). Contribuciones del análisis de la conducta a la investigación del comportamiento pro-ecológico. Revista Mexicana de análisis de la conducta, diciembre, 111-127.

Corral, V. V., Tapia, C., Frías, M., Fraijo, B. y González, D. (2009). Orientación a la sostenibilidad como base para el comportamiento prosocial y proecológico. Medio ambiente y Comportamiento Humano, 10(3), 195-215

Corral Verdugo, Víctor, \& Domínguez Guedea, Rosario Leticia. (2011). El rol de los eventos antecedentes y consecuentes en la conducta sustentable. Revista mexicana de análisis de la conducta, 37(2), 9-29. https://dx.doi.org/10.5514/rmac.v37.i2.26137

Corte Constitucional, Sala octava de Revisión. (18 de febrero de 2015) Sentencia T-070/15. [MP Martha Victoria Sáchica Méndez]

Corte Constitucional. (2005). Sentencia C-060/05. Recuperado a partir de http://www.corteconstitucional.gov.co/relatoria/2005/c-060-05.htm 
Cortés-Peña, O.F. (2011) Comportamiento proambiental y pensamiento económico en la construcción del desarrollo sostenible. Cultura, Educación y Sociedad, 2(1), pp. 43-56

Coutiño, J. (2011) La educación ambiental como una filosofía de vida. Revista electrónica Educare 15(2), 231-235.

Darner, R. (2012) An empirical test of self-determination theory as a guide to fostering environmental motivation, Environmental Education Research, 18:4, 463-472, DOI: $10.1080 / 13504622.2011 .638739$

De Castro, R. (2002) ¿Estamos dispuestos a proteger nuestro ambiente?, Intención de conducta y comportamiento proambiental. Medio Ambiente y Comportamiento humano. 3(2) 107118

De Nardo, M. . (2016). Exploring Salient Attributes and Status Perception of Proenvironmental Behavior (Master's thesis, The Ohio State University, 2016) (pp. 1-196). Ohio: The Ohio State University.

d'Entremont, A. (2007) Sustainable development and the Family. Persona y bioética, 1(28) 9-22

De Pina Vara, R (2005) Diccionario de Derecho. Editorial, Porrúa. México.

Díaz-Pulido, A., Chingaté-Hernández, N., Muñoz-Moreno, D., Olaya-González, W., Perilla-Castro, C., Sánchez-Ojeda, F., \& Sánchez-González, K. (2009). Desarrollo sostenible y el agua como derecho en Colombia. Estudios socio-jurídicos, 11(1), 84-116.

Díez, A. (2011) Familia y Escuela. Educar(nos), 56, 5-8.

Dresner, M., Handelman, C., Braun, S. \& Rollwagen Bollens, G. (2015) Environmental identity, pro-environmental behaviors, and civic engagement of volunteer stewards in Portland area parks, Environmental Education Research, 21:7, 991-1010, DOI: 10.1080/13504622.2014.964188

Dujo, Á, \& Rodríguez, J. (2013). Enfoques tradicionales y enfoques emergentes en la construcción del marco teórico de la Educación Ambiental para el Desarrollo Sostenible. Revista Española De Pedagogía, 71:255, 209-225. Disponible en: http://www.jstor.org/stable/23766960

Dyck, S.L. (2013) Engaging families in environmental education: how action, critical thinking, and social learning can foster change, Environmental Education Research, 19:2, 254-255, DOI: $10.1080 / 13504622.2012 .732039$

Eilers, E. C. (2014). Exploring the Association Between Norm Conflict and Pro-Environmental Behavior (Master's thesis, The Ohio State University, 2014) (pp. 1-67). Ohio: Graduate Program in Environment and Natural Resources. 
Ellis, Andrew \& Korzenny, Felipe. (2012, March). Black, White, or Green: The powerful influence of ethnicity on pro-environmental attitudes and behaviors. Association of Marketing Theory and Practice Proceedings, pp. 1-15..

ElSawah, S., Mclucas, A. \& Mazanov, J. Water (2013) Using a Cognitive Mapping Approach to Frame the Perceptions of Water Users About Managing Water Resources: A Case Study in the Australian Capital Territory. Resour Manage 27: 3441. doi:10.1007/s11269-0130357-5

Enciclopedia Británica (2009) Familia, tipos y evolución, versión en español. Disponible en: https://goo.gl/qGgPND

Encrenaz, T. (2007) Searching for water in the universe, Berlín:Springer

Escobar, N. (2007). Las voces del medio ambiente: creencias, conocimientos, conductas y conciencia medio Ambiental. Universidad de La Sabana, (pp. 1-67). Chía, Cundinamarca: Pasantía Social Facultad de Psicología

Escuela nueva ambiental (s.f.) Comité Ambiental Escolar. Disponible en: https://goo.gl/KVrdLz

Espitia, R \& Montes, M. (2009) Influencia de la familia en el proceso educativo de los menores del barrio costa azul de Sincelejo (Colombia). Investigación y desarrollo. 17(1) 84 - 105.

Evans, S., \& Gill, M. (1996). Schoolchildren as educators: The indirect influence of environmental education in schools on. Journal Of Biological Education (Society Of Biology), 30(4), 243.

Fagua, R. E., Moreno, D. M., Medina, N. F., Angarita, Serrato, F. M., \& Velásquez, G. P. (2016). Influencia de los espacios escolares en los comportamientos Proambientales de los estudiantes de tres colegios públicos de Bogotá (Universidad de La Sabana) (pp. 1-869). Chía, Cundinamarca: Trabajo de grado para optar el título de Magíster en Educación.

Febvre, L (1961) La tierra y la evolución humana. Introducción geográfica a la historia. Segunda edición en español. Colección la evolución de la humanidad. Tomo 4. México: Unión Tipográfica, Editorial Hispanoamericana.

Ferreiro, J., Putrino, N., Caballero, R., Moreno, C., Streiker-Díaz, J., Franco, P., Mazzeo, N., \& Jakovcevic, A. (2013). Uso de Claves visuales para la promoción de una conducta proambiental. Suma Psicológica, 20:1, 101-110. Disponible en:https://goo.gl/a8MDUW

Flores, R. C. (2012). Investigación en educación ambiental. Revista Mexicana e investigación educativa, 17(55), 1019-1033. Disponible en: https://goo.gl/piobHU 
Flores, R. (2013) Diálogos entre la pedagogía y la educación ambiental. Revista de educación y desarrollo social 7:1 95-107

Fominaya, C. (2015) Cuándo familia y escuela caminan de la mano. Participación educativa, 4:7 71-74. Disponible en: https://goo.gl/hUdfWa

Frederiks, E.R.; Stenner, K.; Hobman, E.V. (2015) The Socio-Demographic and Psychological Predictors of Residential Energy Consumption: A Comprehensive Review. Energies. 8, 573-609. DOI:10.3390/en8010573

Fuerza Aérea Colombiana (2014) Biografìa Capitàn Antonio Ricaurte. Disponible en: https://goo.gl/b92s1t

Galli, F.; Bolzan De Campos, C.; Bedin, L. M. And Castella Sarriera, J. (2013) Actitudes hacia el medio ambiente en la infancia: un análisis de niños del sur de Brasil. Revista latinoamericana de Psicología 45(3), 459-471.http://dx.doi.org/10.14349/rlp.v45i3.1487.

García, C., Carreón, J., Hernández, J., López, M., \& Bustos, J. (2013). Actitudes, consumo de agua y sistema de tarifas del servicio de abastecimiento de agua potable. Polis (Santiago), 12:34, 363-401. DOI: 10.4067/S0718-65682013000100019

Li, J., \& Liu, C. (2016). Intergenerational influence on adolescents' proenvironmental behavior. Social Behavior and Personality, 44(4), 589-602. DOI:10.2224/sbp.2016.44.4.589

Galvis, B (2009). Influencia del nucleo familiar en la formación ambiental del niño - niña. Estudio de caso: Institució preescolar Liceo Ifantil Casita Encantada. Localidad Barrios Unidos. Bogota D.C. Universidad Javeriana. Facultad de estudios ambientales y rurales.

García, E.; Baldi, G. (2006). Una aproximación a la psicología ambiental. Fundamentos en Humanidades. 157-168.

Genc, M. (2015) The project-based learning approach in environmental education. International Research in Geographical and Environmental Education, 24:2, 105-117, DOI: $10.1080 / 10382046.2014 .993169$

Girón, M.H. \& Leyva, J.C. 2013 El eje ambiental en la escuela "La Esperanza". Un estudio sobre actitudes y comportamientos ambientales. Innovación Educativa. 13(63). 117-147.

Goldman D., Zvi Assaraf, O. \& Shaharabani, D. (2013) Influence of a Non-formal Environmental Education Programme on Junior High-School Students' Environmental Literacy, International Journal of Science Education, 35:3, 515-545, DOI: $10.1080 / 09500693.2012 .749545$

González-Gaudiano, E. (2002). La alfabetización ambiental frente a los retos de Johannesburgo, Decisio, 19-22. 
Grønhøj, A. \& Thøgerse, J. (2012) Action speaks louder than words: The effect of personal attitudes and family norms on adolescents' pro-environmental behaviour. Journal of Economic Psychology. 33(1) 292-302. DOI: 2011.10.001

Haq, G., Cambridge, H., \& Owen, A. (2013). A targeted social marketing approach for community pro-environmental behavioural change. Local Environment, 18(10), 11341152. DOI:10.1080/13549839.2013.787974

IDEAM. (2014). Estudio Nacional del Agua. Bogotá: Panamericana Formas e Impresos S.A.

Iwata, O. (2001) Relationships Between Proenvironmental Attitudes and Concepts of Nature. The Journal of Social Psychology, 141:1, 75-83, DOI: 10.1080/00224540109600524

Jara, P. O. (2014). Dimensiones del comportamiento proambiental y su relación con la conectividad e identidad ambientales Editora da Pontifícia Universidade Católica do Rio Grande do Sul (EDIPUCRS)

Jianan, L., \& Chunlin, L. (2016). Intergenerational influence on adolescents' proenvironmental behavior. Social Behavior \& Personality: An International Journal, 44(4), 589-602. doi:10.2224/sbp.2016.44.4.589

Kollmuss, A. \& Agyeman, J. (2002) Mind the Gap: Why do people act environmentally and what are the barriers to pro-environmental behavior?, Environmental Education Research, 8:3, 239-260. DOI: 10.1080/13504620220145401

Kopnina, H. (2014) Future Scenarios and Environmental Education, The Journal of Environmental Education, 45:4, 217-231, DOI: 10.1080/00958964.2014.941783

Kunz Shuman, D. \& Ham, S.H. (1997) Toward a Theory of Commitment to Environmental Education Teaching, The Journal of Environmental Education, 28:2, 25-32, DOI: 10.1080/00958964.1997.9942820

Leff, E. (2006) Aventuras de la epistemología ambiental. México: Editorial Siglo XXI.

Leger, M. \& Pruneau, D. (2012) Changing family habits: A case study into climate change mitigation behavior in families. International Electronic Journal of Environmental Education, 2(2) 77-87 Disponible en: https://goo.gl/4cfsBB

Leppänen, J.M., Haahla, A.E., Lensu, A.M. \& Kuitunen, M.T. (2012) Parent-Child Similarity in Environmental Attitudes: A Pairwise Comparison, The Journal of Environmental Education, 43:3, 162-176, DOI: 10.1080/00958964.2011.634449

Lewis, H. B (1940) Studies in the principles of' judgments and attitudes: 11. The influence of political attitude on the organization and stability of judgments. Journal of Social Psychology . 11, 121-146. 
Leyva, F. (2012) ¡Aguas con la salud! México: Instituto Mexicano de Tecnología del Agua.

Li, Jia (2015) Exploring Social Factors and Pro-environmental Behaviors. The Hikone Ronso. 403. $154-168$

Londoño, B. (2010) El medio ambiente sano, un derecho de todos. Cartilla de aprendizaje Grupo de acciones públicas. (Universidad del Rosario). Bogotá: Editorial Universidad del Rosario.

López-Larrosa, S. (2003) Familia y escuela: Trabajando conjuntamente. Revista galegoportuguesa de psicoloxía y educación: revista de estudios e investigación en psicología y educación, 9, 291-298. Disponible en:_https://goo.gl/WCy090

Lundholm, C. \& Plummer R. (2010) Resilience and learning: a conspectus for environmental education, Environmental Education Research, 16:5-6, 475-491, DOI: 10.1080/13504622.2010.505421

Lynn, P. (2014) Distinguishing Dimensions of Pro-environmental Behaviour. Institute for Social and Economic Research, University of Essex 19. 1-19

Maiteny, P.T. (2002) Mind in the Gap: Summary of research exploring 'inner' influences on prosustainability learning and behaviour, Environmental Education Research, 8:3, 299-306

Maki, A. \& Rothman, A.J. (2016): Understanding proenvironmental intentions and behaviors: The importance of considering both the behavior setting and the type of behavior, The Journal of Social Psychology, DOI: 10.1080/00224545.2016.1215968

Mandel, P. (2005, 30 de Abril) Children as Change Agents: The Influence of Integrating Environmental Education into Home Learning Projects on Families and Community Members. [Conferencia], COERC 2005: Proceedings of the Fourth Annual College of Education Research, College of Education, Florida International University, Miami, USA. Disponible en: https://goo.gl/LDVc3y

Markowitz, E. M., Goldberg, L. R., Ashton, M. C., \& Lee, K. (2012). Profiling the 'ProEnvironmental Individual': A Personality Perspective. Journal Of Personality, 80(1), 81111. doi:10.1111/j.1467-6494.2011.00721.x

Martínez-Soto, J. (Invierno de 2004). Comportamiento proambiental. Una aproximación al estudio del desarrollo sustentable con énfasis en el comportamiento persona-ambiente, Theomai 99. Disponible en: goo.gl/umz4iO

Martinportugués, C., Canto, J. \& Hombrados, M.I., (2007) Habilidades proambientales en la separación y depósito de residuos sólidos urbanos. Medio ambiente y comportamiento humano. 8(1y2) 71-92 
Martínez-Soto, J. (2006). Comportamiento proambiental. Una aproximación al estudio del desarrollo sustentable con énfasis en el comportamiento persona-ambiente. Red Theomai.

Massung, E., Coyle, D., Cater, K. F., Jay, M., \& Preist, C. W. (2013). Using Crowdsourcing to Support Pro-Environmental Community Activism. In Proceedings of the SIGCHI conference on Human Factors in Computing Systems 2013. (pp. 371-380). Association for Computing Machinery (ACM). DOI: 10.1145/2470654.2470708

Medina, I. \& Páramo, P. (2014) La investigación en educación ambiental en América Latina: un análisis bibliométrico. Revista colombiana de Educación, 66, 55-72.DOI: 10.17227/01203916.66rce55.72

Meeusen, C. (2014) The Intergenerational Transmission of Environmental Concern: The Influence of Parents and Communication Patterns Within the Family. The Journal of Environmental Education, 45:2, 77-90, DOI: 10.1080/00958964.2013.846290

Mena, U. (2008) Localidad de Kennedy: Ficha Básica. Bogotá: Secretaría de Cultura, Recreación y Deportes Observatorios de Culturas. Disponible en: https://goo.gl/ntzCqE

Mena, U. (2008) Localidad Rafael Uribe Uribe: Ficha Básica. Bogotá: Secretaría de Cultura, Recreación y Deportes Observatorios de Culturas. Disponible en: https://goo.gl/xEq5Ds

Mendieta Hernández, Milena Paola, \& Gutiérrez Gómez, Gloria Leonor. (2014). Actitudes ambientales hacia el agua, una exploración en estudiantes del municipio de Ventaquemada (boyacá): Luna Azul, (39), 40-62. Retrieved April 06, 2017, Disponible en: http://www.scielo.org.co/scielo.php?script=sci_arttext\&pid=S1909$24742014000200004 \& \operatorname{lng}=$ en\&tlng=es.

Ministerio de Educación Nacional (1996) Plan Decenal de Educación, Bogotá: Editorial Magisterio

Ministerio de Educación Nacional (8 de Julio de 2015). Gobierno Nacional firma acuerdo marco para la Educación Ambiental de país. Disponible en: https://goo.gl/mtRa8z

Ministerio de Medio Ambiente \& Ministerio de Educación. (2002). Política Nacional de Educación Ambiental. Bogotá.

Ministerio de Ambiente y Desarrollo Sostenible (2014) Código Nacional de Recursos Naturales Renovables y de Protección al Medio Ambiente: Decreto Ley 2811 de 1974. Bogotá: Ministerio de Ambiente y Desarrollo Sostenible.

Miranda, L. (2013). Cultura ambiental: un estudio desde las dimensiones de valor, creencias, actitudes y comportamientos ambientales. Producción + Limpia 8 (2). Disponible en: https://goo.gl/cVHuiA. 
Miranda, A. (2014). Educación ambiental en el proceso de enseñanza-aprendizaje en Primaria, Secundaria y Preuniversitario. Revista Vinculando. disponible en: https://goo.gl/cCa5TL

MMA.MEN. Política Nacional de Educación Ambiental SINA. Bogotá. Colombia. 2002.

Morrissey, K. M., \& Werner-Wilson, R. (2005). The relationship between out-of-school activities and positive youth development: an investigation of the influences of communities and family. Adolescence, 40(157), 67-85. Disponible en: https://goo.gl/Wd1oYZ

Noguera, A. (2006) Pensamiento ambiental complejo y gestión del riesgo: una propuesta epistémico-ético- estética. Taller internacional sobre gestión del riesgo a nivel local. Manizales: Universidad Nacional de Colombia.

Nye, M., \& Hargreaves, T. (2010).Exploring the Social Dynamics of Proenvironmental Behavior Change. Journal Of Industrial Ecology, 14(1), 137-149. DOI:10.1111/j.15309290.2009.00193.x

OECD (2009) Household Behaviour and the Environment Reviewing the Evidence. OECD Publishing.

Organización de las Naciones Unidas (1948) Declaración universal de los derechos humanos, Resolución 217A. Asamblea general de la ONU. París, Francia.

Organización de las Naciones Unidas, Consejo Económico y Social (1968), Resolución 1346 (XLV) Cuestión de la convocatoria de una conferencia internacional sobre los problemas de medio humano, Nueva York: ONU.

Organización de las Naciones Unidas (1972) Declaración de Estocolmo sobre el medio ambiente humano. Estocolmo: ONU.

Organización de las Naciones Unidas (1996) Declaración de Río sobre el Medio Ambiente y el Desarrollo. Disponible en: https://goo.gl/kp7RVB

Organización de las Naciones Unidas (2002) Declaración de Johannesburgo sobre desarrollo sustentable. Johannesburgo:ONU. Disponible en: https://goo.gl/i3mzDR

Özden, M. (2008) Environmental Awareness and Attitudes of Student Teachers: An Empirical Research. International Research in Geographical and Environmental Education, 17:1, 40-55, DOI: $10.2167 /$ irgee227.0

Palacios, J. R., Bustos, J. M. y Soler, F. L. (2015). Factores socioculturales vinculados al comportamiento proambiental en jóvenes. Revista de Psicología, 24(1), 1-16. DOI:10.5354/0719-0581.2015.36900 
Páramo, P. (2015). Reglas proambientales: una alternativa para disminuir la brecha entre el decirhacer en la educación ambiental. Universidad Pedagógica Nacional, Bogotá, D.C. Colombia.

Páramo, P., y Gómez, F., Actitudes hacia el medio ambiente: su medición a partir de la teoría de facetas. Revista Latinoamericana de Psicología, vol. 29, núm. 2, 1997, pp. 243-266 Fundación Universitaria Konrad Lorenz Bogotá, Colombia

Payne, P. G. (2010) Moral spaces, the struggle for an intergenerational environmental ethics and the social ecology of families: an 'other' form of environmental education, Environmental Education Research, 16:2, 209-231, DOI: 10.1080/13504620903580545

Pensini, P., Slugoski,B., Caltabiano, N. (2012) "Predictors of environmental behaviour: a comparison of known groups", Management of Environmental Quality: An International Journal, 23(5), 536-545, doi: 10.1108/14777831211255114

Prati, G., Albanesi, C. \& Pietrantoni, L. (2017) The interplay among environmental attitudes, pro-environmental behavior, social identity, and pro-environmental institutional climate. A longitudinal study, Environmental Education Research, 23:2, 176-191, DOI: 10.1080/13504622.2015.1118752

Programa Mundial de Evaluación de los Recursos Hídricos (WWAP) (2003) Primer Informe de las Naciones Unidas sobre el desarrollo de los Recursos Hídricos en el mundo. París :ONU.

Programa Mundial de Evaluación de los Recursos Hídricos (WWAP) (2015) Informe de las Naciones Unidas sobre el desarrollo de los Recursos Hídricos en el mundo. París: ONU.

Rainear, A. \& Christensen, J. (2017) Protection Motivation Theory as an Explanatory Framework for Proenvironmental Behavioral Intentions. Communication Research Reports. 1-10. DOI: $10.1080 / 08824096.2017 .1286472$.

Rashid, N. \& Wahid, N. (2013) Positive Spillover of Pro-Environmental Behavior Phenomenon: The Influence of Organizational and Family Factors. International Proceedings of Economics Development \& Research. 56(16) 79-83. DOI:10.7763/IPEDR. 2012. V56. 16

Redondo, I. \& Puelles, M. (2017) The connection between environmental attitude-behavior gap and other individual inconsistencies: a call for strengthening self-control, International Research in Geographical and Environmental Education, 26:2, 107-120, DOI: 10.1080/10382046.2016.1235361

Robertson, J. L. \& Barling, J. (2013), Greening organizations through leaders' influence on employees' pro-environmental behaviors. J. Organiz. Behav., 34 176-194. doi:10.1002/job. 1820 
Rodríguez Cruz, I., \& Bezunartea Valencia, M. (2016). Capacidad movilizadora de la información sobre medio ambiente: la importancia de la calidad periodística para promover una actitud proambiental. Estudios Sobre El Mensaje Periodístico, 22(1), 517 530. doi:10.5209/rev_ESMP.2016.v22.n1.52611

Santiago, J. (2008). La problemática del ambiente, la educación ambiental y el uso didáctico de los medios de comunicación social. Investigación y posgrado, 23 (2.), 241-270. Recuperado en 16 de junio de 2017, de: https://goo.gl/SydyVH

Sanvichith, J. (2011) Do Gardens Make You Green?: Home Gardens, Identity, and ProEnvironmental Behavior Among Southeast Asian American UC Berkeley Students. Home gardens, Identity and Pro-environmental behavior. Spring 1-17

Secretaria de Cultura, Recreación y Deporte. - SCRD (2014). Bogotá y sus localidades. Disponible en: https://goo.gl/qVWZ8W

Secretaría Distrital de Ambiente (2008), Observatorio ambiental de Bogotá. Disponible en: https://goo.gl/d8PM8J

Secretaría Distrital de Planeación (2009) Conociendo la localidad de Bosa: Diagnóstico de los aspectos físicos, demográficos y socioeconómicos. Bogotá: SDP. Disponible en: https://goo.gl/5Gn1Mh

Secretaría Distrital de Planeación (2009) Conociendo la localidad de Los Mártires: Diagnóstico de los aspectos físicos, demográficos y socioeconómicos. Bogotá: SDP. Disponible en: https://goo.gl/Uvnt5D

Shiva, V. (2004) Las guerras del agua: Privatización, contaminación y lucro. México: Siglo Veintiuno Editores.

Sonja, P. (2013) An Investigation of Gender Differences in Pro-environmental Attitudes and Behaviors. Honors Scholar Theses.Paper . Disponible en: https://goo.gl/rQc4kU

Sosa, J. (2009) Evolución de la relación familia-escuela. Tendencias pedagógicas, 14, 251-26 Disponible en: https://goo.gl/QkpbvX.

Steg, L., Vlek, C. (2009) Encouraging pro-environmental behaviour: An integrative review and research agenda. Journal of Environmental Psychology. 29 309-317. DOI:10.1016/j.jenvp.2008.10.004.

Stevenson, K.T., M. Peterson, N., Carrier, S.J., Strnad, R.L., Bondell, H.D., Kirby-Hathaway, T. \& Moore, S.E. (2014) Role of Significant Life Experiences in Building Environmental Knowledge and Behavior Among Middle School Students, The Journal of Environmental Education, 45:3, 163-177, DOI: 10.1080/00958964.2014.901935 
Thompson, N. (2010). The power of one: The impact of family and consumer sciences education on environmental sustainability. Journal of Family and Consumer Sciences, 102(2), 64-67. Disponible en: https://goo.gl/mYXLxf

Torres-Hernández, T., Barreto, I. \& Rincón, J.C. (2015) Creencias y normas subjetivas como predictores de intención de comportamiento proambiental. Suma Psicológica 22. 86-92. DOI:10.1016/j.sumpsi.2015.09.003.

Torres, L., Elisa. (2011) Medio Ambiente y Proyecto Ambiental Escolar PRAE, en el Colegio Nicolás Esguerra. Universidad Nacional de Colombia Facultad de Ciencias Bogotá, Colombia. 15.

Tovar, E. (2016). Incidencia de la educación ambiental en el cambio de prácticas culturales orientadas al cuidado y preservación del recurso hídrico. Caso: Empresa de Acueducto y Secretaria de Ambiente de Bogotá. (Tesis para optar al Título de: Magister en Desarrollo Sustentable y Gestión Ambiental). Universidad Distrital Francisco José de Caldas. Bogotá.

Varela-Losada, M., Vega-Marcote, P., Pérez-Rodríguez, U. \& Álvarez-Lires, M. (2016) Going to action? A literature review on educational proposals in formal Environmental Education, Environmental Education Research, 22:3, 390-421, DOI: 10.1080/13504622.2015.1101751

Vaughan, C., Gack, J., Solorazano, H. \& Ray, R. (2003) The Effect of Environmental Education on Schoolchildren, Their Parents, and Community Members: A Study of Intergenerational and Intercommunity Learning, The Journal of Environmental Education, 34:3, 12-21. DOI:10.1080/00958960309603489.

Vega, Pedro; Álvarez, Pedro; (2009). Actitudes ambientales y conductas sostenibles. Implicaciones para la educación ambiental. Revista de Psicodidáctica, 245-260.

Vidart D. (1997) Filosofía Ambiental. El ambiente como sistema. Bogotá : Editorial Nueva América

Villalobos, D. (2016) Resumen de la Ley 99 de 1993: Ley General Ambiental de Colombia. Red por la justicia ambiental en Colombia. Disponible en: https://goo.gl/zq32xE

Viveros, F. (2013) El agua no es recurso hídrico. El quinto poder. Disponible en: https://goo.gl/a11z2c

Willuweit, L. (2009). Promoting Pro-Environmental Behavior : An Investigation of the crosscultural environmental behavior patterns. The Case of Abu Dhabi (Dissertation). Disponible en: https://goo.gl/iZ2JB1 
Zaleha, B. D. (2013). 'Our Only Heaven': Nature Veneration, Quest Religion, and ProEnvironment Behavior. Journal for The Study Of Religion, Nature \& Culture, 7(2), 131153. doi:10.1558/jsrnc.v7i2.131

Zamudio, C. (2013). Sobre la Educación Ambiental. En I. d. Universidad Distrital Francisco José de Caldas. Investigaciones y proyectos en educación ambiental UD (2008-2011) (pág. 27). Bogotá: UD Colección Tierra y Vida. 
Anexos

Anexo 1. Encuesta Diagnóstica

\section{ENTREVISTA INICIAL MANEJO ADECUADO DEL AGUA}

Un grupo de profesores, estudiantes de la Maestría en Educación, de la Universidad de la Sabana, solicitan a ustedes muy respetuosamente, nos colaboren respondiendo esta encuesta, con fines pertinentes a la realización de nuestra tesis, cuyo temática es el uso adecuado del agua desde los colegios proyectada hacia los hogares.

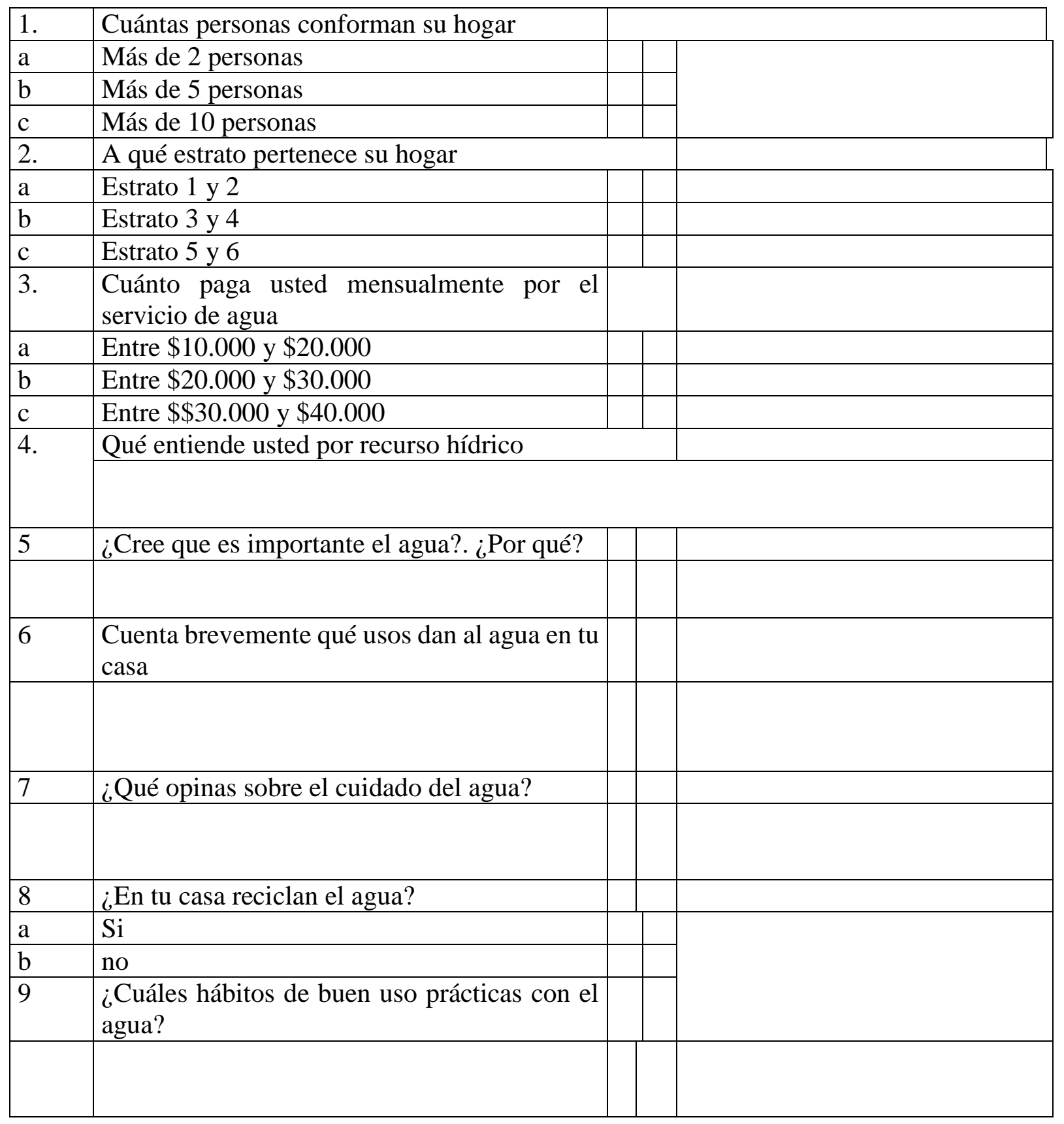




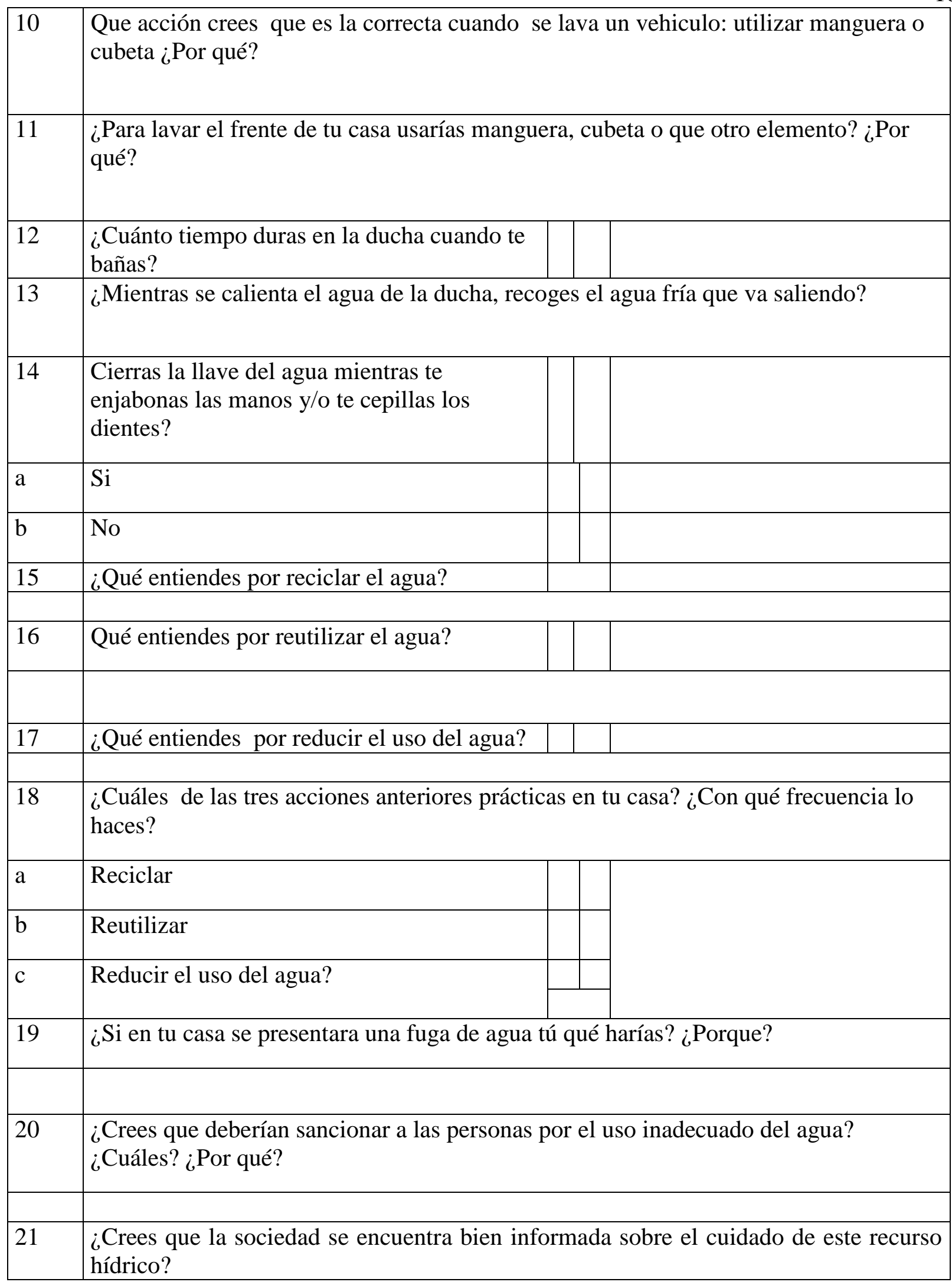


22 ¿Qué sugerencias darías para que en los hogares se utilice racionalmente el agua?

23 ¿Has imaginado nuestro planeta sin agua? ¿Cómo crees que sería? 
Anexo 2. Entrevista inicial y transcripciones

\section{Entrevista estudiante Colegio: Reino de Holanda Curso: 604}

El código es un concepto que elaboramos. Es una etiqueta, un nombre (palabra, frase u oración) que asignamos a un fenómeno/situación. Ese nombre capta la esencia de lo que creemos que nos dicen los datos

1. Codifique la entrevista empleando códigos abiertos o en vivo. Use un nombre para describir lo que ocurre considerando la pregunta de investigación.

2. Compare y contraste sus códigos con los de sus compañeros. Establezca patrones que se repiten (considere también los "outliers"). Agrupe las ideas y asigne un nombre a ese agrupamiento (codificación axial)

3. Realice un diagrama para establecer posibles conexiones entre las agrupaciones que haya hecho (trate de establecer el tipo de relación: causa-efecto por ejemplo)

4. Elabore una explicación del diagrama que sea la respuesta a la pregunta de investigación

\begin{tabular}{|c|c|}
\hline \multicolumn{2}{|c|}{$\begin{array}{c}\text { Pregunta: ¿Cómo puede la Institución Educativa promover en la familia } \\
\text { comportamientos } \\
\text { pro-ambientales en relación con el recurso hídrico?? }\end{array}$} \\
\hline $\begin{array}{l}\text { Transcripción entrevista elaborada por } \\
\text { Nancy Portilla Toro }\end{array}$ & Codificación abierta \\
\hline $\begin{array}{l}\text { Entrevista NICOLAS GARCIA } \\
\text { N.P. Cuál es tu nombre? } \\
\text { N.G: NICOLAS ANDRES GARCIA REALES } \\
\text { N.Gr: En qué colegio estudias? } \\
\text { N.G: En el Reino de Holanda } \\
\text { N.P: Qué grado estás haciendo } \\
\text { N.G sexto } \\
\text { N.P: ¿vives con quién? } \\
\text { N.G: con mi mamá, mi papá, mis hermanos, mi } \\
\text { abuelo y mi tío } \\
\text { N.P: ¿son varias personas las que viven en tu } \\
\text { casa verdad? } \\
\text { N.G: si. } \\
\text { N.P: ¿de qué forma utilizan el agua en tu } \\
\text { colegio?, que miras por ejemplo en el baño } \\
\text { N.G que la gastan } \\
\text { N.P ¿en qué forma la gastan? } \\
\text { N.G se llenan las manos y empiezan a botarla } \\
\text { a los demás }\end{array}$ & $\begin{array}{l}\text { mal uso del agua dentro de los baños de niños } \\
\text { y niñas } \\
\begin{array}{l}\text { ausencia de campañas ambientales en el } \\
\text { colegio }\end{array}\end{array}$ \\
\hline
\end{tabular}


N.P: $\quad$ Como se manejan los residuos sólidos de tu colegio, o sea que hacen con la basura, en la hora de descanso

N.G: la dejan tirada en el piso

N.P, o sea, es más los que la dejan en el piso o más los que dejan en las canecas

N.G: es más lo que dejan en el piso

N.P: ¿en tu colegio se hacen campañas ambientales, de lo que estás aquí, has visto que el colegio haga campañas ambientales?

N.G no, señora

N.P: ¿nunca?, ¿no?

N.G: (asiente con su cabeza, que no)

N.P: ¿crees que estas campañas que por ejemplo tu miras en la televisión, o en el

N.G: si barrio, ayudan y favorecen algún cambio?

N.P: por ejemplo, como cuál, recuerdas tú, qué campañas hacen en la televisión

N.G: campañas de... de... campañas de reciclaje, de ahorro de agua, de energía.

N.P: ¿esas campañas que tu mira, si crees que son positivas?

N.G: si

N.P: por qué crees que es importante aprender a cuidar el ambiente y los recursos naturales, porque es importante

N.G: porque sirve para tener un futuro mejor, por qué o sea, que para que se preserve la naturaleza.

N.P: muy bien, actúas de alguna forma para cuidar el ambiente en el barrio donde vives, o sea tú colaboras con el medio ambiente, tu hace ... digamos que tienes conductas positivas con relación al ambiente

N.G: sí señora

N.P: como que, que haces

N.G: no dejar la basura tirada en cualquier parte, si hay basura cerca de las alcantarillas quitarla,

N.P: ¿por ejemplo, con el agua, tu qué haces?

N.G: tener un uso apropiado de ella

N.P: para ti son importantes los ríos que encuentras en la ciudad, por ejemplo, en el barrio, por aquí cerca al colegio, al algún río que tu conozcas las campañas de la televisión, tienen gran impacto en los estudiantes

concienciación ante la posible escasez de agua en el futuro.

responsabilidad comunitaria de limpieza de las calles y otras áreas comunes.

reconoce el valor ecosistémicos de los rio urbanos.

reutiliza y ahorro de agua en el hogar

reutilizar el agua en el hogar

capacitación en la separación de residuos

existen programas de formación para el cuidado del medio ambiente en los colegios

control y seguimiento en los recibos de los servicios públicos 
N.G: no señora

N.P: tú crees que esos ríos son importantes

N.G si

N.P: para quién

N.G: son importantes, porque alrededor de los ríos hay naturaleza o también hay animales que la necesitan

N.P: ¿Realizas alguna actividad para cuidar el agua en tu casa?

N.G: $\mathrm{Si}$,

N.P: ¿qué hacen?

N.G pues, si, cuando hacemos aseo, por ejemplo, lavar la loza, cogemos dos coquitas, metemos en una la que en la que está el jabón y luego a la otra para enjuagarla.

N.P: qué estrategias emplean en tu casa para que ahorren el agua, a parte de esa que tu me hablas sobre el lavado de la loza. Que más hacen

N.G: reutilizar el agua,

N.G: esa agua en que la reutilizan, en la lavadora, para lavar el baño, para hartas cosas

N.P: en el colegio, te enseñan educación ambiental , te insinúan algo? Sobre cuidar el agua, sobre botar papeles.

N.G: si algo, pero...

N.P: ¿poco?, tu mira que estamos como cortos en el colegio en eso?

N.G: si, señora

N.P: ¿De qué manera te enseñan educación ambiental en el colegio, o sea, como te enseñan, en las clases te dictan algo? Para...

N.G: pues no, porque ahí, como los representantes del comité ambiental, pues ellos van y nos dicen que no dejemos la basura tirada, que alcemos, que reciclemos.

N.P: ¿en tu familia revisan los recibos de agua? N.G: sí, señora

N.P: para que los revisan

N.G: pues, para ver el consumo, cuanto se ha consumido

N.P: y ustedes si miran que el consumo ha aumentado, qué estrategias toman ustedes o qué medidas toman implementación de estrategias educativas para

el uso adecuado del agua. 
N.G: pues, si aumentan pues, empezamos a hacer las cosas que hacemos como reutilizar el agua, y hacer con menos consumo de agua.

N.P: ¿en el colegio qué alternativas han tomado para el uso del agua, para botar la basura en las canecas, que medidas han empleado?

N.G: pues, yo digo, dicen que hay que alzar la basura, porque las señoras del aseo, a lo que salimos nosotros no tienen tanto tiempo para arreglar, para los de la noche

N.P: Gracias Nicolás por tu colaboración. 
Anexo 3. Caracterización del Comité Ambiental Escolar.

\section{Universidad de la Sabana - Maestría en Educación ENCUESTA A ESTUDIANTES VIGÍAS AMBIENTALES CARACTERIZACIÓN SOBRE COMPORTAMIENTOS Y ACTITUDES PROAMBIENTALES EN EL HOGAR}

El colegio Ricaurte, con el acompañamiento de la Universidad de la Sabana, se encuentra desarrollando una encuesta dirigida a los estudiantes (vigías ambientales), pertenecientes al Comité Ambiental Escolar (CAE) con el fin de indagar hacer de los comportamientos y actitudes proambientales que presentan en su colegio y en sus hogares.

Este tiene como objetivo principal la creación del plan estratégico de incorporación de una cultura en pro de la conservación y cuidado del recurso hídrico en los hogares y en la institución educativa, por ello nos encontramos en la etapa de diagnóstico y solicitamos que responda las siguientes preguntas con la mayor sinceridad posible.

Teniendo en cuenta que las actitudes y los comportamientos pro-ambientales son aquellas conductas y acciones deliberadas, responsables y efectivas que presentan los seres humanos al responder adecuadamente a los requerimientos ambientales, de forma individual y colectiva dentro de la sociedad, dando como resultado beneficios de cuidado, conservación y protección del medio ambiente.

\begin{tabular}{|c|c|c|c|}
\hline 1 & SEXO & Femenino & Masculino \\
\hline & LLM & 8 & 9 \\
\hline & $\mathrm{MZO}$ & 18 & 16 \\
\hline & $\mathrm{CR}$ & 11 & 6 \\
\hline & RH & 8 & 11 \\
\hline & TOTAL & 45 & 42 \\
\hline
\end{tabular}

\begin{tabular}{|c|c|c|c|c|c|c|c|c|c|c|c|}
\hline 2 & GRADO & & $4^{\circ}$ & $5^{\circ}$ & $6^{\circ}$ & $7^{\circ}$ & $8^{\circ}$ & $9^{\circ}$ & $10^{\circ}$ & $11^{\circ}$ & TOTAL \\
\hline & & LLM & 2 & 2 & 2 & 2 & 2 & 2 & 3 & 2 & 17 \\
\hline & & $\mathrm{MZO}$ & 4 & 4 & 4 & 4 & 6 & 4 & 4 & 4 & 34 \\
\hline & & $\mathrm{CR}$ & & & 4 & 2 & 3 & 4 & 2 & 2 & 17 \\
\hline & & $\mathrm{RH}$ & & 6 & 8 & 2 & 0 & 0 & 2 & 1 & 19 \\
\hline & & TOTAL & 6 & 12 & 18 & 10 & 11 & 10 & 11 & 9 & 87 \\
\hline
\end{tabular}




\begin{tabular}{|l|l|l|l|l|}
\hline 3 JORNADA & Mañana & Tarde & Otro \\
\hline & LLM & & 17 & \\
\hline & MZO & 34 & & \\
\hline CR & & 17 & \\
\hline RH & & 19 & \\
\hline TOTAL & 34 & 53 & 0 \\
\hline
\end{tabular}

\begin{tabular}{|c|c|c|c|c|c|c|c|c|c|c|c|c|c|}
\hline 4 & $E D A D$ & 9 & 10 & 11 & 12 & 13 & 14 & 15 & 16 & 17 & 18 & 18 & $\begin{array}{l}\text { TOT } \\
\text { AL } \\
\end{array}$ \\
\hline & LLM & 2 & 1 & 2 & 2 & 1 & 3 & 3 & 3 & & & & 17 \\
\hline & $\mathrm{MZO}$ & 4 & 3 & 4 & 4 & 5 & 4 & 3 & 4 & 3 & & & 34 \\
\hline & $\mathrm{CR}$ & & & & 3 & 2 & 3 & 2 & 3 & 3 & 1 & & 17 \\
\hline & $\mathrm{RH}$ & & & 10 & 4 & 2 & & 3 & & & & & 19 \\
\hline & TOTAL & 6 & 4 & 16 & 13 & 10 & 10 & 11 & 10 & 6 & 1 & 0 & 87 \\
\hline
\end{tabular}

\begin{tabular}{|c|c|c|c|c|c|}
\hline 5 & ESTRATO & 1 & 2 & 3 & Total \\
\hline & LLM & 2 & 15 & & 17 \\
\hline & MZO & & 34 & & 34 \\
\hline & CR & 1 & 1 & 15 & 17 \\
\hline & RH & & 16 & 3 & 19 \\
\hline & TOTAL & 3 & 66 & 18 & 87 \\
\hline
\end{tabular}

\begin{tabular}{|l|l|l|l|}
\hline 6 ACCESO A INTERNET & SI & NO \\
\hline & LLM & 15 & 2 \\
\cline { 2 - 4 } & MZO & 34 & \\
\cline { 2 - 4 } & CR & 14 & 2 \\
\hline & RH & 14 & 5 \\
\hline & TOTAL & 77 & 9 \\
\hline
\end{tabular}

\begin{tabular}{|l|l|l|}
\hline 7 LOCALIDAD & Escriba aquí las localidades y barrios más frecuentes en sus encuestas \\
\hline LLM & $\begin{array}{l}\text { localidad 7. Amistad, Nueva Granada, Bosa la estación, San José, Balcanes, San Pablo, El } \\
\text { Porvenir, Soacha }\end{array}$ \\
\cline { 2 - 3 } MZO & $\begin{array}{l}\text { localidad 8. patio bonito II, altamar, tierrabuena, riveras, maria paz, dindalito } \\
\text { progreso, Ed Santos, Santa Isabel. Loc. Simón Bolívar (lucero alto). Loc. Puente aranda } \\
\text { (asunción) }\end{array}$ \\
\hline CR
\end{tabular}




\begin{tabular}{|l|l|l|l|l|l|}
\hline 8 TIPO DE VIVIENDA & CASA & HAB & APART & APAREST \\
\hline & LLM & 9 & & 8 & \\
\cline { 2 - 7 } & MZO & 11 & & 23 & \\
\hline & CR & 6 & & 11 & \\
\hline & RH & 14 & & 5 & \\
\hline & TOTAL & 40 & 0 & 47 & \\
\hline
\end{tabular}

\section{COND. VIVIENDA}

\begin{tabular}{|c|c|c|c|}
\hline & PROPIA & FAMILIAR & ARREND \\
\hline LLM & 5 & & 12 \\
\hline MZO & 9 & 13 & 12 \\
\hline $\mathrm{CR}$ & 1 & 1 & 15 \\
\hline RH & 7 & 5 & 7 \\
\hline TOTAL & 22 & 19 & 46 \\
\hline
\end{tabular}

\section{0 ¿Cuánto tiempo hace que es vigía ambiental?}

\begin{tabular}{|l|l|l|l|l|} 
& $\begin{array}{l}<3 \\
\text { mese }\end{array}$ & $<6$ meses & $<$ año & años \\
\hline LLM & & & 13 & 4 \\
\hline MZO & & & 14 & 20 \\
\hline CR & 4 & 1 & 8 & 4 \\
\hline RH & & & 1 & \\
\hline TOTAL & 4 & 1 & 36 & 28 \\
\hline
\end{tabular}

\section{\begin{tabular}{l|l}
\hline ¿Cree que son importantes los vigías ambientales? \\
\hline
\end{tabular}}

\begin{tabular}{|l|l|l|} 
& SI & NO \\
\hline LLM & 17 & \\
\hline MZO & 34 & \\
\hline CR & 17 & \\
\hline RH & 19 & \\
\hline TOTAL & 87 & 0 \\
\hline
\end{tabular}

12 ¿Por qué?
Escriba aquí las palabras clave de las respuestas

LLM AYUDAN A CUIDAR EL MEDIO AMBIENTE

$\mathrm{MZO}$

ección del medio ambiente, cuidado del planeta, conservación de la vida, uso adecuado de los recursos naturales

comprometidos con el ma, ayudar al cuidar el planeta, no contaminar, enseñan a cuidar el ma, para que las demás personas ayuden a cuidar el ma. hacer un cambio en nuestro planeta., ayuda con el reciclaje., dar la importancia al medio ambiente, ayudan al ambiente, animan a otras a cuidar el ma.dar ejemplo a demás estudiantes. alternativas para cuidar el ma. influenciar a los otros para que ayuden. tienen conocimientos sobre el medio ambiente. ayudamos a que las personas sean conscientes de la problemática ambiental. ayuda cuidado del entorno 
13 ¿Qué lo motiva a hacer parte del comité ambiental escolar CAE?

Escriba aquí las palabras clave de las respuestas

\begin{tabular}{|c|c|}
\hline LLM & AYUDAR AL MEDIO AMBIENTE Y AL COLEGIO, PROCESO DIFERENTES \\
\hline MZO & trabajar por un ambiente sano, cuidado de las especies y sus hábitat, portar al medio ambiente \\
\hline $\mathrm{CR}$ & $\begin{array}{l}\text { APORTAR PARA MEJORAR EL MEDIO AMBIENTE. AYUDAR AL PLANETA, UN } \\
\text { FUTURO MEJOR, AMOR A LA NATURALEZA, CUIDAR AGUA, LOS ANIMALES, } \\
\text { LAS PLANTAS, PUEDO CAMBIAR MI TRATO CON EL MEDIO AMBIENTE. TEMA } \\
\text { MUY INTERESANTE Y APORTAR UN MEJOR MAÑANA. APORTAR PARA UN } \\
\text { COLEGIO SANO Y UN MUNDO SANO. PUEDO HACER ALGO POR EL PLANETA Y } \\
\text { CONOCER NUEVOS TEMAS, A PROSPERAR COMO PERSONA SANA Y SANAR AL } \\
\text { MEDIO AMBIENTE. PARA QUE LAS PERSONAS REACCIONEN. ORGANIZAR EL } \\
\text { COLEGIO, ME MOTIVA LA INSTITUCIÓN Y EL ENTORNO DE LOS ESTUDIANTES. } \\
\text { RECICLAR, AHORRAR AGUA Y LO QUE SEA NECESARIO. ME INTERESA } \\
\text { BASTANTE. CUIDAR LOS RÍOS. TENER UN MEJOR PLANETA. }\end{array}$ \\
\hline $\mathrm{RH}$ & CONTRIBUIR CON EL CUIDAD DEL COLEGIO, LA CASA, EL BARRIO \\
\hline
\end{tabular}

\begin{tabular}{|c|c|c|c|c|c|c|c|}
\hline 14 & Personas con las que vive: & Promedios & LLM & MZO & CR & RH & \begin{tabular}{|l}
$\begin{array}{l}\text { Promed } \\
\text { io }\end{array}$ \\
\end{tabular} \\
\hline & & Número de habitantes en la vivienda & 5 & 4 & & 6 & 5 \\
\hline & & $\begin{array}{l}\text { Número de habitantes menores de } 10 \\
\text { años }\end{array}$ & 0 & 1 & & 2 & 1 \\
\hline & & $\begin{array}{l}\text { Número de habitantes mayores de } 11 \\
\text { y menores de } 20 \text { años }\end{array}$ & 1 & 2 & & 4 & $\begin{array}{l}2,3333 \\
33\end{array}$ \\
\hline & & $\begin{array}{l}\text { Número de habitantes mayores de } 20 \\
\text { años }\end{array}$ & 4 & 2 & & 4 & $\begin{array}{l}3,3333 \\
33 \\
\end{array}$ \\
\hline
\end{tabular}

\section{Grupo étnico}

\begin{tabular}{|l|l|l|l|l|l|} 
& Afro & Gitano & Indígena & Mestizo & Ninguno \\
\hline LLM & & & & 17 & \\
\hline MZO & 2 & & 1 & 31 & \\
\hline CR & 1 & & & 14 & \\
\hline RH & 4 & & & 15 & \\
\hline TOTAL & 7 & 0 & 1 & 77 & 0 \\
\hline
\end{tabular}

16 El promedio de pago bimensual de la factura del acueducto y alcantarillado de su vivienda oscila entre

\begin{tabular}{|l|l|l|l|l|l|} 
& $\begin{array}{l}\$ 10000 \mathrm{y} \\
\$ 20000\end{array}$ & $\begin{array}{l}\$ 21000 \text { y } \$ \\
30000\end{array}$ & $\begin{array}{l}\$ 31000 \text { y } \$ \\
40000\end{array}$ & $\begin{array}{l}\$ 41000 \text { y } \$ \\
50000\end{array}$ & $\begin{array}{l}\text { \$51000 o } \\
\text { más }\end{array}$ \\
\hline LLM & & & 3 & 8 & 4 \\
\hline MZO & & & 8 & 17 & 9 \\
\hline CR & 4 & 1 & 1 & & 8 \\
\hline RH & 3 & 5 & 1 & 3 & 7 \\
\hline TOTAL & 7 & 6 & 13 & 28 & 28 \\
\hline
\end{tabular}




\begin{tabular}{|l|l|l|l|} 
& $\begin{array}{l}\text { En } \\
\text { lavadora }\end{array}$ & $\begin{array}{l}\text { En } \\
\text { lavadero } \\
\text { (a mano) }\end{array}$ & $\begin{array}{l}\text { Utiliza } \\
\text { baldes o } \\
\text { tinas }\end{array}$ \\
\hline LLM & 12 & 3 & \\
\hline MZO & 34 & & \\
\hline CR & 14 & 2 & \\
\hline RH & 12 & 8 & \\
\hline TOTAL & 72 & 13 & 0 \\
\hline
\end{tabular}

18

\begin{tabular}{|c|c|c|c|c|c|}
\hline \multirow{7}{*}{$\begin{array}{l}\text { Cuántas veces en la semana } \\
\text { (no número de días sino } \\
\text { número de lavadas) hacen } \\
\text { con uso de lavadora en su } \\
\text { casa (sólo responda si en su } \\
\text { casa hay lavadora) }\end{array}$} & \\
\hline & & $\begin{array}{l}1 \text { a } 3 \\
\text { veces }\end{array}$ & $\begin{array}{l}3 \text { a } 5 \\
\text { veces }\end{array}$ & $\begin{array}{l}6 \text { a } 8 \\
\text { veces }\end{array}$ & $\begin{array}{l}\text { Más de } 8 \\
\text { veces }\end{array}$ \\
\hline & LLM & 9 & 5 & & \\
\hline & MZO & 19 & 6 & 9 & \\
\hline & CR & 11 & 3 & 1 & \\
\hline & RH & 10 & 2 & & \\
\hline & TOTAL & 49 & 16 & 10 & 0 \\
\hline
\end{tabular}

19 En el lavado de la loza en su casa se acostumbra a

\begin{tabular}{|l|l|l|l|l|l|}
\hline Promedios & LLM & MZO & CR & RH & TOTAL \\
\hline $\begin{array}{l}\text { Lavar cada vez que se usa algún } \\
\text { utensilio }\end{array}$ & & 6 & 3 & 3 & 12 \\
\hline Lavar la loza después de cada comida & 15 & 24 & 8 & 14 & 61 \\
\hline $\begin{array}{l}\text { Acumular la loza del día y hacer una } \\
\text { sola lavada }\end{array}$ & 2 & 4 & 7 & 2 & 15 \\
\hline
\end{tabular}

\section{En el lavado de dientes en su casa}

\begin{tabular}{|l|l|l|l|l|l|l|l|}
\hline \multicolumn{1}{|l|}{ Promedios } & LLM & MZO & \multicolumn{1}{l|}{ CR } & \multicolumn{2}{l|}{ RH } & \multicolumn{1}{l|}{ TOTAL } \\
\hline $\begin{array}{l}\text { Abren la lleva del agua cada vez para enjuagarse la boca } \\
\text { y lavar el cepillo }\end{array}$ & & 3 & 16 & 31 & 4 & 5 & 56 \\
\hline $\begin{array}{l}\text { Mantienen la llave abierta del agua mientras se cepillan, } \\
\text { se enjuagan la boca y lavan el cepillo }\end{array}$ & 1 & & & & & 28 \\
\hline
\end{tabular}

\section{Para realizar el aseo de los pisos en su casa}

\begin{tabular}{|l|l|l|l|l|l|l|}
\hline \multicolumn{1}{|l|}{ Promedios } & LLM & MZO & \multicolumn{1}{l|}{ CR } & \multicolumn{2}{l|}{ RH } & TOTAL \\
\hline $\begin{array}{l}\text { Llenan un balde con suficiente agua y la riegan por todos } \\
\text { lados tanto para enjabonar como para enjuagar }\end{array}$ & & 2 & 5 & 7 & 14 \\
\hline $\begin{array}{l}\text { Recogen en un balde agua para ir enjuagando el trapero } \\
\text { cada vez que sea necesario }\end{array}$ & 17 & 31 & 12 & 11 & 71 \\
\hline $\begin{array}{l}\text { Dejan salir agua indiscriminadamente de alguna llave } \\
\text { para mojar los pisos }\end{array}$ & & 1 & & 1 & 2 \\
\hline
\end{tabular}


22 En el momento de ducharse

\begin{tabular}{|l|l|l|l|l|l|l|}
\hline & LLM & MZO & CR & \multicolumn{2}{l|}{ RH } & TOTAL \\
\hline $\begin{array}{l}\text { Mantienen la llave del agua abierta } \\
\text { mientras se enjabonan }\end{array}$ & & 4 & 2 & & 6 \\
\hline Cierran la llave mientras se enjabonan & 5 & 29 & 14 & 15 & 63 \\
\hline $\begin{array}{l}\text { Abren la llave del agua únicamente cuando } \\
\text { es necesario }\end{array}$ & 12 & 1 & 2 & 4 & 19 \\
\hline
\end{tabular}

\section{Usted:}

\begin{tabular}{|l|l|l|l|l|l|}
\hline & LLM & MZO & CR & RH & TOTAL \\
\hline $\begin{array}{l}\text { Participa en campañas ambientales dentro o } \\
\text { fuera de la institución }\end{array}$ & 11 & 26 & 14 & 11 & 62 \\
\hline $\begin{array}{l}\text { Incentiva la realización de campañas } \\
\text { ambientales en su comunidad }\end{array}$ & 4 & & 2 & 2 & 8 \\
\hline $\begin{array}{l}\text { Incentiva campañas ambientales dentro de } \\
\text { la institución educativa }\end{array}$ & 3 & 8 & 5 & 8 & 24 \\
\hline
\end{tabular}

Qué actividades ambientales como miembro del CAE promociona dentro de la institución educativa (señale)

\begin{tabular}{|l|l|l|l|l|l|}
\cline { 5 - 7 } Promedios & LLM & MZO & CR & RH & TOTAL \\
\hline Conferencias & 1 & 2 & 3 & 0 & 6 \\
\hline Celebración fechas ambientales & 7 & 14 & 11 & 8 & 40 \\
\hline Capacitación a docentes & 2 & 4 & 1 & 4 & 11 \\
\hline Capacitación a estudiantes & 1 & 6 & 3 & 5 & 15 \\
\hline Capacitación a vigías & 3 & 3 & 5 & 2 & 13 \\
\hline Capacitación a padres & & 5 & 2 & 0 & 7 \\
\hline Otras & & & 3 & & 3 \\
\hline
\end{tabular}

\section{Asiste a caminatas o salidas ambientales y ecológicas}

\begin{tabular}{|l|l|l|} 
& SI & NO \\
\hline LLM & 17 & \\
\hline MZO & 34 & \\
\hline CR & 19 & 7 \\
\hline RH & 7 & 12 \\
\hline TOTAL & 77 & 19 \\
\hline
\end{tabular}

\section{$26 \quad$ Realiza auto capacitaciones sobre temas ambientales}

\begin{tabular}{|l|l|l|} 
& SI & NO \\
\hline LLM & 17 & \\
\hline MZO & 24 & 10 \\
\hline CR & 2 & 14 \\
\hline RH & 4 & 15 \\
\hline TOTAL & 47 & 39 \\
\hline
\end{tabular}


27 Genera espacios de concientización con los miembros de su familia

\begin{tabular}{|l|l|l|} 
& SI & NO \\
\hline LLM & 17 & \\
\hline MZO & 28 & 6 \\
\hline CR & 8 & 8 \\
\hline RH & 16 & 3 \\
\hline TOTAL & 69 & 17 \\
\hline
\end{tabular}

28

Genera espacios de concientización con los miembros de su comunidad

\begin{tabular}{|l|l|l|} 
& SI & NO \\
\hline LLM & 17 & \\
\hline MZO & 11 & 23 \\
\hline CR & 2 & 13 \\
\hline RH & 5 & 14 \\
\hline TOTAL & 35 & 50 \\
\hline
\end{tabular}




\section{Anexo 4. Rejillas de Seguimiento de Conductas proambientales.}

\begin{tabular}{|c|c|c|c|c|c|c|}
\hline \multirow{2}{*}{$233 / 2017$} & \multicolumn{6}{|c|}{ rejilla para trabajar con estudiartes y pares. ENCUENTRO.docx - Documentoe de Google } \\
\hline & \multicolumn{6}{|c|}{$\begin{array}{l}\text { INSTITUCION EDUCATIVA LUIS LÓPEZ DE MESA } \\
\text { LOCALIDAD SÉPTIMA DE BOSA }\end{array}$} \\
\hline \multicolumn{7}{|c|}{$\begin{array}{l}\text { SEGUIMIENTO DE CONDUCTAS PROAMBIENTALES DESDE LO } \\
\text { DEL AGUA. }\end{array}$} \\
\hline \multicolumn{7}{|c|}{ Nombre del Estudiante_Anni Giseth Ruiz cifuentes } \\
\hline \multicolumn{7}{|l|}{ Nombre del padre de familia } \\
\hline \multicolumn{7}{|l|}{ Dirección de la residencia: } \\
\hline \multicolumn{7}{|l|}{ Estrato: $\quad 2$} \\
\hline \multicolumn{7}{|c|}{ Cuántas personas viven en la vivienda: 10 . Con quien (s) vive: mama douela } \\
\hline \multirow{2}{*}{ ACCIONES CON EL. USO DEL AGUA. } & \multicolumn{3}{|c|}{ Padres } & \multicolumn{3}{|c|}{ Estudiante } \\
\hline & Nunca & $\begin{array}{c}\text { Algunas } \\
\text { wecer }\end{array}$ & Siempre & Nuncu & $\begin{array}{c}\text { Algunas } \\
\text { veces }\end{array}$ & Siempre \\
\hline Cerrar la llave al cepillarse & & & X & & & $x$ \\
\hline Dejar corre el agua, cuando se ducha & $x$ & & 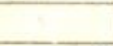 & & & $x$ \\
\hline Tomar duchas mas largas & $x^{\prime}$ & & & & $x$ & \\
\hline $\begin{array}{l}\text { Olvidarse de cerrar el agua del lavamanos, } \\
\text { laviplatos o lavadero, después de usarla }\end{array}$ & X & & & & $x$ & \\
\hline Reutilizar el agua de la lavadora & & & $x$ & & & $x$ \\
\hline Recolectar agua lluvia & & $x$ & & $x$ & & \\
\hline Reutilizar el agua (llavia, ducha) & & & $x$ & & & $x$ \\
\hline $\begin{array}{l}\text { Dejar corret el agua, cuando lava ropa a } \\
\text { mano }\end{array}$ & & & & $x$ & & $!$ \\
\hline Dejar correr el agua, cuando lava la lora & & $x$ & & $x$ & & \\
\hline $\begin{array}{l}\text { Cambia de actitud, frente al consumo del } \\
\text { agua, después de revisar su factura de } \\
\text { pago? }\end{array}$ & 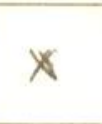 & & & & & \\
\hline $\begin{array}{l}\text { Afecta su háhito de uso del agua, la } \\
\text { publicidad de todos los medio, que sugiere } \\
\text { hacer un uso udecuado del agua. }\end{array}$ & & & & & & \\
\hline $\begin{array}{l}\text { Los hábitos que usted (s), tiene an casa } \\
\text { fiente al uho del agua, los proyecta en otros } \\
\text { sitios? (colegio, centros comerciales, } \\
\text { viviendas de fimiliares y amigos. }\end{array}$ & & & & & & \\
\hline
\end{tabular}

Qué acciones y con qué frecuencia realizan ustedes en sus hogares las diferentes acciones que aparecen en el cuadro,

relacionadas con el uso y manejo del agua? 


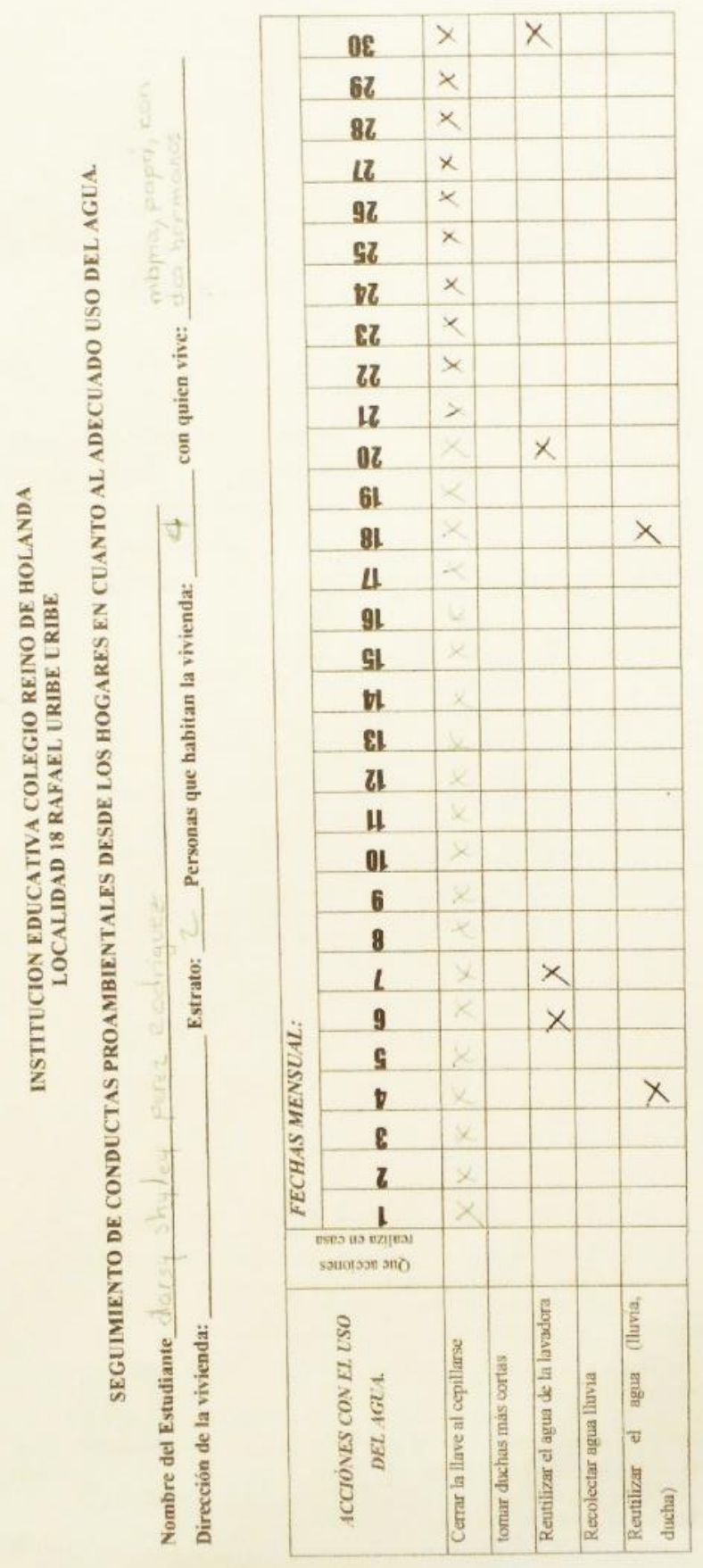


INSTITUCION EDUCATIVA MANUEL ZAPATA OLIVELLA

LOCALIDAD OCTAVA DE KENNEDY

SEGUIMIENTO DE CONDUCTAS PROAMBIENTALES DESDE LOS HOGARES EN CUANTO AL ADECUADO USO DEL AGUA.

Nombre del Estudiante. Marlon Zahir Galindo

Nombre del padre de familia Albo Didz

Dirección de la residencia. ( $\mathrm{r} 85$ d 36 b 55 sur

Estrato: 2

Cuàntas personas viven en la vivienda: 4 Con quien (s) vive: mamá, PaPa, hermana y yo.

\begin{tabular}{|c|c|c|c|c|c|c|}
\hline \multirow{2}{*}{ ACCIONES CON EL USO DEL.AGU.A. } & \multicolumn{3}{|c|}{ Padres } & \multicolumn{3}{|c|}{ Estudiante } \\
\hline & Nunca & $\begin{array}{c}\text { Algunas } \\
\text { weces }\end{array}$ & Sicmpre & Nunca & $\begin{array}{l}\text { Algunas } \\
\text { veres }\end{array}$ & Siemper \\
\hline Cerrar la llave al cepillarse & & & $x$ & & & \\
\hline Dejar correr el agua cuando se ducha & $x$ & & & & & \\
\hline Tomar duchas mass largas & $x$ & & & & & \\
\hline $\begin{array}{l}\text { Olvidarse de cerrat el agua del lavamanos, } \\
\text { lavaplatos o lavadero, despues de usarla }\end{array}$ & $X$ & & & & & \\
\hline Reutilizar el agua de la lavadora & & & $x$ & & $x$ & \\
\hline Recolectar agua lluvia & $X$ & & & & 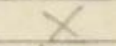 & \\
\hline Reutilizar el agua (lluvia, ducha) & & & $A$ & & X & \\
\hline $\begin{array}{l}\text { Dejar correr el agua, cuando lava ropa a } \\
\text { mano }\end{array}$ & & & & & & \\
\hline Dejar correr el agua, cuando lava la loza & $x$ & & ' & $x$ & & \\
\hline $\begin{array}{l}\text { Cambia de actitud, frente al consumo del } \\
\text { agua, despucs de revisar su factura de } \\
\text { pago? }\end{array}$ & & & & & & \\
\hline $\begin{array}{l}\text { Afecta su hábito de uso del agua. la } \\
\text { publicidad de todos los medio, que sugiere } \\
\text { hacer un uso adecuado del agua. }\end{array}$ & & & & & & \\
\hline $\begin{array}{l}\text { Los habitos que usted (\$), tiene en casa } \\
\text { frente al uso del agua, los proyecta en otros } \\
\text { sitios? (colegio, centros comerciales, } \\
\text { viviendas de familiares y amigos. }\end{array}$ & & & & & & \\
\hline
\end{tabular}

Qué acciones y con qué frecuencia realizan ustedes en sus hogares las diferentes acciones que aparecen en el cuadro, relacionadas con el uso y manejo del agua? 
Anexo 5A. Diagnósticos PRAE de las cuatro instituciones educativas.

Instrumento de Evaluación PRAE (Adaptado de Instrumento de evaluación de PRAE de la Secretaría de Educación Distrital).

\begin{tabular}{|c|c|}
\hline \multicolumn{2}{|c|}{ INFORMACIÓN GENERAL DEL ESTABLECIMIENTO EDUCATIVO } \\
\hline Nombre del establecimiento educativo & I.E.D. LUIS LÓPEZ DE MESA \\
\hline Dirección & DIRECCIÓN CALLE 65 H N. 78 A 03 \\
\hline Teléfono & 7750440 \\
\hline UPZ & BOSA CENTRAL \\
\hline Barrio & BOSA LA AMISTAD \\
\hline \multicolumn{2}{|l|}{ Código DANE } \\
\hline Nombre del Rector & LUCY ZAMORA DE GARCÍA \\
\hline Teléfono del Rector & 3204706936 \\
\hline E-mail & cedluislopezdemes7@redp.edu.co \\
\hline Nombre del responsable del PRAE & SONIA MONTERO \\
\hline Teléfono responsable del PRAE & 3123134914 \\
\hline E-mail & sonia725mc@hotmail.com \\
\hline Localidad & SÉPTIMA \\
\hline Cargo del responsable del PRAE & PROFESORA DE CIENCIAS NATURALES \\
\hline Preescolar & NO HAY \\
\hline Primaria & $\begin{array}{c}\text { NO HAY } \\
\text { DORIS ROCHA }\end{array}$ \\
\hline Secundaria y Media & $\begin{array}{l}\text { JHON JAIRO, WILLIAM } \\
\text { MATIZ, SONIA, Ma EUGENIA }\end{array}$ \\
\hline Total de docentes & 4 \\
\hline Directivos docentes & Ma DEL PILAR CAICEDO \\
\hline Administrativos & NO HAY \\
\hline Personas de servicios generales & NO HAY \\
\hline
\end{tabular}




\begin{tabular}{|c|c|c|}
\hline \multicolumn{2}{|l|}{ Énfasis del PEI } & COMUNICACIÓN \\
\hline \multicolumn{2}{|c|}{ Enfoque pedagógico que orienta el PEI } & $\begin{array}{l}\text { DOCUMENTAL-DESCRIPTIVO } \\
\text { PEDAGOGICO }\end{array}$ \\
\hline \multicolumn{2}{|c|}{ Estimado de población educativa que habita en la localidad } & $85 \%$ \\
\hline \multicolumn{2}{|c|}{ *¿Reconoce el territorio ambiental en el que se encuentra inmersa la institución? } & sí \\
\hline \multicolumn{2}{|l|}{ Territorio Ambiental } & HUMEDAL, RÍO TUNJUELITO \\
\hline \multicolumn{3}{|c|}{ 2. EL PRAE, UN PROYECTO DE INVESTIGACIÓN } \\
\hline ¿SU PEI incluye un PRAE? & \multicolumn{2}{|c|}{ sí } \\
\hline $\begin{array}{c}\text { ¿En qué nivel de desarrollo se encuentra el PRAE de su } \\
\text { institución? }\end{array}$ & \multicolumn{2}{|c|}{ FASE DE EJECUCIÓN } \\
\hline ¿Cuál es el título del PRAE? & \multicolumn{2}{|c|}{$\begin{array}{l}\text { HACIA UNA EDUCACIÓN AMBIENTAL EN EL } \\
\text { MANEJO DE RESIDUOS SÓLIDOS PARA LOGRAR } \\
\text { UN CAMBIO DE ACTITUD HACIA EL HUMEDAL } \\
\text { TIBANICA EN EL COLEGIO LUIS LÓPEZ DE } \\
\text { MESA. }\end{array}$} \\
\hline \multicolumn{3}{|c|}{ 3. PROBLEMATIZACIÓN } \\
\hline $\begin{array}{c}\text { ¿Cuál es el problema de investigación que aborda el } \\
\text { PRAE? }\end{array}$ & \multicolumn{2}{|c|}{ Manejo de Residuos Sólidos } \\
\hline $\begin{array}{l}\text { La formulación del PRAE en la institución obedece } \\
\text { principalmente a: }\end{array}$ & \multicolumn{2}{|c|}{$\begin{array}{l}\text { Falta de conocimientos y concientización para el manejo } \\
\text { y utilización apropiada de los recursos naturales. }\end{array}$} \\
\hline $\begin{array}{c}\text { ¿Cuál o cuáles diagnósticos ambientales fueron tenidos en } \\
\text { cuenta para la elaboración del PRAE? }\end{array}$ & \multicolumn{2}{|c|}{$\begin{array}{l}\text { 1. Disposición inadecuada de residuos sólidos } \\
\text { 2. Contaminación de los ríos Bogotá y Tunjuelito } \\
\text { 3. Grave deterioro de los humedales la Tibanica y } \\
\text { Campo Verde } \\
\text { 4. Invasión de rondas e inundaciones } \\
\text { 5. Contaminación atmosférica por industrias y } \\
\text { fuentes móviles (buses servicio público) }\end{array}$} \\
\hline $\begin{array}{l}\text { ¿En cuál de las siguientes categorías se puede incluir el } \\
\text { problema de investigación del PRAE de su Institución? }\end{array}$ & \multicolumn{2}{|c|}{$\begin{array}{l}\checkmark \quad \text { Cultura ambiental } \\
\checkmark \quad \text { Actitudes y comportamientos pro-ambientales }\end{array}$} \\
\hline $\begin{array}{l}\text { ¿En cuál o cuáles problemáticas ambientales de la } \\
\text { localidad, se centra el PRAE? }\end{array}$ & \multicolumn{2}{|c|}{$\begin{array}{ll}\checkmark & \text { FALTA DE ACCIONES QUE LOGREN CAMBIAR LAS } \\
& \text { ACTITUDES Y COMPORTAMIENTOS HACIA EL MANEJO DE } \\
& \text { LOS RESIDUOS SOLIDOS. } \\
\checkmark & \text { FALTA DE APROPIACION DEL TERRITORIO DEL HUMEDAL } \\
\checkmark & \text { DE TIBANICA } \\
\checkmark & \text { FALTAN ESPACIOS DE PARTICIPACION EN EL HUMEDAL } \\
\checkmark & \text { FALTA QUE LOS ENTES ADMINISTRATIVOS PARTICIPEN } \\
& \text { DE LOS ESPACIOS PEDAGOGICOS }\end{array}$} \\
\hline
\end{tabular}




\begin{tabular}{|c|c|}
\hline $\begin{array}{c}\text { ¿Qué instrumentos fueron utilizados para identificar el } \\
\text { problema de investigación del PRAE? }\end{array}$ & DIARIOS DE CAMPO, CUESTIONARIOS, ENTREVISTAS. \\
\hline \multicolumn{2}{|c|}{ 4. OBJETIVOS } \\
\hline $\begin{array}{l}\text { ¿Cuáles son los objetivos generales propuestos para el } \\
\text { PRAE? }\end{array}$ & $\begin{array}{l}\text { * Generar un cambio de comportamiento y de actitud de los } \\
\text { ciudadanos (docentes-estudiantes- padres de familia...) frente } \\
\text { su entorno, a través de la toma de conciencia, de la interrelación } \\
\text { de los problemas ambiéntales como la salubridad, la higiene, el } \\
\text { buen uso de los servicios básicos, el manejo de los residuos } \\
\text { sólidos en cada actividad cotidiana. }\end{array}$ \\
\hline $\begin{array}{c}\text { ¿Cuáles son los objetivos específicos propuestos para el } \\
\text { PRAE? }\end{array}$ & $\begin{array}{l}\text { Reconocer las problemáticas ambientales de la localidad } \\
\text { séptima relacionadas con el rio Bogotá, rio Tunjuelito, } \\
\text { humedal tibanica y Campo verde durante el año lectivo } \\
\text { Dar a conocer a la comunidad educativa en general las } \\
\text { problemáticas identificadas a través del grupo ecológico, } \\
\text { relacionadas con invasión de rondas e inundaciones durante el } \\
\text { año lectivo } \\
\text { Participar en la construcción de redes ambientales locales } \\
\text { encaminadas a la conservación del humedal de Tibanica. } \\
\text { Sensibilizar, educar y movilizar a la comunidad educativa en } \\
\text { general para lograr que en su práctica cotidiana, protejan su } \\
\text { derecho a un ambiente sano y cumplan con sus deberes para } \\
\text { conservarlo. } \\
\text { Desarrollar la creatividad de los estudiantes mediante la } \\
\text { reutilización de los residuos sólidos en cada actividad diaria. }\end{array}$ \\
\hline $\begin{array}{l}\text { ¿En que aspectos centran la atención los objetivos del } \\
\text { PRAE? }\end{array}$ & $\begin{array}{l}\text { Los objetivos del PRAE, centran la atención en los } \\
\text { cambios de comportamientos y actitudes hacia el } \\
\text { buen uso, gestión y manejo de recursos naturales } \\
\text { como el agua, energía, manejo de recursos sólidos. }\end{array}$ \\
\hline $\begin{array}{c}\text { ¿Cuál es el alcance de los objetivos planteados en el } \\
\text { PRAE? }\end{array}$ & $\begin{array}{c}\text { El alcance de los objetivos planteados en el PRAE, están } \\
\text { condicionados a la aplicación y colaboración de los } \\
\text { participantes de la comunidad educativa, como el } \\
\text { seguimiento y ejecución por parte de los que lideran } \\
\text { dicho proyecto. }\end{array}$ \\
\hline $\begin{array}{l}\text { ¿Cuál o cuáles de los siguientes documentos fueron } \\
\text { consultados como marco de referencia del PRAE? }\end{array}$ & $\begin{array}{l}\text { La Nueva Constitución Política de Colombia de 1991, a través de } \\
\text { la Descentralización político-administrativa y, su intención, } \\
\text { traducida en leyes orgánicas como la Ley } 99 \text { de Diciembre de } \\
\text { 1993, la Ley de Plan de Desarrollo - Ley 152/94, la Ley de } \\
\text { Ordenamiento Territorial - Ley 388/97, en cuya } \\
\text { aplicación sobresale la disparidad de enfoques, conceptos, } \\
\text { definiciones, diferencias en la capacidad institucional de los entes } \\
\text { planificadores territoriales, precaria investigación, reducida } \\
\text { socialización e insignificante participación ciudadana. } \\
\text { Por la situación anterior, surge con especial trascendencia la } \\
\text { Ley General de Educación (Ley 115/94), y sus respectivos } \\
\text { Decretos reglamentarios. }\end{array}$ \\
\hline $\begin{array}{l}\text { ¿Cuáles de los siguientes principios rectores para la } \\
\text { Educación Ambiental, se tienen en cuenta en el PRAE? }\end{array}$ & Los principios que están en los lineamientos según la SED \\
\hline
\end{tabular}


202

\begin{tabular}{|c|c|}
\hline $\begin{array}{l}\text { ¿Cuáles referentes fundamentan conceptualmente el } \\
\text { PRAE? }\end{array}$ & \\
\hline $\begin{array}{c}\text { ¿Desde el PRAE, que se entiende por Ambiente y } \\
\text { Educación Ambiental? }\end{array}$ & No se han establecido conceptualmente estos aspectos. \\
\hline \multicolumn{2}{|c|}{ 6. METODOLOGÍA } \\
\hline $\begin{array}{c}\text { ¿A qué tipo de investigación responde la metodología } \\
\text { desarrollada en el PRAE de su institución? }\end{array}$ & Descriptiva \\
\hline $\begin{array}{l}\text { ¿Cuáles son las principales actividades, en los dos últimos } \\
\text { años, que se han liderado desde el PRAE en su institución? }\end{array}$ & El reciclaje, basura cero \\
\hline $\begin{array}{c}\text { ¿EI PRAE cuenta con un cronograma que oriente el } \\
\text { desarrollo de las actividades? }\end{array}$ & Si, el que se encuentra en el POA \\
\hline $\begin{array}{l}\text { ¿Qué periodicidad tiene el cronograma propuesto en el } \\
\text { PRAE? }\end{array}$ & $\begin{array}{l}\text { ANUAL Y ALGUNAS ACTIVIDADES COMO RECOLECCION } \\
\text { DE RESIDUOS SÓLIDOS SON DIARIAMENTE }\end{array}$ \\
\hline ¿A qué obedece la ejecución del PRAE? & $\begin{array}{l}\text { A LOS LINEAMIENTOS DE LA SECRETARIA DE EDUCACION } \\
\text { Y A LOS INTERESES PARTICULARES DE LA INSTITUCION }\end{array}$ \\
\hline ¿Cuál es el tiempo destinado para la planeación del PRAE? & NO HAY \\
\hline ¿Con qué frecuencia se reúnen los integrantes del PRAE? & $\begin{array}{l}\text { UN MIERCOLES CADA VEINTE DÍAS SEGÚN CONOGRAMA } \\
\text { INSTITUCIONAL }\end{array}$ \\
\hline ¿Qué dificultades limitan el desarrollo del PRAE? & $\begin{array}{c}\text { LOS DOCENTES NO TIENEN TIEMPO DISPONIBLE PARA } \\
\text { REALIZAR LAS REUNIONES FALTA UNIFICACION DE } \\
\text { HORARIOS }\end{array}$ \\
\hline $\begin{array}{c}\text { ¿Cuáles son los mecanismos de participación que } \\
\text { contempla el PRAE? }\end{array}$ & $\begin{array}{c}\text { ELECCION DE LOS REPRESENTANTES DE CADA CURSO Y } \\
\text { ELECCION DE PADRES DE FAMILIA Y DE DOCENTES DE } \\
\text { CADA ÁREA TODO DEMOCRATICAMENTE }\end{array}$ \\
\hline $\begin{array}{l}\text { ¿Cuáles son las fortalezas que tiene el PRAE de su } \\
\text { institución? }\end{array}$ & $\begin{array}{l}\text { LA CULTURA DEL CUIDADO Y CONSERVACION DEL } \\
\text { ENTORNO Y PACTO POR EL TESORO. }\end{array}$ \\
\hline En el desarrollo del PRAE, la Institución cuenta con: & $\begin{array}{l}\text { POSEE INFRAESTRUCTURA UE FACILITA LA APROPIACION } \\
\text { DE LA CULTURA AMBIENTAL. }\end{array}$ \\
\hline \multicolumn{2}{|c|}{ 7. ACTORES Y PARTICIPACIÓN } \\
\hline $\begin{array}{l}\text { ¿La Institución cuenta con un Comité Ambiental Escolar - } \\
\text { CAE? }\end{array}$ & Sí \\
\hline $\begin{array}{l}\text { ¿Cuál fue el proceso llevado a cabo para la conformación } \\
\text { del CAE? }\end{array}$ & $\begin{array}{l}\text { ELECCION DEMOCRATICA DE MONITORES EN CADA } \\
\text { CURSO, IGUAL DE PADRES Y DOCENTES. }\end{array}$ \\
\hline \multicolumn{2}{|c|}{ ¿Quiénes conforman el Comité Ambiental Escolar - CAE - en su institución? ¿Cuántos actores participan? } \\
\hline Directivos & 0 \\
\hline
\end{tabular}




\begin{tabular}{|c|c|c|}
\hline \multicolumn{2}{|l|}{ Administrativos } & 0 \\
\hline \multicolumn{2}{|l|}{ Padres de familia } & 8 \\
\hline \multicolumn{2}{|l|}{ Personas de servicio general } & 2 \\
\hline \multicolumn{2}{|l|}{ Egresados } & 0 \\
\hline \multicolumn{2}{|c|}{$\begin{array}{l}\text { Docentes en Ciencias Sociales, historia, geografía, constitución política, economía, } \\
\text { ciencia política y democracia }\end{array}$} & 2 \\
\hline \multicolumn{2}{|c|}{ Docentes en Ciencias Naturales y Educación Ambiental } & 2 \\
\hline \multicolumn{2}{|c|}{ Docentes en Educación Artística y cultural } & 2 \\
\hline \multicolumn{2}{|c|}{ Docentes en Educación en ética y valores humanos } & 0 \\
\hline \multicolumn{2}{|c|}{ Docentes En educación Física, recreación y deporte } & 0 \\
\hline \multicolumn{2}{|l|}{ Docentes en Educación religiosa } & 0 \\
\hline \multicolumn{2}{|c|}{ Docentes en Humanidades, lengua castellana e idioma extranjero } & 2 \\
\hline \multicolumn{2}{|l|}{ Docentes en Matemáticas } & 1 \\
\hline \multicolumn{2}{|l|}{ Docentes en tecnología e informática } & 0 \\
\hline \multicolumn{2}{|l|}{ Estudiantes de Preescolar } & 0 \\
\hline \multicolumn{2}{|l|}{ Estudiantes de básica primaria } & 30 \\
\hline \multicolumn{2}{|l|}{ Estudiantes de básica secundaria } & 28 \\
\hline \multicolumn{2}{|l|}{ Estudiantes de Media Vocacional } & 12 \\
\hline ¿Con qué instancia(s) de la institución se relaciona el CAE? & \multicolumn{2}{|c|}{ COORDINACION ACADÉMICA Y CONVIVENCIAL } \\
\hline $\begin{array}{l}\text { ¿Cuál es el tiempo de permanencia de los integrantes del } \\
\text { CAE? }\end{array}$ & \multicolumn{2}{|c|}{ UN AÑO } \\
\hline $\begin{array}{l}\text { ¿Qué considera respecto al tiempo de permanencia de los } \\
\text { miembros que conforman el CAE? }\end{array}$ & \multicolumn{2}{|c|}{$\begin{array}{l}\text { LOS MIEMBROS QUE CONFORMAN EL CAE } \\
\text { GENERALMENTE QUIEREN SEGUIR EL SIGUIENTE AÑO }\end{array}$} \\
\hline $\begin{array}{l}\text { ¿Cuáles son las estrategias para la comunicación entre los } \\
\text { miembros del CAE y la Comunidad Educativa? }\end{array}$ & \multicolumn{2}{|c|}{ USO DE MEDIOS ELECTRÓNICOS Y CIRCULARES } \\
\hline $\begin{array}{l}\text { ¿Qué factores dificultan los procesos participativos del } \\
\text { CAE? }\end{array}$ & \multicolumn{2}{|c|}{$\begin{array}{c}\text { PROBLEMAS DE INTERFERENCIA DE COMUNICACIÓN Y } \\
\text { PARTICIPACION ACTIVA DE LA COMUNIDAD EXTERNA AL } \\
\text { COLEGIO }\end{array}$} \\
\hline $\begin{array}{l}\text { ¿Cuáles espacios físicos facilitan la participación de los } \\
\text { miembros del CAE? }\end{array}$ & \multicolumn{2}{|c|}{ SALONES DE CLASE, SALA DE PROFESORES, PATIOS } \\
\hline
\end{tabular}




\begin{tabular}{|c|c|}
\hline ¿En qué tiempo se reúne el CAE? & $\begin{array}{l}\text { LOS VIERNES CADA QUINCE DIAS SEGÚN CRONOGRAMA } \\
\text { INSTITUCIONAL }\end{array}$ \\
\hline \multicolumn{2}{|c|}{ Identifique que Actores Sociales han apoyado o apoyan el PRAE y su nivel de participación. } \\
\hline Estudiantes & DIARIA \\
\hline Docentes de ciencias naturales & DIARIA \\
\hline Docentes de otras áreas & DIARIA \\
\hline Padres de familia o acudientes & SEMESTRAL \\
\hline Egresados & NO \\
\hline Directivos & NINGUNA \\
\hline Coordinadores & NINGUNA \\
\hline Administradores escolares & NO \\
\hline Personas de servicios generales & DIARIA \\
\hline Comité ambiental escolar CAE & DIARIA \\
\hline Sector productivo & NO \\
\hline Comité local de Educación Ambiental & NO \\
\hline Gestores ambientales locales & NO \\
\hline Junta de acción comunal JAC & NO \\
\hline Organizaciones no gubernamentales ONG & FUNDACIÓN SANAR \\
\hline Otros & NO \\
\hline \multicolumn{2}{|c|}{ Identifique que Actores Institucionales han apoyado o apoyan el PRAE y su nivel de participación } \\
\hline Ministerio de educación nacional MEN & NO \\
\hline Secretaria de Educación Distrital SED & SEMESTRALMENTE \\
\hline Secretaria Distrital de Ambiente & SEMESTRAL \\
\hline Jardín Botánico José Celestino Mutis & SEMESTRAL \\
\hline Ministerio de Ambiente, Vivienda y Desarrollo Territorial & NO \\
\hline Secretaria de Hábitat & NO \\
\hline Alcaldía mayor & NO \\
\hline
\end{tabular}




\begin{tabular}{|c|c|c|}
\hline \multicolumn{2}{|l|}{ Alcaldías locales } & NO \\
\hline \multicolumn{2}{|l|}{ Unidades ejecutivas locales UEL } & NO \\
\hline \multicolumn{2}{|c|}{$\begin{array}{l}\text { Unidad Administrativa Especial del Sistema de Parques Nacionales } \\
\qquad \text { Naturales }\end{array}$} & NO \\
\hline \multicolumn{2}{|c|}{ Unidades Ambientales de los Grandes Centros Urbanos } & NO \\
\hline \multicolumn{2}{|l|}{ Institutos de Investigación Ambiental } & NO \\
\hline \multicolumn{2}{|l|}{ Policía Ecológica } & NO \\
\hline \multicolumn{2}{|c|}{ Unidades locales de Administración Técnica Agropecuaria y Ambiental } & NO \\
\hline \multicolumn{2}{|l|}{ Secretaria de salud } & NO \\
\hline \multicolumn{2}{|l|}{ Universidades públicas } & NO \\
\hline \multicolumn{2}{|l|}{ Universidades privadas } & NO \\
\hline \multicolumn{2}{|l|}{ Otras } & NO \\
\hline \multicolumn{3}{|c|}{ 8. RECURSOS Y PRESUPUESTO } \\
\hline ¿Con qué recursos cuenta el desarrollo del PRAE? & \multicolumn{2}{|c|}{$\begin{array}{l}\text { ECONÓMICOS, HUMANOS, TECNOLÓGICOS, } \\
\text { INFRAESTRUCTURA }\end{array}$} \\
\hline $\begin{array}{c}\text { ¿A través de qué mecanismos se han obtenido los } \\
\text { recursos para el desarrollo } \\
\text { del PRAE? }\end{array}$ & \multicolumn{2}{|c|}{$\begin{array}{c}\text { DE LOS DINERSO QUE DESTINA LA Secretaria de } \\
\text { Educación, dirigido por la pagadora con el aval de la } \\
\text { rectora }\end{array}$} \\
\hline $\begin{array}{l}\text { ¿Cuenta EI PRAE con un presupuesto para su } \\
\text { financiación? }\end{array}$ & & \\
\hline ¿Cuál es la asignación presupuestal para el PRAE por año? & & \\
\hline \multicolumn{3}{|c|}{ 9. EVALUACIÓN Y SEGUIMIENTO } \\
\hline $\begin{array}{l}\text { ¿Qué actor o actores participan en la evaluación del } \\
\text { PRAE? }\end{array}$ & \multicolumn{2}{|c|}{ LA COMUNIDAD EDUCATIVA } \\
\hline ¿Con qué frecuencia se evalúa el PRAE? & \multicolumn{2}{|c|}{ ANUALMENTE } \\
\hline $\begin{array}{c}\text { ¿Cuáles son los mecanismos Externos de evaluación y } \\
\text { seguimiento del PRAE? }\end{array}$ & \multicolumn{2}{|c|}{$\begin{array}{l}\text { GESTION DE PIGA QUE ES LA QUE EVALUA LA } \\
\text { ISTITUCION HACIA LA SECRETARIA DE EDUCACION }\end{array}$} \\
\hline $\begin{array}{c}\text { ¿Cuáles son los mecanismos internos de evaluación y } \\
\text { seguimiento del PRAE? }\end{array}$ & \multicolumn{2}{|c|}{$\begin{array}{c}\text { FORMATO DE EVALUACION DE ACTIVIDADES REALIZADAS } \\
\text { EN CADA UNO DE LOS PROYECTOS }\end{array}$} \\
\hline $\begin{array}{c}\text { ¿A través de qué espacios o medios se comunican los } \\
\text { resultados del PRAE? }\end{array}$ & \multicolumn{2}{|c|}{ CRONOGRAMA INSTITUCIONAL } \\
\hline
\end{tabular}




\begin{tabular}{|c|c|c|c|c|c|c|c|}
\hline \multicolumn{4}{|c|}{ Los resultados derivados del PRAE se relacionan con } & \multicolumn{4}{|c|}{ EL PACTO CON EL TESORO } \\
\hline \multicolumn{4}{|c|}{ El impacto que tiene proyectado el desarrollo del PRAE es } & \multicolumn{4}{|c|}{$\begin{array}{l}\text { INCLUIR A LA COMUNIDAD EDUCATIVA EN LOS PROCESOS } \\
\text { RELACIONADAS CON LOS CINCO EJES TEMÁTICOS }\end{array}$} \\
\hline \multicolumn{8}{|c|}{ I10. EL PRAE- UN PROYECTO TRANSVERSAL E INTERDISCIPLINAR } \\
\hline \multicolumn{4}{|c|}{$\begin{array}{l}\text { ¿EI PRAE, reconoce el principio de interdisciplinariedad } \\
\text { que orienta la educación ambiental? }\end{array}$} & \multicolumn{4}{|c|}{ sí } \\
\hline \multicolumn{4}{|c|}{$\begin{array}{l}\text { ¿De qué manera las áreas de conocimiento apoyan el } \\
\text { desarrollo del PRAE? }\end{array}$} & \multicolumn{4}{|c|}{$\begin{array}{l}\text { DESARROLLANDO ACTIVIDADES TRANSVERSALMENTE } \\
\text { DESDE LA HERRAMIENTA PARA LA VIDA }\end{array}$} \\
\hline \multicolumn{4}{|c|}{$\begin{array}{c}\text { ¿Qué resultados se han obtenido en relación con la } \\
\text { perspectiva interdisciplinar y la solución a los problemas } \\
\text { planteados en el PRAE? }\end{array}$} & \multicolumn{4}{|c|}{$\begin{array}{l}\text { Todas las áreas están aportando desde su disciplina a } \\
\text { fomentar el buen uso de los recursos. }\end{array}$} \\
\hline \multicolumn{8}{|c|}{ 11. EL PRAE- COMPONENTES CURRICULARES } \\
\hline \multicolumn{4}{|c|}{$\begin{array}{c}\text { ¿EI PRAE incide o se relaciona con otros proyectos } \\
\text { curriculares? Sí } \\
\text { su respuesta es negativa justifique su respuesta }\end{array}$} & \multicolumn{4}{|c|}{ SI, EL PROYECTO DE AGRICULTURA URBANA } \\
\hline \multicolumn{4}{|c|}{$\begin{array}{l}\text { ¿A través de qué estrategias se ha incluido la dimensión } \\
\text { ambiental en el contexto escolar? }\end{array}$} & \multicolumn{4}{|c|}{$\begin{array}{c}\text { CHARLAS, CONFERENCIAS, ACTIVIDADES PRÁCTICAS } \\
\text { COMO FOROS, CINEFOROS, TALLERES, LECTURAS } \\
\text { CRÍTICAS }\end{array}$} \\
\hline \multicolumn{8}{|c|}{$\begin{array}{c}\text { Marque con una }(\mathrm{X}) \text { ¿Con cuál o cuáles de los componentes curriculares se relaciona el PRAE y en qué momento se } \\
\text { articula el Proyecto Ambiental Escolar con estos? }\end{array}$} \\
\hline & Formulación & Desarrollo & Fortalecir & hiento & Transformación & $\begin{array}{l}\text { Evaluación y } \\
\text { seguimiento }\end{array}$ & $\begin{array}{l}\text { No se } \\
\text { relaciona }\end{array}$ \\
\hline $\begin{array}{l}\text { Proyectos de } \\
\text { aula }\end{array}$ & & & & & & & $x$ \\
\hline $\begin{array}{l}\text { Proyectos de } \\
\text { área }\end{array}$ & & & $\mathrm{X}$ & & & & \\
\hline Plan de estudios & & & & & $\mathrm{X}$ & & \\
\hline \multicolumn{8}{|l|}{ Investigación } \\
\hline $\begin{array}{c}\text { Prácticas } \\
\text { pedagógicas }\end{array}$ & & & $x$ & & $x$ & & \\
\hline $\begin{array}{l}\text { Constitución e } \\
\text { instrucción cívica }\end{array}$ & & & & & & & $\mathrm{X}$ \\
\hline $\begin{array}{l}\text { Aprovechamient } \\
\text { o del tiempo } \\
\text { libre }\end{array}$ & & & & & & & $X$ \\
\hline
\end{tabular}




\begin{tabular}{|c|c|c|c|c|c|}
\hline $\begin{array}{c}\text { Enseñanza para } \\
\text { la protección del } \\
\text { ambiente }\end{array}$ & & & $x$ & $x$ & \\
\hline $\begin{array}{l}\text { Educación para } \\
\text { la justicia, la paz } \\
\text { y la democracia }\end{array}$ & $x$ & $x$ & & & \\
\hline $\begin{array}{l}\text { La educación } \\
\text { sexual }\end{array}$ & & & & & $x$ \\
\hline $\begin{array}{l}\text { Prevención y } \\
\text { gestión del } \\
\text { riesgo }\end{array}$ & & & $x$ & $x$ & \\
\hline & & & & & \\
\hline
\end{tabular}

Anexo 5B.

Instrumento de Evaluación PRAE (Adaptado de Instrumento de evaluación de PRAE de la Secretaría de Educación Distrital).

\begin{tabular}{|c|c|}
\hline \multicolumn{2}{|c|}{ INFORMACIÓN GENERAL DEL ESTABLECIMIENTO EDUCATIVO } \\
\hline Nombre del establecimiento educativo & I.E.D. MANUEL ZAPATA OLIVELLA \\
\hline Dirección & CALLE 1 BIS No. 87-84 \\
\hline Teléfono & 4512820 \\
\hline UPZ & 82 \\
\hline Barrio & PATIO BONITO II SECTOR \\
\hline Código DANE & 111001033898 \\
\hline Nombre del Rector & MARIA DEL PILAR TENJO PEÑUELA \\
\hline Teléfono del Rector & 3005642549 \\
\hline E-mail & patiobonitoii@yahoo.es \\
\hline Cargo del responsable del PRAE & ADRIANA MONTES FLOREZ \\
\hline Teléfono responsable del PRAE & 3124454584 \\
\hline E-mail & nanitazmf@hotmail.com \\
\hline Localidad & OCTAVA \\
\hline
\end{tabular}




\begin{tabular}{|c|c|c|}
\hline \multicolumn{2}{|l|}{ Preescolar } & NO HAY \\
\hline \multicolumn{2}{|l|}{ Primaria } & $\begin{array}{l}\text { ADRIANA MONTES } \\
\text { WALTER MENA }\end{array}$ \\
\hline \multicolumn{2}{|l|}{ Secundaria y Media } & $\begin{array}{l}\text { LYDA CASALLAS } \\
\text { SANDRA GONZALEZ }\end{array}$ \\
\hline \multicolumn{2}{|l|}{ Total de docentes } & 4 \\
\hline \multicolumn{2}{|l|}{ Directivos docentes } & $\begin{array}{l}\text { GUSTAVO MONROY } \\
\text { BEJARANO }\end{array}$ \\
\hline \multicolumn{2}{|l|}{ Administrativos } & NO HAY \\
\hline \multicolumn{2}{|l|}{ Personas de servicios generales } & NO HAY \\
\hline \multicolumn{2}{|l|}{ Énfasis del PEI } & $\begin{array}{l}\text { Solidaridad con } \\
\text { proyección empresarial }\end{array}$ \\
\hline \multicolumn{2}{|c|}{ Enfoque pedagógico que orienta el PEI } & $\begin{array}{l}\text { Social cognitivo y } \\
\text { aprendizaje significativo }\end{array}$ \\
\hline \multicolumn{2}{|c|}{ Estimado de población educativa que habita en la localidad } & $100 \%$ \\
\hline \multicolumn{2}{|c|}{$\begin{array}{c}\text { ¿¿Reconoce el territorio ambiental en el que se encuentra inmersa la } \\
\text { institución? }\end{array}$} & $\mathrm{Si}$ \\
\hline \multicolumn{2}{|l|}{ Territorio Ambiental } & $\begin{array}{l}\text { Humedales Vaca, Burro, } \\
\text { Techo, ríos Fucha y } \\
\text { Bogotá }\end{array}$ \\
\hline \multicolumn{3}{|c|}{ 2. EL PRAE, UN PROYECTO DE INVESTIGACIÓN } \\
\hline ¿SU PEI incluye un PRAE? & \multicolumn{2}{|c|}{ sí } \\
\hline $\begin{array}{l}\text { ¿En qué nivel de desarrollo se encuentra el PRAE de } \\
\text { su institución? }\end{array}$ & \multicolumn{2}{|c|}{ Fase de ejecución } \\
\hline ¿Cuál es el título del PRAE? & \multicolumn{2}{|c|}{$\begin{array}{l}\text { Herramienta pedagógica para el fortalecimiento del } \\
\text { sentido de pertenencia y la cultura ambiental en la } \\
\text { comunidad educativa del colegio Manuel Zapata } \\
\text { Olivella }\end{array}$} \\
\hline \multicolumn{3}{|c|}{ 3. PROBLEMATIZACIÓN } \\
\hline $\begin{array}{c}\text { ¿Cuál es el problema de investigación que aborda el } \\
\text { PRAE? }\end{array}$ & \multicolumn{2}{|c|}{$\begin{array}{c}\text { Manejo de Residuos Sólidos y cuidado del agua y la } \\
\text { energía }\end{array}$} \\
\hline
\end{tabular}




\begin{tabular}{|c|c|}
\hline $\begin{array}{l}\text { La formulación del PRAE en la institución obedece } \\
\text { principalmente a: }\end{array}$ & $\begin{array}{l}\text { Falta de conocimientos sobre el uso adecuado de } \\
\text { los recursos naturales. }\end{array}$ \\
\hline $\begin{array}{l}\text { ¿Cuál o cuáles diagnósticos ambientales fueron } \\
\text { tenidos en cuenta para la elaboración del PRAE? }\end{array}$ & $\begin{array}{l}\text { - Manejo inadecuad de residuos sólidos y las } \\
\text { basuras } \\
\text { - Contaminación de los ríos Fucha y Bogotá } \\
\text { - Deterioro ambiental que presentan los humedales } \\
\text { Vaca, Burro y Techo. } \\
\text { - Contaminación atmosférica por industrias y fuentes } \\
\text { móviles (alto flujo vehicular) }\end{array}$ \\
\hline $\begin{array}{c}\text { ¿En cuál de las siguientes categorías se puede } \\
\text { incluir el problema de investigación del PRAE de su } \\
\text { Institución? }\end{array}$ & $\begin{array}{ll}\text { - } & \text { Cultura ambiental } \\
\text { - } & \text { Conocimientos ambientales } \\
\text { - } & \text { Actitudes y comportamientos pro- } \\
& \text { ambientales } \\
\text { - } & \text { Socio cultural - biofísico } \\
\text { - } & \text { Cultura del reciclaje - Programa Basura Cero }\end{array}$ \\
\hline $\begin{array}{l}\text { ¿En cuál o cuáles problemáticas ambientales de la } \\
\text { localidad, se centra el PRAE? }\end{array}$ & $\begin{array}{ll}\text { - } & \text { Manejo de residuos sólidos. } \\
\text { - } & \text { Uso racional del recurso hídrico. } \\
\text { - } & \text { Huerta escolar. } \\
\text { - } & \text { Fortalecimiento de valores de respeto y } \\
& \text { tolerancia. } \\
\text { - } & \text { Uso adecuado de la energía } \\
\text { - } & \text { falta de apropiación del territorio de los } \\
\text { humedales burro, techo y vaca } \\
\text { - } \quad \text { poca presencia de entes administrativos } \\
\text { que participen en espacios pedagógicos y } \\
\text { culturales }\end{array}$ \\
\hline $\begin{array}{l}\text { ¿Qué instrumentos fueron utilizados para identificar } \\
\text { el problema de investigación del PRAE? }\end{array}$ & Diarios de campo y entrevistas. \\
\hline \multicolumn{2}{|c|}{ 4. OBJETIVOS } \\
\hline $\begin{array}{c}\text { ¿Cuáles son los objetivos generales propuestos para } \\
\text { el PRAE? }\end{array}$ & $\begin{array}{l}\text { Generar cambios de actitud en los estudiantes de la } \\
\text { I.E.D. MANUEL ZAPATA OLIVELLA frente al buen } \\
\text { uso de su entorno escolar y ambiental, que denote la } \\
\text { apropiación que tiene por el mismo. }\end{array}$ \\
\hline $\begin{array}{c}\text { ¿Cuáles son los objetivos específicos propuestos } \\
\text { para el PRAE? }\end{array}$ & $\begin{array}{l}\text { - Orientar a la comunidad educativa sobre la } \\
\text { importancia del adecuado manejo de los residuos } \\
\text { sólidos, mediante la separación del mismo y } \\
\text { posterior aprovechamiento. } \\
\text { - Contribuir al fortalecimiento de valores de respeto y } \\
\text { tolerancia que disminuyan los niveles de agresividad } \\
\text { y violencia en la institución. }\end{array}$ \\
\hline
\end{tabular}




\begin{tabular}{|c|c|}
\hline & $\begin{array}{l}\text { - Utilizar el reciclaje de papel como forma de } \\
\text { fortalecer su compromiso ciudadano con la } \\
\text { conservación del medio ambiente. } \\
\text { - Contribuir a la disminución de los altos niveles de } \\
\text { ruido en la institución. } \\
\text { - Motivar mediante diferentes estrategias, el uso } \\
\text { racional del recurso hídrico y eléctrico en la } \\
\text { institución y demás espacios. } \\
\text { - Hacer de la institución un espacio más verde, } \\
\text { agradable, saludable y sostenible a través de la } \\
\text { implementación de la huerta escolar. }\end{array}$ \\
\hline $\begin{array}{c}\text { ¿En qué aspectos centran la atención los objetivos } \\
\text { del PRAE? }\end{array}$ & $\begin{array}{l}\text { Están centrados en generar estrategias } \\
\text { enfocadas a lograr cambios positivos en los } \\
\text { conocimientos, actitudes y comportamientos } \\
\text { sobre el uso adecuado y gestión de recursos } \\
\text { naturales y el manejo de los recursos sólidos y } \\
\text { las basuras. }\end{array}$ \\
\hline $\begin{array}{c}\text { ¿Cuál es el alcance de los objetivos planteados en el } \\
\text { PRAE? }\end{array}$ & $\begin{array}{c}\text {, están condicionados a la aplicación y colaboración } \\
\text { de los participantes de la comunidad educativa, } \\
\text { como el seguimiento y ejecución por parte de los } \\
\text { que lideran dicho proyecto. }\end{array}$ \\
\hline $\begin{array}{l}\text { ¿Cuál o cuáles de los siguientes documentos fueron } \\
\text { consultados como marco de referencia del PRAE? }\end{array}$ & $\begin{array}{l}\text {-Según el decreto } 1743 \text { del } 3 \text { de agosto de } 1994 \text { se } \\
\text { instituye el proyecto de educación ambiental para } \\
\text { todos los niveles de educación formal, con el fin de } \\
\text { coadyuvar a la resolución de problemas ambientales } \\
\text { específicos. } \\
\text {-Artículo } 79 \text { de la constitución política: "todas las } \\
\text { personas tienen derecho a gozar de un ambiente } \\
\text { sano } \\
\text {-Proyecto de acuerdo } 517 \text { de } 2006 \text { : Por el cual se } \\
\text { establecen disposiciones para la construcción y } \\
\text { ejecución de la política de educación ambiental de } \\
\text { Bogotá D.C. } \\
\text {-Artículo } 5 \text {. Fines de la educación, de conformidad } \\
\text { con el artículo } 67 \text { de la constitución política. } \\
\text {-Política nacional educación ambiental } \\
\text {-Decreto } 061 \text { de } 2003 \text { - plan de gestión ambiental } \\
2001-2009 \\
\text {-Plan de ordenamiento territorial-pot (decreto } 190 \text { de } \\
2004 \text { ) } \\
\text {-Decreto } 617 \text { de } 2007 \text { (diciembre } 28 \text { ) Por el cual se } \\
\text { adopta y reglamenta la política pública distrital de } \\
\text { educación ambiental. } \\
\text {-La constitución política de Colombia de 1991, a } \\
\text { través de la descentralización político-administrativa } \\
\text { y, su intención, traducida en leyes orgánicas como }\end{array}$ \\
\hline
\end{tabular}




\begin{tabular}{|c|c|}
\hline & $\begin{array}{l}\text { la ley } 99 \text { de diciembre de } 1993 \text {, la ley de plan de } \\
\text { desarrollo - ley } 152 / 94 \text {, la ley de ordenamiento } \\
\text { territorial - ley } 388 / 97 \text {. } \\
\text {-La ley general de educación (ley } 115 / 94 \text { ), y sus } \\
\text { respectivos decretos reglamentarios. }\end{array}$ \\
\hline $\begin{array}{c}\text { ¿Cuáles de los siguientes principios rectores para la } \\
\text { Educación Ambiental, se tienen en cuenta en el } \\
\text { PRAE? }\end{array}$ & $\begin{array}{l}\text { Justicia y equidad: Garantía del bien común sobre } \\
\text { el particular, en correspondencia con la valoración } \\
\text { de la diversidad. } \\
\text { - Autonomía: Decidir en lo propio como expresión } \\
\text { de los deberes y derechos. Comprensión de lo } \\
\text { soberano, de lo propio y la tolerancia. } \\
\text { - Austeridad: Autorregulación frente al consumo, } \\
\text { manejo y racionalización de los recursos. } \\
\text { - Corresponsabilidad y solidaridad: Compromisos } \\
\text { particulares diferenciados y colectivos encaminados } \\
\text { a la construcción de una vida digna. } \\
\text { - Armonía y concertación: Construcción de } \\
\text { acuerdos sin detrimento de sus particularidades. } \\
\text { - Aprendizaje colectivo y educación diferencial: } \\
\text { Encuentro de saberes que se desprenden de la } \\
\text { diversidad cultural y social en el Distrito Capital. } \\
\text { - Participación: Ejercicio social que busca elevar la } \\
\text { capacidad ciudadana para la gestión y para el } \\
\text { control social frente a lo público. }\end{array}$ \\
\hline $\begin{array}{l}\text { ¿Cuáles referentes fundamentan conceptualmente el } \\
\text { PRAE? }\end{array}$ & \\
\hline $\begin{array}{c}\text { ¿Desde el PRAE, que se entiende por Ambiente y } \\
\text { Educación Ambiental? }\end{array}$ & $\begin{array}{l}\text { Es el proceso educativo que se desarrolla en la } \\
\text { familia, en el establecimiento educativo, en el } \\
\text { ambiente y en la sociedad. } \\
\text { La educación en el ambiente es aquella que se } \\
\text { practica en los espacios pedagógicos diferentes a } \\
\text { los familiares y escolares mediante la utilización del } \\
\text { tiempo libre de los educandos. }\end{array}$ \\
\hline \multicolumn{2}{|c|}{ METODOLOGÍA } \\
\hline $\begin{array}{c}\text { ¿A qué tipo de investigación responde la } \\
\text { metodología desarrollada en el PRAE de su } \\
\text { institución? }\end{array}$ & Descriptiva \\
\hline $\begin{array}{c}\text { ¿Cuáles son las principales actividades, en los dos } \\
\text { últimos años, que se han liderado desde el PRAE en } \\
\text { su institución? }\end{array}$ & $\begin{array}{c}\text { Manejo de los residuos sólidos, reciclaje, basura } \\
\text { cero, jardinería y agricultura urbana }\end{array}$ \\
\hline
\end{tabular}




\begin{tabular}{|c|c|}
\hline $\begin{array}{l}\text { ¿EI PRAE cuenta con un cronograma que oriente el } \\
\text { desarrollo de las actividades? }\end{array}$ & Se encuentra establecido en el instrumento POA \\
\hline $\begin{array}{c}\text { ¿Qué periodicidad tiene el cronograma propuesto en } \\
\text { el PRAE? }\end{array}$ & $\begin{array}{c}\text { Presenta un periodo anual para la realización de las } \\
\text { actividades programadas }\end{array}$ \\
\hline ¿A qué obedece la ejecución del PRAE? & $\begin{array}{l}\text { A los lineamientos curriculares de la secretaria de } \\
\text { educación y a necesidades e intereses particulares } \\
\text { de la comunidad educativa }\end{array}$ \\
\hline $\begin{array}{l}\text { ¿Cuál es el tiempo destinado para la planeación del } \\
\text { PRAE? }\end{array}$ & $\begin{array}{l}\text { Anualmente se actualiza la planeación de este } \\
\text { proyecto }\end{array}$ \\
\hline $\begin{array}{l}\text { ¿Con qué frecuencia se reúnen los integrantes del } \\
\text { PRAE? }\end{array}$ & $\begin{array}{l}\text { todos los viernes se reúnen las docentes miembros } \\
\text { del PRAE y cada } 20 \text { días se realiza reunión con } \\
\text { estos mismos docentes y los estudiantes miembros } \\
\text { del CAE }\end{array}$ \\
\hline ¿Qué dificultades limitan el desarrollo del PRAE? & $\begin{array}{l}\text { - La falta de apoyo por parte de los docentes } \\
\text { de los demás proyectos } \\
\text { - El incumplimiento algunos vigías } \\
\text { ambientales a las reuniones } \\
\text { - La falta de compromiso de algunos vigías } \\
\text { ambientales en la realización de actividades } \\
\text { programadas } \\
\text { - La falta de tiempo para realizar } \\
\text { capacitaciones a docentes, padres y otros } \\
\text { miembros de la comunidad. } \\
\text { - La dificultad para generar espacios } \\
\text { pedagógicos ambientales donde se reúnan } \\
\text { las dos jornadas escolares }\end{array}$ \\
\hline $\begin{array}{l}\text { ¿Cuáles son los mecanismos de participación que } \\
\text { contempla el PRAE? }\end{array}$ & $\begin{array}{l}\text { - Capacitación al inicio y final del año con los } \\
\text { docentes } \\
\text { - Capacitación al inicio del año a los } \\
\text { miembros del servicios generales de la } \\
\text { institución } \\
\text { - Elección de los representantes vigías } \\
\text { ambientales ( } 2 \text { vigías por curso) } \\
\text { - Elección de los padres representantes de } \\
\text { cada área }\end{array}$ \\
\hline $\begin{array}{l}\text { ¿Cuáles son las fortalezas que tiene el PRAE de su } \\
\text { institución? }\end{array}$ & $\begin{array}{l}\text { - Cultura del cuidado y protección de lo } \\
\text { publico } \\
\text { - Cultura del cuidado del entorno }\end{array}$ \\
\hline En el desarrollo del PRAE, la Institución cuenta con: & $\begin{array}{ll}\text { - } & \text { infraestructura física } \\
\text { - } & \text { Recursos presupuestales } \\
\text { - } & \text { Espacios y zonas para implementación de } \\
& \text { actividades (huerta, jardinería, laboratorio) }\end{array}$ \\
\hline \multicolumn{2}{|c|}{ 7. ACTORES Y PARTICIPACIÓN } \\
\hline
\end{tabular}




\begin{tabular}{|c|c|c|}
\hline $\begin{array}{c}\text { ¿La Institución cuenta con un Comité Ambiental } \\
\text { Escolar - CAE? }\end{array}$ & & sí \\
\hline $\begin{array}{l}\text { ¿Cuál fue el proceso llevado a cabo para la } \\
\text { conformación del CAE? }\end{array}$ & \multicolumn{2}{|c|}{$\begin{array}{c}\text { Elección democrática en cada curso, (elección de } \\
\text { dos estudiantes) }\end{array}$} \\
\hline \multicolumn{3}{|c|}{ ¿Quiénes conforman el Comité Ambiental Escolar - CAE - en su institución? ¿Cuántos actores participan? } \\
\hline \multicolumn{2}{|l|}{ Directivos } & 0 \\
\hline \multicolumn{2}{|l|}{ Administrativos } & 1 \\
\hline \multicolumn{2}{|l|}{ Padres de familia } & 2 \\
\hline \multicolumn{2}{|l|}{ Personas de servicio general } & 1 \\
\hline \multicolumn{2}{|l|}{ Egresados } & 0 \\
\hline \multicolumn{2}{|c|}{$\begin{array}{c}\text { Docentes en Ciencias Sociales, historia, geografía, constitución política, } \\
\text { economía, ciencia política y democracia }\end{array}$} & 0 \\
\hline \multicolumn{2}{|c|}{ Docentes en Ciencias Naturales y Educación Ambiental } & 4 \\
\hline \multicolumn{2}{|c|}{ Docentes en Educación Artística y cultural } & 0 \\
\hline \multicolumn{2}{|c|}{ Docentes en Educación en ética y valores humanos } & 0 \\
\hline \multicolumn{2}{|c|}{ Docentes En educación Física, recreación y deporte } & 0 \\
\hline \multicolumn{2}{|l|}{ Docentes en Educación religiosa } & 0 \\
\hline \multicolumn{2}{|c|}{ Docentes en Humanidades, lengua castellana e idioma extranjero } & 0 \\
\hline \multicolumn{2}{|l|}{ Docentes en Matemáticas } & 0 \\
\hline \multicolumn{2}{|l|}{ Docentes en tecnología e informática } & 0 \\
\hline \multicolumn{2}{|l|}{ Estudiantes de Preescolar } & 6 \\
\hline \multicolumn{2}{|l|}{ Estudiantes de básica primaria } & 24 \\
\hline \multicolumn{2}{|l|}{ Estudiantes de básica secundaria } & 18 \\
\hline \multicolumn{2}{|l|}{ Estudiantes de Media Vocacional } & 6 \\
\hline $\begin{array}{l}\text { ¿Con qué instancia(s) de la institución se relaciona el } \\
\text { CAE? }\end{array}$ & \multicolumn{2}{|c|}{$\begin{array}{l}\text { Bajo el proyecto PRAE, en el área de ciencias } \\
\text { naturales y Coordinación de convivencia }\end{array}$} \\
\hline $\begin{array}{l}\text { ¿Cuál es el tiempo de permanencia de los } \\
\text { integrantes del CAE? }\end{array}$ & \multicolumn{2}{|c|}{$\begin{array}{c}\text { Un año, siempre y cuando al siguiente año por curso } \\
\text { tomen la decisión de cambiar de representantes } \\
\text { vigías ambientales }\end{array}$} \\
\hline $\begin{array}{l}\text { ¿Qué considera respecto al tiempo de permanencia } \\
\text { de los miembros que conforman el CAE? }\end{array}$ & \multicolumn{2}{|c|}{$\begin{array}{l}\text { Los vigías ambientales son estudiantes con mucho } \\
\text { interés por el cuidado del medio ambiente, por lo } \\
\text { general no se presentan cambios significativos de }\end{array}$} \\
\hline
\end{tabular}




\begin{tabular}{|c|c|c|}
\hline & \multicolumn{2}{|c|}{$\begin{array}{l}\text { año a año ya que la permanencia hace que el } \\
\text { proceso continúe a través del tiempo }\end{array}$} \\
\hline $\begin{array}{c}\text { ¿Cuáles son las estrategias para la comunicación } \\
\text { entre los miembros del CAE y la Comunidad } \\
\text { Educativa? }\end{array}$ & \multicolumn{2}{|c|}{$\begin{array}{ll}\text { - } & \text { Reuniones } \\
\text { - } & \text { Información maneja por medio de circulares } \\
\text { - } & \text { Uso de correo electrónico } \\
\text { - } & \text { Manejo de redes sociales }\end{array}$} \\
\hline $\begin{array}{c}\text { ¿Qué factores dificultan los procesos participativos } \\
\text { del CAE? }\end{array}$ & \multicolumn{2}{|c|}{$\begin{array}{l}\text { - Espacios en tiempo para la realización de } \\
\text { reuniones }\end{array}$} \\
\hline $\begin{array}{l}\text { ¿Cuáles espacios físicos facilitan la participación de } \\
\text { los miembros del CAE? }\end{array}$ & \multicolumn{2}{|c|}{$\begin{array}{ll}\text { - } & \text { Aulas de clase } \\
\text { - } & \text { Biblioteca } \\
\text { - } & \text { Salas de informática } \\
\text { - } & \text { Auditorio } \\
\text { - } & \text { Patios y canchas }\end{array}$} \\
\hline ¿En qué tiempo se reúne el CAE? & \multicolumn{2}{|c|}{$\begin{array}{l}\text { Cada } 20 \text { días, un día diferente cada semana para } \\
\text { no afectar el horario de clases }\end{array}$} \\
\hline \multicolumn{3}{|c|}{ Identifique que Actores Sociales han apoyado o apoyan el PRAE y su nivel de participación. } \\
\hline \multicolumn{2}{|l|}{ Estudiantes } & Diaria \\
\hline \multicolumn{2}{|l|}{ Docentes de ciencias naturales } & Diaria \\
\hline \multicolumn{2}{|l|}{ Docentes de otras áreas } & Diaria \\
\hline Padres de familia o acudientes & & Cuando se les requiere \\
\hline Egresados & & No \\
\hline Directivos & & Cuando se le requiere \\
\hline Coordinadores & & Diario \\
\hline Administradores escolares & & No \\
\hline Personas de servicios generales & & Diaria \\
\hline Comité ambiental escolar CAE & & Diaria \\
\hline Sector productivo & & Tres veces por semana \\
\hline Comité local de Educación Ambiental & & No \\
\hline Gestores ambientales locales & & No \\
\hline Junta de acción comunal JAC & & No \\
\hline \multicolumn{2}{|l|}{ Organizaciones no gubernamentales ONG } & No \\
\hline Otros & & No \\
\hline
\end{tabular}




\begin{tabular}{|c|c|c|}
\hline \multicolumn{2}{|l|}{ Ministerio de educación nacional MEN } & Anual \\
\hline \multicolumn{2}{|l|}{ Secretaria de Educación Distrital SED } & Periódicamente \\
\hline \multicolumn{2}{|l|}{ Secretaria Distrital de Ambiente } & Periódicamente \\
\hline \multicolumn{2}{|l|}{ Jardín Botánico José Celestino Mutis } & periódicamente \\
\hline \multicolumn{2}{|c|}{ Ministerio de Ambiente, Vivienda y Desarrollo Territorial } & No \\
\hline \multicolumn{2}{|l|}{ Secretaria de Hábitat } & No \\
\hline \multicolumn{2}{|l|}{ Alcaldía mayor } & No \\
\hline \multicolumn{2}{|l|}{ Alcaldías locales } & No \\
\hline \multicolumn{2}{|l|}{ Unidades ejecutivas locales UEL } & No \\
\hline \multicolumn{2}{|c|}{$\begin{array}{l}\text { Unidad Administrativa Especial del Sistema de Parques Nacionales } \\
\qquad \text { Naturales }\end{array}$} & No \\
\hline \multicolumn{2}{|c|}{ Unidades Ambientales de los Grandes Centros Urbanos } & No \\
\hline \multicolumn{2}{|l|}{ Institutos de Investigación Ambiental } & No \\
\hline \multicolumn{2}{|l|}{ Policía Ecológica } & No \\
\hline \multicolumn{2}{|c|}{$\begin{array}{l}\text { Unidades locales de Administración Técnica Agropecuaria y } \\
\text { Ambiental }\end{array}$} & No \\
\hline \multicolumn{2}{|l|}{ Secretaria de salud } & No \\
\hline \multicolumn{2}{|l|}{ Universidades públicas } & No \\
\hline \multicolumn{2}{|l|}{ Universidades privadas } & No \\
\hline \multicolumn{2}{|l|}{ Otras } & No \\
\hline \multicolumn{3}{|c|}{ 8. RECURSOS Y PRESUPUESTO } \\
\hline ¿Con qué recursos cuenta el desarrollo del PRAE? & \multicolumn{2}{|c|}{$\begin{array}{l}\text { Económicos, humanos, tecnológicos, infraestructura } \\
\text { física }\end{array}$} \\
\hline $\begin{array}{c}\text { ¿A través de qué mecanismos se han obtenido los } \\
\text { recursos para el desarrollo } \\
\text { del PRAE? }\end{array}$ & \multicolumn{2}{|c|}{$\begin{array}{l}\text { Los recursos económicos que destina la Secretaria } \\
\text { de Educación, por medio de Rectoría y pagaduría de } \\
\text { la institución. }\end{array}$} \\
\hline $\begin{array}{l}\text { ¿Cuenta EI PRAE con un presupuesto para su } \\
\text { financiación? }\end{array}$ & \multicolumn{2}{|c|}{$\mathrm{Si}$} \\
\hline $\begin{array}{c}\text { ¿Cuál es la asignación presupuestal para el PRAE } \\
\text { por año? }\end{array}$ & \multicolumn{2}{|c|}{$\begin{array}{l}\text { El monto depende de las necesidades que presente } \\
\text { para el siguiente año lectivo según lo trabajado en el } \\
\text { año inmediatamente anterior, por lo general oscila } \\
\text { entre } 2500000 \text { y } 3000000\end{array}$} \\
\hline
\end{tabular}




\begin{tabular}{|c|c|c|c|c|c|c|}
\hline \multicolumn{7}{|c|}{ 9. EVALUACIÓN Y SEGUIMIENTO } \\
\hline \multicolumn{3}{|c|}{$\begin{array}{l}\text { ¿Qué actor o actores participan en la evaluación del } \\
\text { PRAE? }\end{array}$} & \multicolumn{4}{|c|}{ La comunidad educativa } \\
\hline \multicolumn{3}{|c|}{ ¿Con qué frecuencia se evalúa el PRAE? } & \multicolumn{4}{|c|}{ Anualmente, al final de cada año escolar } \\
\hline \multicolumn{3}{|c|}{$\begin{array}{c}\text { ¿Cuáles son los mecanismos Externos de evaluación } \\
\text { y seguimiento del PRAE? }\end{array}$} & \multicolumn{4}{|c|}{ Gestión Piga } \\
\hline \multicolumn{3}{|c|}{$\begin{array}{l}\text { ¿Cuáles son los mecanismos internos de evaluación } \\
\text { y seguimiento del PRAE? }\end{array}$} & \multicolumn{4}{|c|}{$\begin{array}{l}\text { Rectoría por medio de la evaluación de desempeño } \\
\text { docente }\end{array}$} \\
\hline \multicolumn{3}{|c|}{$\begin{array}{c}\text { ¿A través de qué espacios o medios se comunican } \\
\text { los resultados del PRAE? }\end{array}$} & \multicolumn{4}{|c|}{$\begin{array}{ll}\text { - } & \text { En reunión y seguimiento de área } \\
\text { - } & \text { Cuando lo requiere la Sed en forma virtual } \\
\text { - } & \text { En la evaluación de los DOFA } \\
\text { - } & \text { Al final de cada año escolar en reunión de } \\
\text { docentes }\end{array}$} \\
\hline \multicolumn{7}{|c|}{$\begin{array}{l}\text { Los resultados derivados del PRAE se relacionan } \\
\qquad \text { con }\end{array}$} \\
\hline \multicolumn{3}{|c|}{$\begin{array}{l}\text { El impacto que tiene proyectado el desarrollo del } \\
\text { PRAE es }\end{array}$} & \multicolumn{4}{|c|}{$\begin{array}{l}\text { Mantener el desarrollo del proyecto con la } \\
\text { participación de la comunidad educativa }\end{array}$} \\
\hline \multicolumn{7}{|c|}{ 110. EL PRAE- UN PROYECTO TRANSVERSAL E INTERDISCIPLINAR } \\
\hline \multicolumn{3}{|c|}{$\begin{array}{c}\text { ¿El PRAE, reconoce el principio de } \\
\text { interdisciplinariedad que orienta la educación } \\
\text { ambiental? }\end{array}$} & \multicolumn{4}{|c|}{$\mathrm{Si}$} \\
\hline \multicolumn{3}{|c|}{$\begin{array}{c}\text { ¿De qué manera las áreas de conocimiento apoyan } \\
\text { el desarrollo del PRAE? }\end{array}$} & \multicolumn{4}{|c|}{$\begin{array}{l}\text { Con la realización de actividades con las áreas de } \\
\text { manera transversal }\end{array}$} \\
\hline \multicolumn{3}{|c|}{$\begin{array}{c}\text { ¿Qué resultados se han obtenido en relación con la } \\
\text { perspectiva interdisciplinar y la solución a los } \\
\text { problemas planteados en el PRAE? }\end{array}$} & \multicolumn{4}{|c|}{$\begin{array}{l}\text { El apoyo y aporte en la aplicación de estrategias que } \\
\text { conlleven al fomento del uso adecuado de los } \\
\text { recursos naturales y de desechos diarios. }\end{array}$} \\
\hline \multicolumn{7}{|c|}{ 11. EL PRAE- COMPONENTES CURRICULARES } \\
\hline \multicolumn{3}{|c|}{$\begin{array}{c}\text { ¿EI PRAE incide o se relaciona con otros proyectos } \\
\text { curriculares? Sí } \\
\text { su respuesta es negativa justifique su respuesta }\end{array}$} & \multicolumn{4}{|c|}{$\begin{array}{l}\text { Si, con los proyectos de agricultura urbana, } \\
\text { jardinería y biotecnología }\end{array}$} \\
\hline \multicolumn{3}{|c|}{$\begin{array}{l}\text { ¿A través de qué estrategias se ha incluido la } \\
\text { dimensión ambiental enel contexto escolar? }\end{array}$} & \multicolumn{4}{|c|}{$\begin{array}{l}\text { Conferencias, actividades prácticas como foros, cine } \\
\text { foros, talleres, capacitaciones, actividades en } \\
\text { relación al cronograma ambiental nacional }\end{array}$} \\
\hline \multicolumn{7}{|c|}{$\begin{array}{c}\text { Marque con una }(X) \text { ¿Con cuál o cuáles de los componentes curriculares se relaciona el PRAE y en qué } \\
\text { momento se articula el Proyecto Ambiental Escolar con estos? }\end{array}$} \\
\hline Formulación & $\begin{array}{l}\text { Desarroll } \\
\quad 0\end{array}$ & $\begin{array}{r}\text { Fortalec } \\
0\end{array}$ & mient & Transformación & $\begin{array}{l}\text { Evaluación } \\
y \\
\text { seguimient } \\
0\end{array}$ & $\begin{array}{l}\text { No se } \\
\text { relaciona }\end{array}$ \\
\hline
\end{tabular}




\begin{tabular}{|c|c|c|c|c|c|}
\hline $\begin{array}{l}\text { Proyectos de } \\
\text { aula }\end{array}$ & & $X$ & & & \\
\hline $\begin{array}{l}\text { Proyectos de } \\
\text { área }\end{array}$ & & $x$ & $x$ & & \\
\hline $\begin{array}{l}\text { Plan de } \\
\text { estudios }\end{array}$ & $x$ & & & $x$ & \\
\hline Investigación & $x$ & & & & \\
\hline $\begin{array}{c}\text { Prácticas } \\
\text { pedagógicas }\end{array}$ & $x$ & $x$ & $x$ & $x$ & \\
\hline $\begin{array}{l}\text { Constitución e } \\
\text { instrucción } \\
\text { cívica }\end{array}$ & & $x$ & & & \\
\hline $\begin{array}{l}\text { Aprovechamien } \\
\text { to del tiempo } \\
\text { libre }\end{array}$ & & $x$ & & & \\
\hline $\begin{array}{l}\text { Enseñanza } \\
\text { para la } \\
\text { protección del } \\
\text { ambiente }\end{array}$ & $x$ & $x$ & $x$ & $x$ & \\
\hline $\begin{array}{c}\text { Educación para } \\
\text { la justicia, la } \\
\text { paz y la } \\
\text { democracia }\end{array}$ & & $X$ & $x$ & $x$ & \\
\hline $\begin{array}{l}\text { La educación } \\
\text { sexual }\end{array}$ & & & & & $x$ \\
\hline $\begin{array}{l}\text { Prevención y } \\
\text { gestión del } \\
\text { riesgo }\end{array}$ & & $x$ & $x$ & & \\
\hline & & & & & \\
\hline
\end{tabular}

Anexo 5C.

\section{DIAGNÓSTICO DEL ESTADO DEL PROYECTO AMBIENTAL ESCOLAR PRAE COLEGIO RICAURTE I.E.D}

\section{INFORMACIÓN GENERAL DEL ESTABLECIMIENTO}

1.- INFORMACIÓN GENERAL DEL ESTABLECIMIENTO EDUCATIVO

Nombre del establecimiento educativo: Colegio Ricaurte I.E.D.

Dirección: Cra. 27 No 7-48

Teléfono: 2475199

UPZ: 102 (Sabana) 
Barrio: Ricaurte

Código DANE: 11100141452

Nombre del rector: Estanislao Guido Caicedo Yela

Teléfono del rector: 3132922513

E-mail: cedricaurte14@redp.edu.co-praericaurte@gmail.com

Nombre del responsable del PRAE: César Augusto Cruz Baquero

Teléfono responsable del PRAE: 3134047620

E-mail: dragoncesar2005@yahoo.com

2.- Localidad

Los Mártires (14)

3. Cargo del responsable del PRAE

Docente 
4. Número de estudiantes, docentes y administrativos que hacen parte de la institución. Si no cuenta con alguno de ellos, escriba 0 como respuesta

Preescolar: 78

Primaria: 582

Secundaria: 552

Media: 252

No. total de docentes: 60

No. de directivos docentes: 4

No. de administradores: 4

No. de personas de servicios generales: 12

5. Indique el énfasis del PEI

Ética y Valores

Académico

6. ¿Cuál es el enfoque pedagógico que orienta el PEI?

El quehacer de los miembros de la comunidad educativa debe evidenciarse en el desarrollo de una actitud propositiva y proactiva a partir del pensamiento crítico-reflexivo. La institución debe fortalecer la comunicación con una mirada crítica, reflexiva y proactiva hacía las nuevas tecnologías, aprovechando al máximo su potencialidad.

7. Estime que porcentaje de la población educativa habita en la localidad en la que se encuentra la institución

Del $51 \%$ al $70 \%$

8. ¿Reconoce usted cuál es el territorio ambiental en el que se encuentra inmersa la Institución Educativa?

$\mathrm{Si}$

8.1. Indique en cuál de los siguientes territorios ambientales se encuentra inmersa su institución RIO FUCHA (San Cristóbal, Rafael Uribe Uribe, Antonio Nariño, Puente Aranda, Candelaria, Kennedy, Fontibón, Mártires)

\section{El PRAE, UN PROYECTO DE INVESTIGACIÓN}

9. ¿Su Proyecto Educativo Institucional (PEI) incluye un Proyecto Ambiental Escolar (PRAE)?

$\mathrm{Si}$

10. ¿En qué nivel de desarrollo se encuentra el PRAE de su institución?

Evaluación y seguimiento 
11. ¿Cuál es el título del PRAE?

Desarrollo y fortalecimiento de una cultura ambiental por medio de la integración de las áreas del conocimiento en la formación de ciudadanos ambientales

\section{PROBLEMATIZACIÓN}

12. ¿Cuál es el problema de investigación que aborda el PRAE?

Cómo desarrollar trabajo interdisciplinario alrededor del cuidado del recurso hídrico, que contribuya al desarrollo de los objetivos propuestos en el PRAE

13. La formulación del PRAE en la institución obedece principalmente a:

El requerimiento legal

La preocupación por la solución de una problemática apremiante ambiental local

El trabajo participativo de la comunidad educativa con otros actores externos

El PRAE surgió del interés específico de un maestro

14. ¿Cuál o cuáles diagnósticos ambientales fueron tenidos en cuenta para la elaboración del PRAE?

Diagnóstico Ambiental de la Institución Educativa

15. ¿En cuál de las siguientes categorías se puede incluir el problema de investigación del PRAE de su Institución?

Sistema Hídrico de Bogotá

Resignificación del territorio

Uso racional de los recursos naturales

Liderazgo y gestión ambiental

16. ¿En cuál o cuáles problemáticas ambientales de la localidad, se centra el PRAE?

Contaminación por residuos sólidos y escombros

Contaminación atmosférica

Contaminación auditiva

Comercio informal

Contaminación Visual

Contaminación de fuentes hídricas

Vertimientos ilegales

Elevado tráfico vehicular

Alta población flotante

17. ¿Qué instrumentos fueron utilizados para identificar el problema de investigación del PRAE?

Observación directa

Matriz de Vester 


\section{OBJETIVOS}

18. ¿Cuáles son los objetivos generales propuestos para el PRAE?

Fortalecer el PRAE, como el proyecto rector de la educación ambiental en la IED, a través del desarrollo de acciones pedagógicas en contexto, con la participación de la comunidad educativa, especialmente del CAE en el marco de la normatividad vigente.

19. ¿Cuáles son los objetivos específicos propuestos para el PRAE?

- Evaluar el impacto alcanzado del PRAE en la institución

- Implementar estrategias de comunicación para la socialización

- Sistematizar la experiencia PRAE

- Promover la investigación como estrategia pedagógica del PRAE.

- Diseñar y desarrollar estrategias que permitan integrar una visión de sostenibilidad dentro de la institución educativa

- Capacitar a los padres de familia y a miembros clave de la comunidad aledaña en temas ambientales en contexto

- Diseñar e integrar una estrategia de Servicio Social ambiental que responda a las necesidades del PRAE.

- Vincular a la comunidad educativa en el desarrollo de las acciones PRAE

- Generar espacios pedagógicos para socializar y retroalimentar PRAE

- Fortalecer alianzas con instituciones distritales

- Identificar los impactos generados por el ser humano en el ambiente.

- Desarrollar y fortalecer hábitos de manejo adecuado de los residuos sólidos por parte de la comunidad educativa.

- Reconocer las características y problemáticas del territorio ambiental Cerros y Cuencas de los ríos Comuneros y Fucha

- Renaturalizar la IED por medio de la creación de espacios verdes y murales ambientales tanto en las zonas comunes como dentro de cada una de las aulas.

20. ¿En qué aspectos centran la atención los objetivos del PRAE?

Sensibilizar a la comunidad educativa acerca de un problema ambiental

Desarrollar actividades que propendan por mejorar el ambiente natural

Desarrollar Cultura ambiental

Articular la Educación Ambiental al currículo

21. ¿Cuál es el alcance de los objetivos planteados en el PRAE?

La institución escolar

La localidad

\section{MARCO REFERENCIAL}


22. ¿Cuál o cuáles de los siguientes documentos fueron consultados como marco de referencia del PRAE?

Constitución Política de Colombia 1991, Art. 67, 79

Ley 99 de 1993

Ley General de Educación 115 de 1994

Decreto 1743 de 1994

Política Nacional de Educación Ambiental 2002

Decreto Distrital 617 de 2007. Alcaldía Mayor de Bogotá

Acuerdo 166 de 2005 Concejo de Bogotá

Política Pública Distrital de Educación Ambiental PPDEA. 2007

El Plan de Ordenamiento Territorial POT

Planes de manejo ambiental para humedales

Proyecto Educativo Institucional (P.E.I)

Documentos de la institución

23. ¿Cuáles de los siguientes principios rectores para la Educación Ambiental, se tienen en cuenta en el PRAE?

Interdisciplinariedad

Formación en valores

Gestión y resolución de problemas

Autonomía

Armonía y concertación

Aprendizaje colectivo y educación referencial

24. ¿Cuáles referentes fundamentan conceptualmente el PRAE?

Desarrollo sostenible

Formación en valores

Educación ambiental

Conservación, manejo y uso de los recursos

Investigación escolar

Ambiente

25. ¿Desde el PRAE, que se entiende por Ambiente y Educación Ambiental? En caso que el PRAE no cuente con un concepto establecido de Ambiente o Educación Ambiental marque una $X$ en la casilla No aplica

Educación ambiental: Es la reorientación y articulación de las diversas disciplinas y experiencias educativas que facilitan la percepción integrada del medio ambiente, haciendo posible una acción más racional y capaz de responder a las necesidades sociales

\section{METODOLOGÍA}


26. ¿A qué tipo de investigación responde la metodología desarrollada en el PRAE de su institución?

La metodología desarrollada en el PRAE no responde a ningún tipo de investigación en particular

27. ¿Cuáles son las principales actividades, en los dos últimos años, que se han liderado desde el PRAE en su institución?

Talleres de sensibilización a la comunidad educativa

Salidas ecológicas

Proyectos de investigación

Ornato del colegio

Participación en discusiones ambientales a nivel local

Difusión de información relativa al ambiente en las aulas

28. ¿EI PRAE cuenta con un cronograma que oriente el desarrollo de las actividades?

$\mathrm{Si}$

29. ¿Qué periodicidad tiene el cronograma propuesto en el PRAE?

Anual

30. ¿A qué obedece la ejecución del PRAE?

A una planeación previa organizada dentro del Cronograma del PRAE. Aunque su

desarrollo es ocasional de acuerdo a las necesidades institucionales.

31. ¿Cuál es el tiempo destinado para la planeación del PRAE?

Reuniones de proyecto

32. ¿Con qué frecuencia se reúnen los integrantes del PRAE?

Semanal

33. ¿Qué dificultades limitan el desarrollo del PRAE?

Recursos económicos

Apoyo administrativo

Escaso material didáctico

Falta coordinación entre las actividades planeadas desde el PRAE y otras actividades propuestas por la institución o por actores externos

Renuencia de otros docentes a participar

Desarrollo de reuniones poco estructuradas, sin objetivos claros, que desmotivan para nuevas convocatorias

34. ¿Cuáles son los mecanismos de participación que contempla el PRAE?

Reuniones periódicas

Talleres de formación

Salidas ambientales

Servicio Social Ambiental 
Vigías Ambientales

Comisión Ambiental Local

35. ¿Cuáles son las fortalezas que tiene el PRAE de su institución?

Apoyo administrativo

Espacios físicos

Recursos humanos

Autogestión del PRAE

Asesoría no gubernamentales

Articulación con las diferentes áreas

36. En el desarrollo del PRAE, la Institución cuenta con:

Vigías Ambientales

Grupos de servicio social ambiental 


\section{ACTORES Y PARTICIPACIÓN}

37. ¿La Institución cuenta con un Comité Ambiental Escolar - CAE?

$\mathrm{Si}$

No

38. ¿Cuál fue el proceso llevado a cabo para la conformación del CAE?

Democrático

A través de méritos

Invitación personal

Por afinidad con la temática

Otro, ¿Cuál?

39. ¿Quiénes conforman el Comité Ambiental Escolar - CAE - en su institución?

¿Cuántos actores participan? Escriba 0 en caso de no contar con alguno de los ítems.

Directivos; 0

Administrativos; 0

Padres de familia: 1

Personas de servicio general: 0

Egresados: 0

Docentes en Ciencias Sociales, historia, geografía, constitución política,

Economía, ciencias políticas y democracia; 0

Docentes en Ciencias Naturales y Educación Ambiental: 2

Docentes en Educación artística y cultural; 0

Docentes en Educación en ética y valores humanos: 0

Docentes en Educación física, recreación y deporte: 1

Docentes en Educación religiosa: 0

Docentes en Humanidades, lengua castellana e idioma extranjero: 2

Docentes en Matemáticas: 0

Docentes en Tecnología e Informática: 1

Estudiantes de Preescolar: 0

Estudiantes de Básica Primaria: 8

Estudiantes de Básica secundaria: 16

Estudiantes de Media Vocacional: 8

40. ¿Con qué instancia(s) de la institución se relaciona el CAE?

Rector

Coordinación Académica

Coordinación de Convivencia

41. ¿Cuál es el tiempo de permanencia de los integrantes del CAE?

Los miembros no tienen un tiempo de permanencia establecido. La permanencia fluctúa de acuerdo a los tiempos, intereses y compromisos de los integrantes del CAE 
42. ¿Qué considera respecto al tiempo de permanencia de los miembros que conforman el CAE?

Genera compromiso en sus integrantes

Limita el desarrollo de los procesos

Se tiene un referente de los líderes ambientales a largo plazo

43. ¿Cuáles son las estrategias para la comunicación entre los miembros del CAE y la Comunidad Educativa?

De manera directa (comunicación personal)

Asambleas generales

Emisora escolar

Espacios virtuales

44. ¿Qué factores dificultan los procesos participativos del CAE?

Falta de tiempo

Falta de espacios físicos para reunión

Falta de espacios académicos para trabajar

Recursos insuficientes

Falta de interés de la comunidad educativa

45. ¿Cuáles espacios físicos facilitan la participación de los miembros del CAE?

Oficina propia

Biblioteca institucional

Sala de profesores

Oficinas de coordinación

Rectoría

Salones de clase

Auditorio

Cafetería

Zonas comunes

Lugares externos a la institución escolar

EI CAE no cuenta con un espacio físico en particular que facilite su participación

46. ¿En qué tiempo se reúne el CAE?

Horario establecido por el Consejo Directivo

Dentro de la jornada escolar durante las horas clase

Dentro de la jornada escolar durante los descansos

Horario extra clase

EI CAE no cuenta con un tiempo establecido para sus reuniones, éstas se llevan a

Cabo de acuerdo a los requerimientos en el desarrollo del PRAE 
47. Identifique que Actores Sociales han apoyado o apoyan el PRAE y su nivel De participación. Marque una sola opción por fila.

\begin{tabular}{|l|c|c|c|}
\hline & Nunca & Ocasional & Permanente \\
\hline Estudiantes & & & $\mathrm{X}$ \\
\hline Docentes de ciencias naturales & & & $\mathrm{X}$ \\
\hline Docentes de otras áreas & & $\mathrm{X}$ & \\
\hline Padres de familia ó acudientes & $\mathrm{X}$ & & \\
\hline Egresados & $\mathrm{X}$ & & \\
\hline Directivos & $\mathrm{X}$ & & \\
\hline Coordinadores & $\mathrm{X}$ & & \\
\hline Administradores escolares & & $\mathrm{X}$ & \\
\hline Personas de servicios generales & & $\mathrm{X}$ & \\
\hline Comité ambiental Escolar - CAE & $\mathrm{X}$ & & \\
\hline Sector productivo & $\mathrm{X}$ & & \\
\hline Comité Local de Educación Ambiental - CLEA & $\mathrm{X}$ & & \\
\hline Gestores ambientales locales & & $\mathrm{X}$ & \\
\hline Junta de Acción Comunal - JAC & & $\mathrm{X}$ & \\
\hline Organizaciones No Gubernamentales -ONG & & & \\
\hline Otros & & & \\
\hline
\end{tabular}

48. Identifique que Actores Institucionales han apoyado o apoyan el PRAE y su nivel de participación. Marque una sola opción por fila.

\begin{tabular}{|l|c|c|c|}
\hline Ministerio De Educación Nacional (MEN) & Nunca & Ocasional & Permanente \\
\hline Secretaría de Educación Distrital SED & & & \\
\hline Secretaría Distrital de Ambiente & & $\mathrm{X}$ & \\
\hline Jardín Botánico José Celestino Mutis & & $\mathrm{X}$ & \\
\hline Ministerio de Ambiente Vivienda y Desarrollo territorial & $\mathrm{X}$ & & \\
\hline Secretaría de Hábitat & $\mathrm{X}$ & & \\
\hline Alcaldía Mayor & $\mathrm{X}$ & & \\
\hline Alcaldías Locales & & $\mathrm{X}$ & \\
\hline Unidades Ejecutivas Locales UEL & $\mathrm{X}$ & & \\
\hline $\begin{array}{l}\text { Unidad Administrativa Especial del Sistema de Parques } \\
\text { Nacionales Naturales }\end{array}$ & $\mathrm{X}$ & & \\
\hline Unidades Ambientales de los Grandes & $\mathrm{X}$ & & \\
\hline Centros Urbanos & $\mathrm{X}$ & & \\
\hline Institutos de Investigación Ambiental & $\mathrm{X}$ & & \\
\hline Policía Ecológica & $\mathrm{X}$ & & \\
\hline Unidades Locales de Administración & $\mathrm{X}$ & & \\
\hline Técnica Agropecuaria y Ambiental & $\mathrm{X}$ & & \\
\hline Secretaria de Salud & $\mathrm{X}$ & & \\
\hline Universidades públicas & & $\mathrm{X}$ & \\
\hline $\begin{array}{l}\text { Universidades privadas } \\
\text { Otras }\end{array}$ & $\mathrm{X}$ & & \\
\hline
\end{tabular}


8. RECURSOS Y PRESUPUESTO

49. ¿Con qué recursos cuenta el desarrollo del PRAE?

Humanos

Económicos

Tecnológicos

50. ¿A través de qué mecanismos se han obtenido los recursos para el desarrollo del PRAE?

Autogestión del PRAE

Asignación de recursos propios de la institución

Participación en concursos

51. ¿Cuenta EI PRAE con un presupuesto para su financiación?

$\mathrm{Si}$

52. ¿Cuál es la asignación presupuestal para el PRAE por año?

2.500 .000

\section{EVALUACIÓN Y SEGUIMIENTO}

53. ¿Qué actor o actores participan en la evaluación del PRAE?

El Comité Ambiental Escolar (CAE)

Secretaría de Educación

Líderes de proyecto

54. ¿Con qué frecuencia se evalúa el PRAE?

Una vez en el año

55. ¿Cuáles son los mecanismos Externos de evaluación y seguimiento del PRAE? Radicación del PRAE en el CADEL

Diligenciamiento de formatos de autoevaluación suministrados por el CADEL

56. ¿Cuáles son los mecanismos internos de evaluación y seguimiento del PRAE? Informes institucionales

Reuniones del Comité Ambiental Escolar para la socialización de avances

57. ¿A través de qué espacios o medios se comunican los resultados del PRAE?

Reuniones de profesores

Eventos académicos

Página Web del colegio

Izadas de bandera

Redes o comunidades virtuales 
58. Los resultados derivados del PRAE se relacionan con:

Uso racional de los recursos naturales

Concienciación del uso de los recursos públicos

Establecer cooperación con otras organizaciones para apoyar acciones de conservación del medio ambiente

Elaboración de un diagnóstico bien realizado

Articulación de las temáticas ambientales al currículo

Incremento en el desarrollo de procesos investigativos relacionados con el ambiente

Mayor participación de la comunidad educativa en las actividades propuestas desde

el PRAE

Incremento en la asignación horaria y presupuestal para el PRAE

59. El impacto que tiene proyectado el desarrollo del PRAE es

Institucional

Local

10. EL PRAE- UN PROYECTO TRANSVERSAL E INTERDISCIPLINAR

60. ¿EI PRAE, reconoce el principio de interdisciplinariedad que orienta la educación ambiental?

$\mathrm{Si}$

61. Si el PRAE reconoce la dimensión interdisciplinar. ¿Cuál es la comprensión que acerca de interdisciplinariedad soporta el proyecto?

62. Metodológicamente. ¿Cómo se implementa la interdisciplinariedad en el PRAE?

Se realizan actividades puntuales en donde participan algunas áreas

63. ¿A través de cuáles estrategias, se ha concretado la interdisciplinariedad como principio de la Educación Ambiental en las prácticas escolares? (indique el nivel en el que usualmente se llevan a cabo) Marque una $X$ según corresponda

\begin{tabular}{|l|c|c|c|}
\hline & Preescolar & Básica & Media \\
\hline Integración por temas & & $\mathrm{X}$ & $\mathrm{X}$ \\
\hline Integración por actividades & & $\mathrm{X}$ & $\mathrm{X}$ \\
\hline Integración en torno a un tópico generador & & $\mathrm{X}$ & \\
\hline Resolución de problemas & & $\mathrm{X}$ & \\
\hline Integración en torno a un relato & & $\mathrm{X}$ & $\mathrm{X}$ \\
\hline Proyectos & & & \\
\hline No se lleva a cabo ninguna estrategia & & \\
\hline
\end{tabular}

64. Señale las asignaturas de básica y media que se vinculan en el proyecto PRAE desde una propuesta interdisciplinar.

Biología y Educación Ambiental

Español

Educación física 
Tecnología

65. Señale cuáles de las siguientes dimensiones se vinculan en el proyecto PRAE desde una propuesta interdisciplinar

Comunicativa

Cognitiva

Corporal

Estética

66. ¿De qué manera las áreas de conocimiento apoyan el desarrollo del PRAE?

Se agrupan maestros de distintas disciplinas para tratar un mismo tema o problema ambiental y cada uno desde su área aporta a la solución

67. ¿Qué resultados se han obtenido en relación con la perspectiva interdisciplinar y la solución a los problemas planteados en el PRAE?

Mayor participación de la comunidad educativa

Articulación de áreas y asignaturas

Generar una educación más integral e integradora

La elaboración de un diagnóstico participativo

Desarrollo de proyectos de investigación integrados por diferentes áreas

\section{EL PRAE- COMPONENTES CURRICULARES}

68. ¿EI PRAE incide o se relaciona con otros proyectos curriculares? Sí su respuesta es negativa justifique su respuesta

69. Marque con una $(X)$ ¿Con cuál o cuáles de los componentes curriculares se relaciona el PRAE y en qué momento se articula el Proyecto Ambiental Escolar con estos?

\begin{tabular}{|l|l|c|c|c|c|c|}
\hline & $\begin{array}{l}\text { For } \\
\text { mula } \\
\text { ción }\end{array}$ & $\begin{array}{l}\text { Desa } \\
\text { rroll } \\
\text { o }\end{array}$ & $\begin{array}{l}\text { Fort } \\
\text { aleci } \\
\text { mien } \\
\text { to }\end{array}$ & $\begin{array}{l}\text { Tran } \\
\text { sfor } \\
\text { maci } \\
\text { on }\end{array}$ & $\begin{array}{l}\text { Eval } \\
\text { uaci } \\
\text { on y } \\
\text { segu } \\
\text { imie } \\
\text { nto }\end{array}$ & $\begin{array}{l}\text { No } \\
\text { se } \\
\text { relac } \\
\text { iona }\end{array}$ \\
\hline Proyectos de aula & & $\mathrm{X}$ & $\mathrm{X}$ & & & \\
\hline Proyectos de área & & & & & & $\mathrm{X}$ \\
\hline Plan de estudios & & $\mathrm{X}$ & & & & \\
\hline Investigación & & $\mathrm{X}$ & $\mathrm{X}$ & & & \\
\hline Prácticas pedagógicas & $\mathrm{X}$ & & & & & \\
\hline Constitución e instrucción cívica & $\mathrm{X}$ & $\mathrm{X}$ & & & & \\
\hline Aprovechamiento del tiempo libre & $\mathrm{X}$ & & & & & \\
\hline Enseñanza para la protección del ambiente & $\mathrm{X}$ & & & & & \\
\hline $\begin{array}{l}\text { Educación para la Justicia, la Paz y la } \\
\text { Democracia }\end{array}$ & $\mathrm{X}$ & & & & & $\mathrm{X}$ \\
\hline La Educación Sexual & & & & & \\
\hline
\end{tabular}


70. ¿A través de qué estrategias se ha incluido la dimensión ambiental en el contexto escolar?

Creación de grupos de ciencia y tecnología

Servicio Social

Formación y actualización docente

Producción y publicación de materiales impresos y audiovisuales sobre el tema ambiental Celebraciones institucionales relacionadas con el tema ambiental (día del agua, día de la tierra,...)

Enriquecimiento del trabajo en la resolución de problemas

\section{Anexo 5D. DIAGNÓSTICO PRAE INSTITUCIÓN EDUCATIVA REINO DE HOLANDA LOCALIDAD 18}

La Institución Educativa Distrital Reino de Holanda, cuenta con tres sedes, ubicadas en el Barrio Marco Fidel Suárez, perteneciente a la Localidad 18 Rafael Uribe Uribe, donde se enmarcan las siguientes características:

\section{EXTENSIÓN}

La localidad cubre 1.310,1 hectáreas, de las cuales el 6,8\% (88,8 ha.) son zonas protegidas; el 97,6\% es considerado área urbana; el 59,08\%, está amanzanada; y el 2,4\%, área por desarrollar, que son terrenos no urbanizados. Esta localidad no tiene suelo de expansión ni suelo rural y es la sexta localidad en el Distrito con menos área.

\section{POBLACIÓN LOCAL}

Por número de habitantes, Rafael Uribe Uribe es la octava localidad más grande; según el Censo de 2005, con 375.625 personas, un 6,2\% del total de la Ciudad; y es el número uno en densidad de población (323 personas por hectárea), por encima del promedio de Bogotá (42 p/Ha). Por sexo, el 52\% son mujeres y el $48 \%$ hombres. Por edad, el $60 \%$ de su población está entre los 15 y los 55 años.

\section{RIESGOS NATURALES}

Amenaza por remoción en masa: En Rafael Uribe Uribe existe un área total de 820,82 ha. en zonas de amenaza por remoción en masa, donde se localizan 1.412 manzanas. De ese total hay 191 manzanas, que ocupan un área de 123,2 ha., clasificada como zona de remoción en amenaza alta; hay además 1.104 manzanas que ocupan 461,3 ha, clasificadas como zona de remoción en amenaza media y 117 manzanas en un área de 236,3 ha, clasificada como zona de remoción en amenaza baja.

\section{PROBLEMAS AMBIENTALES PRESENTES EN LA ID. REINO DE HOLANDA}

\begin{tabular}{|c|l|}
\hline No. & \multicolumn{1}{|c|}{ PROBLEMATICAS PRESENTADAS } \\
\hline $\mathbf{1}$ & Presencia de basuras en las calles por falta de compromiso por parte de la comunidad \\
\hline $\mathbf{2}$ & Presencia de roedores en insectos \\
\hline $\mathbf{3}$ & Presencia de mascotas en la calle \\
\hline $\mathbf{4}$ & Presencia de piojos y pulgas \\
\hline $\mathbf{5}$ & Problemas de aseo personal \\
\hline $\mathbf{6}$ & Vías de acceso en mal estado \\
\hline $\mathbf{7}$ & Recicladores que dañan las bolsas de la basura y dejándolas esparcidas en la calle \\
\hline $\mathbf{8}$ & Personas que arrojan la basura desde sus ventanas \\
\hline $\mathbf{9}$ & Tabaquismo y alcoholismo en general \\
\hline $\mathbf{1 0}$ & Uso y consumo de pegante, bazuco, marihuana cerca al colegio \\
\hline $\mathbf{1 1}$ & Los borrachos dejan las botellas tiradas en la calle \\
\hline
\end{tabular}


CATEGORIZACION DE PROBLEMAS

\begin{tabular}{|l|l|ll|}
\hline No. & CATEGORIZACIÓN & PROBLEMÁTICA PRESENTE \\
\hline 1 & INADECUADO MANEJO DE & $\checkmark$ & Presencia de basuras en las calles por falta de compromiso por parte de la \\
& RESIDUOS SOLIDOS & & comunidad \\
& & $\checkmark$ & Las personas dedicadas al reciclaje dejan la basura tirada en los andenes y las calles \\
& & $\checkmark$ & Falta de cultura en la clasificación de las basuras \\
\hline 2 & PRESECIA DE PLAGAS & $\checkmark$ & Presencia de roedores \\
& & $\checkmark$ & Presencia de insectos \\
& & $\checkmark$ & Epidemias de piojos \\
& & $\checkmark$ & Epidemia de pulgas \\
\hline 3 & INADECUADA TENENCIA DE & $\checkmark$ & Personas que sacan a sus mascotas durante el día a la calle y lo dejan entrar solo \\
& MASCOTAS & & hasta la noche \\
& & $\checkmark$ & Presencia de perros y otros animales callejeros \\
& & $\checkmark$ & Contaminación por excremento de animales en las calles \\
\hline 4 & CONSUMO Y EXPENDIO DE & $\checkmark$ & Agresión física, verbal y psicológica \\
& SUSTANCIAS & $\checkmark$ & Violencia intrafamiliar \\
& PSICOACTIVAS & $\checkmark$ & Carencia de valores ambientales \\
& & $\checkmark$ & Problemática de convivencia entre los habitantes del sector \\
& & $\checkmark$ & Discriminación a estudiantes con problemáticas especificas (pediculosis, racial, \\
& & & desaseo) \\
& & $\checkmark$ & Riñas y peleas entre estudiantes dentro y fuera de la institución \\
& & $\checkmark$ & Presencia de pandillas y delincuencia \\
& &
\end{tabular}

\section{PROBLEMÁTICA AMBIENTAL LOCALES IDENTIFICADOS}

\begin{tabular}{|c|c|c|c|}
\hline TIPO & DIAGNOSTICO & CAUSAS & EFECTOS \\
\hline AGUA & $\begin{array}{l}\text { Contaminación de la quebrada Chiguaza, } \\
\text { por el vertimiento de aguas negras y lluvias } \\
\text { a través del canal que recoge las aguas } \\
\text { negras de barrios como Diana Turbay, Villa } \\
\text { Ester, Reconquista, Serranía, Palermo Sur }\end{array}$ & $\begin{array}{l}\text { Vertimiento de aguas } \\
\text { residuales, invasión de la } \\
\text { ronda hídrica de la quebrada } \\
\text { Chiguaza }\end{array}$ & $\begin{array}{lr}\text { Riesgo de } & \text { inundación de } \\
\text { vivencias, proliferación de } \\
\text { vectores, r deterioro } \\
\text { paisajístico }\end{array}$ \\
\hline AIRE & $\begin{array}{l}\text { Contaminación por partículas de los } \\
\text { procesos extractivos en las cantera de las } \\
\text { montañas y chimeneas de chircales }\end{array}$ & $\begin{array}{l}\text { Contaminación } \\
\text { atmosfera }\end{array}$ & $\begin{array}{l}\text { Problemas de salud en la } \\
\text { población }\end{array}$ \\
\hline RUIDO & $\begin{array}{l}\text { Contaminación por ruido en las vías } \\
\text { principales de la localidad debido al tráfico } \\
\text { vehicular y al sector comercial de la avenida } \\
\text { Caracas, carrera } 30 \text {, calle } 22 \text { sur. }\end{array}$ & Contaminación auditiva & $\begin{array}{l}\text { Afectación de la calidad de } \\
\text { vida de las personas }\end{array}$ \\
\hline $\begin{array}{l}\text { MALLA } \\
\text { VERDE }\end{array}$ & $\begin{array}{l}\text { Déficit de zonas verdes, en especial la parte } \\
\text { alta de la localidad (barrios Molinos, Diana } \\
\text { Turbay, Palermo Sur, Marruecos) }\end{array}$ & $\begin{array}{l}\text { Perdida de cubertura } \\
\text { vegetal, mayor porcentaje } \\
\text { de suelos construidos }\end{array}$ & $\begin{array}{l}\text { Calidad de vida } \\
\text { población }\end{array}$ \\
\hline $\begin{array}{l}\text { RESIDUOS } \\
\text { SOLIDOS }\end{array}$ & $\begin{array}{l}\text { Disposición inadecuada de residuos sólidos } \\
\text { en los canales y corrientes de la localidad, } \\
\text { presencia de plagas, contaminación visual y } \\
\text { contaminación de suelos. Los barrios de } \\
\text { Santa Lucia, Ingles, y Quiroga en ocasiones } \\
\text { disponen desechos sobre las calles, sin tener } \\
\text { en cuenta las frecuencias de recolección del } \\
\text { servicio de aseo }\end{array}$ & $\begin{array}{l}\text { Contaminación del suelo, } \\
\text { contaminación de fuentes } \\
\text { hídricas }\end{array}$ & $\begin{array}{l}\text { Presencia de vectores } \\
\text { olores ofensivos. }\end{array}$ \\
\hline
\end{tabular}


Anexo 6. DOFA de las cuatro instituciones educativas.

\section{CONSOLIDADO DOFAS 4 COLEGIOS}

\begin{tabular}{|c|c|c|c|c|}
\hline$S$ & DEBILIDADES & OPORTUNIDADES & FORTALEZAS & AMENAZAS \\
\hline \begin{tabular}{l}
\multicolumn{1}{c}{ C } \\
EGIO \\
UIS \\
PEZ \\
PE \\
ESA
\end{tabular} & $\begin{array}{r}\text { Falta de trabajo en Equipo. } \\
\text { No hubo unificación } \\
\text { de criterios entre jornadas } \\
\text { No hay hábitos de } \\
\text { mantener el aseo sin acoso } \\
\text { La comunidad que } \\
\text { rodea el colegio debe } \\
\text { colaborar más con el aseo }\end{array}$ & $\begin{array}{r}\text { Incentivar el trabajo } \\
\text { en equipo. } \\
\text { Más jornadas de } \\
\text { integración para unificar } \\
\text { criterios } \\
\text { La comunidad que } \\
\text { rodea el colegio debe } \\
\text { colaborar más con el aseo }\end{array}$ & $\begin{array}{r}\text { En algunas } \\
\text { actividades hay trabajo } \\
\text { continuo. } \\
\text { La planeación es } \\
\text { responsable frente a los } \\
\text { compromisos }\end{array}$ & $\begin{array}{r}\text { No hay trabajo } \\
\text { institucional. } \\
\text { Hábitos en contra de } \\
\text { edidas del medio ambiente }\end{array}$ \\
\hline \begin{tabular}{|l}
$\quad$ C \\
LEGI \\
O \\
$A N U$ \\
EL \\
PAT \\
A \\
IVE \\
LA
\end{tabular} & $\begin{array}{r}\text { En la aplicación de las } \\
\text { trategias de concientización y } \\
\text { acitación a estudiantes (vigías } \\
\text { nbientales), padres de familia, } \\
\text { ocentes, personal de servicios } \\
\text { rales y vigilancia se presentan } \\
\text { ultades por el incumplimiento } \\
\text { con la asistencia a las } \\
\text { capacitaciones, también los } \\
\text { participantes no multiplican } \\
\text { idamente la información a las } \\
\text { personas a quienes tienen que } \\
\text { rsela, se presenta poco interés } \\
\text { aplicar las estrategias que dan } \\
\text { para el fortalecimiento de la } \\
\text { ultura ambiental institucional, } \\
\text { además es muy difícil que se } \\
\text { cumplan ya que no hay } \\
\text { participación en el trabajo en } \\
\text { equipo de toda la comunidad } \\
\text { educativa. }\end{array}$ & $\begin{array}{r}\text { Se abren los espacios } \\
\text { necesarios para capacitar y } \\
\text { sibilizar a los miembros de la } \\
\text { comunidad educativa } \\
\text { programando actividades y } \\
\text { campañas ambientales como } \\
\text { pañas de cuidado del agua, de } \\
\text { ciclaje, de trabajo con la tierra } \\
\text { ardinería y agricultura urbana, } \\
\text { se capacitan por medio de } \\
\text { onas especializadas en temas } \\
\text { ambientales, las docentes } \\
\text { ncargadas del proyecto PRAE } \\
\text { hbién se capacitan y capacitan } \\
\text { igual manera a representantes } \\
\text { e cada grupo de la comunidad } \\
\text { Icativa (estudiantes miembros } \\
\text { CAE, administrativos, padres } \\
\text { familia, personal de servicios } \\
\text { generales y vigilancia, y a los } \\
\text { ocentes estos en su totalidad) }\end{array}$ & $\begin{array}{r}\text { Se adquirieron puntos } \\
\text { lógicos para los corredores, el } \\
\text { o, la cancha y cada una de las } \\
\text { aulas y oficinas, se dio } \\
\text { acitación a toda la comunidad } \\
\text { e estudiantes y docentes sobre } \\
\text { idados y consecuencias del no } \\
\text { dado del medio ambiente, por } \\
\text { e de la empresa Araneario de } \\
\text { Colombia, se capacitaron los } \\
\text { ías ambientales miembros del } \\
\text { CAE sobre la importancia y la } \\
\text { ma correcta del manejo de los } \\
\text { residuos sólidos, se trabajó en } \\
\text { padrinamiento de los niños de } \\
\text { primer grado por parte de los } \\
\text { niños de quinto grado para } \\
\text { abajar en la huerta escolar en } \\
\text { cultura urbana y se sembraron } \\
\text { ogieron verduras y hortalizas, } \\
\text { ealizaron recolecta de botellas } \\
\text { plásticas que se taquearon con } \\
\text { do el plástico resultante de las } \\
\text { vidades escolares y aportes de } \\
\text { hogares de los estudiantes y se } \\
\text { hicieron jardinéeles con estos } \\
\text { envases en las zonas verdes } \\
\text { ternas y materas para adornar } \\
\text { entes espacios del colegio, se } \\
\text { zo convenio con una empresa } \\
\text { cladora que recogió durante el } \\
\text { el plástico de los refrigerios y } \\
\text { apel y cartón resultante de las } \\
\text { vidades escolares y con quien } \\
\text { ontinuara trabajando a futuro. }\end{array}$ & $\begin{array}{l}\text { La zona de la carrera } 88 \\
\text { convertida en un botadero de } \\
\text { ura por parte de los habitantes } \\
\text { sector, que lo hacen fuera del } \\
\text { rrio de recolección del camión } \\
\text { asura, por lo tanto los perros y } \\
\text { s habitantes de calle rompen y } \\
\text { iegan esas basuras y desechos } \\
\text { osa que genera malos olores y } \\
\text { a presentación en este espacio } \\
\text { del colegio, en esta parte se } \\
\text { cuentra ubicada la zona verde } \\
\text { rna que es separada del andén } \\
\text { por una reja, en esta parte se } \\
\text { uentra ubicados los jardines y } \\
\text { uerta escolar por lo tanto esto } \\
\text { ntamina estos espacios que se } \\
\text { jan dentro del colegio con los } \\
\text { estudiantes pero no se pueden } \\
\text { pumir los alimentos que allí se } \\
\text { cosechan por los gases que } \\
\text { eneran las descomposición de } \\
\text { estos residuos. }\end{array}$ \\
\hline $\begin{array}{l}\text { C } \\
\text { EGI } \\
\text { O } \\
C A U \\
\text { RTE } \\
E D\end{array}$ & $\begin{array}{l}\text { Falta vinculación de } \\
\text { miembros de la } \\
\text { unidad educativa en el } \\
\text { ecto } \\
\text { No hay participación } \\
\text { s padres. }\end{array}$ & $\begin{array}{l}\text { Dos de los líderes del } \\
\text { E están adelantando sus } \\
\text { jos de grado de maestría } \\
\text { marco del PRAE. } \\
\text { El PRAE tendrá } \\
\text { or visualización al }\end{array}$ & $\begin{array}{l}\text { El PRAE tiene un } \\
\text { nocimiento institucional y } \\
\text { Se ha desarrollado e } \\
\text { rporado al manual de }\end{array}$ & $\begin{array}{l}\text { Hay una sobreoferta } \\
\text { ctividades relacionadas } \\
\text { el PRAE que parecen } \\
\text { arar demasiado tiempo y } \\
\text { erzo. }\end{array}$ \\
\hline
\end{tabular}




\begin{tabular}{|c|c|c|c|c|}
\hline & $\begin{array}{l}\text { El presupuesto } \\
\text { hado por la institución es } \\
\text { ficiente } \\
\text { Falta la } \\
\text { matización adecuada de } \\
\text { ctividades desarrolladas } \\
\text { proyecto. } \\
\text { Hace falta } \\
\text { imiento y apoyo de } \\
\text { lades externas para } \\
\text { rrollar procesos adecuados } \\
\text { tanejo de residuos }\end{array}$ & $\begin{array}{l}\text { entarse tanto a los Premios } \\
\text { partir como en el premio } \\
\text { novación Educativa. } \\
\text { Se pretende vincular a } \\
\text { docentes, especialmente } \\
\text { rimaria al desarrollo de las } \\
\text { idades del PRAE } \\
\text { Constantemente se } \\
\text { oportunidades para } \\
\text { cipar en distintos eventos } \\
\text { e Educación ambiental. }\end{array}$ & $\begin{array}{l}\text { ivencia una propuesta de } \\
\text { icio Social Ambiental. } \\
\text { Se han hecho } \\
\text { esos de reconocimiento } \\
\text { erritorio ambiental. } \\
\text { El proyecto cuenta } \\
\text { canales de socialización } \\
\text { o es el caso de página } \\
\text { y Canal de YouTube. } \\
\text { Se han elaborado } \\
\text { llas y artículos con los } \\
\text { tados alcanzados hasta } \\
\text { a. }\end{array}$ & $\begin{array}{l}\text { Hay una falta de } \\
\text { ulación de esfuerzos tanto } \\
\text { la JAL, la alcaldía y el } \\
\text { pr educativo. } \\
\text { Se presenta apatía por } \\
\text { sarrollo del proyecto en } \\
\text { nos grupos de docentes. } \\
\text { El proyecto aún } \\
\text { nde demasiado de sus } \\
\text { es. } \\
\text { Debido al proyecto de } \\
\text { ia Fortalecida no habrá } \\
\text { diantes que puedan } \\
\text { rrollar su servicio social } \\
\text { iental }\end{array}$ \\
\hline \begin{tabular}{|l} 
\\
\multicolumn{1}{r}{$C$} \\
$E G I$ \\
$O$ \\
EINO \\
DE \\
PLAN \\
DA
\end{tabular} & $\begin{array}{l}\quad \text { El poco compromiso } \\
\text { ss estudiantes con el } \\
\text { ecto, hace que pierda } \\
\text { inuidad y las metas y } \\
\text { promisos que se } \\
\text { plecen no llegan a } \\
\text { plirse, en cuanto a su labor } \\
\text { sus pares. } \\
\text { Las acciones } \\
\text { rrolladas, se limitan a dos } \\
\text { s durante el año, pero en } \\
\text { ante del proyecto no se } \\
\text { ve a saber }\end{array}$ & \begin{tabular}{l}
\multicolumn{1}{c}{ Se programan los } \\
cios para capacitaciones y \\
ganizan actividades \\
ientales dentro y fuera de \\
stitución, con el fin de que \\
los estudiantes como el \\
mo se concienticen de la \\
prtancia del proyecto. \\
Se realizan campañas \\
o el uso adecuado del \\
, especialmente para las \\
s, se ubicaron las canecas \\
ciclaje en puntos \\
tégicos del colegio, para \\
a través de la visualización \\
studiantes se familiaricen \\
el proyecto y se adecuo el \\
n con el fin de que los \\
diantes asuman la \\
onsabilidad de cuidarlo.
\end{tabular} & $\begin{array}{l}\quad \text { El colegio asumió el } \\
\text { ecto como uno de sus } \\
\text { es, ha hecho uso de } \\
\text { entos que fortalecen el } \\
\text { rrollo del proyecto como } \\
\text { uación de puntos de } \\
\text { laje. Se adquirieron } \\
\text { os ecológicos para los } \\
\text { edores, se crearon puntos } \\
\text { es y se adecuo el jardín } \\
\text { que los chicos cuiden de } \\
\text { prtaleciendo en ellos el } \\
\text { do de la responsabilidad y } \\
\text { oderarlos en el proyecto, } \\
\text { pacitan a los docentes y } \\
\text { diantes y sobre la } \\
\text { prtancia de adquirir } \\
\text { luctas pro ambientales, de } \\
\text { l manera se capacitaron } \\
\text { igías ambientales } \\
\text { nbros del CAE sobre la } \\
\text { rtancia y la forma } \\
\text { ecta del manejo de los } \\
\text { luos sólidos y ubicación de } \\
\text { stillas ecológicas en las } \\
\text { s de clase, para depositar } \\
\text { ojas de los cuadernos que } \\
\text { o utilizan. }\end{array}$ & $\begin{array}{l}\text { El entorno se ha } \\
\text { ertido en una de las } \\
\text { ores amenazas, puesto que } \\
\text { abitantes del sector no } \\
\text { an las calles, botan la } \\
\text { ra en las aceras, no tienen } \\
\text { ltura de sacar los perritos } \\
\text { acompañamiento, por lo } \\
\text { el colegio sufre mucho } \\
\text { los desechos de estos } \\
\text { os, de igual manera tienen } \\
\text { stumbre de sacar las cosas } \\
\text { ss a las esquinas, por lo } \\
\text { una de las sedes recurrió } \\
\text { mbrar en llantas plantas } \\
\text { que la gente se abstenga } \\
\text { acar basura. }\end{array}$ \\
\hline
\end{tabular}


Anexo 7. Talleres y actividades del plan de acción.

\section{TALLER - CARTA A LA TIERRA}

"Buscar desarrollar e conocimiento, las habilidades, las perspectivas y los valores para "empoderar" a la gente de todas la edades a asumir la responsabilidad de crear y disfrutar un futuro sostenible" UNESCO

\section{GUIA DE TRABAJO}

I. Observe el video que se muestra relacionado con la CARTA A LA TIERRA y con ayuda del documento físico, desarrolle las siguientes actividades.

1. Redacte una breve descripción de la idea central del video, cual es la percepción que usted tuvo del video

2. Cuáles son los aspectos que usted cree, se deben tener en cuenta para la conservación de la tierra.

3. Explique con sus propias palabras, lo que usted entiende de la siguiente expresión: “la producción y consumo están causando devastación ambiental”

4. "Formar una sociedad global para cuidar la Tierra y cuidarnos unos a otros o arriesgarnos a la destrucción de nosotros mismos y de la diversidad de la vid" que significa para usted esta expresión, está de acuerdo o no con la anterior expresión y porque.

5. Según el video y la Carta a la Tierra, ¿qué es para usted, responsabilidad universal?

6.

Mencione 2 principios que se detallan en la Carta a la Tierra y explíquelos, según su criterio.

7. La carta a la tierra, resalta la importancia de Proteger y restaurar la integridad de los sistemas ecológicos de la Tierra, ¿qué aspectos deben tenerse en cuenta?

8. Que se necesita, según el video "Carta a la tierra", para Adoptar patrones de producción, consumo que salvaguarden las capacidades regenerativas de la Tierra.

9. Mencione que elementos son esenciales para lograr una JUSTICIA SOCIAL Y ECONÓMICA, según lo manifiesta la Carta a la Tierra.

10. Escriba dos conclusiones, que usted considere son importantes, después de ver y leer la Carta a la Tierra, y ¿cuál será su actitud frente a la conservación y protección al medio ambiente? 


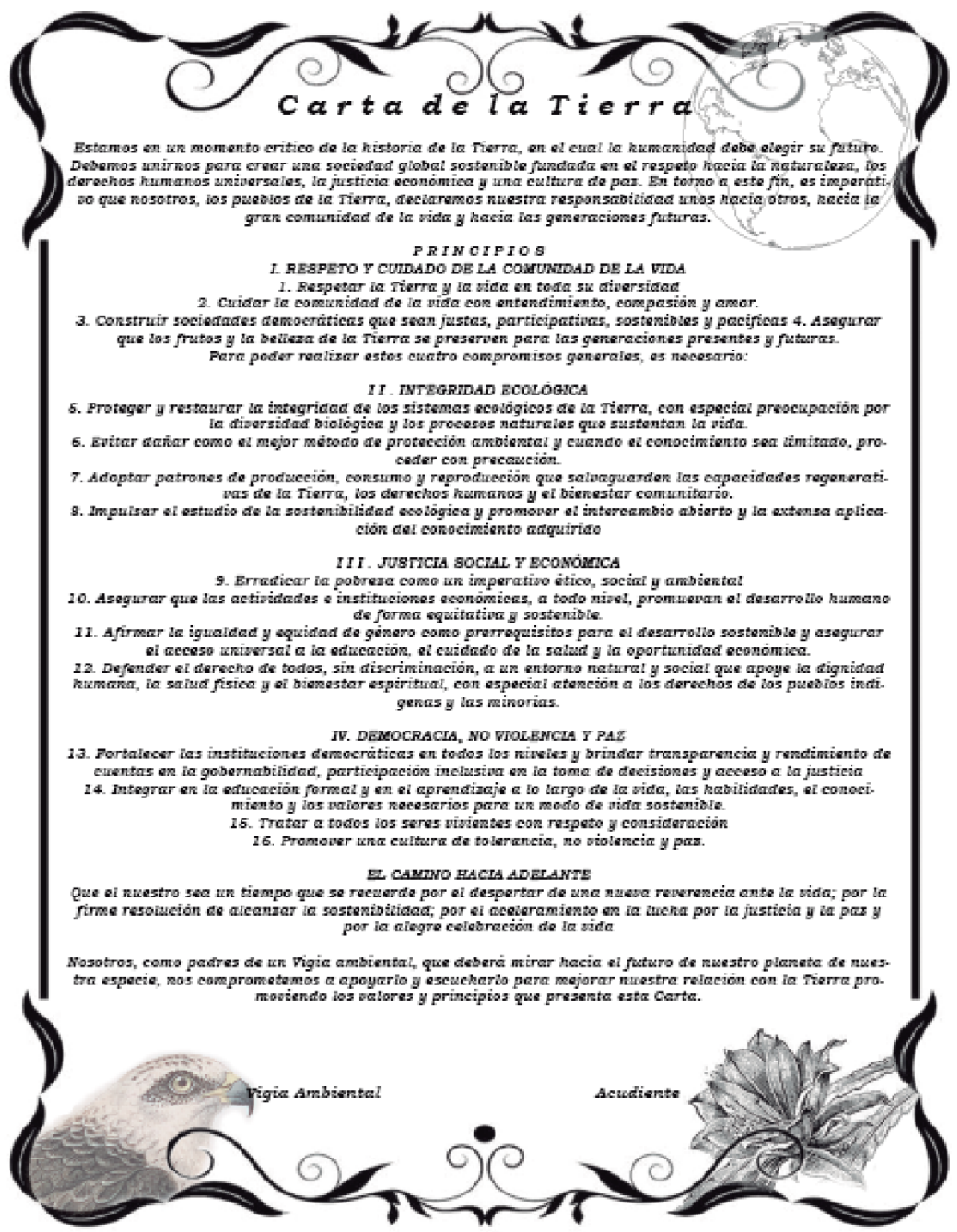




\footnotetext{
1.
}

2.

3.

4.

5.

6.

7.

8.

9.

10.

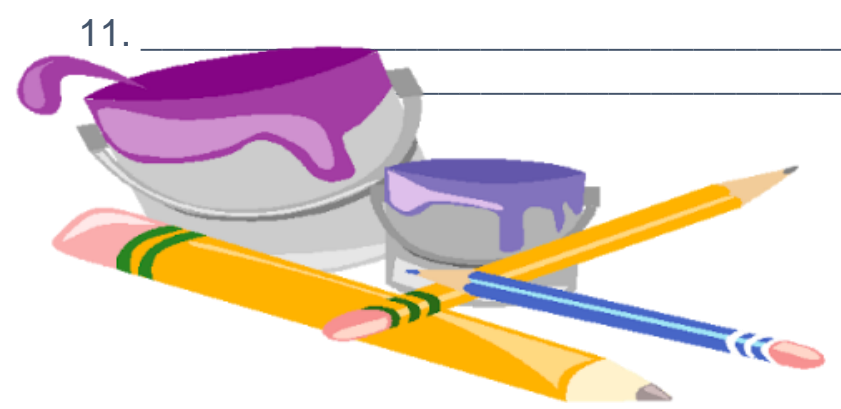


Anexo 8. Diarios de campo

Los diarios de campo de esta investigación están disponibles en carpeta Drive por medio de este enlace:

https://drive.google.com/drive/folders/0B-Nm_vp_2GZ3NFNjWkVHQjROSm8?usp=sharing 
Anexo 9. RAES.

\begin{tabular}{|l|l|}
\hline Elaborado por & Nancy Portilla \\
\hline Titulo & $\begin{array}{l}\text { LA INVESTIGACION DEL ENTORNO NATURAL: UNA ESTRATEGIA DIDACTICA PARA LA } \\
\text { ENSEÑANZA DE LAS CIENCIAS NATURALES } \\
\text { JULIO ALEJANDRO CASTRO }\end{array}$ \\
\hline Futor & \begin{tabular}{l} 
UNIVERSIDAD PEDAGOGICA CENTRAL \\
\hline Año
\end{tabular} \\
\hline Descripción & $\begin{array}{l}\text { La propuesta del proyecto, es generar en el estudiante otras maneras de } \\
\text { aprendizaje, a partir de crear ciertas condiciones de problematización que conlleve } \\
\text { al estudiante a tomar otra postura, más colectiva, activa y autónoma, que le permita } \\
\text { construir sus propios conocimientos sobre su entorno natural. } \\
\text { Pero, para que este propósito se cumpla es necesario que se realicen algunos } \\
\text { cambios en la forma de enseñanza-aprendizaje, comenzando con la manera de } \\
\text { como el maestro enseña, que ya no es la vieja costumbre de transmitir datos y } \\
\text { conceptos, sino por el contrario es pertinente generar en el estudiantes las } \\
\text { condiciones necesarias para que él cuestione las condiciones problemáticas y a } \\
\text { partir de esto despliegue saberes y procederes que lo lleven a nuevos } \\
\text { conocimientos. }\end{array}$ \\
\hline Contenido & \\
\hline Palabras claves & \\
\hline
\end{tabular}

RESUMEN ANALÍTICO ESPECIALIZADO 


\begin{tabular}{|c|c|}
\hline Elaborado por & Nancy Portilla \\
\hline Título & $\begin{array}{l}\text { UNA MIRADA A LOS COMPORTAMIENTOS PROAMBIENTALES DE ESTUDIANTES DE GRADO } \\
\text { NOVENO DE UN COLEGIO PÚBLICO DE BOGOTÁ D.C. EN EL CONTEXTO ESCOLAR }\end{array}$ \\
\hline Autor & $\begin{array}{l}\text { Barreto Tovar Carlos Humberto } \\
\text { Martha Bibiana González Jiménez }\end{array}$ \\
\hline Fuente & UNIVERSIDAD DE LA SABANA \\
\hline Año & 2015 \\
\hline Descripción & $\begin{array}{l}\text { Este estudio, constituye la base para diseñar posteriormente estrategias pedagógicas que } \\
\text { permitan que los estudiantes, de una manera consciente, deliberada y autónoma, } \\
\text { transformen sus prácticas culturales hacia estilos de vida más sustentables, mediante la } \\
\text { promoción de comportamientos proambientales que puedan luego instaurarse en } \\
\text { contextos más amplios a nivel institucional, familiar, local y global. }\end{array}$ \\
\hline Contenido & $\begin{array}{l}\text { Este artículo muestra avances de la investigación que viene desarrollándose en el marco de } \\
\text { la Maestría en Pedagogía de la Universidad de la Sabana, titulada "Implementación de } \\
\text { estrategias pedagógicas para la promoción de comportamientos proambientales en } \\
\text { estudiantes de noveno grado de básica secundaria en el colegio Costa Rica IED". } \\
\text { Para ello, se tomaron algunos elementos provenientes de la Psicología Ambiental para } \\
\text { trabajarlos en la escuela, disciplina que constituye un referente fundamental en la } \\
\text { comprensión de las interrelaciones entre las personas, el ambiente y los espacios socio } \\
\text { físicos, para lograr un acercamiento desde la percepción individual y colectiva sobre el } \\
\text { ambiente (Moser, 2014). Autores como Bayón (2006), citado por Miranda (2013), definen la } \\
\text { cultura ambiental, como "La forma en la que los seres humanos se relacionan con el medio } \\
\text { ambiente, incluyendo el conjunto de estilos, costumbres y condiciones de vida de una } \\
\text { sociedad con una identidad propia, basada en tradiciones, valores y conocimientos". Con } \\
\text { base en ésta definición, la escuela como espacio de interacción social, posee unas dinámicas } \\
\text { únicas y complejas frente a los procesos de construcción de la cultura ambiental que han } \\
\text { sido hasta hoy, poco estudiadas. } \\
\text { Dada la amplitud del concepto de cultura ambiental, éste estudio se enfoca en los aspectos } \\
\text { referentes a las actitudes, entendidas como los sentimientos favorables o desfavorables que } \\
\text { se tienen hacia alguna característica del medio, o como una predisposición aprendida } \\
\text { para actuar en forma favorable o desfavorable con respecto a la elección de un objeto; de } \\
\text { acuerdo con esto, las actitudes pueden ser abordadas desde tres elementos: cognitivos, } \\
\text { afectivos y conductuales (Fishbein y Azjen, 1975, citado por Páramo y Gómez, 1997). En este } \\
\text { sentido, una visión de la Educación Ambiental desde la perspectiva de las actitudes } \\
\text { y los comportamientos proambientales, permite ir más allá de un enfoque reduccionista del } \\
\text { ambiente, que se limita a la inclusión de contenidos ecológicos dentro del currículo, para } \\
\text { dar relevancia, visibilizar y movilizar emociones, comportamientos, conocimientos y } \\
\text { competencias proambientales vinculadas a acciones concretas sobre el cuidado del entorno. }\end{array}$ \\
\hline Palabras claves & $\begin{array}{l}\text { Educación Ambiental, conocimientos ambientales, actitudes proambientales, } \\
\text { comportamientos proambientales, cultura ambiental, Proyecto Ambiental Escolar (PRAE). }\end{array}$ \\
\hline Elaborado por & Nancy Portilla \\
\hline Titulo & EFICIENCIA EN EL CONSUMO DE AGUA DE USO RESIDENCIAL \\
\hline Autor & $\begin{array}{l}\text { Deibys Gildardo Manco Silva } \\
\text { Jhoniers Guerrero Erazo } \\
\text { Ana María Ocampo Cruz }\end{array}$ \\
\hline
\end{tabular}




\begin{tabular}{|c|c|}
\hline Fuente & Universidad de Medellín \\
\hline Año & 2012 \\
\hline Descripción & $\begin{array}{l}\text { Este artículo de revisión aborda los principales referentes acerca de la gestión } \\
\text { de la demanda de agua desde una visión tecnológica y cultural como estrategia para } \\
\text { el uso eficiente en sistemas de acueductos urbanos. Se hace necesario conocer las } \\
\text { dinámicas y los factores que afectan el consumo de agua en las viviendas con el fin } \\
\text { de generar procesos de gestión desde este nivel y trascender a niveles superiores. } \\
\text { En la primera parte se presenta la revisión sobre la gestión de la demanda y se } \\
\text { exponen algunas experiencias investigativas; luego se describen los aspectos } \\
\text { técnicos y tecnológicos de los equipos de medición y los dispositivos de bajo } \\
\text { consumo de agua; finalmente se enumeran los mecanismos sociales para lograr un } \\
\text { uso eficiente de agua. }\end{array}$ \\
\hline Contenido & $\begin{array}{l}\text { El desarrollo urbano, el cambio climático, el crecimiento demográfico, la contaminación del } \\
\text { agua y los cambios en los patrones de consumo han contribuido al desbalance entre la } \\
\text { disponibilidad de fuentes hídricas de calidad y la demanda de agua. } \\
\text { El uso eficiente de agua trae consigo beneficios, tanto a las empresas prestadoras del } \\
\text { servicio de agua potable y alcantarillado en ahorro, en desarrollo y construcción de nueva } \\
\text { infraestructura, disminución en pérdidas comerciales, disminución de costos operativos, } \\
\text { manejo de sequías y corte de suministro, como a los usuarios, quienes obtienen un ahorro } \\
\text { de dinero en el pago por el consumo y por el servicio de alcantarillado [4]. Entre los } \\
\text { beneficios ambientales, se encuentra la disminución de la presión en la demanda del recurso } \\
\text { y la disminución en las descargas generadas a las fuentes hídricas receptoras. } \\
\text { Es necesario conocer las dinámicas del consumo en los hogares a fin de generar procesos de } \\
\text { gestión desde este nivel y así trascender a niveles superiores. }\end{array}$ \\
\hline Palabras claves & $\begin{array}{l}\text { dispositivos de medición, conservación de agua, gestión del agua, } \\
\text { participación social. }\end{array}$ \\
\hline
\end{tabular}




\begin{tabular}{|c|c|}
\hline Elaborado por & NANCY PORTILLA \\
\hline Título & Aproximaciones al estudio de la conducta sustentable \\
\hline Autor & Víctor Corral-Verdugo José de Queiroz Pinheiro \\
\hline Fuente & $\begin{array}{l}\text { Universidad de Sonora, México } \\
\text { Universidade Federal do Rio Grande do Norte, Brasil }\end{array}$ \\
\hline Año & 2004 \\
\hline Descripción & $\begin{array}{l}\text { La conducta sustentable es el tema de un gran número de estudios en psicología } \\
\text { ambiental, sin embargo no se detectan definiciones de este término en la } \\
\text { literatura. El presente escrito aborda la conducta sustentable distinguiendo tres } \\
\text { etapas en la historia de su investigación. Se definen los términos } \\
\text { sustentabilidad, conducta proambiental y conducta sustentable planteando sus } \\
\text { similitudes y particularidades. Se proponen cinco dimensiones psicológicas de la } \\
\text { sustentabilidad: la efectividad, la deliberación, la anticipación, la solidaridad y la } \\
\text { austeridad, las cuales se ilustran con un estudio acerca de conductas de ahorro } \\
\text { de agua. }\end{array}$ \\
\hline Contenido & $\begin{array}{l}\text { El documento pretende definir nuevos conceptos, que permitan claridad y } \\
\text { solución a los problemas que se han profundizado actualmente dada las nuevas } \\
\text { exigencias mundiales, que han puesto en peligro la permanencia del hombre } \\
\text { dentro de su entorno. } \\
\text { Las conductas sustentables la cual inicialmente aborda factores psicológicos que } \\
\text { afectan y que son afectados por la interacción individuo-medio ambiente. En lo } \\
\text { general, se ha concebido a la sustentabilidad como una forma de vida que } \\
\text { satisface las necesidades del presente sin comprometer las necesidades de las } \\
\text { futuras generaciones (World Commission on Environment and Development, } \\
\text { 1987, p. 43). En esta definición queda implícito el papel del comportamiento } \\
\text { ambiental responsable, pero, en ausencia de una delimitación del rol que juega } \\
\text { este comportamiento en la sustentabilidad no queda claro qué es exactamente } \\
\text { conducta sustentable. Tampoco se especifican con claridad las dimensiones } \\
\text { psicológicas de ese constructo y mucho menos se ofrecen modelos que hagan } \\
\text { corresponder las definiciones de sustentabilidad con las dimensiones } \\
\text { propuestas.. }\end{array}$ \\
\hline Palabras claves & Conducta sustentable, dimensiones psicológicas, ahorro de agua \\
\hline
\end{tabular}




\begin{tabular}{|c|c|}
\hline Elaborado por & NANCY PORTILLA \\
\hline Titulo & $\begin{array}{l}\text { Fortalecimiento de la cultura ambiental a partir del desarrollo de competencias } \\
\text { científicas y pro ambientales en estudiantes de grado noveno de básica secundaria de un } \\
\text { colegio público de Bogotá, D.C }\end{array}$ \\
\hline Autor & GONZALEZ MARTHA VIVIANA \\
\hline Fuente & UNIVERSIDAD DE LA SABANA \\
\hline Año & 2016 \\
\hline Descripción & $\begin{array}{l}\text { La presente investigación, se realizó en el Colegio Costa Rica IED, ubicado en la Localidad } \\
\text { de Fontibón, durante el período comprendido entre } 2014 \text { y 2015; en ella participaron } 28 \\
\text { estudiantes del grado noveno, con quienes se realizó un diagnóstico sobre actitudes } \\
\text { ambientales y una intervención pedagógica con el objetivo de fortalecer los procesos de } \\
\text { construcción de la cultura ambiental, a través de cuatro rutinas de pensamiento } \\
\text { ambiental, diseñadas para potenciar algunas competencias científicas y pro ambientales, } \\
\text { tales como observar, indagar y comunicar. } \\
\text { Este trabajo pretende responder a la necesidad urgente por un cambio de paradigma } \\
\text { que conduzca a los futuros ciudadanos a actuar de forma más consciente y responsable } \\
\text { con su entorno, reconociendo la importancia de la escuela en una formación centrada } \\
\text { en las competencias que le permitan a nuestros niños, niñas y jóvenes hacer frente a los } \\
\text { retos actuales. Se realizó bajo un enfoque cualitativo, con un diseño que obedece a los } \\
\text { criterios de la Investigación Acción Pedagógica y con un alcance descriptivo, mediante el } \\
\text { cual se logró un acercamiento a las dinámicas de construcción de la cultura ambiental } \\
\text { escolar, particularmente en el aula de clase. } \\
\text { Este documento muestra la implementación de estrategias pedagógicas para fortalecer } \\
\text { la cultura ambiental escolar, basadas en la visibilización del pensamiento mediante las } \\
\text { rutinas de pensamiento ambiental y en el desarrollo de competencias científicas para } \\
\text { observar, indagar y comunicar en torno a las situaciones ambientales del contexto. }\end{array}$ \\
\hline Contenido & $\begin{array}{l}\text { El documento resalta la importancia que tiene la educación ambiental como medio } \\
\text { fundamental para redireccionar los comportamientos ambientales de los ciudadanos, } \\
\text { con miras a lograr una transformación de la relación hombre - ambiente, de tal manera } \\
\text { que se logre conservar y preservar el entorno partiendo de elementos físicos, culturales, } \\
\text { sociales, políticos y económicos. } \\
\text { Este trabajo, se desarrolló bajo un enfoque cualitativo, dentro de los lineamientos de la } \\
\text { Investigación Acción Educativa, buscando abordar de forma reflexiva los aspectos } \\
\text { relacionados con la construcción de una cultura ambiental escolar mediante estrategias } \\
\text { pedagógicas tendientes a la promoción de comportamientos pro ambientales al interior } \\
\text { del aula de clase, para lo cual se implementó la propuesta en cuatro fases de estudio: } \\
\text { diagnóstico, diseño, implementación y evaluación. }\end{array}$ \\
\hline Palabras claves & $\begin{array}{l}\text { Cultura ambiental escolar, actitudes ambientales, competencias científicas, } \\
\text { competencias pro ambientales, rutinas de pensamiento, didáctica de las ciencias. }\end{array}$ \\
\hline
\end{tabular}




\begin{tabular}{|l|l|}
\hline Elaborado por & NANCY PORTILLA \\
\hline Titulo & LINEAMIENTO PARA FORMADORES EN EDUCACIÓN AMBIENTAL \\
\hline Autor & NOHORA INES PEDRAZA N, AMANDA MEDINA \\
\hline Fuente & \begin{tabular}{l} 
UNIVERSIDAD PEDAGOGICA CENTRAL \\
\hline Año
\end{tabular} \\
\hline Descripción & $\begin{array}{l}\text { La propuesta del proyecto, es generar en el estudiante otras maneras de } \\
\text { aprendizaje, a partir de crear ciertas condiciones de problematización } \\
\text { que conlleve al estudiante a tomar otra postura, más colectiva, más } \\
\text { activa, más autónoma, que le permita construir sus propios } \\
\text { conocimientos sobre su entorno natural. } \\
\text { Pero para que este propósito se cumpla es necesario que se realicen } \\
\text { algunos cambios en la forma de enseñanza-aprendizaje, comenzando } \\
\text { con la manera de cómo el maestro enseña, que ya no es la vieja } \\
\text { costumbre de transmitir datos y conceptos, sino por el contrario es } \\
\text { pertinente generar en el estudiantes las condiciones necesarias para que } \\
\text { él cuestione las condiciones problemáticas y a partir de esto despliegue } \\
\text { saberes y procederes que lo lleven a nuevos conocimientos. }\end{array}$ \\
\hline Contenido & $\begin{array}{l}\text { El texto, realiza un análisis sobre cómo la humanidad se ha desconectado del el } \\
\text { medio ambiente dentro de su quehacer diario, por lo tanto lo que pretende la } \\
\text { autora, es que a través del proyecto de educación ambiental, lograr sensibilizar } \\
\text { y concientizar a la población de la importancia de la relación: Medio-Hombre, y } \\
\text { conjuntamente con sus conocimientos tome una posición positiva ante el medio } \\
\text { y logre mejorarlo para que a partir de formulación de metas a corto plazo, } \\
\text { posibilite el logro de metas a largo plazo. }\end{array}$ \\
\hline educación, concientizar, sensibilizar \\
\hline Palabras claves
\end{tabular}




\begin{tabular}{|c|c|}
\hline Elaborado por & Nancy Portilla \\
\hline Titulo & $\begin{array}{l}\text { CULTURA AMBIENTAL EN ESTUDIANTES DE BACHILLERATO. } \\
\text { ESTUDIO DE CASO DE LA EDUCACIÓN AMBIENTAL EN EL NIVEL MEDIO SUPERIOR DE } \\
\text { CAMPECHE }\end{array}$ \\
\hline Autor & $\begin{array}{l}\text { Isaac-Márquez, R., García, S., Orlando, O., Eastmond Spencer, A., Arcipreste, A., } \\
\text { Esther, M., ... \& Manzanero Acevedo, L. A }\end{array}$ \\
\hline Fuente & REVISTA ELECTRÓNICA DE INVESTIGACIÓN EDUCATIVA \\
\hline Año & 2011 \\
\hline Descripción & $\begin{array}{l}\text { El trabajo analiza el estado que guarda la educación ambiental en el nivel } \\
\text { medio superior, mediante el estudio de caso del municipio de Campeche. } \\
\text { Se realizó una investigación de carácter exploratorio que combina métodos } \\
\text { cuantitativos y cualitativos para diagnosticar el grado de cultura ambiental } \\
\text { de los estudiantes de preparatoria y el tipo de educación ambiental que } \\
\text { reciben. Los resultados indican que } \\
\text { los estudiantes poseen un nivel de cultura ambiental bajo y carecen de los } \\
\text { conocimientos y habilidades necesarias para realizar cambios } \\
\text { ambientalmente favorables en sus estilos de vida. Aunque manifiestan } \\
\text { interés por la temática ambiental, tanto el contexto institucional como el } \\
\text { bajo nivel de habilitación de los maestros operan como factores que } \\
\text { desincentivan a los alumnos. Los resultados permiten identificar ventanas } \\
\text { de oportunidad para la educación ambiental a la luz de las actitudes } \\
\text { positivas de los alumnos, su interés por aprender prácticas sustentables y } \\
\text { la importancia de la escuela como fuente de información ambiental. }\end{array}$ \\
\hline Contenido & $\begin{array}{l}\text { El texto plantea diversas manera de afrontar la crisis ambiental, } \\
\text { caracterizado principalmente por el cambio climático, la biodiversidad y } \\
\text { el deterioro ambiental, producido además por desastres naturales, } \\
\text { escasez de agua, entre otros, que está modificando los patrones de vida } \\
\text { actuales y que compromete las expectativas de las generaciones } \\
\text { futuras. La manera en que se afronte la crisis ambiental será decisiva } \\
\text { para determinar la calidad de vida a la que pueden aspirar las } \\
\text { generaciones presentes y las posibilidades de vida de las generaciones } \\
\text { futuras. El margen de acción, sin embargo, no es muy amplio, los } \\
\text { especialistas consideran que en cuestión de décadas podemos llegar al } \\
\text { punto en el cual las alteraciones sobre los ecosistemas sean de carácter } \\
\text { irreversible. }\end{array}$ \\
\hline Palabras claves & $\begin{array}{l}\text { Educación ambiental, desarrollo sustentable, educación media superior, } \\
\text { México. }\end{array}$ \\
\hline
\end{tabular}




\begin{tabular}{|c|c|}
\hline Elaborado por & Nancy Portilla \\
\hline Titulo & $\begin{array}{l}\text { LA INVESTIGACION DEL ENTORNO NATURAL: UNA ESTRATEGIA DIDACTICA PARA LA } \\
\text { ENSEÑANZA DE LAS CIENCIAS NATURALES }\end{array}$ \\
\hline Autor & JULIO ALEJANDRO CASTRO \\
\hline Fuente & UNIVERSIDAD PEDAGOGICA CENTRAL \\
\hline Año & 2005 \\
\hline Descripción & $\begin{array}{l}\text { La propuesta del proyecto, es generar en el estudiante otras maneras de } \\
\text { aprendizaje, a partir de crear ciertas condiciones de problematización que conlleve } \\
\text { al estudiante a tomar otra postura, mas colectiva, más activa, mas autónoma, que } \\
\text { le permita construir sus propios conocimientos sobre su entorno natural. } \\
\text { Pero para que este propósito se cumpla es necesario que se realicen algunos } \\
\text { cambios en la forma de enseñanza-aprendizaje, comenzando con la manera de } \\
\text { como el maestro enseña, que ya no es la vieja costumbre de transmitir datos y } \\
\text { conceptos, sino por el contrario es pertinente generar en el estudiantes las } \\
\text { condiciones necesarias para que él cuestione las condiciones problemáticas y a } \\
\text { partir de esto despliegue saberes y procederes que lo lleven a nuevos } \\
\text { conocimientos. }\end{array}$ \\
\hline Contenido & \\
\hline Palabras claves & \\
\hline
\end{tabular}


Anexo 10. Referencias Estado del Arte

\begin{tabular}{|c|c|c|c|}
\hline \multicolumn{4}{|c|}{ Hallazgos sobre Comportamientos proambientales } \\
\hline \multicolumn{2}{|c|}{ Creencias, normas, factores } & \multicolumn{2}{|l|}{ Estrategias y prácticas } \\
\hline $\begin{array}{c}\text { Abraham, J. , Pane, M. \& Chairiyani, R. } \\
(2015)\end{array}$ & Indonesia & Bergman, B. (2016) (B) & EEUU \\
\hline $\begin{array}{c}\text { Amérigo, M., García, J. A. \& Sánchez, T. } \\
\text { (2013) }\end{array}$ & España & Berthou, S. K. G. (2013) & Dinamarca \\
\hline $\begin{array}{c}\text { Aoyagi, M., Vinken, H. \& Kuribayashi, A. } \\
\text { (2003) }\end{array}$ & $\begin{array}{l}\text { Japón, } P . \\
\text { bajos }\end{array}$ & Carrico, A. (2009) & EEUU \\
\hline $\begin{array}{l}\text { Bertoldo,R.; Castro, P. \& Bousfield, A. B. } \\
\text { (2013) }\end{array}$ & $\begin{array}{c}\text { Portugal y } \\
\text { Brasil }\end{array}$ & Chawla, L. \& Flanders-Cushing, D. (2007) & EEUU \\
\hline Broom, C. (2017) & Australia & Darner, R. (2012) & EEUU \\
\hline Bruun-Jensen, B. (2002) & Dinamarca & $\begin{array}{c}\text { Ferreiro, Julián, Putrino, Natalia, } \\
\text { Caballero, Romina, Moreno, Camilo, } \\
\text { Streiker-Díaz, Johann, Franco, Paul, } \\
\text { Mazzeo, Nadia, \& Jakovcevic, Adriana. } \\
(2013) .\end{array}$ & Argentina \\
\hline $\begin{array}{c}\text { Carmi, N. (2013) Caring about tomorrow: } \\
\text { future orientation, environmental attitudes } \\
\text { and behaviors }\end{array}$ & Israel & $\begin{array}{l}\text { Goldman D., Zvi Assaraf, O. \& } \\
\text { Shaharabani, D. (2013) }\end{array}$ & Israel \\
\hline $\begin{array}{l}\text { Chen, X., Peterson, M., Hull, V., Lu, C., } \\
\text { Lee, G., Hong, D., \& Liu, J. (2011) }\end{array}$ & China & $\begin{array}{c}\text { Haq, G., Cambridge, H., \& Owen, A. } \\
\text { (2013) }\end{array}$ & UK \\
\hline Clayton, S. \& Kilinc, A. (2013) & $\begin{array}{l}\text { USA y } \\
\text { Turquía }\end{array}$ & $\begin{array}{l}\text { Martinportugués, C., Canto, J. \& } \\
\text { Hombrados, M.I., (2007) }\end{array}$ & España \\
\hline $\begin{array}{l}\text { Cordano, M., Welcomer, S., Scherer, R., } \\
\text { Pradenas, L., \& Parada, V. (2010) }\end{array}$ & $\begin{array}{l}\text { USA y } \\
\text { Chile }\end{array}$ & $\begin{array}{c}\text { Massung, E., Coyle, D., Cater, K. F., Jay, } \\
\text { M., \& Preist, C. W. (2013) }\end{array}$ & UK \\
\hline Corral Verdugo, Víctor; (2006) & México & Özden, M. (2008) & Turquía \\
\hline $\begin{array}{l}\text { Corral, V. V., Tapia, C., Frías, M., Fraijo, } \\
\text { B. y González, D. (2009) }\end{array}$ & México & $\begin{array}{c}\text { Rodríguez Cruz, I., \& Bezunartea } \\
\text { Valencia, M. (2016) }\end{array}$ & España \\
\hline De Castro, R. (2002) & España & $\begin{array}{c}\text { Varela-Losada, M., Vega-Marcote, P., } \\
\text { Pérez-Rodríguez, U. \& Alvarez-Lires, M. } \\
\text { (2016) }\end{array}$ & España \\
\hline
\end{tabular}




\begin{tabular}{|c|c|c|c|}
\hline De Nardo, M. . (2016) & EEUU & Cano-Sterling, L. (2012) & Colombia \\
\hline $\begin{array}{c}\text { Dresner, M., Handelman, C., Braun, S. \& } \\
\text { RollwagenBollens, G. (2015) }\end{array}$ & EEUU & Furrow, C.B. (2015) & EEUU \\
\hline Eilers, E. C. (2014) & EEUU & García, J. \& Vilá, C. (2015) & Colombia \\
\hline $\begin{array}{c}\text { Ellis, Andrew \& Korzenny, Felipe. (2012, } \\
\text { March) }\end{array}$ & EEUU & Yee-Kee, H. (2013) & Malasia \\
\hline Escobar, N. (2007) & Colombia & Pacheco, C.H. (2012) & Colombia \\
\hline $\begin{array}{c}\text { Fagua, R. E., Moreno, D. M., Medina, N. } \\
\text { F., Angarita, Serrato, F. M., \& Velasquez, } \\
\text { G. P. (2016) }\end{array}$ & Colombia & Toole, J. (2010) & EEUU \\
\hline $\begin{array}{c}\text { Galli, F.; Bolzan De Campos, C.; Bedin, L. } \\
\text { M. And Castella Sarriera, J. (2013) }\end{array}$ & Brasil & & \\
\hline Giron, M.H. \& Leyva, J.C. 2013 & México & & \\
\hline Iwata, O. (2001) & Japón & & \\
\hline $\begin{array}{c}\text { Jara, P. O., Talayero, F., Aragonés, J. \& } \\
\text { Moyano-Diaz, E. (2014) }\end{array}$ & $\begin{array}{l}\text { España y } \\
\text { Chile }\end{array}$ & & \\
\hline Kollmuss, A. \& Agyeman, J. (2002) & EEUU & & \\
\hline Li, Jia (2015) & Japón & & \\
\hline Lynn, P. (2014) & UK & & \\
\hline Maiteny, P.T. (2002) & UK & & \\
\hline Maki, A. \& Rothman, A.J. (2016) & EEUU & & \\
\hline $\begin{array}{c}\text { Markowitz, E. M., Goldberg, L. R., Ashton, } \\
\text { M. C., \& Lee, K. (2012) }\end{array}$ & EEUU & & \\
\hline Nye, M., \& Hargreaves, T. (2010) & UK & & \\
\hline $\begin{array}{l}\text { Palacios, J. R., Bustos, J. M. y Soler, F. L. } \\
\text { (2015) }\end{array}$ & México & & \\
\hline
\end{tabular}




\begin{tabular}{|c|c|c|}
\hline $\begin{array}{l}\text { Pensini, P., Slugoski,B., Caltabiano, N. } \\
(2012)\end{array}$ & Australia & \\
\hline $\begin{array}{l}\text { Prati, G., Albanesi, C. \& Pietrantoni, L. } \\
(2017)\end{array}$ & Italia & \\
\hline Rainear, A. \& Christensen, J. (2017) & EEUU & \\
\hline Redondo, I. \& Puelles, M. (2017) & España & \\
\hline Sanvichith, J. (2011) & EEUU & \\
\hline Sonja, P. (2013) & EEUU & \\
\hline Steg, L., Vlek, C. (2009) & $\begin{array}{l}\text { Países } \\
\text { bajos }\end{array}$ & \\
\hline $\begin{array}{c}\text { Stevenson, K.T., M. Peterson, N., Carrier, } \\
\text { S.J., Strnad, R.L., Bondell, H.D., Kirby- } \\
\text { Hathaway, T. \& Moore, S.E. (2014) }\end{array}$ & EEUU & \\
\hline $\begin{array}{c}\text { Torres-Hernández, T., Barreto, I. \& } \\
\text { Rincón, J.C. (2015) }\end{array}$ & Colombia & \\
\hline Álvarez, P.; Vega, P (2009) & España & \\
\hline Willuweit, L. (2009) & Suecia & \\
\hline Zaleha, B. D. (2013) & EEUU & \\
\hline Bolzan, C. (2008) & España & \\
\hline Gaspar, R.F. (2009) & Portugal & \\
\hline Goplen, J. (2014) & EEUU & \\
\hline Hill, D. (2008) & EEUU & \\
\hline Maki, A. (2015) & EEUU & \\
\hline Nag, M. (2012) & EEUU & \\
\hline
\end{tabular}




\begin{tabular}{|c|c|l|l|}
\hline Ching, Y. \& Tse, C. (2007) & EEUU & & \\
\hline Wade, J. (2012) & EEUU & & \\
\hline Winter, J. (2008) & UK & & \\
\hline Yatsko, L.K. (2010 & EEUU & & \\
\hline
\end{tabular}

\begin{tabular}{|c|c|c|c|}
\hline \multicolumn{2}{|c|}{$\begin{array}{l}\text { Hallazgos acerca de Ed. Ambiental } \\
\text { y familia }\end{array}$} & \multicolumn{2}{|c|}{$\begin{array}{l}\text { Hallazgos sobre cuidado del agua y } \\
\text { familia }\end{array}$} \\
\hline Ardoin, N.M., Clark, C. \& Kelsey, E. (2013) & $\begin{array}{l}\text { USA, } \\
\text { Canada, } \\
\text { Australia, }\end{array}$ & $\begin{array}{c}\text { Canto, J.M., Hidalgo, M.C., García, M.A., } \\
\text { Martimportugués, C. (2002) }\end{array}$ & España \\
\hline Clover, D. (2002) & Canadá & $\begin{array}{c}\text { Coban, Gul Unal, Ercan Akpınar, Evren } \\
\text { Kucukcankurtaran, Eylem Yıldız, and Omer } \\
\text { Ergin. (2011) }\end{array}$ & Turquía \\
\hline Colvin-Williams, C. \& Chawla, L. (2016) & EEUU & $\begin{array}{c}\text { EISawah, S., Mclucas, A. \& Mazanov, J. } \\
\text { Water (2013) }\end{array}$ & Australia \\
\hline $\begin{array}{l}\text { Cook, E.M., Hall, S.J. \& Larson, K.L. } \\
\text { (2012) }\end{array}$ & EEUU & $\begin{array}{c}\text { García Lirios, Cruz, Carreón Guillén, } \\
\text { Javier, Hernández Valdés, Jorge, López } \\
\text { Lena, María Montero, \& Bustos Aguayo, } \\
\text { José Marcos. (2013) }\end{array}$ & México \\
\hline Cortés-Peña, O.F. (2011) & Colombia & $\begin{array}{l}\text { Mendieta Hernández, Milena Paola, \& } \\
\text { Gutiérrez Gómez, Gloria Leonor. (2014) }\end{array}$ & Colombia \\
\hline Flores, R. C. (2012) & México & & \\
\hline Flores, R.C. (2013) & México & & \\
\hline $\begin{array}{l}\text { Frederiks, E.R.; Stenner, K.; Hobman, E.V. } \\
\qquad(2015)\end{array}$ & Australia & & \\
\hline Genc, M. (2015) & Turquía & & \\
\hline Kopnina, H. (2014) & Países Bajos & & \\
\hline
\end{tabular}




\begin{tabular}{|c|c|l|l|} 
Kunz Shuman, D. \& Ham, S.H. (1997) & $\begin{array}{c}\text { Canadá y } \\
\text { USA }\end{array}$ & & \\
\hline Lundholm, C. \& Plummer R. (2010) & $\begin{array}{c}\text { Países Bajos } \\
\text { y Canadá }\end{array}$ & & \\
\hline OECD (2009) & Internacional & & \\
\hline
\end{tabular}

\section{Artículos sobresalientes}

Ando, K., Yorifuji, K., Ohnuma, S.

Matthies, E., \& Kanbara, A. (2015) (A)

Japón

\begin{tabular}{|l|l}
\hline & \\
\hline
\end{tabular}

Baur, A. \& Hans-Martin Haase (2015)

Alemania

\begin{tabular}{|c|c|}
\hline Blackwell, S. (2009) & $\begin{array}{l}\text { Nueva } \\
\text { Zelanda }\end{array}$ \\
\hline Chapman, J., \& Walton, H. (2012). & Australia \\
\hline Clark, C., Kotchen, M. \& Moore, M. (2003) & EEUU \\
\hline Dyck, S.L. (2013) & Canadá \\
\hline Thompson, N. (2010) & EEUU \\
\hline García Q., E.; Baldi L.z, G. (2006) & Argentina \\
\hline Grønhøj, A. \& Thøgerse, J. (2012) & Dinamarca \\
\hline Jianan, L.. \& Chunlin, L.. (2016) & China \\
\hline $\begin{array}{l}\text { Leppänen, J.M., Haahla, A.E., Lensu, } \\
\text { A.M. \& Kuitunen, M.T. (2012) }\end{array}$ & Finlandia \\
\hline
\end{tabular}




\begin{tabular}{|c|c|}
\hline Meeusen, C. (2014) & Bélgica \\
\hline $\begin{array}{c}\text { Morrissey, K. M., \& Werner-Wilson, R. } \\
\text { (2005) }\end{array}$ & EEUU \\
\hline Payne, P. G. (2010) & Australia \\
\hline Rashid, N. \& Wahid, N. (2013) & Malasia \\
\hline Robertson, J. L. \& Barling, J. (2013) & Canadá \\
\hline $\begin{array}{c}\text { Vaughan, C., Gack, J., Solorazano, H. \& } \\
\text { Ray, R. (2003) }\end{array}$ & $\begin{array}{c}\text { USA, Costa } \\
\text { Rica, } \\
\text { Paraguay }\end{array}$ \\
\hline Griffioen, K. (2015) & Países bajos \\
\hline Tovar Avellaneda, E. (2016) & Colombia \\
\hline $\begin{array}{l}\text { Videras,J. , Owen,A., Conover, E. \& Wu, S. } \\
(2012)\end{array}$ & EEUU \\
\hline
\end{tabular}

Número de artículos por país

\begin{tabular}{|r|l|c|}
\hline 1 & Estados Unidos & 32 \\
\hline 2 & España & 9 \\
\hline 3 & Colombia & 9 \\
\hline 4 & México & 7 \\
\hline 5 & Australia & 6 \\
\hline 6 & Reino Unido & 6 \\
\hline 7 & Dinamarca & 3 \\
\hline 8 & Países Bajos & 3 \\
\hline 9 & Turquia & 3 \\
\hline 10 & Canadá & 2 \\
\hline 11 & Israel & 2 \\
\hline 12 & China & 2 \\
\hline 13 & Argentina & 2 \\
\hline 14 & Japón & 2 \\
\hline 15 & Malasia & 2 \\
\hline 16 & Suecia & 1 \\
\hline 17 & Japón y Países Bajos & 1 \\
\hline 18 & Portugal y Brasil & 1 \\
\hline
\end{tabular}




\begin{tabular}{|c|l|c|}
19 & Indonesia & 1 \\
\hline 20 & USA y Turquia & 1 \\
\hline 21 & USA y Chile & 1 \\
\hline 22 & España y Chile & 1 \\
\hline 23 & USA, Canada, Australia & 1 \\
\hline 24 & USA, Costa Rica, Paraguay & 1 \\
\hline 25 & Internacional & 1 \\
\hline 26 & Países Bajos y Canadá & 1 \\
\hline 27 & Alemania & 1 \\
\hline 28 & Nueva Zelanda & 1 \\
\hline 29 & Canadá y USA & 1 \\
\hline 30 & Brasil & 1 \\
\hline 31 & Portugal & 1 \\
\hline 32 & Italia & 1 \\
\hline 33 & Finlandia & 1 \\
\hline 34 & Bélgica & 1 \\
\hline \multirow{2}{*}{} & & 109 \\
\cline { 2 - 3 }
\end{tabular}

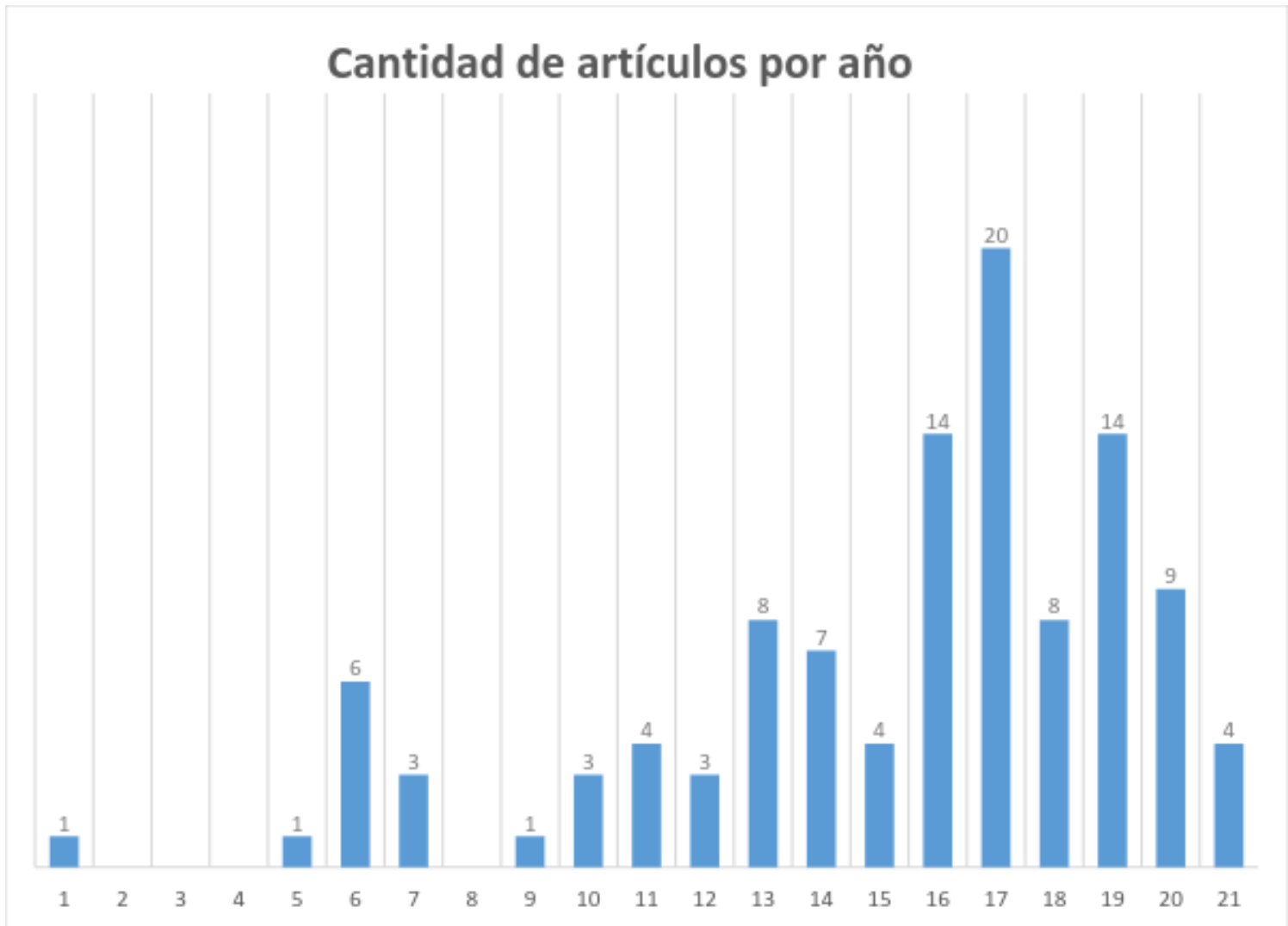


Anexo 12. Recibos del agua

ANTES

\section{\#9}

$$
{ }_{2} \text { MESES }
$$
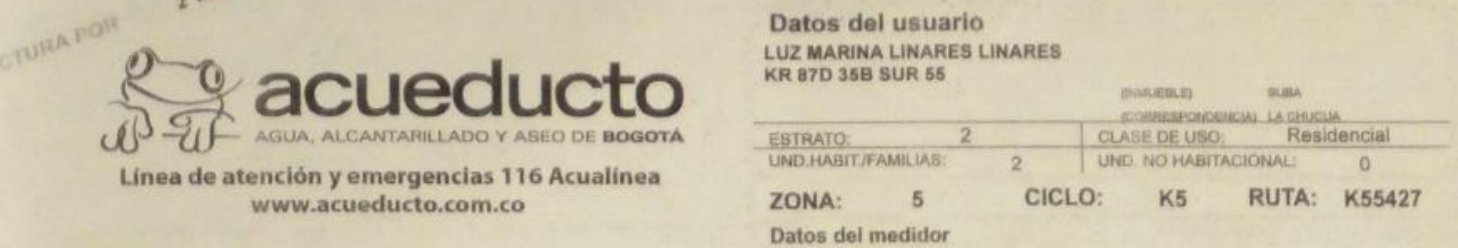

sex. nas.sen opt. 1

MARCA WATERTECH NOMERO: 11-1312733 TIFO: VELOOTST2 DIAMETRO: $\mathrm{Y}^{\prime \prime}$

CUENTA CONTRATO

Número para cualquier consulta

Datos del consumo

Factura de Servicios Públicos No. Númaro para pagos

10406754

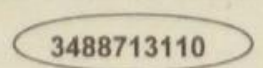

\section{TOTAL A PAGAR}

Agua + Alcantarillado + Aseo (ver al respaldo)

Fecha de pago oportuno

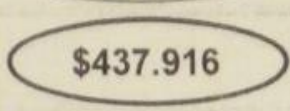

Fecha limite de pago para evitar suspension

AGO/10/2015

AGO/ $3 / 2015$

Resumen de su cuenta

\begin{tabular}{l} 
Descripción \\
\hline Acueducto \\
\hline Cargo fijo residencial \\
Consumo residencial basico(0-40m3) \\
Consumo residencial superior a básico \\
Cargo fijo no residencial \\
Consumo no residencial (m3) \\
\hline Subtotal Acueducto (1) \\
\hline Alcantariflacio \\
Cargo fijo residencial \\
Consumo residenclal basico(0-40m3) \\
Consumo reaidencial superior a báulco \\
Cargo fijo no residencial \\
Consumo no residencial (m3) \\
\hline Subtotal Alcantariliado (2)
\end{tabular}

FECHADE EXPEDICION JUL/27/2015

ÜTIMLALCTURA

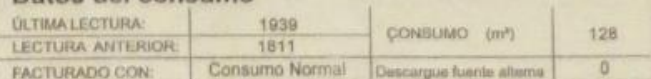
FACTURADO CON:

Úttimos consumos $\mathrm{m}^{\prime}$
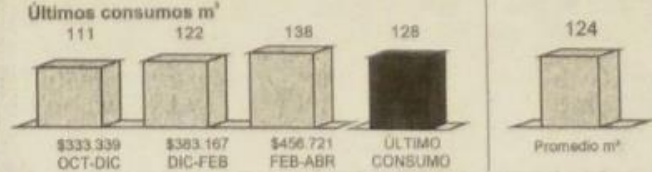

Periodo facturado ABR/28/2015 - JUN/25/2015

FECHA ESPERUDA DELAPROXIMAFACTURA OCT/01/2015

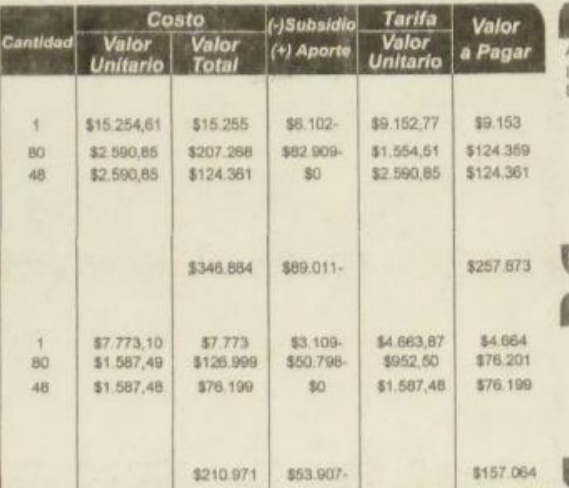

\begin{tabular}{|l|l|l|l|l|}
\hline Otros Cobros & No. Cuota Interes Total Saldo
\end{tabular}

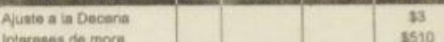

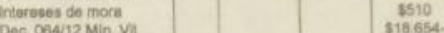

518.654
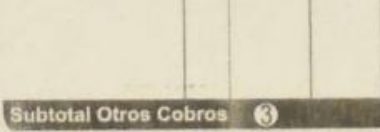

sie. 14.5

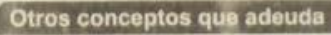

Valor Total

\section{Descuento minimo vital ( 12 metros cúbicos sin costo en estrato 1 y 2 )}

$\$ 18.654-$

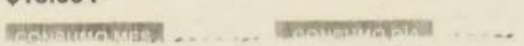




\section{DESPUES}

\section{\#q}

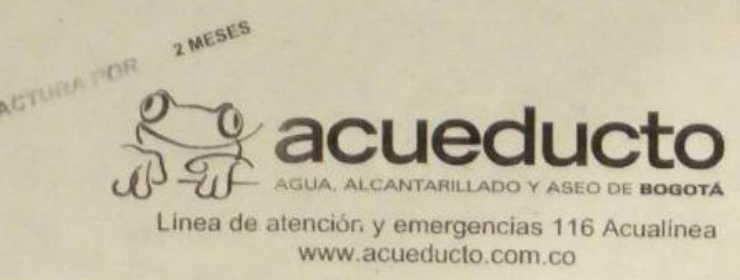

CUENTA CONTRATO

Número para cualquier consulta

NTr a90900.004.1

10406754

Factura de Servicios Públicos No. Número para pagos

\section{TOTAL A PAGAR \\ Agua + Alcantarillado + Aseo (ver al respaldo)}

Fecha de pago oportuno

Fecha limite de pago para evitar suspensión
7774839117

$\$ 350.134$

FEB/08/2017

FEB/13/2017
Datos del usuario

LUZ MARINA LINARES LINARES

KR 870 35B SUR 55

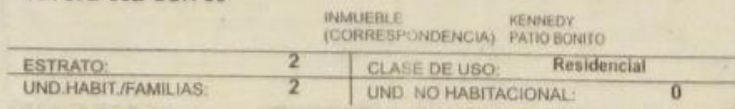

ZONA: 5 CICLO: K5 RUTA: K55423

Datos del medidor

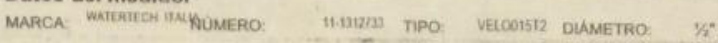

Datos del consumo

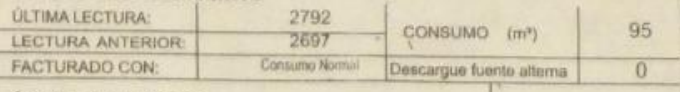
FACTURADO CON:

Últimos fonsumos $\mathrm{m}^{\prime}$
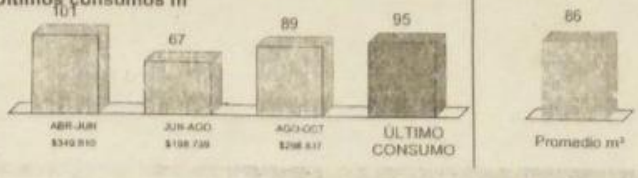

Periodo facturado OCT/20/2016 - DIC/19/2.016

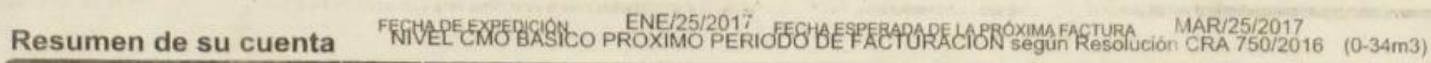

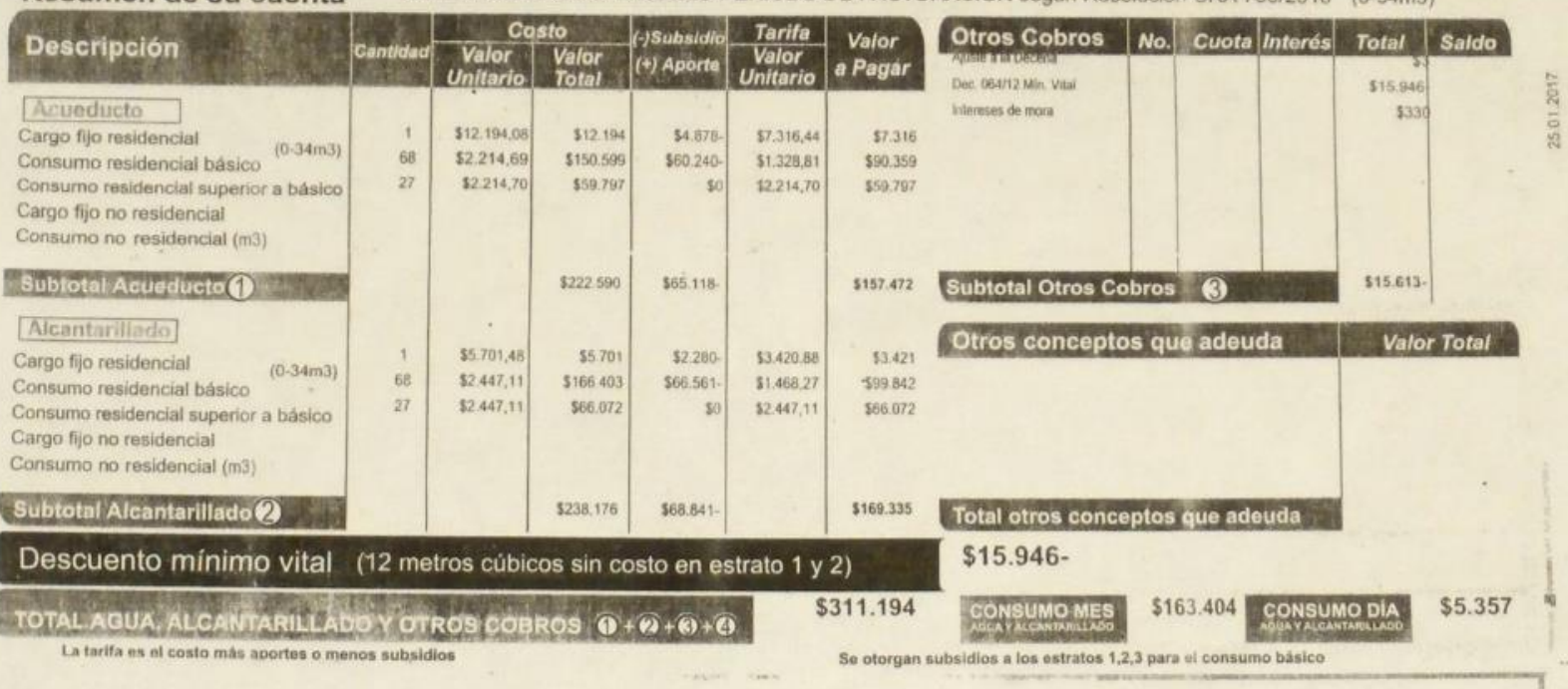


INFORMACION DE LAS FACTURAS PARA EL SERVICIO DE ACUEDUCTO COLEGIO RICAURTE

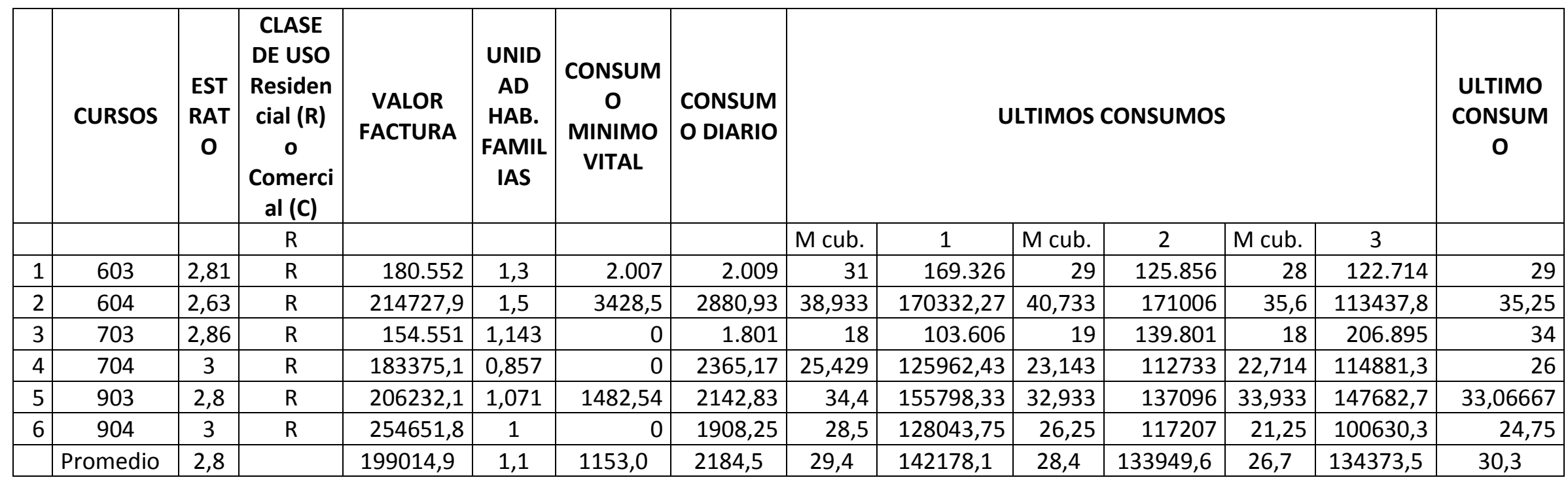

INFORMACION DE LAS FACTURAS PARA EL SERVICIO DE ACUEDUCTO COLEGIO LUIS LOPEZ DE MESA

\begin{tabular}{|c|c|c|c|c|c|c|c|c|c|c|c|c|c|c|}
\hline & \multirow[t]{2}{*}{ NOMBRES } & $\begin{array}{l}\text { EST } \\
\text { RAT }\end{array}$ & $\begin{array}{c}\text { CLASE } \\
\text { DE USO } \\
\text { Residen } \\
\text { cial (R) }\end{array}$ & $\begin{array}{l}\text { VALOR } \\
\text { FACTURA }\end{array}$ & $\begin{array}{l}\text { UNID } \\
\text { AD } \\
\text { HAB. }\end{array}$ & $\begin{array}{c}\text { CONSUM } \\
0 \\
\text { MINIMO }\end{array}$ & $\begin{array}{l}\text { CONSUM } \\
\text { O DIARIO }\end{array}$ & \multicolumn{6}{|c|}{ ULTIMOS CONSUMOS } & \multirow{2}{*}{$\begin{array}{c}\text { ULTIMO } \\
\text { CONSUM } \\
0\end{array}$} \\
\hline & & & $\mathrm{R}$ & & & & & M cub. & 1 & M cub. & 2 & M cub. & 3 & \\
\hline 1 & 802 & 2 & $\mathrm{R}$ & 122.441 & & 66.449 & 1.717 & 31 & & 33 & & 30 & & 29 \\
\hline 2 & 1002 & 2,05 & $\mathrm{R}$ & 178643,3 & 1,211 & 51403,3 & 1646,28 & & 89169,368 & & 93887,1 & & 97819,89 & \\
\hline 3 & 1102 & 2,08 & $\mathrm{R}$ & 123.306 & 1,64 & 18.694 & 1.633 & & & & & & & 31 \\
\hline & Promedio & 2,04 & $\mathrm{R}$ & 141463,2 & 1,425 & 45515,5 & 1665,44 & 30,944 & 89169,368 & 32,5 & 93887,1 & 30,235 & 97819,89 & 29,94118 \\
\hline
\end{tabular}


INFORMACION DE LAS FACTURAS PARA EL SERVICIO DE ACUEDUCTO COLEGIO REINO DE HOLANDA

\begin{tabular}{|c|c|c|c|c|c|c|c|c|c|c|c|c|c|c|}
\hline & \multirow[t]{2}{*}{ NOMBRES } & \multirow{2}{*}{\begin{tabular}{|c} 
EST \\
RAT \\
0
\end{tabular}} & \multirow{2}{*}{\begin{tabular}{|c} 
CLASE DE \\
USO \\
Residenc \\
ial (R) o \\
Comerci \\
al (C) \\
R \\
\end{tabular}} & \multirow[t]{2}{*}{$\begin{array}{c}\text { VALOR } \\
\text { FACTURA }\end{array}$} & \multirow{2}{*}{$\begin{array}{l}\text { UNID } \\
\text { AD } \\
\text { HAB. } \\
\text { FAMI } \\
\text { LIAS }\end{array}$} & \multirow{2}{*}{$\begin{array}{c}\text { CONSU } \\
\text { MO } \\
\text { MINIM } \\
0 \\
\text { VITAL }\end{array}$} & \multirow{2}{*}{$\begin{array}{c}\text { CONSU } \\
\text { MO } \\
\text { DIARIO }\end{array}$} & \multicolumn{6}{|c|}{ ULTIMOS CONSUMOS } & \multirow{2}{*}{$\begin{array}{c}\text { ULTIM } \\
0 \\
\text { CONSU } \\
\text { MO }\end{array}$} \\
\hline & & & & & & & & M cub. & 1 & M cub. & 2 & M cub. & 3 & \\
\hline 1 & sextos & 2,12 & $R$ & 36.694 & & & & 8 & 34.118 & 8 & 33.133 & 8 & 33.315 & 8 \\
\hline 2 & & & & & & & & & & & & & & \\
\hline 3 & & & & & & & & & & & & & & \\
\hline & Promedio & 2,1 & $\mathrm{R}$ & 36693,8 & & & & 8,4 & 34118,2 & 8,3 & 33133,4 & 8,0 & 33315,3 & 8,1 \\
\hline
\end{tabular}

INFORMACION DE LAS FACTURAS PARA EL SERVICIO DE ACUEDUCTO COLEGIO MANUEL ZAPATA OLIVELLA

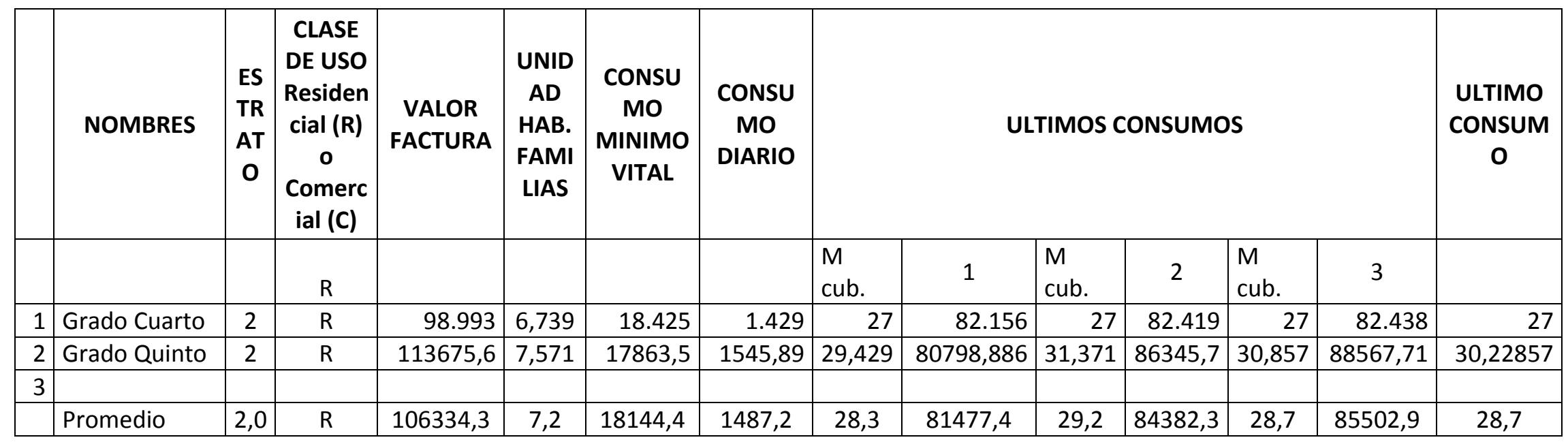


INFORMACIÓN DE LAS FACTURAS PARA EL SERVICIO DE ACUEDUCTO CUATRO COLEGIOS OBJETO DE ESTUDIO

\begin{tabular}{|c|c|c|c|c|c|c|c|c|c|c|c|c|c|c|}
\hline & \multirow[t]{2}{*}{ CURSOS } & \multirow{2}{*}{$\begin{array}{c}\text { EST } \\
\text { RAT } \\
0\end{array}$} & $\begin{array}{c}\text { CLASE } \\
\text { DE } \\
\text { USO } \\
\text { Reside } \\
\text { ncial }\end{array}$ & $\begin{array}{l}\text { VALOR } \\
\text { FACTU }\end{array}$ & $\begin{array}{c}\text { UNI } \\
\text { DA } \\
\text { D } \\
\text { HA } \\
B\end{array}$ & $\begin{array}{l}\text { CONS } \\
\text { UMO } \\
\text { MINI }\end{array}$ & $\begin{array}{l}\text { CONS } \\
\text { UMO } \\
\text { DIARI }\end{array}$ & \multicolumn{6}{|c|}{ ÚLTIMOS CONSUMOS } & \multirow{2}{*}{$\begin{array}{l}\text { ULTI } \\
\text { MO } \\
\text { CONS } \\
\text { UMO }\end{array}$} \\
\hline & & & $\mathrm{R}$ & & & & & $\begin{array}{l}\text { M } \\
\text { cub. }\end{array}$ & 1 & $\begin{array}{l}\text { M } \\
\text { cub. }\end{array}$ & 2 & $\begin{array}{l}\text { M } \\
\text { cub. }\end{array}$ & 3 & \\
\hline 1 & COLEGIO RICAURTE & $\begin{array}{c}2,8 \\
5 \\
\end{array}$ & $\mathrm{R}$ & 199015 & 1 & 1153 & 2185 & 29 & $\begin{array}{r}14217 \\
8 \\
\end{array}$ & 28 & $\begin{array}{r}13395 \\
0 \\
\end{array}$ & 27 & $\begin{array}{r}13437 \\
3 \\
\end{array}$ & 30 \\
\hline 2 & COLEGIO LUIS LOPEZ DE MESA & $\begin{array}{c}2,0 \\
4\end{array}$ & $\mathrm{R}$ & 141463 & 1 & 45516 & 1665 & 31 & 89169 & 33 & 93887 & 30 & 97820 & 30 \\
\hline 3 & COLEGIO REINO DE HOLANDA & $\begin{array}{c}2,1 \\
2\end{array}$ & $\mathrm{R}$ & 43941 & & & & 16 & 49491 & 15 & 45187 & 14 & 43212 & 14 \\
\hline 4 & $\begin{array}{l}\text { COLEGIO MANUEL ZAPATA } \\
\text { OLIVELLA }\end{array}$ & 2 & $\mathrm{R}$ & 106334 & 7 & 18144 & 1487 & 28 & 81477 & 29 & 84382 & 29 & 85503 & 29 \\
\hline & Promedio & 2,3 & & 122688 & 3 & 21604 & 1779 & 26 & 90579 & 26 & 89352 & 25 & 90227 & 26 \\
\hline
\end{tabular}

